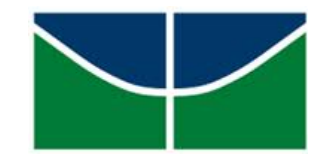

Universidade de Brasília (UnB)

Faculdade de Ciência da Informação (FCl)

Programa de Pós-Graduação em Ciência da Informação

\title{
GESTÃO DE TESES E DISSERTAÇÕES ELETRÔNICAS NO CONTEXTO DO ACESSO ABERTO À INFORMAÇÃO CIENTÍFICA NO BRASIL
}

Tainá Batista de Assis

Brasília

Abril de 2015 


\begin{abstract}
Dissertação apresentada à banca examinadora como requisito parcial à obtenção do Título de Mestre em Ciência da Informação pelo Programa de PósGraduação em Ciência da Informação (PPGCInf) da Faculdade de Ciência da Informação, Universidade de Brasília (UnB), sob a orientação do Prof. Dr. Fernando César Lima Leite e co-orientação da Dra. Bianca Amaro de Melo.
\end{abstract}


Aos meus pais, Maria Lucia e Djalmir, por todo ensinamento e amor. 


\section{AGRADECIMENTOS}

Agradecer é manifestar gratidão àqueles que, de alguma forma, contribuíram para o desenvolvimento e concretização desta etapa em minha vida.

Agradeço muito ao Prof. Dr. Fernando Leite por toda orientação, apoio, paciência, por não hesitar em compartilhar seus conhecimentos e acreditar na realização deste estudo. Muito obrigada!

Agradeço muito a Dra. Bianca Amaro por me manter firme e confiante durante todo o processo de desenvolvimento desta pesquisa, pelos seus ensinamentos profissionais e de vida e pela sua amizade. O meu sincero respeito e admiração. Muito obrigada!

Agradeço muito a Profa. Dra. Lillian Alvares por toda a sua atenção, orientações, simplicidade e por me transmitir tranquilidade para o desenvolvimento deste estudo. Muito obrigada!

Agradeço muito a Profa. Dra. Angélica Miranda por suas valiosas contribuições no decorrer desta pesquisa. Muito obrigada!

Agradeço muito a minha família pelo apoio incondicional e carinho no decorrer desta pesquisa. Em especial, agradeço a minha avó, Antônia, pelo acolhimento e suas sábias palavras. Também, ao Alceu, o papagaio, por suas maravilhosas gargalhadas inesperadas. Muito obrigada!

Agradeço muito ao Instituto Brasileiro de Informação em Ciência e Tecnologia (IBICT) que há 4 anos e 6 meses vem me desafiando e me proporcionando a certeza de que não poderia ter escolhido outra formação profissional. Muito obrigada!

Agradeço muito aos amigos que fiz no IBICT. Sou grata por toda ajuda, pelas discussões construtivas e as vibrações positivas. Assim, Michelli Costa, Danyelle Silva, Teila Carvalho, Washington Ribeiro, Alan Oliveira, Rayanne Silva, Luísa Café, Maria Fernanda Melis e Raquel Viana, muito obrigada!

Agradeço muito aos meus amigos da Biblioteconomia pela bela amizade e os magníficos encontros. Assim, Fabiane Freitas, Yaciara Duarte, Viviane Rocha, Wanne Silva, Jonniery Moreira, Mariana Saldanha, Ana Flávia Kama, Diego Henrique e Alan Freires, muito obrigada!

Agradeço muito às amigas que fiz durante a vida e que souberam compreender a minha ausência em alguns (ou vários) momentos. Assim, Camila Hipólito, Juliana Hipólito, Rebeca Barbosa, Leidiane Boaventura, Cinthia Bonatto e Thaiana Corrêa, muito obrigada! 
"Tudo é uma questão de manter

A mente aberta

A espinha ereta E o coração tranquilo".

Walter Franco 


\section{RESUMO}

Objetiva identificar características dos sistemas brasileiros de gestão de teses e dissertações eletrônicas no contexto do acesso aberto à informação científica. As bibliotecas digitais de teses e dissertações desenvolvidas em todo o mundo, impulsionadas, principalmente, pela criação da Networked Digital Library of Theses and Dissertations (NDLTD) tornaram-se espaços para o gerenciamento e disseminação desses conteúdos eletrônicos seguindo os princípios da Iniciativa dos Arquivos Abertos (OAi). Quase dez anos após, o pressuposto do acesso aberto à informação científica já consolidado internacionalmente passou a integrar também as teses e dissertações como uma tipologia documental que deve estar acessível e livre de restrições por meio da internet, em repositórios institucionais. Do ponto de vista metodológico, esta pesquisa é de natureza descritiva, com abordagem dos métodos mistos. Os dados para a realização da pesquisa foram coletados por meio de um checklist e envio de questionários e aplicação de entrevistas com os gestores dos sistemas de informação. Como resultado principal observou-se que as universidades brasileiras como um todo, tanto públicas quanto privadas, gerenciam suas teses e dissertações eletrônicas por meio de sistemas de informação de acesso aberto. Esse feito contribui para o destaque do Brasil frente aos outros países tanto na região da América Latina como em todo o mundo no que concerne à visibilidade dos resultados de pesquisa de mestrado e doutorado.

Palavras-chave: Teses e dissertações eletrônicas (ETDs). Acesso Aberto. Repositório institucional. Comunicação científica. Sistema de informação. 


\begin{abstract}
Aims to identify characteristics of Brazilian management electronic theses and dissertations systems in the context of Open Access to scientific information. Digital libraries of theses and dissertations developed worldwide, driven mainly by the creation of the Networked Digital Library of Theses and Dissertations (NDLTD) have become spaces for the management and dissemination of these electronic content following the principles of the Open Archives Initiative (OAi). Almost ten years later, the assumption of Open Access to Scientific Information already established internationally also started to integrate theses and dissertations as a document type that should be accessible and free of restrictions through the internet, in institutional repositories. From a methodological point of view, this research is descriptive in nature, with mixed methods approach. Data for the research were collected through a checklist and sending questionnaires and application of interviews with the managers of information systems. The main result showed that Brazilian universities as a whole, both public and private, manage their electronic theses and dissertations by means of open access information systems. This effect contributes to the highlight of the Brazil front of other countries both in the Latin American region and around the world regarding the visibility of master's and doctoral research results.
\end{abstract}

Keywords: Electronic theses and dissertations (ETDs). Open Access. Institutional repository. Scientific communication. Information system. 


\section{LISTA DE FIGURAS}

Figura 1: Definição das instituições participantes da pesquisa ................................... 32

Figura 2: O sistema de comunicação científica ............................................................ 40

Figura 3: Modelo de comunicação científica de Garvey e Griffith (1979) ..................... 45

Figura 4: Proposta de modelo de comunicação científica com a presença da tese de

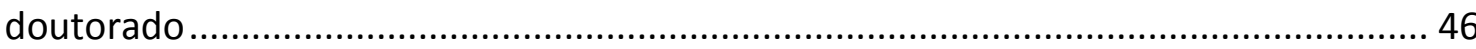

Figura 5: Modelo de comunicação científica A-0 de Björk (2007) ................................ 49

Figura 6: Modelo de comunicação científica - Modelo A32131 de Björk (2007).......... 50

Figura 7: Fatores envolvidos com as teses e dissertações eletrônicas ........................... 66

Figura 8: Estágios para a implantação de um programa de ETD ................................. 69

Figura 9: Partes interessadas em um programa de ETD .............................................. 70

Figura 10: Número de depósitos por mês no arXiv (1991-2000) .................................. 74

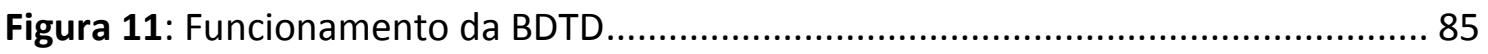

Figura 12: Distribuição das instituições participantes da BDTD por regiões geográficas

Figura 13: A relação entre o MTD-BR, ETD-MS e o Dublin Core ..................................... 90

Figura 14: Custos da Association of Research Libraries ............................................ 93

Figura 15: Abrangência dos tipos de documentos dos repositórios........................... 100

Figura 16: Tipos de documentos nos repositórios institucionais da América Latina... 100

Figura 17: Metadados obrigatórios no Novo Padrão de Metadados da BDTD ............. 103

Figura 18: Modelo conceitual da pesquisa.............................................................. 110

Figura 19: Estrutura para o projeto (interconexão das concepções, estratégias de investigação e métodos de pesquisa) …................................................................... 113

Figura 20: Estratégia de triangulação concomitante ................................................. 115

Figura 21: Modelo visual detalhado aplicado à pesquisa ........................................ 116

Figura 22: Busca avançada do Portal e-MEC ............................................................. 118

Figura 23: Definição das seções para análise e discussão dos resultados ................... 127

Figura 24: Percepções dos estudantes quanto à disponibilização das ETDs ............... 162 


\section{LISTA DE TABELAS}

Tabela 1: Evolução das matrículas da educação superior brasileira (1964-1994).......... 26

Tabela 2: Estatísticas gerais da educação superior em 2013......................................... 26

Tabela 3: Evolução dos gastos públicos no ensino superior em relação ao PIB ............. 26

Tabela 4: Evolução do número de instituições e de matrículas de educação superior

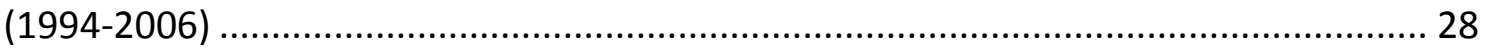

Tabela 5: Distribuição de discentes de pós-graduação no Brasil (2013) ....................... 30

Tabela 6: Definição da amostra de acordo com a sua proporção ao universo da

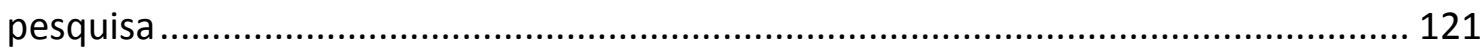

Tabela 7: Retorno de respostas dos questionários e os valores da amostra estratificada

Tabela 8: Expansão das universidades federais por região ....................................... 130

Tabela 9: Dados coletados pelo checklist em relação ao sistema de informação....... 136

Tabela 10: Tipo de sistema de informação x natureza da universidade...................... 137

Tabela 11: Dados coletados pelo checklist em relação ao software do sistema de informação

Tabela 12: Possibilidades de recuperação das ETDs nos sistemas identificados 156

Tabela 13: Sobre materiais não textuais complementares às ETDs 168

Tabela 14: Formas para o gerenciamento de ETDs. 169 


\section{LISTA DE QUADROS}

Quadro 1: Alterações dos processos com a inserção das TICs ..................................... 38

Quadro 2: Comunicação formal x Comunicação informal ........................................... 53

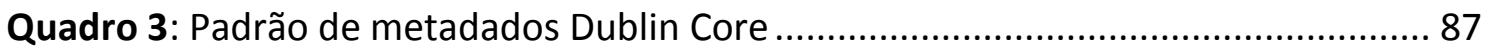

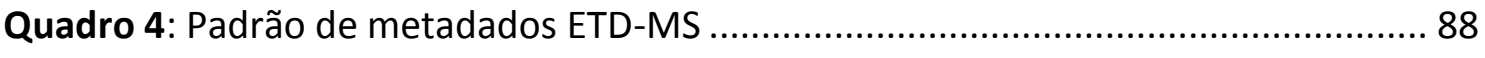

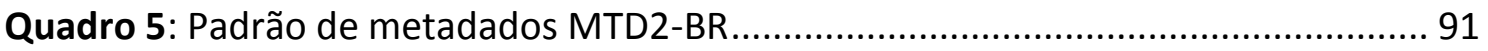

Quadro 6: Funcionamento do processo de comunicação científica.............................. 95

Quadro 7: Relação entre os instrumentos de coletas de dados, os objetivos específicos,

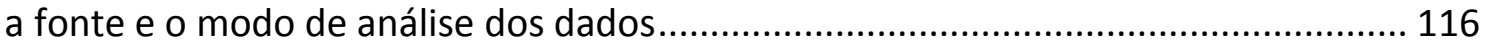

Quadro 8: Síntese das estratégias e procedimentos desta pesquisa ........................ 126 


\section{LISTA DE GRÁFICOS}

Gráfico 1: Caracterização das universidades que possuem ETDs ............................... 129

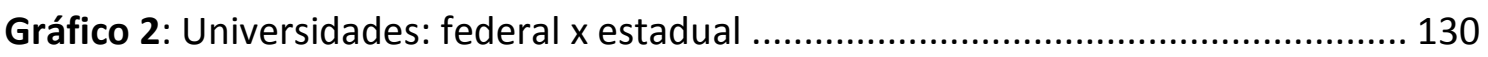

Gráfico 3: Quantidade de pessoas que formam parte da equipe de gestão das ETDs 131

Gráfico 4: Cenário da gestão das ETDs nas universidades ........................................ 134

Gráfico 5: Escolha do software para gestão de ETDs.............................................. 140

Gráfico 6: ETDs e outros tipos de conteúdos nos sistemas de informação .................. 141

Gráfico 7: Modalidade de depósito das ETDs no sistema........................................ 142

Gráfico 8: Existência de política formal para estimular o depósito de ETDs ............... 146

Gráfico 9: Caráter da política de depósito de ETDs ................................................. 147

Gráfico 10: Período de embargo para ETDs ............................................................. 148

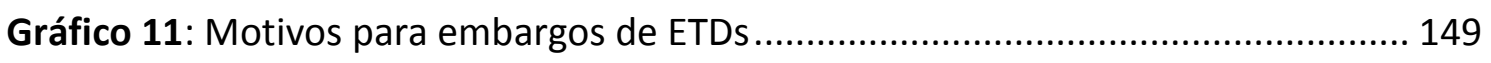

Gráfico 12: Atribuição do preenchimento dos metadados às ETDs .......................... 153

Gráfico 13: Preenchimento de metadados em outro idioma .................................... 154

Gráfico 14: Uso de identificadores persistentes ...................................................... 155

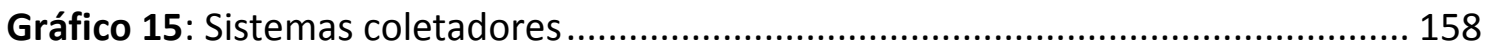

Gráfico 16: Universidades que não possuem ETDs x Natureza da instituição............. 159

Gráfico 17: Identificação dos motivos para o não gerenciamento das ETDs................ 160

Gráfico 18: Identificação de alguma experiência relacionada com ETDs .................... 163

Gráfico 19: Escolha do sistema de informação para a gestão de ETDs ...................... 164 


\section{LISTA DE ABREVIATURAS E SIGLAS}

ADT

ARL

BDB

BDTD

bdtds

BOAI

CAPES

Cl

CLIR

CNI

CNPq

CTC

DLF

DOAJ

DTD

EAD

EAGLE

ENEM

ETD-MS

ETDs

FID

FIES

FINEP

Gl

Hep-th

HTTP

IBBD
Australian Digital Theses Program

Association of Research Libraries

Biblioteca Digital Brasileira

Biblioteca Digital Brasileira de Teses e Dissertações

Biblioteca Digital de Teses e Dissertações

Budapest Open Access Initiative

Coordenação de Aperfeiçoamento de Pessoal de Nível Superior

Ciência da Informação

Council on Library and Information Resources

Coalition for Networked Information

Conselho Nacional de Desenvolvimento Científico Tecnológico

Comitê Técnico-Consultivo

Digital Library Federation

Directory of Open Access Journals

Document Type Definition

Educação à distância

European Association for Grey Literature Exploitation

Exame Nacional do Ensino Médio

Interoperability Metadata Standard for Theses and Dissertations

Teses e Dissertações Eletrônicas

Federação Internacional de Documentação (FID)

Fundo de Financiamento Estudantil

Financiadora de Estudos e Pesquisas

Gestão da Informação

High Energy Physics - Theory

Hypertext Transport Protocol

Instituto Brasileiro de Bibliografia e Documentação (IBBD) 


\begin{tabular}{|c|c|}
\hline IBICT & Instituto Brasileiro de Informação em Ciência e Tecnologia \\
\hline IDEFO & Integration Definition for Function Modeling \\
\hline IESALC & $\begin{array}{l}\text { Instituto Internacional da UNESCO para a Educação Superior na } \\
\text { América Latina e Caribe }\end{array}$ \\
\hline IFLA & $\begin{array}{l}\text { Federação Internacional de Associações e Instituições } \\
\text { Bibliotecárias }\end{array}$ \\
\hline INEP & Instituto de Estudos e Pesquisas Educacionais Anísio Teixeira \\
\hline INIST-CNRS & Institut de I'Information Scientifique et Techinique \\
\hline LA Referencia & $\begin{array}{l}\text { Red Federada de Repositorios Institucionales de Publicaciones } \\
\text { Científicas }\end{array}$ \\
\hline LANL & Los Alamos National Laboratory \\
\hline LISA & Library and Information Science Abstracts \\
\hline MEC & Ministério da Educação \\
\hline MIT & Massachusetts Institute of Technology \\
\hline MTD-BR & Padrão Brasileiro de Metadados de Teses e Dissertações \\
\hline NCSTRL & Networked Computer Science Technical Reference Library \\
\hline NDLTD & Networked Digital Library of Theses and Dissertations \\
\hline NISO & National Information Standards Organization \\
\hline OAi & Open Archives Initiative \\
\hline OAI - PMH & Open Archives Initiative Protocol for Metadata Harvesting \\
\hline OAMS & Open Archives Metadata Set \\
\hline oasisbr & Portal Brasileiro de Acesso Aberto à Informação Científica \\
\hline ODLIS & Online Dictionary for Library \& Information Science \\
\hline OpenDOAR & Directory of Open Access Repositories \\
\hline OSF & Open Society Foundations \\
\hline PIB & Produto Interno Bruto \\
\hline PDF & Portable Document Format \\
\hline PPGCInf & Programa de Pós-Graduação em Ciência da Informação \\
\hline Prouni & Programa Universidade para Todos \\
\hline PUC-Rio & Pontifícia Universidade Católica do Rio de Janeiro \\
\hline
\end{tabular}




\begin{tabular}{|c|c|}
\hline RePEc & Research Papers in Economics \\
\hline Rls & Repositórios Institucionais \\
\hline RICYT & $\begin{array}{l}\text { Red de Indicadores de Ciencia y Tecnología - Iberoamericana e } \\
\text { Interamericana }\end{array}$ \\
\hline ROAR & Registry of Open Access Repository Mandates and Policies \\
\hline SCl & Science Citation Index \\
\hline SGML & Standard Generalized Markup Language \\
\hline SIGLE & System for Information on Grey Literature in Europe \\
\hline SISU & Sistema Informatizado do MEC \\
\hline SITE & Sistema de Teses \\
\hline SNBU & Seminário Nacional de Bibliotecas Universitárias \\
\hline SPARC & Scholarly Publishing \& Academic Resources Coalition \\
\hline TEDE & Sistema de Publicação Eletrônica de Teses e Dissertações \\
\hline TICs & Tecnologias de Informação e Comunicação \\
\hline TDC@t & Proyecto de Tesis Doctorales Electrônicas de Cataluña \\
\hline UBA & Universidade de Buenos Aires \\
\hline UDUAL & União de Universidades da América Latina \\
\hline UFSC & Universidade Federal de Santa Catarina \\
\hline UMI & Universal Microfilms International \\
\hline UNAM & Universid Nacional Autónoma de México \\
\hline UnB & Universidade de Brasília \\
\hline UNESCO & $\begin{array}{l}\text { Organização das Nações Unidas para a Educação, a Ciência e a } \\
\text { Cultura }\end{array}$ \\
\hline USP & Universidade de São Paulo \\
\hline USP & Universal Preprint Service \\
\hline Virginia Tech & Virginia Polytechnic Institute and State University \\
\hline XML & Extensible Markup Language \\
\hline WEBOMETRICS & Ranking Web of Repositories \\
\hline
\end{tabular}




\section{SUMÁRIO}

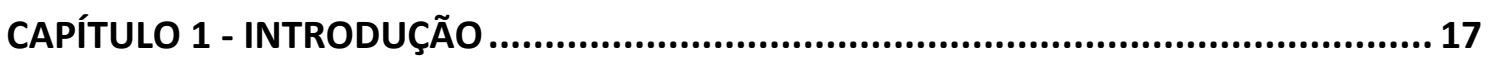

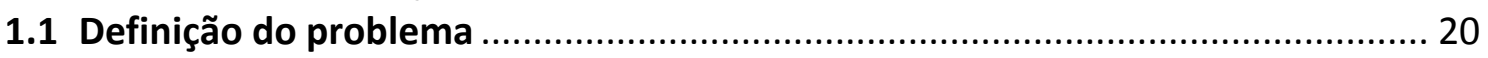

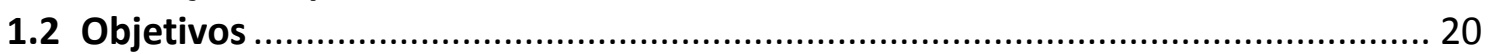

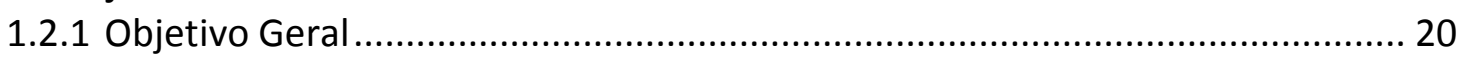

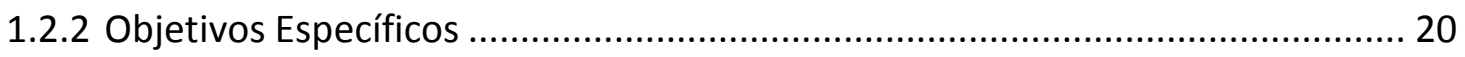

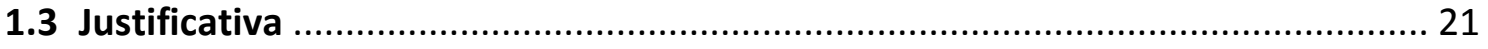

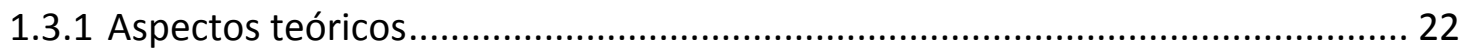

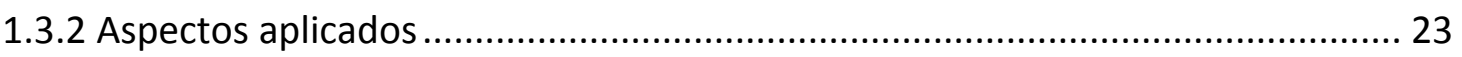

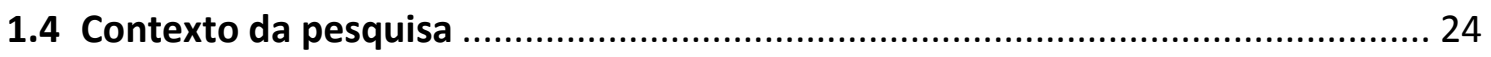

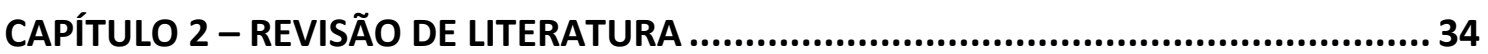

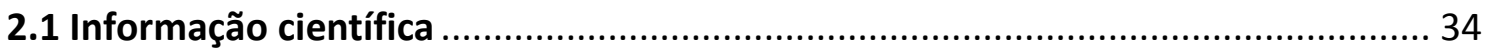

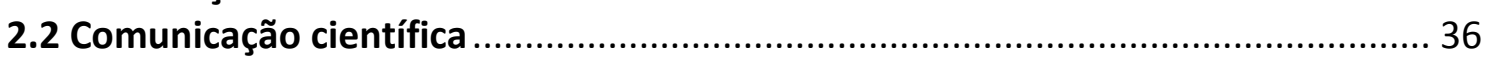

2.2.1 Modelos de comunicação científica................................................................ 41

2.2.1.1 Modelo de Garvey e Griffith (1979)......................................................... 42

2.2.1.2 Modelo de Björk (2007) ........................................................................ 47

2.2.2 Comunicação formal x Comunicação informal ................................................. 51

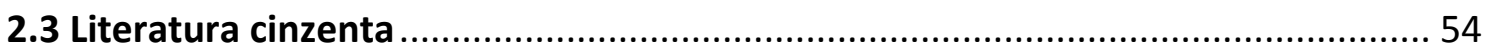

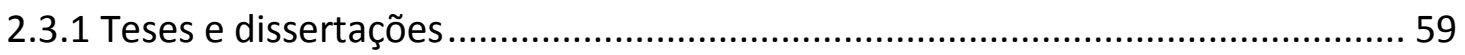

2.3.1.1 Teses e dissertações eletrônicas (ETDs) ………………………………........ 62

2.4 Acesso Aberto à Informação Científica ............................................................... 71

2.4.1 Open Archives Initiative (OAi): a Convenção de Santa Fé.................................. 75

2.4.1.1 As bibliotecas digitais de teses e dissertações ............................................. 79

2.4.2 O Movimento de Acesso Aberto à Informação Científica................................... 92

2.4.2.1 Os repositórios digitais de acesso aberto ................................................... 95

2.4.3 A coexistência das bibliotecas digitais de teses e dissertações e os repositórios institucionais no contexto do Acesso Aberto à informação científica..................... 98

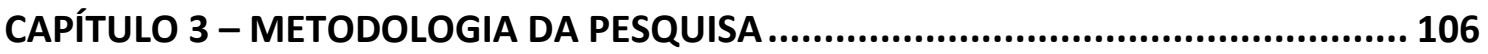

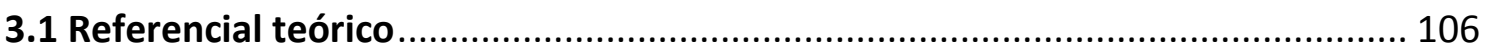

3.1.1 Relação entre os elementos relevantes para a pesquisa.................................. 106

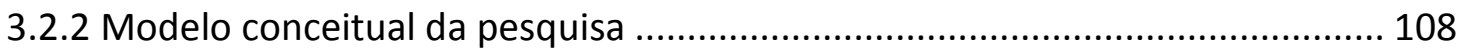

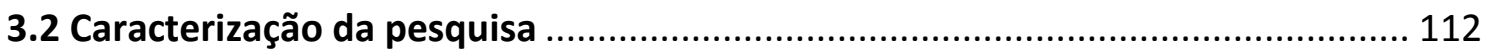

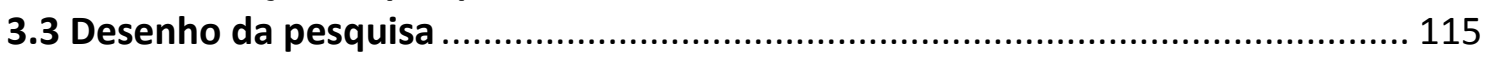

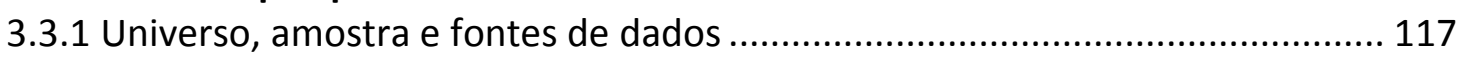

3.3.2 Métodos, técnicas e instrumentos da pesquisa .............................................. 122

CAPÍTULO 4 - ANÁLISE E DISCUSSÃO DOS RESULTADOS....................................... 127

4.1 Universidades que possuem gerenciamento de ETDs..................................... 128

4.1.1 Caracterização das universidades respondentes............................................ 128

4.1.2 Tipo de sistema e tecnologia adotados para a gestão de ETDs ......................... 133

4.1.3 Obtenção das ETDs nos sistemas de informação ............................................ 142

4.1.4 Organização das ETDs nos sistemas de informação ......................................... 151

4.1.5 Preservação das ETDs nos sistemas de informação ........................................ 154

4.1.6 Recuperação das ETDs nos sistemas de informação ........................................ 156 


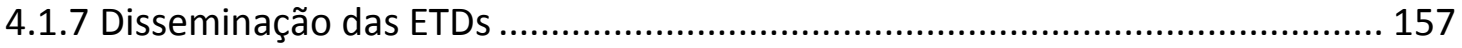

4.2 Universidades que não possuem gerenciamento de ETDs ................................. 158

4.2.1 Caracterização das universidades que não gerenciam ETDs ............................. 158

4.2.2 Identificação dos motivos para o não gerenciamento das ETDs ...................... 159

4.2.3 Existência de experiência com a gestão de ETDs............................................ 162

4.2.4 Sobre o sistema de informação mais apropriado para a gestão de ETDs ........ 164

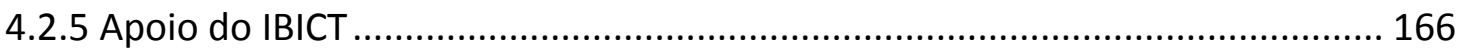

4.3 Análise da opinião das universidades quanto às ETDs ................................... 167

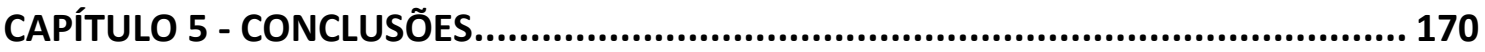

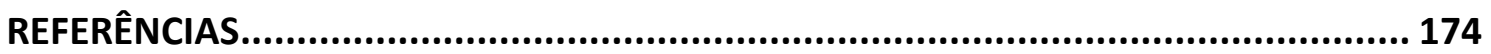

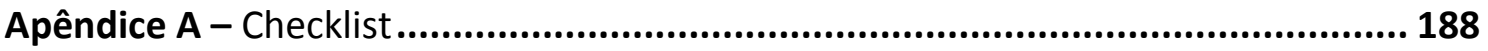

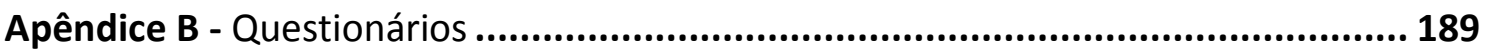

Apêndice C - Roteiro das entrevistas ............................................................ 194

Anexo I - Padrão Brasileiro de Metadados de Teses e Dissertações (MTD2-BR) ....... 200

Anexo II - Novo Padrão Brasileiro de Metadados da Biblioteca Digital Brasileira de Teses e Dissertações (BDTD) ............................................................................ 206 


\section{CAPÍTULO 1}

\section{INTRODUÇÃO}

Tanto para sua legitimação quanto para a difusão e apropriação dos resultados de pesquisa, a ciência deve ser comunicada. Meadows (1999, p. vii) afirmou que à pesquisa “(...) não cabe reivindicar com legitimidade este nome enquanto não houver sido analisada e aceita pelos pares. Isso exige, necessariamente, que seja comunicada". A comunicação científica é o conjunto de processos que envolvem a produção, disseminação e uso da informação entre os pesquisadores sobre suas pesquisas. Por esta razão, diz-se que a pesquisa não se trata de uma atividade individual, uma vez que é compartilhada entre os pares.

Diversos são os espaços que possibilitam a produção, disseminação e uso da informação científica, como os laboratórios, as indústrias, os grupos de reflexão e as sociedades científicas. Entretanto, é nas universidades onde se percebe maior a sua intensidade. Embora o papel dessas instituições como protagonistas do sistema de produção do conhecimento científico já tenha sido questionado por Gibbons et al (1994), Godin e Gingras (2000), ao medirem a presença das universidades no sistema de produção, afirmaram que esse protagonismo não decresceu, uma vez que os outros espaços, tais como nas indústrias, em sua maioria, relacionam suas pesquisas com essas instituições. Nesse sentido, Leydesdorff e Etzkowitz (2001, web) consideraram que a universidade assumiu novos papeis. Segundo os autores, a universidade passou a compartilhar suas ações com outros agentes institucionais, o Estado e a indústria. No contexto indústria-universidade-governo não há mais papeis fixos, pois é necessária a interação entre as diferentes funções, que levam à "chave para o conhecimento de desenvolvimento econômico".

Ao longo dos anos, a função das universidades tem se adaptado diante das novas realidades. Beraza Garmendia e Rodríguez Castellanos (2007) discorrem sobre essa evolução das universidades. Às duas missões consideradas como clássicas das universidades, a docência e a pesquisa, foi somada uma terceira vertente, a extensão. Segundo os autores, deve-se considerar a universidade como uma instituição de educação para toda a vida e de prestação de serviços científicos mediante a 
transferência de tecnologia ao setor produtivo com o último objetivo de ajudar a conseguir uma vantagem competitiva tanto nacional ou regional (BERAZA GARMENDIA e RODRÍGUEZ CASTELLANOS, 2007, p. 50).

O ensino da pós-graduação, compreendido pelos programas de pós-graduação, constitui, ao mesmo tempo, em um importante espaço e estratégia tanto de formação de recursos humanos para a pesquisa quanto de produção do conhecimento científico. Sua função social é, portanto, formar novos quadros de cientistas e docentes de nível superior, bem como a produção de conhecimento, de tecnologia e de aprendizagem, como sugeriram Batomé e Kubo (2002). No contexto brasileiro, Población e Noronha (2002) concordaram com o peso das universidades na produção científica quando afirmaram que, com o passar do tempo, os programas de pós-graduação tornaram-se o "maior polo gerador da produção científica brasileira". O censo realizado no Brasil pelo Conselho Nacional de Desenvolvimento Científico Tecnológico (CNPq) ${ }^{1}$, no ano de 2010, apontou para o crescimento do número de instituições cadastradas no Diretório dos Grupos de Pesquisa no Brasil, passando de 99 instituições, em 1999, para 452 instituições em 2010. Quanto à filiação dos pesquisadores, observa-se que do total de 159.722 pesquisadores cadastrados, aproximadamente $47 \%$ são filiados às universidades públicas.

Na medida em que a capacidade científica e tecnológica decorre da integração das atividades de ensino (formação de novos pesquisadores) e pesquisa (produção de conhecimento científico), desenvolvidas por programas de pós-graduação, um tipo específico de produção científica ganha importância: as teses e dissertações.

As teses e dissertações, diferentemente da literatura científica formalmente publicada, não estão incluídas em um sistema de publicação e distribuição comercial. Assim sendo, durante muito tempo as teses e dissertações formavam um tipo de literatura com acesso restrito e difícil, tendo sua função de canal de comunicação científica limitada. Todavia, o avanço das tecnologias de informação no decorrer dos últimos anos provocou mudanças significativas no fluxo tradicional da comunicação científica, reorganizando os processos de disseminação dos resultados de pesquisa (LEITE, 2011). No que concerne às teses e dissertações, percebe-se que houve uma

\footnotetext{
${ }^{1}$ Dados sobre o Censo 2010 do Conselho Nacional de Desenvolvimento Científico Tecnológico (CNPq) <http://lattes.cnpq.br/web/dgp/por-instituicao1>.
} 
significativa modificação em sua função como canal de comunicação científica. $\mathrm{Na}$ medida em que a tecnologia passou a ser utilizada na produção e, especialmente, na disseminação de resultados de pesquisa, as teses e dissertações tornaram-se canais de comunicação que veiculam, antes mesmo da literatura científica publicada, resultados de pesquisa. Isto foi possível graças ao surgimento de iniciativas de sistemas de informação digitais na internet para a obtenção, organização, armazenamento, preservação, recuperação e disseminação de teses e dissertações em todo o mundo. Em maior parte, esses sistemas de informação diziam respeito às bibliotecas digitais de teses e dissertações.

Vinte anos depois despontou o Movimento em prol do acesso aberto à informação científica. O Movimento surgiu de uma reação dos próprios pesquisadores em resposta ao modelo de comunicação tradicional de publicação e, sobretudo, aos preços exorbitantes impostos pelos editores para as assinaturas dos periódicos científicos. De acordo com Lynch (2003), o acesso aberto significa a disponibilização livre e irrestrita dos resultados da pesquisa científica em texto completo, por meio da internet. Desta forma, em razão da convergência de suas motivações, que era tornar a informação científica disponível e acessível amplamente na internet, as iniciativas de sistemas de gestão de teses e dissertações eletrônicas até então existentes, incorporaram as ideias do Movimento em favor do acesso aberto. Agruparam no sentido em que bibliotecas digitais de teses e dissertações, cuja gênese antecede o surgimento de repositórios institucionais, incorporaram os pressupostos de acesso aberto. E foram inclusas no sentido em que o povoamento de repositórios institucionais de universidades passou a ser iniciado por meio do depósito de teses e dissertações. De acordo com dados obtidos no Directory of Open Access Repositories (OpenDOAR), teses e dissertações figuram como o segundo tipo de conteúdo mais frequente entre os repositórios institucionais, ficam atrás apenas de artigos de periódicos científicos. Esse número é explicado por Leite (2011), quando afirma que teses e dissertações constituem os primeiros documentos a serem depositados em repositórios institucionais e são o "carro-chefe de seu povoamento". Uma possível explicação para esse fato é que as teses e dissertações constitui um tipo de produção científica cuja obtenção, distribuição e uso prescindem dos editores e, portanto, têm seu fluxo mais facilitado. 
Ao mesmo tempo em que a convergência das iniciativas significou contribuição para a consolidação do acesso aberto, impactou tanto a gestão quanto a comunicação da informação científica materializada em teses e dissertações.

\subsection{Definição do problema}

Considerando a perspectiva que norteou o surgimento dos sistemas de gerenciamento de teses e dissertações eletrônicas associada à perspectiva da gestão e comunicação da informação científica e aos pressupostos do acesso aberto, esta pesquisa pretende responder a seguinte pergunta: Quais as características dos sistemas de gestão de teses e dissertações eletrônicas brasileiros no contexto do Acesso Aberto?

Para responder à questão da pesquisa, os objetivos a seguir se fazem necessários.

\subsection{Objetivos}

\subsubsection{Objetivo Geral}

Identificar características dos sistemas de gestão de teses e dissertações eletrônicas no contexto do Acesso Aberto nas universidades brasileiras.

\subsubsection{Objetivos Específicos}

1. Mapear os sistemas de informação utilizados para a gestão das teses e dissertações eletrônicas no Brasil;

2. Identificar características e processos realizados pelos sistemas de informação utilizados para a gestão de teses e dissertações eletrônicas no Brasil;

3. Identificar, com base na percepção dos gestores, fatores que influenciam a gestão de teses e dissertações eletrônicas nos sistemas de informação.

4. Identificar características, com base na percepção dos gestores de informação, fatores que impedem a gestão de teses e dissertações eletrônicas. 


\subsection{Justificativa}

Teses e dissertações constituem um dos primeiros relatos de pesquisa de doutorado e mestrado. Tais como outros produtos de informação científica, necessitam ser gerenciadas apropriadamente, isto é, reunidas, organizadas, armazenadas, preservadas, recuperadas e disseminadas amplamente, de modo que possam alimentar novos processos de produção do conhecimento científico. Orera Orera (2003) reconheceu a importância desses documentos como insumos às novas atividades de pesquisa uma vez que, partindo de informações anteriores, abrem novas linhas de trabalho para estudos futuros.

As teses e dissertações são resultados primários de pesquisa que, submetidos à avaliação de especialistas, podem estar imediatamente acessíveis à comunidade tão logo tenham sido aprovadas ${ }^{2}$, mas que se existirem apenas em formato impresso, terão sua circulação limitada e, por consequência, o seu impacto reduzido.

O avanço das tecnologias de informação possibilitou que as teses e dissertações possuam versão eletrônica e que sejam gerenciadas em sistemas de informação de acesso aberto, passando a ser mais amplamente disseminadas e acessíveis à comunidade científica. Mueller, Campello e Dias (1996, p. 13) já apontavam para a necessidade da existência de sistemas de recuperação para teses e dissertações "bem elaborados e atualizados", com a possibilidade de alguns filtros de busca.

Desta forma, a atual realidade em que as teses e dissertações eletrônicas estão inseridas implica na necessidade de se investigar o modo como esse tipo de literatura científica está sendo gerenciado. Assim, a pesquisa proposta se justifica tanto por razões teóricas, relacionadas com contribuições ao corpo de conhecimento da Ciência da Informação, mais especificamente na comunicação científica, quanto por razões práticas, na medida em que fornece insumos para a melhoria de processos dos sistemas de informação envolvidos. Cada uma destas dimensões será discutida a seguir.

\footnotetext{
${ }^{2}$ Salvo aquelas que possuem informações que possibilitem a geração de patentes.
} 


\subsubsection{Aspectos teóricos}

A Ciência da Informação (Cl) se dedica, dentre outras questões, a investigar os fenômenos que circundam a informação científica (BORKO, 1968). Assim sendo, entendido que as teses e dissertações incorporam o rol de informação científica, esta pesquisa é de interesse para a Ciência da Informação. Tendo em vista que esta pesquisa objetivou investigar as práticas que têm sido adotadas para o gerenciamento das teses e dissertações no contexto do acesso aberto, argumentam-se aspectos relevantes para a área com base em conceitos apresentados na literatura científica. Desta forma, relacionam-se os conceitos com os aspectos desta dissertação para a sua posterior explanação da justificativa e relevância para a disciplina.

O primeiro conceito, apontado por Borko (1968), apresenta os processos que envolvem a Ciência da Informação. De acordo com o autor, a $\mathrm{Cl}$ é a disciplina que "investiga as propriedades e o comportamento da informação, as forças que governam o fluxo e os meios de processá-las para otimizar sua acessibilidade e uso". Ainda segundo Borko (1968), a Cl é compreendida como um corpo de conhecimento ligado à origem, coleta, organização, armazenagem, recuperação, interpretação, transformação e utilização da informação. O segundo conceito, selecionado para complementar a ideia de Borko (1968), é o exposto por Goffman (1975) que afirmou que a $\mathrm{Cl}$ deve ser "um corpo organizado de conhecimentos, (...) e deve buscar descobrir e formular, em termos gerais, as condições sob as quais ocorrem fatos e eventos relacionados com a geração, transmissão e uso da informação".

A identificação das práticas para a gestão das teses e dissertações possibilitará discutir aspectos que fundamentam a $\mathrm{Cl}$ de acordo com os autores acima citados. No primeiro caso, o mapeamento dos fluxos, dos meios e das propriedades dessa tipologia documental de informação (teses e dissertações) resulta das ações das instituições de ensino e pesquisa para a otimização dos processos, objetivando a gestão das teses e dissertações. Para isto, essas instituições fazem uso de sistemas de informação - as bibliotecas digitais de teses e dissertações e os repositórios digitais de acesso aberto.

O segundo caso está relacionado com a identificação das características dos sistemas de informação sob a ótica da gestão da informação para a análise do ciclo 
apresentado por Borko (1968) - origem, coleta, organização, armazenamento, recuperação, interpretação, transformação e utilização da informação.

Por fim, o terceiro caso está fundamentado diretamente na ideia exposta por Goffman (1975) que, a partir da discussão das teses e dissertações e ao novo contexto que estão inseridas, auxiliaram para o entendimento dos fatos pelos quais as instituições se consolidaram e às mudanças na própria comunicação científica.

Diante do apresentado, esta dissertação se enquadra no Programa de PósGraduação em Ciência da Informação (PPGCInf) da Universidade de Brasília (UnB), e se insere na linha de pesquisa Comunicação e Mediação da Informação, com enfoque em Comunicação Científica.

\subsubsection{Aspectos aplicados}

As teses e dissertações eletrônicas têm sido objeto de debate no campo da Comunicação Científica e mais recentemente também tema de discussão no contexto do acesso aberto à informação científica. Neste sentido, os repositórios institucionais de acesso aberto têm surgido como novos espaços para a reunião, armazenamento e disseminação das teses e dissertações, em conjunto com os demais tipos de produção científica.

O Brasil possui uma das maiores bibliotecas digitais de todo o mundo dedicada a armazenar e dar visibilidade às teses e dissertações brasileiras. Ao longo dos seus treze anos de funcionamento, as formas de gerenciamento dessa tipologia documental nas instituições de ensino e pesquisa têm se alterado e se adaptado aos novos sistemas de informação. Tais mudanças implicam na realização de estudos e acompanhamento constante das ações e necessidades dessas instituições quanto ao gerenciamento das teses e dissertações eletrônicas.

Este estudo busca, primeiramente, compreender as discussões que acercam as teses e dissertações eletrônicas na literatura científica e, assim, identificar como tem sido o comportamento das instituições quanto ao gerenciamento desse tipo de documento. O mapeamento dos principais processos realizados pelas instituições, aliado às percepções dos gestores acerca do fenômeno investigado, permitiu retratar as reais necessidades e as práticas adotadas para o gerenciamento das teses e dissertações 
eletrônicas. Os resultados que alcançados poderão vir a colaborar para as próximas ações relacionadas com o desenvolvimento e integração das teses e dissertações aos sistemas de informação de acesso aberto. Espera-se ainda que os resultados a serem obtidos possam se traduzir em contribuições para o avanço do movimento de acesso aberto no Brasil.

\subsection{Contexto da pesquisa}

Para uma melhor compreensão do contexto aonde esta pesquisa é realizada, o Brasil, considera-se importante traçar um retrato da formação das universidades na América Latina e Caribe e de seus programas de pós-graduação.

Freitas Neto (2011, p. 64) afirma que a presença das universidades no mundo hispano-americano "remonta às origens do domínio colonial e é um registro das heranças culturais europeias no Novo Mundo". No modelo das universidades nascidas na Europa durante a Idade Média, a educação era controlada por jesuítas e por pequenos grupos que buscavam prestígio. Segundo Alvarez Aragón (1998, p. 15), as instituições de educação superior "constituíram, no início, modelos trasladados dos centros colonizadores, orientados para preparar as elites superiores e intermediárias do aparato de dominação colonial". Entretanto, essas características já não mais acompanhavam as mudanças provocadas pelos novos tempos, como os "processos de globalização econômica exigentes de maior agilidade no desenvolvimento e difusão do conhecimento científico" (OLIVEIRA e AZEVEDO, 2008, p. 68).

Na Universidade Nacional de Córdoba que, em seu início, oferecia cursos como filosofia e teologia e, ainda no século XX, preservava características do período colonial (FREITAS NETO, 2011), os estudantes universitários passaram a exigir reformas que buscassem a modernização e a democratização do ensino e da universidade. Em 1918, teve início na Argentina, um movimento estudantil que se estendeu a outras universidades do país e da América Latina. Oliveira e Azevedo (2008) relacionaram as propostas levantadas na chamada Revolução de Córdoba: cogestão (administração partilhada entre professores, estudantes e egressos), autonomia universitária plena, não obrigatoriedade de frequência às aulas, liberdade e periodicidade de cátedra e estabelecimento de concursos para professores. Segundo os autores, a Reforma de 
Córdoba é marcada como a primeira reforma universitária na América Latina. Segundo Freitas Neto (2011),

\begin{abstract}
o legado deixado por este movimento na educação superior latino-americana foi a defesa da autonomia universitária, a mudança no processo de ensino e docência e a democratização da universidade, tanto em sua gestão como na garantia da permanência de estudantes de todos os grupos sociais (FREITAS NETO, 2011, p. 68).
\end{abstract}

Alvarez Aragón (1998, p. 15) afirmou que no Brasil, mesmo sem possuir a tradição da Universidade Teológica Colonial, as primeiras instituições surgiram "pouco depois dos movimentos autonomistas inaugurados em Córdoba, compartilhando com seus vizinhos bons números das expectativas, dificuldades e vícios".

Oliveira e Azevedo (2008) complementaram informando que o período é caracterizado pela explosão da universidade com relação ao número significativo de cursos, professores, estudantes e instituições. Ainda, segundo os autores, "tal explosão, se por um lado resultou na expansão do ensino, por outro ampliou em muito a pesquisa acadêmica, estendendo-a a novas áreas do conhecimento" (OLIVEIRA e AZEVEDO, 2008, p. 74).

Entretanto, o modelo nascido a partir da Reforma de Córdoba começou a sofrer graves mudanças. Rama (2006) apontou que a expansão da matrícula não estava acompanhada pelo crescimento do financiamento e, ao final dos anos 1970 , o setor público de diversos países começou a manifestar uma incapacidade crescente em manter as taxas de aumentos financeiros.

Sguissardi (2008, p. 996) apresentou a evolução da educação superior no Brasil, mais precisamente entre o período de 1964 a 1994. Segundo o autor, algumas características podem ser destacadas desse período: i. na era do regime militar, predominava-se a matrícula nas instituições públicas de ensino e pesquisa, "61,6\% contra $38,4 \%$ do contingente de estudantes nas instituições privadas"; ii. nos primeiros dez anos do regime, passou de 142 mil matrículas para 937 mil (aumento de 559,8\%). “As matrículas públicas tiveram um crescimento muito inferior à média $(289,1 \%)$ e muito distante do crescimento das matrículas privadas $(990,1 \%)$ "; iii. "ao longo dos governos 
Sarney, Collor e Itamar Franco, os efetivos da educação superior aumentaram apenas $18,7 \%$, cerca de $1,5 \%$ ao ano".

Tabela 1: Evolução das matrículas da educação superior brasileira (1964-1994)

\begin{tabular}{c|c|c|c|c|c|}
\hline & & \multicolumn{2}{|c}{ Matrículas públicas } & \multicolumn{2}{c}{ Matrículas privadas } \\
\hline Ano & Total & Total & $\%$ & Total & $\%$ \\
\hline $\mathbf{1 9 6 4}$ & 142.386 & 87.665 & 61,6 & 54.721 & 38,4 \\
\hline $\mathbf{1 9 7 4}$ & 937.593 & 341.028 & 36,4 & 596.565 & 63,5 \\
\hline $\mathbf{1 9 8 4}$ & 1.399 .539 & 571.879 & 40,9 & 827.660 & 59,1 \\
\hline $\mathbf{1 9 9 4}$ & 1.661 .034 & 690.450 & 41,6 & 970.584 & 58,4 \\
\hline $\mathbf{1 9 6 4 - 1 9 7 4 \%}$ & 559,8 & 289,1 & - & 990,1 & - \\
\hline $\mathbf{1 9 7 4 - 1 9 8 4} \%$ & 49,3 & 67,7 & - & 38,7 & - \\
\hline $\mathbf{1 9 8 4 - 1 9 9 4} \%$ & 18,7 & 20,7 & - & 17,3 & - \\
\hline $\mathbf{1 9 6 4 - 1 9 9 4} \%$ & $1.065,7$ & 687,6 & - & $1.673,7$ & - \\
\hline
\end{tabular}

Fonte: Sguissardi, 2008.

Ao observar os números mais recentes com relação às matrículas na educação superior, no Brasil, tem-se o crescimento de mais de $300 \%$ comparado com a taxa de 1994.

Tabela 2: Estatísticas gerais da educação superior em 2013

\begin{tabular}{|c|c|c|c|c|c|c|}
\hline \multicolumn{2}{|c|}{ Estatísticas básicas } & \multicolumn{5}{|c|}{ Categoria Administrativa } \\
\hline \multirow{2}{*}{$\begin{array}{l}\text { Número de } \\
\text { instituições }\end{array}$} & \multirow{2}{*}{$\begin{array}{l}\text { Total } \\
\text { Geral }\end{array}$} & \multicolumn{4}{|c|}{ Pública } & \multirow[t]{2}{*}{ Privada } \\
\hline & & Total & Federal & Estadual & Municipal & \\
\hline Educação Superior & 2.391 & 301 & 106 & 119 & 76 & 2.090 \\
\hline Cursos & 32.049 & 10.850 & 5.968 & 3.656 & 1.226 & 21.199 \\
\hline Matrículas & 7.035 .977 & 1.932 .527 & 1.137 .851 & 604.517 & 190.159 & 5.373 .450 \\
\hline Ingresso total & 2.742 .950 & 531.846 & 325.267 & 142.842 & 63.737 & 2.211 .104 \\
\hline Concluintes & 991.010 & 229.278 & 115.336 & 82.892 & 31.050 & 761.732 \\
\hline
\end{tabular}

Fonte: INEP, 2013, com adaptações.

A crise financeira enfrentada pela América Latina nos anos de 1980 e a ela acrescida o aumento da dívida externa da região, provocou a queda de $30 \%$ dos investimentos públicos reais na área da educação (VELLOSO, 2000).

Tabela 3: Evolução dos gastos públicos no ensino superior em relação ao $\mathrm{PIB}^{3}$

\begin{tabular}{ccccc}
\hline $\begin{array}{c}\text { Países / } \\
\text { Período }\end{array}$ & 1980 & 1985 & 1990 & 1993 \\
\hline Argentina & 0,52 & 0,45 & 0,49 & 0,60 \\
Brasil & 0,68 & 0,67 & 0,42 & $0,54^{*}$ \\
\hline
\end{tabular}

\footnotetext{
${ }^{3}$ PIB - Produto Interno Bruto. Tem por objetivo medir a atividade econômica e o nível de riqueza de uma
} determinada região. A proporção é a de quanto mais se produz, mais se está consumindo e investindo. 


\begin{tabular}{ccccc}
\hline Chile & 1,45 & 0,89 & 0,56 & 0,56 \\
Colômbia & 0,43 & 0,64 & 0,58 & 0,59 \\
México & 0,68 & 0,48 & 0,42 & 0,57 \\
Venezuela & 1,45 & 1,41 & 1,04 & - \\
\hline
\end{tabular}

Fonte: Velloso, 2000.

Nas décadas de 1980 e 1990, o modelo universitário presente na América Latina passou a sofrer novas alterações, destacadas a seguir. Segundo Rama (2006), no Chile, as características do novo modelo estão relacionadas à divisão das universidades já existentes e à criação de universidades regionais; na Argentina, com a criação de novas instituições públicas nos subúrbios de Buenos Aires para deter o crescimento da Universidade de Buenos Aires (UBA) e; na Venezuela, com o desenvolvimento das universidades experimentais. No Brasil, a expansão se deu pelo desenvolvimento das universidades regionais e também, pelo surgimento de universidades no âmbito municipal. Segundo a Lei de Diretrizes e Bases de 1996 (Lei no 9.394), as universidades são instituições pluridisciplinares de formação dos quadros profissionais de nível superior, de pesquisa, de extensão e de domínio e cultivo do saber humano, que se caracterizam por: i. produção intelectual institucionalizada mediante o estudo sistemático dos temas e problemas mais relevantes, tanto do ponto de vista científico e cultural, quanto regional e nacional; ii. um terço do corpo docente, pelo menos, com titulação acadêmica de mestrado ou doutorado; iii. um terço do corpo docente em regime de tempo integral.

A segunda reforma universitária ocorrida na região da América Latina contribuiu para a consolidação de um sistema educacional binário. Segundo Alvarez Aragón (1998), principalmente nos anos de 1980, houve um crescimento acelerado do número de instituições privadas. Nesse estudo, o autor apontou que, em 1998, a Argentina tinha uma universidade pública para quase um milhão de habitantes, no México a relação era de uma instituição pública para 2,3 milhões de habitantes e o Brasil possuía uma universidade pública para cada 2,6 milhões de habitantes. Sguissardi (2008, p. 998) apresentou a evolução do número de instituições e de matrículas no ensino superior brasileiro no período de 1994 a 2006. 
Tabela 4: Evolução do número de instituições e de matrículas de educação superior (1994-2006)

\begin{tabular}{|c|c|c|c|c|c|c|c|c|c|c|}
\cline { 2 - 12 } & \multicolumn{4}{|c|}{ Número de instituições } & \multicolumn{4}{c}{ Número de matrículas } \\
\hline Ano & Total & Públ. & $\%$ & Priv. & $\%$ & $\begin{array}{l}\text { Total } \\
\text { (mil) }\end{array}$ & $\begin{array}{l}\text { Públ. } \\
\text { (mil) }\end{array}$ & $\%$ & $\begin{array}{l}\text { Priv. } \\
\text { (mil) }\end{array}$ & $\%$ \\
\hline $\mathbf{1 9 9 4}$ & 851 & 218 & 25,6 & 633 & 74,4 & 1.661 & 690 & 41,6 & 970 & 58,4 \\
\hline $\mathbf{2 0 0 2}$ & 1.637 & 195 & 11,9 & 1.442 & 88,1 & 3.479 & 1.051 & 30,2 & 2.428 & 69,8 \\
\hline $\mathbf{2 0 0 6}$ & 2.270 & 248 & 11,0 & 2.022 & 89,0 & 4.676 & 1.209 & 25,8 & 3.467 & 74,2 \\
\hline $\mathbf{1 9 9 4 - 2 0 0 2} \%$ & 92,4 & $-10,5$ & - & 127,8 & - & 109,5 & 52,3 & - & 150,2 & - \\
\hline $\mathbf{2 0 0 2 - 2 0 0 6 \%}$ & 38,7 & 27,2 & - & 40,2 & - & 34,3 & 15,0 & - & 42,8 & - \\
\hline $\mathbf{1 9 9 4 - 2 0 0 6 \%}$ & 166,7 & 13,7 & - & 219,4 & - & 181,7 & 75,1 & - & 275,2 & - \\
\hline
\end{tabular}

Fonte: Sguissardi, 2008.

Segundo dados de Fundora Herrera (2010, p. 44), em 2004, a América Latina já tinha aproximadamente 14 milhões de estudantes na educação superior e, em 2006, alcançou o número de 17.956 .866 matriculados no ensino superior, sendo este 66,5 vezes maior que em 1950. Os indicadores de desenvolvimento do ensino superior mundial das últimas três décadas, apontam para o crescimento da quantidade de estudantes matriculados na educação superior. Em 1960, houve um aumento de 13 para 65 milhões em 1991; em 1994, para 72 milhões; em 2000, para 79 milhões; em 2004, para 132 milhões e; em 2005, para 137 milhões (FUNDORA HERRERA, 2010, p. 44). Didriksson (2008, p. 30) apontou que aproximadamente $60 \%$ das matrículas de educação superior na região se concentram em três países: Brasil (28\%), México (17\%) e Argentina (14\%).

A terceira reforma universitária na América Latina foi causada pela internacionalização das novas tecnologias de comunicação e informação e as demandas de acesso de setores marginalizados, como os grupos indígenas (RAMA, 2006). Segundo o mesmo autor, nessa etapa houve a passagem do modelo dual (público-privado) para um modelo tripartido (público-privado-transnacional), com forte controle de qualidade e altamente competitivo. $\mathrm{O}$ autor defende que o impacto das novas tecnologias

está mudando o cenário global, permitindo distâncias mais curtas, expandir a educação 'transfronteira', gerando educação virtual e viável, não só uma nova prática pedagógica e uma educação não-sala de aula, mas a expansão da sociedade do conhecimento associado com a estrada da informação para todos intangível e, notadamente, para o ensino superior (RAMA, 2006, p. 19, tradução nossa). 
Uma das características apresentadas na terceira reforma é o surgimento da educação virtual não presencial, ou em outras palavras, educação à distância (EAD) (RAMA, 2006). Segundo o autor, em 2000 existiam 173.000 estudantes virtuais em instituições da própria região, o que representava 1,3\% da matrícula.

Ainda com relação ao crescimento do número de instituições e matrículas na educação superior brasileira, pode-se considerar que as políticas governamentais adotadas, mais precisamente a partir do ano de 2001, contribuíram diretamente para o fato. Citam-se aqui cinco iniciativas do governo quanto à educação superior no Brasil: o programa PROUNI, o ENEM, o SISU, o FIES e o sistema de cotas. O Programa Universidade para Todos (ProUni) foi criado no ano de 2004 e tem por objetivo conceder bolsas de estudo integrais e parciais (50\%), para o nível graduação, em instituições privadas de ensino superior (MEC, 2015). O Fundo de Financiamento Estudantil (FIES) possibilita aos estudantes financiar o seu curso de graduação em instituições de ensino privadas. O Exame Nacional do Ensino Médio (ENEM), criado em 1998, passou a ser utilizado como critério de seleção para os estudantes que desejam concorrer a uma bolsa do ProUni e do Sistema Informatizado do MEC (SISU). O sistema de cotas, regulamentado pela Lei $n$ o 12.711 , de 2012 , determina que instituições federais de educação superior devem reservar, no mínimo, 50\% de suas vagas para estudantes que tenham cursado integralmente o ensino médio em escolas públicas. Alia-se aqui a criação dos Institutos Federais de Educação, Ciência e Tecnologia, em 2008, que se caracterizam por serem instituições de educação superior, básica e profissional, pluricurriculares e multicampi, "especializados na oferta de educação profissional e tecnológica nas diferentes modalidades de ensino, com base na conjugação de conhecimentos técnicos e tecnológicos com as suas práticas pedagógicas" (LEI № 11.892, 2015). Todos esses programas e iniciativas mencionados corroboram para o aumento significativo do número de vagas no sistema de educação superior brasileiro.

Considerando a região da América Latina e Caribe como um todo, Rama (2006, p. 8) indicou que, em 1994, a região tinha 5.438 instituições de educação superior das quais 2.515 eram públicas e 2.923 (53,71\%) eram privadas. Segundo Fundora Herrera (2010, p. 46), no período de 2005-2006, a América Latina e Caribe passou a contar com um total de 8.910 instituições de educação superior públicas e privadas, sendo que 1.210 eram universidades e centros universitários. O autor apontou também que do 
total de instituições de ensino superior em 2010, o Brasil figurava em primeiro lugar com 2.547 instituições, seguido do México (2.397), Peru (1.139), Argentina (604) e Equador (424). Com relação, especificamente, às universidades, o Brasil também aparecia no topo da lista dos países com um total de 303, seguido do México (143) e Argentina (103). Em seu estudo, Didriksson (2008) apresentou como pouco mais de 2.900 o total de universidades, entre públicas e privadas, na América Latina e Caribe ${ }^{4}$. No que concerne à educação da pós-graduação, a partir dos anos 2000 a região da América Latina passou a ter pouco mais de meio milhão de estudantes universitários de pós-graduação, representando 4,36\% do total do número de estudantes de educação superior (MORLES e LEÓN, 2003). O crescimento ao longo dos anos das universidades deu margem também para o aumento do número de programas de pós-graduação. No Brasil, de acordo com os dados fornecido pelo GeoCapes ${ }^{5}$, sob a responsabilidade da Coordenação de Aperfeiçoamento de Pessoal de Nível Superior (CAPES), o País tinha no ano de 2013, 1.267 programas de pós-graduação de mestrado e doutorado, distribuídos por todas as regiões brasileiras. O valor corresponde a um crescimento de $80 \%$ em relação há dez anos. Quanto à distribuição de discentes de pós-graduação, no ano de 2013 , tem-se os números

Tabela 5: Distribuição de discentes de pós-graduação no Brasil (2013)

\begin{tabular}{|c|c|c}
\cline { 2 - 3 } & Matriculado & Titulado \\
\hline Mestrado & 113.881 & 45.067 \\
\hline Doutorado & 87.906 & 15.287 \\
\hline
\end{tabular}

Fonte: GeoCapes, 2015, com adaptações.

Ainda com relação aos discentes de pós-graduação, 57\% pertence às instituições federais; $26,7 \%$ figura em instituições estaduais; $15,8 \%$ está presente em instituições privadas e; apenas $0,4 \%$ está em instituições municipais.

Segundo dados do último Censo da Educação Superior de 2013, realizado pelo Instituto de Estudos e Pesquisas Educacionais Anísio Teixeira (INEP), aproximadamente $87 \%$ dos docentes do ensino superior possui mestrado ou doutorado. Ainda, de acordo

\footnotetext{
${ }^{4}$ Nos dados originais do autor, o número total de universidades, entre públicas e privadas, é de 2.940, pois há uma duplicidade dos dados referente à Guatemala.

${ }^{5}$ GeoCapes Dados Estatísticos -<http://geocapes.capes.gov.br/geocapesds/\#>.
} 
com o Censo, o número de mestres e doutores na rede pública de ensino cresceu $90 \%$ e $136 \%$, respectivamente, nos últimos dez anos. Entretanto, visto o cenário brasileiro e o crescimento do número de mestres e doutores nos outros países, Morles (2005) apontou que a educação quaternária (pós-graduação) é vista ainda como uma atividade científica à parte ou marginalizada e elitista. Segundo o autor,

\begin{abstract}
esta atividade acadêmica pode desempenhar um papel importante nos processos de desenvolvimento humano e social. Em efeito, se consideramos que vivemos em sociedades cada vez mais complexas, mais dependentes da informação, do saber especializado e do trabalho intelectual, e se tomamos conta que os programas de pós-graduação procuram somente os profissionais mais capacitados; se refletirmos sobre esta situação, chegamos à conclusão de que todo país necessita desenvolver ao máximo esta atividade (MORLES, 2005, p. 37, tradução nossa).
\end{abstract}

Visto o contexto que circunda o País, para a aplicação desta pesquisa deve-se delimitar as instituições que serão utilizadas na análise. O conjunto das instituições extraídas para a pesquisa foi alcançado tomando por base as informações do Ministério da Educação (MEC). Justifica-se a escolha desta fonte pois é a instância brasileira responsável por credenciar e recredenciar as instituições brasileiras de educação superior.

Segundo o MEC, para iniciar qualquer atividade, as instituições de educação superior devem solicitar o credenciamento junto ao Ministério. Assim, são credenciadas como: faculdades, centros universitários e universidades (MEC, 2015). A diferença de cada instituição se dá por, segundo o MEC:

- as instituições são credenciadas orginalmente como faculdades;

- as universidades se caracterizam pela indissociabilidade das atividades de ensino, pesquisa e extensão. São instituições pluridisciplinares que se caracterizam por: i. produção intelectual institucionalizada; ii. um terço do corpo docente, pelo menos, com titulação acadêmica de mestrado ou doutorado; iii. um terço do corpo docente em regime de tempo integral. A criação de uma universidade federal deve ser feita mediante projeto de lei, já para a criação de uma universidade privada se dará por 
transformação de instituições de ensino superior já existentes e que atendam ao disposto na legislação pertinente;

- os centros universitários são instituições de ensino superior pluricurriculares, que abrange uma ou mais áreas do conhecimento e têm autonomia para criar, organizar e extinguir, em sua sede, cursos e programas de educação superior.

Quanto à categoria administrativa, as instituições brasileiras de ensino superior podem ser classificadas como "públicas (vinculadas aos governos federal, estadual ou municipal) ou privadas (MEC, 2015).

Desta forma, para a realização desta pesquisa são consideradas as universidades brasileiras, públicas e privadas. Como já dito, o conjunto dessas universidades foi obtido por meio do Portal e-MEC ${ }^{6}$, do Ministério da Educação. Ao todo foram recuperadas 197 universidades, no entanto, uma instituição foi desconsiderada por ter sido descredenciada em 2014. Assim, o total de universidades para este estudo é de 196 instituições que estão distribuídas por todas as regiões geográficas brasileiras.

Figura 1: Definição das instituições participantes da pesquisa

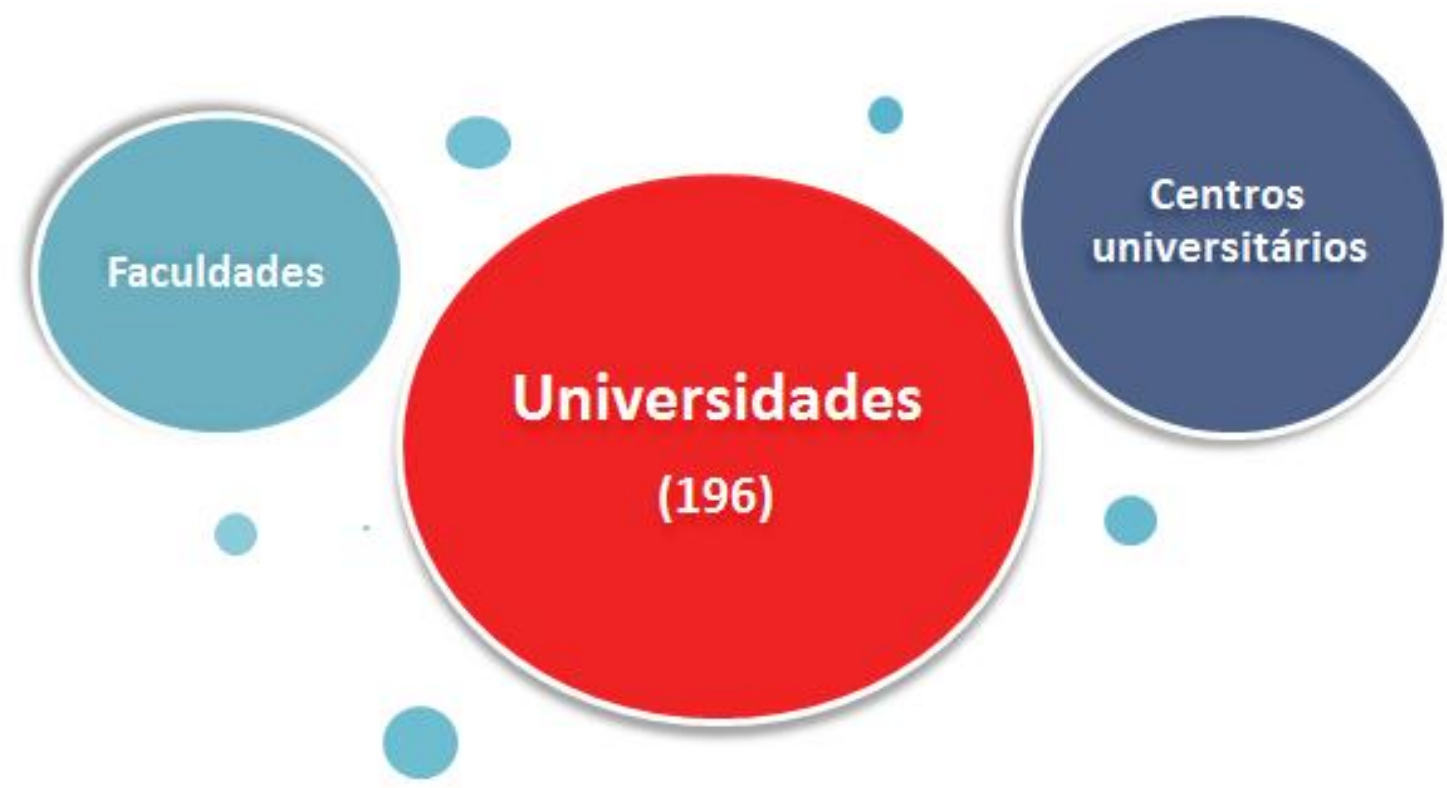

Fonte: Da autora, 2015.

\footnotetext{
${ }^{6}$ Portal de consulta e-MEC <http://emec.mec.gov.br/>.
} 
Este capítulo foi dedicado a apresentar o contexto da pesquisa e delimitadas as instituições que são analisadas, as seções na sequência apresentam a revisão de literatura que serviu de sustentação teórica e a metodologia que foi adotada para a realização deste estudo. 


\section{CAPÍTULO 2}

\section{REVISÃO DE LITERATURA}

\subsection{Informação científica}

A compreensão do conceito de informação científica nesta dissertação se torna imprescindível para a formação e entendimento das discussões que se formam ao longo da pesquisa.

Sabe-se que para a construção da ciência é necessário que haja a circulação da informação entre os seus produtores e seus usuários. A informação que alimenta e que resulta das atividades de pesquisa científica, que constitui componente fundamental do desenvolvimento das nações, é considerada informação científica. Este tipo de informação se diferencia das demais, como é o caso da informação política, informação econômica, informação tecnológica, a informação para indústria ou mesmo informação para cidadania, tanto por sua natureza quanto por seu fluxo e pelo sistema de comunicação no qual está inserida. Isso quer dizer que as forças que governam seus fluxos, as intenções de seus produtores e de seus usuários e demais atores, os canais, cultura estabelecida, entre outros elementos, tornam a informação científica diferente de outros tipos de informação.

O gerenciamento da informação científica é um dos objetos de estudo da Ciência da Informação. Freire (2006) destacou que a partir da II Guerra Mundial se tem a emergência das atividades relacionadas com a informação científica. $\mathrm{O}$ autor apontou que nessa época, os países envolvidos "empregaram um grande número de pessoas que passaram a trabalhar em processos de coleta, seleção, processamento e disseminação de informações que fossem relevantes para o esforço de ganhar a guerra" (FREIRE, 2006, p. 10). O autor ainda apontou iniciativas que dão atenção à gestão da informação científica

a publicação do Journal of Documentation, lançado na Grã Bretanha (ainda em circulação), e do artigo As we may think, do americano Vannevar Bush, ambos em 1945; a Conferência de Informação Científica da Royal Society, realizada em Londres, com quase 500 participantes, em 1948; a publicação do American Documentation, nos Estados Unidos, e do Nachrichten für Dokumentation, na Alemanha, ambos em 1950 e até hoje relevantes 
periódicos da área. Na URSS, o principal indício é a criação, em 1952, do VINITI - Vserossiisky Institut Nauchnoi i Tekhnicheskoi Informatsii (All-Union Institute for Scientific and Technical Information), vinculado à Academia de Ciências da Rússia, com a missão de prover informação para cientistas e especialistas nas ciências técnicas e naturais (FREIRE, 2006, p. 11).

Destaca-se da citação acima, a referência ao Instituto VINITI da antiga União Soviética. A região e os países centrais da Europa já faziam atividades relacionadas com a informação científica e tecnológica. À época, o então diretor e professor Mikhailov do VINITI, publicou em parceria com a Federação Internacional de Documentação (FID), no ano de 1969, o documento chamado FID 435 (Research on Theoretical Basis of Information), no qual apresentavam a Informatika, que tinha como principal objeto de estudo a informação científica e seus processos (FREIRE, 2006). No Brasil, Oddone (2006, p. 46) assinalou para a criação do Instituto Brasileiro de Bibliografia e Documentação $(\operatorname{IBBD})^{7}$, em 1954, como "um órgão de produção e acumulação de informações bibliográficas". De acordo com a autora, o contato com outras instituições internacionais, como a própria FID e a Federação Internacional de Associações e Instituições Bibliotecárias (IFLA),

oferecia acesso a um cenário já em vias de globalizar, enriquecendo o domínio intelectual até ali representado exclusivamente pela biblioteconomia. A convivência com essas novas demandas traduziu-se na adesão da área ao discurso da "informação científica" e à sua progressiva elaboração em termos teóricos e pragmáticos (ODDONE, 2006, p. 46).

Assim, o primeiro curso de mestrado em Ciência da Informação surge, em 1970, no IBBD. O gerenciamento da informação científica passa a ser discutido no País orientou a formação de bibliotecários quanto aos novos serviços que deveriam ser oferecidos para atender à tipologia documental.

Aguiar (1991, p. 10) apontou para as funções da informação científica:

- Divulgar o conhecimento novo obtido a partir de uma pesquisa científica, assegurando assim a prioridade intelectual;

- Constituir insumo para a atividade de pesquisa científica da mesma forma que representa o produto;

\footnotetext{
${ }^{7}$ Atualmente, o IBBD é chamado de Instituto Brasileiro de Informação em Ciência e Tecnologia (IBICT).
} 
- A informação científica, contendo a metodologia seguida na execução da pesquisa, serve como instrumento para possibilitar a própria validação do novo conhecimento.

Reunindo as três funções apresentadas por Aguiar (1991), considera-se, portanto, que a informação científica é constituída por resultados de pesquisas produzidos por pesquisadores ou grupos de pesquisa, que deve ser registrada em um veículo formal de divulgação, no intuito de assegurar a sua autoria. Ademais, essa informação científica, observadas também as metodologias adotadas para a sua produção, serve de insumo para a geração de um novo conhecimento, produzindo uma nova informação científica também registrada formalmente.

Atento a definição de informação científica, as teses e dissertações são tipologias documentais que incorporam também a informação científica. Por esta razão, a análise das práticas adotadas para seu gerenciamento se torna importante para a formação de discussões no escopo de interesse da Ciência da Informação. A próxima seção apresenta o debate acerca da comunicação científica, de um modo amplo, tendo posteriormente um enfoque no processo de comunicação das teses e dissertações.

\subsection{Comunicação científica}

Como apresentado na seção anterior, a informação científica para ser legitimada deve ser divulgada, passar pelo crivo de avaliação e ser aceita pelos demais pesquisadores. A esse processo dá-se o nome de comunicação científica, a qual se torna imprescindível para a realização da própria ciência. A afirmação de que a comunicação científica é parte indissociável da ciência remonta a estudos anteriores, tais como o de Meadows, em 1999, e o de Garvey e Griffith, em 1979. Para Meadows (1999), a comunicação é "tão vital quanto à própria pesquisa" e Garvey e Griffth (1979) ponderaram que a comunicação científica envolve as atividades de produção da pesquisa até a sua disseminação e uso, compreendida desde o momento em que se concebe a ideia do que estudar até o seu aceite pela comunidade científica.

Permeada de métodos e técnicas, a comunicação científica permite que pesquisadores possam divulgar, acessar, usar e desenvolver novas pesquisas. Como 
impactos têm-se o compartilhamento da informação dentro da comunidade científica e a geração de novos conhecimentos. Targino (2000, p. 10) corroborou sobre a importância dessa atividade, ao dizer que a comunicação científica é “indispensável à atividade científica, pois permite somar os esforços individuais dos membros das comunidades científicas". Nesse sentido, a autora afirmou que a comunicação da ciência também proporciona à pesquisa científica credibilidade e visibilidade necessárias no meio social dos pesquisadores e seus pares. Desta forma, a comunicação científica corresponde a uma atividade intelectual e criativa que é passada de um pesquisador para outro (CRANE, 1972). Portanto, a geração de um novo conhecimento necessariamente perpassa o uso de dos resultados de uma pesquisa anterior. E como visto na seção anterior, a informação científica se torna a entrada e a saída no processo de comunicação científica. E apontando para mais um aspecto, o objetivo da comunicação científica é o crescimento do conhecimento, aperfeiçoando a eficácia e eficiência da pesquisa (ROOSENDAAL e GEURTS, 1999). Conclui-se de acordo com o pensamento de Targino (2000) que a informação é um produto e a comunicação um mecanismo que possibilita o intercâmbio de ideias em uma comunidade científica.

Desde as cinco últimas décadas, o avanço das tecnologias de informação e comunicação (TICs) tem provocado alterações significativas também no modo de produção, gerenciamento e disseminação das informações científicas. Meadows (1999) citou que durante a década de 1980,

\footnotetext{
o desenvolvimento da tecnologia da informação e comunicação alcançara a etapa em que podia começar a competir com a impressão em papel como meio universal para difundir informações científicas. Nos últimos anos, portanto, passou a ser razoável examinar a possibilidade de se transferir informações científicas do meio impresso para o meio eletrônico (MEADOWS, 1999, p. 35).
}

Embora a comunicação científica tenha sofrido interferências dos avanços das TICs, a sua finalidade permaneceu estável (BORGMAN, 2007). As TICs são entendidas aqui como importantes ferramentas para o processo da comunicação da ciência. Um dos fatores mais notáveis de sua inserção no processo da comunicação científica, dentre outros inúmeros, é a diminuição do tempo percorrido desde a produção da pesquisa até a sua publicação. Desta forma, o uso dos computadores e da internet tornaram-se 
aliados para os novos modos de produção, armazenamento, gerenciamento, disseminação, recuperação, uso e preservação da informação científica. Tal uso impulsiona para também as novas formas de troca de informações entre os próprios pesquisadores e os pesquisadores e a sociedade, tais como os correios eletrônicos e os fóruns/salas de discussão virtuais. Barreto (2008) apontou para as modificações provocadas pelas TICs. Segundo o autor, as reais alterações são as condições de interatividade e interconectividade do usuário com a informação. Ainda, Barreto (2008) apresentou detalhadamente em um quadro as novas formas de recuperação da informação científica em contrapondo com os antigos locais de pesquisa e armazenamento da informação (Quadro 1).

Quadro 1: Alterações dos processos com a inserção das TICs

\begin{tabular}{|c|c|c|}
\hline PROCESSOS & ANTES DAS TICS & COM AS TICs \\
\hline Pesquisa Bibliográfica & $\begin{array}{c}\text { Livros, periódicos, teses e } \\
\text { dissertações impressas, obras } \\
\text { de referência }\end{array}$ & $\begin{array}{c}\text { Livros e periódicos eletrônicos, } \\
\text { bases de dados, bibliotecas } \\
\text { digitais de teses e dissertações, } \\
\text { portais de periódicos, bases de } \\
\text { referência }\end{array}$ \\
\hline Comunicação entre pares & $\begin{array}{c}\text { Cartas e relatórios impressos, } \\
\text { via correio. Encontros e } \\
\text { conferências }\end{array}$ & $\begin{array}{c}\text { Correio eletrônico, listas de } \\
\text { discussões, grupos em rede, } \\
\text { teleconferências }\end{array}$ \\
\hline Produção & $\begin{array}{c}\text { Relatórios manuscritos, } \\
\text { datilografados, calculadoras } \\
\text { para quantificação de dados }\end{array}$ & $\begin{array}{l}\text { Programas de edição de textos, } \\
\text { softwares estatísticos, } \\
\text { ferramentas de colaboração }\end{array}$ \\
\hline Disseminação da informação & Livros e periódicos impressos & $\begin{array}{c}\text { Periódicos eletrônicos; livros } \\
\text { eletrônicos, sites }\end{array}$ \\
\hline Armazenamento da informação & $\begin{array}{l}\text { Bibliotecas e centros de } \\
\text { documentação }\end{array}$ & $\begin{array}{c}\text { Bibliotecas digitais, repositórios } \\
\text { digitais (open archives), bases } \\
\text { de dados eletrônicas }\end{array}$ \\
\hline Recuperação da informação & $\begin{array}{l}\text { Índices e catálogos; auxílio de } \\
\text { bibliotecários nas instituições }\end{array}$ & $\begin{array}{c}\text { Mecanismos de } \\
\text { busca/recuperação da } \\
\text { informação; serviço de } \\
\text { referência virtual }\end{array}$ \\
\hline Locais de pesquisa & $\begin{array}{l}\text { Bibliotecas e centros de } \\
\text { documentação }\end{array}$ & $\begin{array}{c}\text { Estações de trabalhos } \\
\text { institucionais ou domésticas; } \\
\text { acesso remoto a materiais } \\
\text { eletrônicos }\end{array}$ \\
\hline
\end{tabular}

Fonte: Barreto, 2008, com adaptações.

As atividades desenvolvidas pelos pesquisadores durante o processo de comunicação científica - em um amplo conceito apontadas como comunicação formal e comunicação informal - definem a formação de um sistema de comunicação científica, de acordo com cada área do conhecimento (MUELLER, 2000). Tal sistema de 
comunicação envolve uma variedade de elementos (pesquisadores, informação, os canais formais, os canais informais, instituições (universidades e editoras, por exemplo) e os usuários que são os pesquisadores em potencial) inter-relacionados lhe atribuindo uma complexidade.

Shearer e Birdsall (2002) apresentaram em seu estudo, um sistema de comunicação científica no contexto canadense, que, no entanto, pode ser reaplicado a um contexto internacional. Segundo os autores, o sistema de comunicação tradicional consiste de quatro grandes grupos de atores: pesquisadores, editores, bibliotecas e usuários.

- Os pesquisadores são os que produzem a pesquisa científica;

- Os editores, apontados pelos autores, por "empacotarem" a pesquisa científica e criarem os produtos de informação;

- As bibliotecas que têm o papel de recolher, divulgar e preservar a pesquisa científica;

- Os usuários são responsáveis por traduzirem os resultados das pesquisas científicas.

Diferencia a representação apresentada por Shearer e Birdsall (2002) a referência a fatores externos que têm impactado a comunicação científica ao longo dos últimos anos. São os fatores mencionados pelos autores:

- Tecnologia: a nova tecnologia é mencionada como um dos principais fatores transformador do sistema de comunicação científica. Essa nova tecnologia facilita o acesso aos mais ricos formatos multimídia, possibilitando assim a maior integração de texto, som, imagem e vídeo em altos níveis de interatividade;

- Globalização: os autores apontam para a necessidade dos países em intercambiarem os resultados de suas pesquisas científicas de modo contínuo; 
- Economia: citando como exemplo as dificuldades enfrentadas pelas bibliotecas do Canadá, os autores apontam para o aumento inflacionário dos editores científicos para a aquisição de seus periódicos;

- Mudanças nos padrões de pesquisa: o modo de produção de novas pesquisas está em constante evolução. Surgem novos campos de pesquisa interdisciplinares e multidisciplinares, e também pesquisas colaborativas, apresentam necessidades de informação específicas e exigem mudanças nos sistemas de comunicação científica;

- Política pública: as políticas governamentais e de financiamento à pesquisa científica influenciam fortemente a natureza do sistema de comunicação. Segundo os autores, a comercialização da pesquisa gera questões relacionadas às prioridades de pesquisa, propriedade intelectual, direitos de publicação, entre outras.

Assim, chama-se a atenção para os novos desafios que os atores envolvidos em um sistema de comunicação científica devem enfrentar, mas de um modo conjunto e não separadamente, como o que vem ocorrendo segundo a visão dos autores.

Figura 2: O sistema de comunicação científica

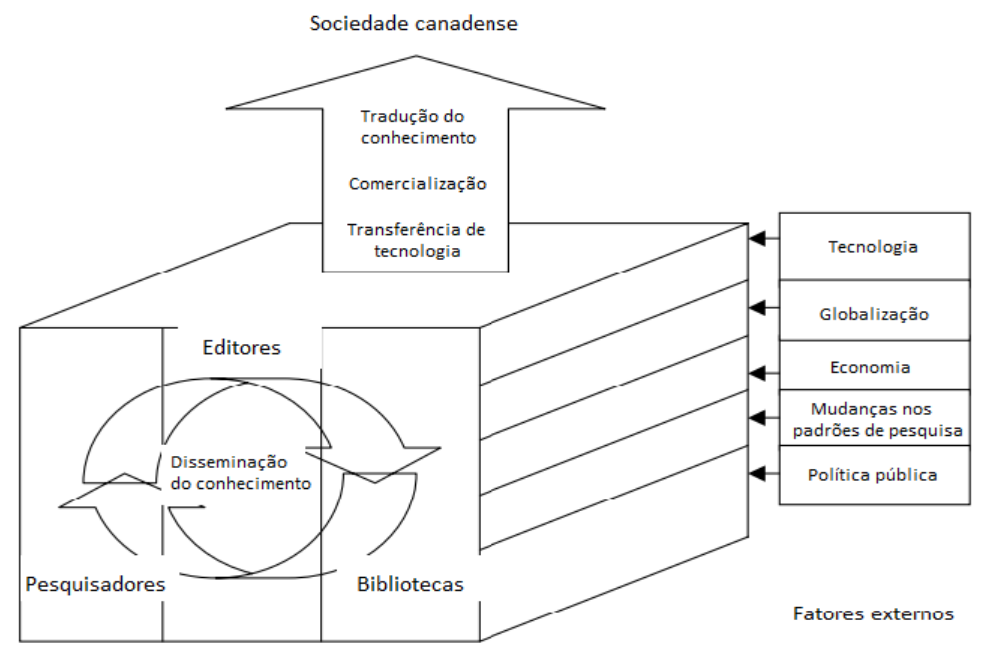

Fonte: Shearer e Birdsall, 2002, com adaptações.

Os fluxos da informação científica presentes em um sistema de comunicação são geralmente representados por modelos. Estes modelos são importantes na medida que 
ajudam a ilustrar os processos envolvidos na comunicação científica e a interação entre os atores do sistema. Neste sentido, a próxima seção explora descritivamente dois modelos de comunicação científica identificados na literatura científica.

\subsubsection{Modelos de comunicação científica}

As representações dos modelos da comunicação científica vêm sendo repensadas e redefinidas ao longo dos anos, graças às alterações provocadas por uma série de fatores que ainda não haviam sido observados nos primeiros esquemas, destacando-se, dentre eles, o uso das tecnologias. Para a proposta desta pesquisa foram selecionados dois modelos que serão abordados com maior profundidade. O primeiro, de Garvey e Griffith e o segundo, o modelo de Björk. Justifica-se a escolha dos dois modelos para esta discussão pelas seguintes razões: o de Garvey e Griffith (1979), por ser uma representação voltada totalmente ao meio impresso, permitindo assim a compreensão das atividades e processos nesse contexto. O modelo foi amplamente divulgado e se tornou referência para o desenvolvimento de outros estudos. O modelo de Björk (2007) por mapear detalhadamente cada processo da comunicação científica e por apresentar as teses e dissertações dentro desse mapeamento.

Ainda que esta pesquisa não explore todos os modelos de comunicação já delineados destacam-se, também, os trabalhos de autores que contribuíram para o entendimento da inserção de novos elementos na comunicação científica. O modelo modernizado de Hurd, de $1996^{8}$ descreve o processo de comunicação científica totalmente baseado nas tecnologias de informação e comunicação, tomando por base o modelo proposto por Garvey e Griffith (1979). Hurd apontou mudanças relevantes no ambiente impresso a partir da inclusão das tecnologias, tais como: a aceleração do processo e a possibilidade de divulgação de resultados obtidos na pesquisa em todas as etapas da comunicação. A autora percebeu também que, por meio das redes de computadores construídas em todo o mundo, o compartilhamento das informações entre os pesquisadores em grandes distâncias foi facilitado. Os trabalhos passaram a ser

\footnotetext{
${ }^{8}$ Hurd publicou, no ano de 1996, modelos de comunicação científica derivados da proposta de Garvey e Griffith (1979): o modelo modernizado, o modelo sem periódico, o modelo sem avaliação por pares e o modelo colaboratório.
} 
construídos colaborativamente, alterando dessa forma, os elementos presentes até então no modelo proposto por Garvey e Griffith. A autora nomeou este modelo de colaboratório.

Outras representações relevantes são as propostas por Costa (1999) e por Leite (2011). Costa propôs um modelo de comunicação híbrido a partir da adaptação das tecnologias de informação e comunicação (meios digitais), apresentadas por Hurd (1996), e da proposta de Garvey e Griffith (meios impressos). Leite (2011) apresentou a sua proposta com base no uso das tecnologias na comunicação científica e o contexto do Acesso Aberto à informação científica.

\subsubsection{Modelo de Garvey e Griffith (1979)}

Na década de 1970, Garvey e Griffith realizaram um estudo empírico no qual observaram como os cientistas da área de psicologia se comunicavam e realizavam a divulgação de suas pesquisas. Baseados na observação propuseram, em 1979, um modelo de comunicação científica que apresenta os processos de comunicação e disseminação da atividade de pesquisa. A apresentação desta proposta de modelo foi importante para a definição dos pilares da comunicação científica quanto à representação dos processos de produção, disseminação e uso.

No modelo proposto por Garvey e Griffith (1979) (Figura 3) no início da pesquisa já é possível produzir relatórios com os primeiros resultados alcançados no estudo. Posteriormente há o direcionamento da pesquisa para os canais científicos informais e formais, como seminários, conferências, convenções, colóquios e a geração de relatórios técnicos. Realizadas as etapas do processo de submissão do manuscrito para um periódico científico, há o envio das versões preliminares para avaliação dos pares. Após a sua aceitação para publicação inicia-se uma série de processos derivados do fluxo editorial. Uma vez publicado em um periódico científico, o impacto da pesquisa será medido por meio das citações em outras publicações que pode vir a impulsionar a realização de novos estudos.

Destaca-se do modelo proposto por Garvey e Griffith o tempo para o reconhecimento da pesquisa após o seu início. De acordo com os autores, $70 \%$ dos pesquisadores já haviam dado início a novos estudos quando a primeira pesquisa 
proposta foi publicada em um periódico científico. Ainda sobre esses pesquisadores, $60 \%$ já tinham concluído uma nova pesquisa. Embora o modelo proposto por Garvey e Griffith tenha estudado o processo de comunicação de uma área específica, passou a ser referência para a representação de outras áreas do conhecimento. O modelo deu margem para outros pesquisadores realizarem adaptações de acordo com as novas demandas e inovações surgidas no decorrer dos anos, como os apresentados anteriormente.

Amparando-se nos estudos de autores citados nesta seção e tomando por base o modelo de Garvey e Griffith (1979), o processo de produção de uma tese e/ou uma dissertação também pode ser relacionado a esse tipo de representação da comunicação científica.

Na proposta a ser apresentada (Figura 4), primeiramente deve-se ponderar que, embora no modelo seja apresentado apenas o termo "Tese", o qual faz referência ao documento produzido para obtenção do grau de doutor, inclui também a dissertação, que faz referência à obtenção do grau de mestre. Ressalta-se que o modelo proposto considera o contexto atual, ou seja, a presença dos meios impressos e os meios eletrônicos. Ademais, considera-se que alguns processos podem não ocorrer de modo linear como a proposta do modelo apresenta, sendo possível assim que algum processo descrito no modelo ocorra anteriormente ou posteriormente a outro.

A produção da tese e/ou dissertação dá início ao processo de comunicação científica no modelo proposto. Os primeiros dados coletados e analisados são lançados em grupos de pesquisa e discussões que auxiliam o pesquisador a avaliar o seguimento da sua pesquisa. Neste momento também são produzidos os relatórios preliminares da tese e/ou dissertação, submetidos para eventos científicos, tais como: conferências, simpósios e colóquios, com a possibilidade do registro desses relatórios nos anais do evento e a publicação nos meios eletrônicos. Ainda no decorrer do desenvolvimento da tese e/ou dissertação, tem-se a fase da qualificação da pesquisa que objetiva avaliar a metodologia proposta para o alcance do objetivo do trabalho. Todo esse processo segue até a conclusão do estudo, momento no qual é feita a sua defesa e, caso o seja considerada satisfatório, dá-se a sua aprovação. Após a sua aprovação, as teses e/ou dissertações podem gerar outras publicações, como artigos científicos. Esta nova produção científica é submetida para avaliação dos editores científicos, quando aceita é 
publicada, podendo o periódico ser indexado em bases de dados, possibilitando uma maior difusão e citação em outros trabalhos.

Quanto ao formato das teses e dissertações, estas podem ser de dois tipos: impresso e digital. A disponibilização em formato impresso requer o espaço físico das bibliotecas e a sua circulação é considerada limitada. Quando da disponibilização digital, as teses e dissertações podem ser armazenadas, com o seu texto completo, em bases de dados de sistemas de informação, como as bibliotecas digitais e os repositórios institucionais. $\mathrm{O}$ alcance a esses documentos em formato eletrônico é maximizado, uma vez que transcende as barreiras físicas e territoriais.

Por fim, a disponibilização dos resultados de pesquisa materializados em teses e dissertações possibilita a citação dos autores na literatura científica. 
Figura 3: Modelo de comunicação científica de Garvey e Griffith (1979)

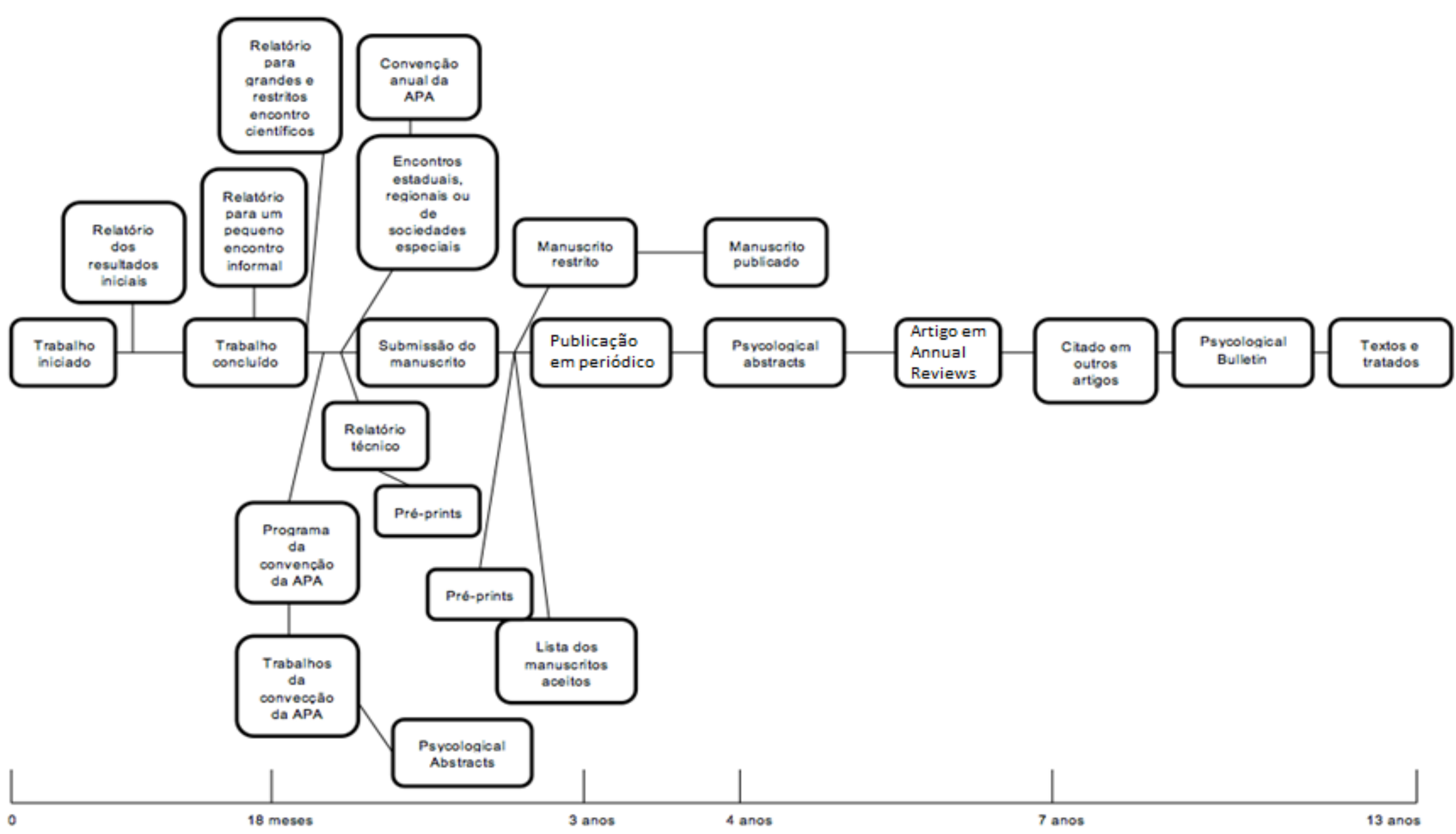

Fonte: Garvey e Griffith, 1979, com adaptações. 
Figura 4: Proposta de modelo de comunicação científica com a presença da tese de doutorado

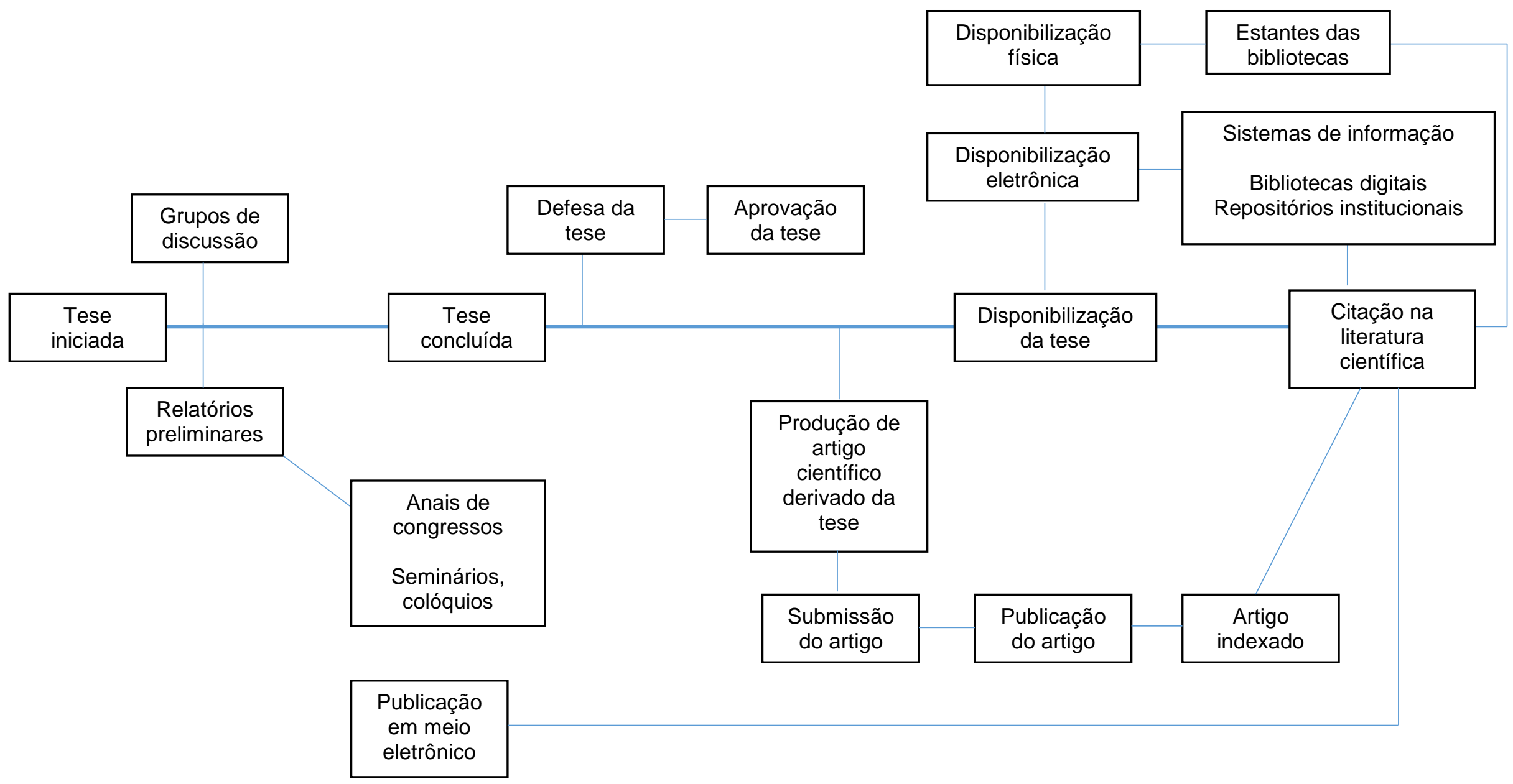

Fonte: Da autora, 2015, adaptado de Garvey e Griffith (1979); Hurd (1996). 


\subsubsection{Modelo de Björk (2007)}

O modelo proposto por Björk (2007) detalha o caminho percorrido para a publicação científica por meio de um mapeamento de processos e atividades da comunicação científica. O processo maior é desdobrado alcançando um detalhamento x, com a avaliação do impacto causado pela internet. Graças à amplitude do modelo, a versão atualizada é chamada de modelo de ciclo de vida da publicação científica.

Embora o estudo desenvolvido por Björk apresente diversas formas da produção científica, a ênfase está na publicação de artigos científicos em periódicos. Deve-se ressaltar que a parte do modelo dele que será destaque neste estudo é da publicação de Monografias (documentos monográficos).

O modelo de Björk (2007) inclui hierarquicamente atividades de todo o processo, abarcando as tarefas dos:

- Pesquisadores que realizam a pesquisa, escrevem as publicações e agem como revisores;

- Financiadores da pesquisa que influenciam fortemente o processo;

- Editores que gerenciam e realizam o processo real de publicação;

- Bibliotecas que ajudam no armazenamento e fornecimento do acesso às publicações;

- Leitores que buscam, recuperam e leem as publicações;

- Profissionais que implementam os resultados de pesquisa direta ou indiretamente.

Para a construção de sua proposta, Björk fez uso do método de modelagem de processos, Integration Definition for Function Modeling (IDEF0). Os principais conceitos do método IDEFO são a atividade e o fluxo. Segundo o autor (2007, p. 6), "as atividades são mostradas como retângulos e seus nomes começam com verbos. Os fluxos são representados por setas e os nomes são substantivos".

Em seu estudo, Björk (2007) propôs 33 diagramas (modelos) apresentados separadamente, com sete níveis de profundidade, totalizando um conjunto de 113 atividades e 250 fluxos. O primeiro diagrama apresentado (Figura 5) retrata a ideia geral 
do estudo. Com apenas uma atividade descrita, o autor justificou que a filosofia do diagrama inicial é mostrar que, a ciência entendida como um sistema global de criação e compartilhamento do conhecimento, pode auxiliar a vida cotidiana, bem como criar novos conhecimentos científicos. Assim, do ponto de vista acadêmico a saída principal são os novos conhecimentos científicos. Do ponto de vista da sociedade que financia a pesquisa o mais importante é a melhoria na qualidade de vida.

Para efeitos de discussão nesta dissertação, selecionou-se a representação do modelo A32131 - Publish as Monograph (Figura 6). Neste modelo são apresentados três tipos distintos de monografias: os relatórios, as teses de doutorado e os livros. Björk (2007, p. 20) apontou que os relatórios são tipicamente produzidos pelo governo ou laboratórios privados de pesquisa ou, em alguns casos, por departamentos universitários. Segundo o autor, esses relatórios eram vendidos, entretanto, frisou que hoje é possível ter acesso a eles livremente por meio da internet. As teses de doutorado são apontadas como um caso especial, que passa por um processo "rigoroso de qualidade" e são mais extensas que os relatórios e artigos de periódicos. Björk (2007) também considerou que, atualmente, cada vez mais as universidades estão disponibilizando-as em seus repositórios institucionais. 
Figura 5: Modelo de comunicação científica A-0 de Björk (2007)

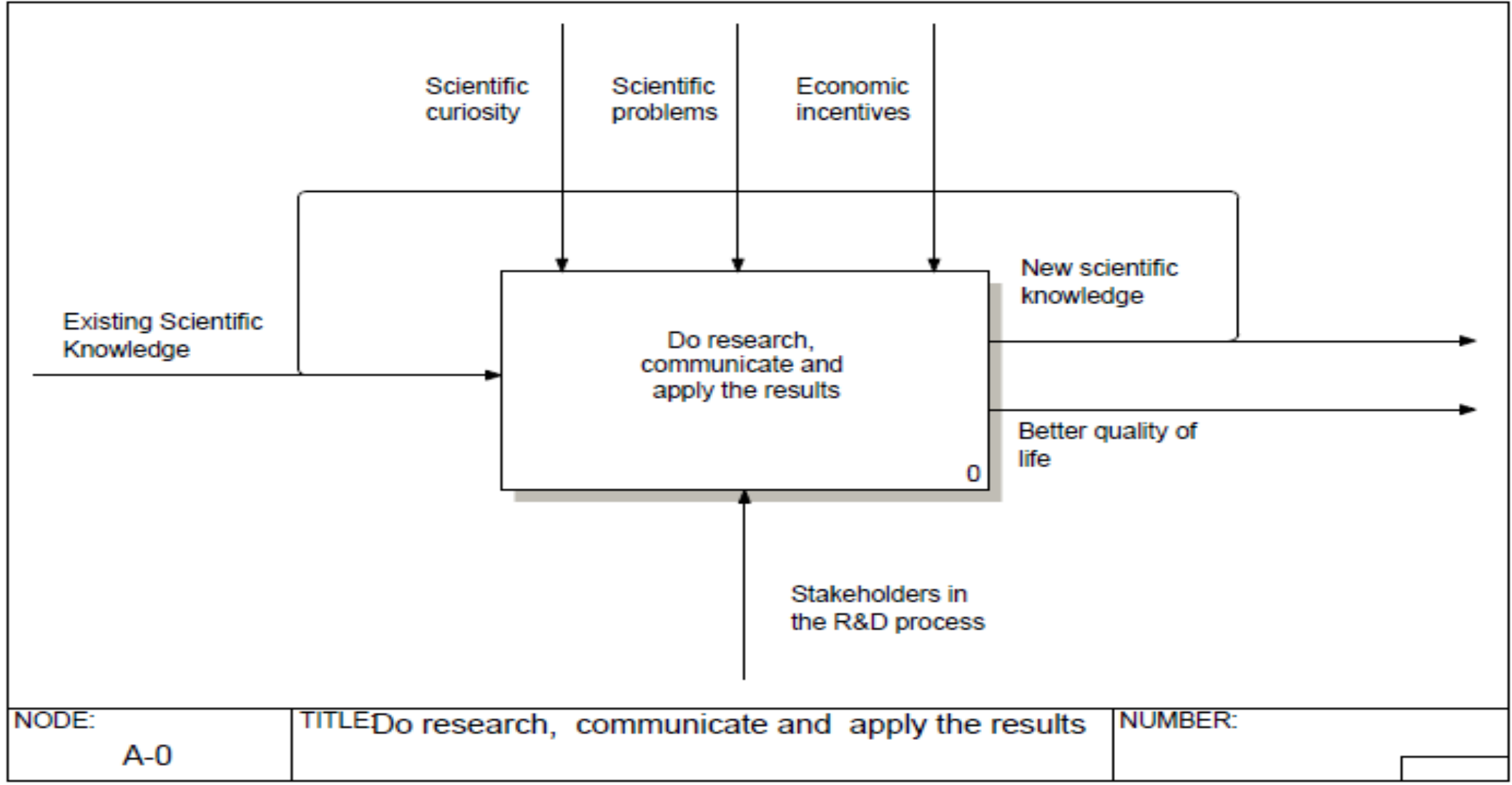

Fonte: Björk, 2007. 
Figura 6: Modelo de comunicação científica - Modelo A32131 de Björk (2007)

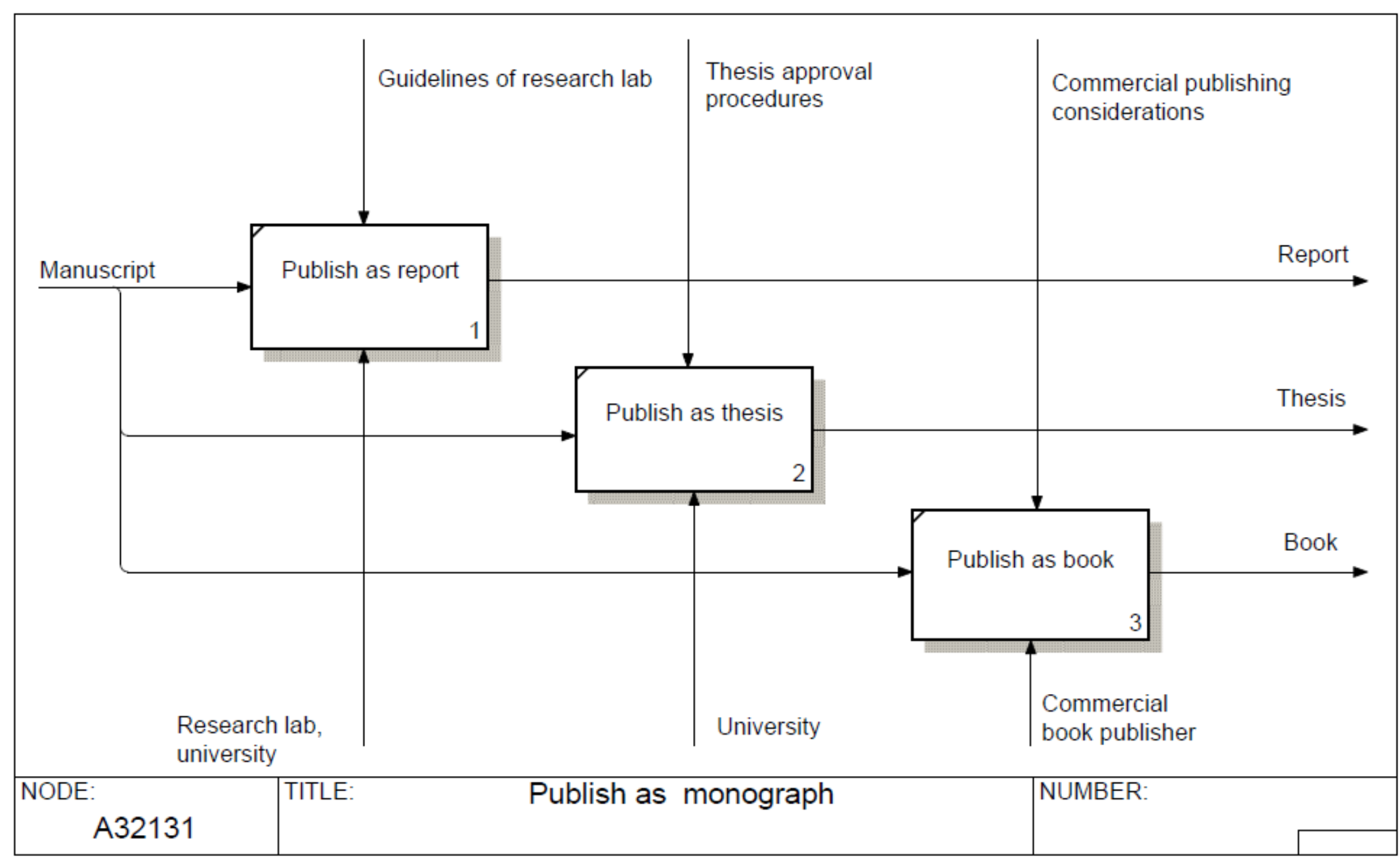

Fonte: Björk, 2007. 
Compreende-se dos modelos supracitados que a comunicação científica se realiza por meio de vários meios, divididos em comunicação formal e comunicação informal, formando assim, um sistema de comunicação científica. Em seu estudo de 1966, Menzel enunciou cinco hipóteses sobre a comunicação científica: 1- a comunicação na ciência constitui um sistema; 2- vários canais podem atuar em cooperação na transmissão de uma mensagem; 3- a comunicação informal tem papel vital no sistema de informação científica; 4- os cientistas constituem público específico; 5- os sistemas de informação científica assumem múltiplas funções.

As obras monográficas, como apresentadas no modelo de Björk (2007), são canais de comunicação científica. Desta forma, a discussão sobre canais formais $x$ informais se torna útil nesta pesquisa.

\subsubsection{Comunicação formal x Comunicação informal}

Como visto, a comunicação científica é definida como o processo que envolve as trocas de informações entre os pesquisadores. Para a máxima disseminação e circulação dos seus resultados de pesquisas no meio científico, esses pesquisadores fazem uso de diversas formas de comunicação. A essas diferentes formas de comunicação no processo de comunicação científica são nomeadas, ou comumente conhecidas, como canais formais e canais informais (MENZEL, 1958; MEADOWS, 1999; CASE, 2002; BORGMAN, 2007).

Embora haja o uso dos dois canais de informação, nenhuma forma se sobrepõe a outra, como afirmou Targino (2000). Segundo a autora, os meios de comunicação

\footnotetext{
não são excludentes ou antagônicos. Ao contrário, complementam-se e interagem. E mais, ora apresentam características formais, ora informais, pois o comportamento dos cientistas no domínio informal inclui em seu escopo aspectos do comportamento formal. Assim, emerge a divisão tradicional: comunicação formal ou estruturada ou planejada e comunicação informal ou não estruturada ou não planejada (grifos da autora), ambas essenciais à evolução do conhecimento como soma renovada de mensagens que atualizam a sociedade no espaço e a perpetuam no tempo (TARGINO, 2000, p. 18).
}

A literatura científica que inclui as discussões na área da comunicação científica apresenta diversas definições que possibilitam identificar as diferenças na natureza das 
comunicações formais e informais. O levantamento das características dos canais formais e informais é importante para posterior análise das mudanças provocadas pelas tecnologias de informação.

As comunicações científicas formais são apontadas como as publicações de maior alcance de público (MEADOWS, 1999; MUELLER, 2000; BORGMAN, 2007). Para Le Coadic (1996), as comunicações formais são denominadas como comunicação escrita. Borgman (2007) afirmou que as comunicações formais são aquelas que estão disponibilizadas por um longo período de tempo. Targino (2000, p. 18) enumerou alguns meios que são caracterizados como comunicação formal: "livros, periódicos, obras de referência em geral, relatórios técnicos, revisões de literatura etc". A literatura também apresenta a comunicação formal como confiável e de qualidade por ser entendido que essa comunicação compreende as pesquisas científicas que passam pela análise, certificação e divulgação.

Por outro lado, a comunicação científica informal é apontada como restrita a um público específico (MEADOWS, 1999; RUSSELL, 2001). Utiliza canais de comunicação em que a informação é repassada por meio de contatos interpessoais, colégios invisíveis, discussões em grupos de pesquisa, reuniões, palestras entre outros. Esse modo de divulgação e disseminação traz um aspecto relevante para as comunicações informais: a rapidez na divulgação da pesquisa para a comunidade científica. Targino (2000, p. 20) considerou que a agilidade da comunicação informal impulsiona a obtenção de informações para trabalhos rotineiros. Segundo a autora, o contato "face a face", em alguns procedimentos, é mais adequado do que a consulta às fontes escritas. A autora seguiu o raciocínio afirmando que

\footnotetext{
a leitura de livros, revistas, relatórios, ainda que indispensável ao processo de aprimoramento profissional, não é suficiente. São fundamentais a correção, a revisão, a retroalimentação e o estímulo que só o contato pessoal oferece. É ele que cria laços humanos, propiciando confidências, trocas de opinião e o fortalecimento do espírito de grupo (TARGINO, 2000, p. 20).
}

Diante disso, Le Coadic (1996) e Meadows (1999) apontaram como maior característica da comunicação informal, a oralidade, denominando-a como comunicação oral. Meadows (1974, p. 93) resumiu a discussão entre a diferença de comunicação formal e informal em um quadro (Quadro 2) a seguir apresentado. 
Quadro 2: Comunicação formal x Comunicação informal

\begin{tabular}{|l|l|}
\hline \multicolumn{1}{|c|}{ COMUNICAÇÃO FORMAL } & \multicolumn{1}{c|}{ COMUNICAÇÃO INFORMAL } \\
\hline Público potencialmente grande & Privada, público restrito \\
\hline Informação armazenada e recuperável & $\begin{array}{l}\text { Informação não armazenada e não } \\
\text { recuperável }\end{array}$ \\
\hline Informação relativamente antiga & Informação recente e atualizada \\
\hline $\begin{array}{l}\text { Fluxo da informação é orientado pelo } \\
\text { usuário }\end{array}$ & $\begin{array}{l}\text { Fluxo da informação é orientado pelo seu } \\
\text { produtor }\end{array}$ \\
\hline Disseminação uniforme & Direção do fluxo escolhida pelo produtor \\
\hline Redundância moderada & Redundância, às vezes, muito importante \\
\hline Pouco feedback para o autor & Feedback significativo para o autor \\
\hline
\end{tabular}

Fonte: Meadows, 1974, p. 93, com adaptações.

Embora sejam apresentadas características distintas para os dois canais de comunicação científica, de acordo com Russell (2001) essas comunicações "estão experimentando alterações radicais, de tal modo que a distinção entre ambas se torna cada vez mais difícil". Para a autora os papeis chamados tradicionais designados ao produtor, ao "processador" e ao usuário também estão sofrendo importantes mudanças.

\footnotetext{
A autopublicação de um informe de pesquisa na rede por parte dos científicos ou das instituições responsáveis do trabalho não pode ser definida com claridade em términos da tradicional divisão de comunicação formal/informal. Informal porque a comunicação não é parte de um formato fixo, como um artigo de revista, e formal, a comunicação não está limitada a um grupo finito, sim disponível para qualquer um que a deseje (RUSSELL, 2001, web).
}

Considera-se que as alterações sinalizadas por Russell são provocadas direta ou indiretamente pelos avanços das TICs e pelo surgimento da internet.

Em 1979, Heloísa Christovão já apontava para o destaque que a comunicação informal havia alcançado nos últimos anos. Sobre essa ascensão dos canais informais de comunicação, a autora afirmou que o seu uso crescente não se deve às falhas no sistema de comunicação formal ou estruturada. Uma das razões apontada por Christovão (1979, p. 4) foi que "seu fortalecimento decorre tanto do permanente esforço dos especialistas na busca contínua de informação atualizada, quanto da demanda inerente à ciência moderna: rápida e acurada comunicação". 
Em 2003, Pinheiro realizou um estudo que tinha por interesse identificar com quais objetivos os pesquisadores utilizavam a internet para o desenvolvimento das suas atividades científicas. Como resultados, a autora destacou que

os maiores índices estão relacionados à comunicação científica entre pares $(96,4 \%)$, seguida do encaminhamento de trabalhos a congresso (92,5\%), a comunicação para fins didáticos $(89,1 \%)$ e a submissão de artigos para periódicos (83,4\%) (PINHEIRO, 2003, p. 68).

Como parte das conclusões de seu estudo, Pinheiro (2003, p. 72) afirmou que a comunicação informal "mantém a sua predominância e é expandida agora por meio de computadores e via rede, tendo o correio eletrônico como recurso principal, secundado pelas listas de discussão". No entanto, observa-se que em um período mais recente, outros recursos viabilizados por meio da internet têm possibilitado também a propagação da comunicação informal, como as redes sociais e os blogs (PANDO, 2013).

No entanto, o não registro escrito da comunicação informal passou a dificultar o seu armazenamento e posterior recuperação. Targino (2007, p. 20) justificou que "por ser flexível e fluida, perde-se num certo espaço de tempo". A informação divulgada a um grupo específico torna também o acesso restrito, difícil e de pouca circulação, como mencionou Meadows (1999).

Como apontado por Russell (2001), os avanços das TICs e as mudanças dos meios impressos para os meios eletrônicos têm provocado profundas mudanças nas comunicações informais. A literatura cinzenta, identificada na literatura científica como o tipo de publicação do canal informal, será tratada na próxima seção e pretende apresentar essas alterações. Sua especial atenção se deve a que, historicamente, as teses e dissertações são classificadas dentro desta tipologia.

\subsection{Literatura cinzenta}

As seções anteriores desta pesquisa apresentaram, dentre outras, questões relacionadas com as mudanças e evoluções ocorridas no processo da comunicação científica. Tais adventos contribuem para o crescente número de pesquisas científicas realizadas em todo o mundo. Na atividade de geração dessas novas pesquisas os canais 
informais de comunicação têm ganhado destaque, aliados às novas tecnologias de comunicação e informação, uma vez que oferecem maior velocidade na transmissão das informações. Neste contexto, a literatura cinzenta, enquadrada como uma tipologia documental pertencente ao canal informal de comunicação, também tem passado por profundas mudanças quanto a sua produção e, principalmente, sua disseminação.

O termo "literatura cinzenta" corresponde à tradução do termo inglês Grey Literature. Essa codificação em cor para uma tipologia documental específica foi adotada pela Inglaterra para identificar as diferentes comunicações. Población (1992) sintetizou essas codificações utilizadas no País.

(...) para identificar novelas apresentadas em edições pouco valorizadas e vendidas a baixo custo, vulgarmente conhecidas como yellow - as amarelinhas. (...) documentos oficiais ingleses, impressos em papel branco, a partir de 1899, passaram a ser conhecidos como os white papers. Essa tendência inglesa levou-os a denominar de green papers, a partir de 1967, os documentos destinados às discussões governamentais. Nas Ilhas Britânicas, a coleção de relatórios oficiais, por serem encadernados com a capa azul, passaram a ser conhecidos por blue books, enquanto os livros do fisco, identificados pela capa preta, caracterizavam os black books. Relacionando a cor com o conteúdo, os ingleses destacam o vermelho como um alerta para visualizar várias listas de espécies perigosas, conhecidas como red data books (POBLACIÓN, 1992, p. 243).

A respeito da adoção da cor cinza, Población (1992, p. 243) sinalizou que tal cor "não traz em si uma conotação negativa que poderia ser interpretada como imprecisa, vaga ou pouco consistente". A autora defendeu a afirmação ao apontar para estudos que mostram o uso de documentos caracterizados como cinzentos como fontes para a produção de outras comunicações.

Nesse sentido, chega-se ao ponto da necessidade de se diferenciar a literatura cinzenta das demais literaturas. Os resultados de pesquisa, publicados de acordo com o modelo de comunicação científica tradicional, podem ser comumente encontrados em sistemas de informação, e por isso a este tipo de informação é dada a denominação de literatura branca. A este tipo de literatura são atribuídos critérios de qualidade e confiabilidade. Às outras fontes de informação que não percorrem o modelo tradicional, conhecidas como não-convencionais, dá-se o nome de literatura cinzenta. Ao aprofundar um pouco mais essa diferenciação, Côrtes (2006, p. 14) definiu como literatura branca aquela em que as "publicações cujos critérios de aceitação - baseados 
em peer-review ou seleção pelos editores - garantem um aval quanto à qualidade dos conceitos emitidos ou metodologia adotada". Segundo o mesmo autor, a literatura cinzenta não sofre o mesmo processo da literatura branca, sendo "em muitos casos, especialmente para as ciências sociais aplicadas, a literatura cinzenta constitui na única fonte primária disponível sobre determinados assuntos" (CÔRTES, 2006, p. 14).

Ao observar algumas definições da literatura cinzenta identificadas na literatura científica há em comum a menção ao aspecto de que essa tipologia documental não é divulgada pelos canais formais ou convencionais e que, portanto, não há o controle dos editores científicos. Neste contexto, Wood (1990) comentou que a literatura cinzenta é o tipo de material que não é disponibilizado por meio de canais de venda. Em 1995, Comberousse definiu a literatura cinzenta como sendo o conjunto de documentos como relatórios, teses e anais de congressos que escapam aos circuitos comerciais, representando uma fonte de informações inéditas. Carvalho (2001) apresentou a definição de literatura cinzenta como "aquela que é produzida em todos os níveis de governo, academias, negócios e indústrias em formato impresso ou eletrônico, mas que não é controlada pelos editores comerciais". Côrtes (2004) apontou a definição de literatura cinzenta como todo o texto técnico ou científico que não é submetido à apreciação ou avaliação sob a forma de peer-review, blind review ou escolha pelos editores ou conselho editorial. E, Brugnollo Filho et al (2006) afirmaram que a literatura cinzenta é

\footnotetext{
um tipo de literatura não convencional e semipublicada. É constituída por um conjunto de publicações formado por materiais que vão desde publicações não revisadas até documentos de conteúdo não muito concreto, entre eles: relatórios, teses, publicações governamentais, traduções avulsas, dissertações, literatura originada de encontros científicos ou gerada durante ou após o término de uma pesquisa, anais de congressos e preprints, que não são disponíveis em esquemas comerciais de venda; é aquela literatura produzida em todos os níveis de governo, nas áreas acadêmicas, do comercio, da indústria, nos formatos impressos e eletrônicos, mas que não é controlada por editores comerciais. Tem pouca ou nenhuma probabilidade de serem adquiridos através de canais usuais de venda de publicações, já que na origem de sua elaboração o aspecto comercialização se contrapõe àquela que designa os documentos formais, a literatura branca (BRUGNOLLO FILHO et al, 2006, p. 5).
}

Desta forma, é possível extrair, das definições apresentadas acima e de outras identificadas na literatura, mas não citadas aqui, alguns aspectos importantes que foram 
utilizados para caracterizar a literatura cinzenta até o momento. Entretanto, até o final desta seção se observará que alguns aspectos já não mais se aplicam à caracterização da literatura científica.

- Documentos que não são publicados em canais habituais de transmissão científica ou canais tradicionais ou comerciais (ÁLVAREZ-OSSORIO, 1988; WOOD, 1990; FARACE e FRANTZEN, 1998);

- Documentos de acesso restrito ou de difícil acesso (ARTUS, 1994; ALMEIDA, 2000);

- Documentos que não possuem controle bibliográfico (ALMEIDA, 2000);

- Documentos com maior rapidez de divulgação (POBLACIÓN, NORONHA e CURRÁS, 1995);

- Documentos que têm como características a falta de intencionalidade de sua publicação (ORERA ORERA, 2003).

A literatura científica aponta que o uso do termo foi consolidado na Europa no Seminário ocorrido em York (UK), no ano de 1978. Entretanto, seu uso pode ser datado desde 1920 na Alemanha, conhecida como Kleinschrifttum (pequena literatura) controlada pela Bibliografia Nacional Alemã (ALMEIDA, 2000). E, ainda, o termo apareceu pela primeira vez na lista de palavras-chave da Library and Information Science Abstracts (LISA), em 1976 (ALBERANI e CASTRO, 2000).

O Seminário de York, organizado pela Comissão das Comunidades Europeias ${ }^{9}$ e pela Biblioteca Britânica, é considerado o marco para a apresentação e início das discussões sobre a literatura cinzenta na Europa (ALBERANI e CASTRO, 2000; ALMEIDA, 2000). A partir da realização do Seminário, em 1978, a Europa foi envolvida por discussões a respeito da literatura cinzenta e suas necessidades de desenvolvimento de novos estudos sobre o tema e as contribuições dessa literatura para a produção de documentos pertencentes à chamada literatura branca. No próprio Seminário de York, os participantes solicitaram à comissão organizadora para que ordenassem um estudo

\footnotetext{
${ }^{9}$ Hoje é chamada de União Europeia.
} 
visando verificar a existências de práticas, padrões e guias para uma boa apresentação, legibilidade e reprodução desses documentos cinzentos (ALBERANI e CASTRO, 2000).

Como fruto desses debates foi criada a European Association for Grey Literature Exploitation (EAGLE), que então desenvolveu, em 1980, o System for Information on Grey Literature in Europe (SIGLE). O SIGLE era um sistema descentralizado que tinha por objetivo identificar e reunir toda a "produção cinzenta" gerada por países da Comunidade Europeia em um banco de dados online, facilitando, assim, o acesso aos documentos. O funcionamento do sistema se dava por meio de uma rede, na qual cada país era representado por centros de documentação ou bibliotecas nacionais dos quais eram enviados os registros dos documentos informando dados catalogados. Como apontou Almeida (2000, p. 51), cada documento registrado no SIGLE era identificado por um código do respectivo país. Desta maneira, após a consulta na base de dados era possível identificar a localização e ter acesso à informação desejada.

O sistema SIGLE funcionou por aproximadamente 25 anos e, no ano de 2005, os membros da EAGLE decidiram por desfazer a associação, interrompendo, assim, a entrada de novos documentos na base e a retirando do ar. Todavia, já no contexto do Movimento de Acesso Aberto à Informação Científica, o Institut de I'Information Scientifique et Technique (INIST-CNRS) lançou o projeto OpenSIGLE. Segundo informações da própria página do projeto ${ }^{10}$, o Instituto transferiu o banco de dados do SIGLE para um novo sistema desenvolvido no software livre DSpace, tornando os documentos disponíveis gratuitamente. Ainda, segundo o histórico apresentado na página web, nos anos de 2009 e 2010, a GreyNet International se juntou à OpenSIGLE acrescentando à base os preprints das Conferências de Literatura Cinzenta. Em 2011, o OpenSIGLE fez uma nova mudança de plataforma e o sistema passou a ser chamado de OpenGrey. De acordo com o OpenGrey (2014, web), a literatura cinzenta é entendida como um campo estudado pela Ciência da Informação que lida com a produção, distribuição e acesso a vários tipos de documentos produzidos em todos os níveis de governo, acadêmico, empresarial e organizacional, em formato eletrônico e impressos, não controlados pela publicação comercial.

\footnotetext{
${ }^{10}$ Página web do projeto OpenGrey <http://www.opengrey.eu/>.
} 
Destaca-se que os avanços tecnológicos e as consequentes alterações nos processos de comunicação científica implicaram na mudança de espaço, tanto de armazenamento quanto de acesso, da literatura cinzenta. Assim, após anos passados do Seminário de York, em 1978, as definições sobre o que caracterizaria a literatura cinzenta voltaram a ser pensadas, uma vez que as primeiras afirmações não mais condizem com a realidade. Neste cenário, há o fenômeno apontado por Población (1997) de "branqueamento" da literatura cinzenta tornando-a menos cinza.

A partir do momento em que os "documentos cinzentos" passam a ser armazenados, organizados e disseminados por meio de sistemas de informação, critérios como dificuldade de acesso, localização, tratamento e divulgação devem ser desconsiderados. Entende-se, assim, a necessidade de redefinir o conceito de literatura cinzenta nos dias atuais. Deste modo, a literatura cinzenta passa a ser constituída de documentos que, por natureza, não seguem o processo de publicação comercial, contudo não significa dizer que não tenham ampla divulgação e acesso, uma vez que a internet e a automatização dos sistemas possibilitam a execução desses processos. Defende-se, portanto, o uso do termo "literatura cinzenta" para diferenciar da literatura comercial. Observar-se-á nas próximas seções desta dissertação o surgimento e a discussão de sistemas de informação desenvolvidos para o armazenamento de literatura cinzenta, como os preprints.

As teses e dissertações (a exemplo de documentos cinzentos e objeto de estudo desta pesquisa), no cenário atual, já podem ser facilmente identificadas e acessadas por meio de sistemas de informação de universidades e institutos de pesquisa. Moreira (2005, p. 60) afirmou que "atualmente, documentos tradicionalmente cinzentos como as teses e dissertações vêm se tornando cada vez mais visíveis graças aos esforços de criação de bibliotecas digitais de teses e dissertações (...)".

A próxima seção buscará retratar as teses e dissertações e as discussões acerca das mudanças provocadas pelas TICs a essa tipologia documental.

\subsubsection{Teses e dissertações}

Considera-se que a qualidade das instituições de ensino e pesquisa é refletida pela qualidade das produções intelectuais de seus alunos. As teses e dissertações 
refletem uma das habilidades da instituição em guiar e dar suporte aos trabalhos originais (UNESCO, 2001). Em sua maioria, as teses e dissertações são os primeiros trabalhos realizados pelos pesquisadores (GOLDSMITH, 2010), desenvolvidas no contexto dos programas de pós-graduação, orientadas por um especialista do tema e rotuladas como literatura cinzenta no sentido de que não fazem uso de um canal comercial de publicação e disseminação (REPP e GLAVIANO, 1987; CAMPELLO, 2000; BHAT E MUDHOL, 2014).

As dissertações são defendidas para a obtenção do grau de mestre e é processo pelo qual o aluno deve demonstrar a sua "capacidade de sistematização e domínio do tema e da metodologia científica" (BRUGNOLLO FILHO et al, 2006, p. 12), enquanto a tese é realizada visando a obtenção do título de doutor. Para tanto, o aluno deve ser capaz de, fazendo uso do que foi apreendido durante o processo de mestrado, realizar, necessariamente, uma pesquisa original (BRUGNOLLO FILHO et al, 2006). Observa-se que as associações apresentadas de dissertações e teses para a obtenção dos títulos de mestre e doutor, respectivamente, é aplicada, neste caso, para o Brasil. Em outras localizações os termos podem ser utilizados para uma aplicação mais generalizada, como na "Grã-Bretanha, o termo tese (thesis) é geralmente utilizado para descrever todo o gênero, independentemente do grau acadêmico a que se refere. Já nos EUA e na Europa continental o termo mais utilizado é dissertação (dissertation) (BRUGNOLLO FILHO et al, 2006, p. 12).

A apresentação de teses e dissertações para a conferência de graus acadêmicos remonta do século XII, no âmbito das universidades medievais (CAMPELLO, 2000). Moxley (2001, p. 62) apontou que a primeira tese submetida, em 1860, compreendia " $a$ six-page, hand written thesis at Yale University". Na definição de Funaro e Noronha (2006), as teses e dissertações correspondem às pesquisas monográficas que possibilitam a verticalização do conhecimento.

Segundo Yiotis (2008), as teses e dissertações de todos os departamentos de uma instituição se tornam parte do acervo de sua biblioteca. Uma vez aprovadas, os estudantes entregam cópias da versão impressa final à biblioteca. Entretanto, o autor ressaltou que, em geral, a circulação desses documentos, em versão impressa, se torna limitada à comunidade universitária. 
Orera Orera (2003) apresentou a função ambivalente das teses e dissertações frente ao debate de sua disponibilização ou restrição ao público. A primeira função é entendida como um documento administrativo apresentado para a obtenção de um grau acadêmico e cuja sua defesa é pública, sendo assim, o documento é de caráter público e que deve ser disponibilizado. Por outro lado, o documento é uma obra original de um autor a qual também deve ser submetida às regras de proteção dos direitos autorais.

Ao retornar à primeira afirmação desta seção - a qualidade das instituições de ensino e pesquisa é refletida pela qualidade das produções intelectuais de seus alunos-, as teses e dissertações representam mecanismos importantes em múltiplos aspectos. São indicadores relevantes para a avaliação, sobretudo, da produção dos programas de pós-graduação, da qualidade das pesquisas científicas desenvolvidas por esses programas, dos professores quanto à modalidade de orientação, possibilidade de mensuração quantitativa das áreas de conhecimento e quanto à análise de transferência da informação, uma vez que a pesquisa final de uma tese e/ou dissertação dá margem para a geração de uma nova pesquisa científica. Coates (2014) apontou estudos de Chu e Law (2007) e de Ismail e Kareem (2011) que constataram que em Hong Kong e na Malásia, respectivamente, as teses e dissertações se constituíram recursos imprescindíveis para alunos que realizavam suas pesquisas também para as conferências de graus de mestres e doutores, pois se apresentavam como documentos que continham informações mais específicas, acadêmicas, com maiores profundidade, amplitude e confiabilidade.

Entretanto, para que suas funções de transferência da informação sejam potencializadas é indispensável que esses documentos estejam facilmente disponibilizados e acessíveis, e não apenas "estocados" nas prateleiras das bibliotecas. Nesse contexto, alguns países adotaram normativas que orientam para que esses documentos sejam depositados em bibliotecas e/ou sistemas de informação. A França, por exemplo, em 1985, estabeleceu que devem ser depositados dois exemplares do trabalho inédito na biblioteca correspondente à universidade na qual o documento foi defendido. Este material deve ser tanto para consulta local como para empréstimo entre bibliotecas universitárias. No entanto, no que concerne ao depósito em sistemas de 
informação, no Brasil, a Portaria no 13/2006 ${ }^{11}$ da Coordenação de Aperfeiçoamento de Pessoal de Nível Superior (CAPES) institui a divulgação digital das teses e dissertações produzidas pelos programas de doutorado e mestrado, reconhecidos pelo Ministério da Educação (MEC). Tal instrumento determina a obrigatoriedade da disponibilização digital desses documentos a partir de março de 2006.

Observa-se que a disponibilização das teses e dissertações caminha para a divulgação em meios eletrônicos. Esta ação é fruto do impacto das tecnologias de informação e comunicação, e neste caso direcionado em tipologias documentais pertencentes à denominada literatura cinzenta. A partir do impacto e inserção das tecnologias de informação no contexto das teses e dissertações, estes documentos passaram a ser produzidos e, sobretudo, disseminados eletronicamente. Surgem, assim, as teses e dissertações eletrônicas (ETDs). Vale ressaltar que as ETDs não diferem em nada em termos de conteúdo em relação às teses e dissertações impressas. No entanto, observa-se sim que há uma maior possibilidade do uso de ferramentas interativas no texto, como os hiperlinks e links, deixando assim o texto mais comprovável robusto e que se relaciona com às suas informações internas e externas.

\subsubsection{Teses e dissertações eletrônicas (ETDs)}

$\mathrm{Na}$ literatura científica identificam-se duas possíveis distinções de teses e dissertações eletrônicas (ETDs): as que são digitalizadas e as que nascem digitais. As primeiras são documentos eletrônicos criados após (ou retrospectivamente) à tese e/ou dissertação impressa. Neste caso, em sua maioria, os documentos são escaneados/digitalizados e armazenados em sistema de informação. As segundas são definidas como puramente digitais (ou nascidas digitais), onde os estudantes criam o documento, convertem para um formato de submissão e as tornam disponíveis online com a sua descrição por meio de metadados (AL SALMI, 2014; ALLARD, 2003; FINEMAN, 2003).

\footnotetext{
${ }^{11}$ Portaria no 013, de 15 de fevereiro de 2006 - Institui a divulgação digital das teses e dissertações produzidas pelos programas de doutorado e mestrado reconhecidos <https://www.capes.gov.br/images/stories/download/legislacao/Portaria_013_2006.pdf>.
} 
As teses e dissertações eletrônicas têm as mesmas definições de teses e dissertações ora já citadas - pesquisas científicas concluídas para a obtenção dos títulos de doutor e mestre, respectivamente. Diferenciam-se, no entanto das teses e dissertações impressas, por serem documentos disponibilizados na versão eletrônica e submetidos a um sistema de informação (AL SALMI, 2014; PARK et al, 2007; ALLARD, 2003; GOLDSMITH, 2002). Assim, as ETDs não se diferenciam pela forma de seu conteúdo, contudo, as possibilidades que lhe são agregadas por meio do uso digital são inúmeras, como o uso dos links e hiperlinks.

De acordo com Harnad (2001), a comunidade científica enxerga as publicações eletrônicas disponíveis em rede como um modo que favorece o aumento de sua visibilidade, aceleração do avanço da ciência e a ampla disseminação dos resultados das pesquisas, vistos como patrimônio da humanidade. As teses e dissertações, como resultados de pesquisas, não fogem a esses benefícios. Nesse sentido, considera-se que as ETDs promovem o acesso rápido e fácil aos seus conteúdos, integram maiores possibilidades de formatos e informações, poupam tempo e espaço de armazenamento, poupam dinheiro (aspecto diretamente relacionados com os próprios estudantes, pela redução do número de impressão, cópias e encadernação e envio do produto final) (MOXLEY, 2001; WEBSTER, 1999). O depoimento de Peter Suber (2006) serve como um exemplo sobre os custos de uma tese e dissertação impressa:

\footnotetext{
I finished my dissertation in 1977 , before the web, before the internet, and even before personal computers. I typed it on an Olivetti typewriter and, when my committee accepted it, I paid the department secretary a dollar a page to retype it according to the formatting specs of the university. I was honored when the university made a copy on acid-free paper, bound it in boards, and put it on the open stacks in the main library. It even had a card in the card catalog. I was also honored when I discovered a week later that someone had stolen the copy from the library. In addition, I sent a copy to University Microfilms International (UMI), which produced priced paper or microfilm copies on-demand. (UMI is now owned by ProQuest.) As far as I know it's still accessible for a price from UMI. I have no idea whether anyone has ever ordered a copy, let alone how many (SUBER, 2006, web).
}

A Organização das Nações Unidas para a educação, a ciência e a cultura (UNESCO, 2001) e Bandra (2002) identificaram outros elementos que são acrescidos aos benefícios das ETDs: 
- O maior acesso à informação e às pesquisas melhora a qualidade das teses e dissertações e o conhecimento em geral;

- ETDs são caminhos para o compartilhamento da produção intelectual porque fazem com que os resultados dos programas de pós-graduação se tornem conhecidos;

- O acesso às teses e dissertações possibilita o entendimento e visualização das técnicas utilizadas em suas metodologias e que podem ser reutilizadas por outros estudantes;

- Aumenta a disponibilidade da pesquisa do estudante e a preservação digital;

- Um programa de ETD introduz bibliotecas digitais na universidade possibilitando que outros projetos floresçam;

- A produção ETDs faz com que os seus resultados sejam conhecidos nacionalmente e internacionalmente e as ETDs possam identificar e conectar os grupos de pesquisas nacionais e internacionais;

- O amplo conhecimento das teses e dissertações de boa qualidade reforça a faculdade, os programas de pós-graduação e da universidade de modo que os programas possam ser avaliados pelo número de teses e dissertações que estão acessíveis por meio eletrônico;

- Teses e dissertações são partes do patrimônio e da história das universidades. Uma vez que são produzidas em papel, por que não produzi-las online onde exigem menos espaços de armazenamento?;

- Nos países em que os autores de teses e dissertações são financiados por financiamentos públicos, espera-se que seus trabalhos se tornem públicos também. As ETDs se consolidam como o modo mais fácil de alcançar esse objetivo.

É certo, portanto, que as teses e dissertações eletrônicas quando disseminadas por meio do uso das tecnologias de informação e comunicação se tornam muito mais visíveis e acessadas quando comparada às suas versões impressas. Moxley (2001) ao discorrer sobre a diferença entre os dois formatos, de que as ETDs são 100 vezes mais fáceis de serem acessadas. O autor apresentou em seus estudos os registros de circulação das teses e dissertações da instituição Virginia Tech. Embora, sejam de 
décadas anteriores, os números exemplificam bem o impacto inicial da tecnologia nessa tipologia documental. Entre os anos de 1990 e 1994, 15.335 teses e dissertações foram aprovadas; 3.967 desses documentos foram visualizados até 1998. Em contraste, de 2000 a 2001, a Virginia Tech tinha 3.393 ETDs em sua coleção, tendo 1.565.151 PDFs baixados.

A ideia da adoção das teses e dissertações eletrônicas foi discutida pela primeira vez, em 1987, pela Universal Microfilms International (UMI), nos Estados Unidos (AL SALMI, 2014). Nesse contexto, já haviam sido iniciadas também discussões a respeito de publicações eletrônicas por meio da internet e a adoção e estabelecimento de softwares/plataformas para o alcance dessa ação. Do debate iniciado no final dos anos de 1980, a UMI em conjunto com a Coalition for Networked Information (CNI), Virginia Polytechnic Institute and State University (Virginia Tech) e o Council of Graduate Schools, deram início ao projeto chamado de "A captura e armazenamento de teses e dissertações eletrônicas" no intuito de promover aplicações e normas para a captura e armazenamento das ETDs (YIOTIS, 2008; CROWE, 1998). Desse projeto, surgiu o programa de dissertações digitais ProQuest da UMI. Segundo Yiotis (2008),

\footnotetext{
em dezembro de 2006, o serviço de pesquisa da UMI migrou para a plataforma Proquest que foi rebatizada de 'Textos completos de teses e dissertações (Dissertations \& Theses @). O serviço era baseado em uma assinatura que possibilitava o acesso livre às citações e resumos das teses $e$ dissertações na base de dados da ProQuest (PQDT), permitindo aos usuários a visualização gratuita das primeiras 24 páginas das dissertações e download das cópias dos textos completo quando disponível. Os usuários também podiam pagar pela impressão ou cópia digital se a sua instituição não assinasse o serviço ProQuest (YIOTIS, 2008, p. 102, tradução nossa).
}

Yiotis (2008) também apontou para outro projeto fruto do trabalho conjunto da UMI e demais instituições. O resultado foi o acordo do CNI para trabalhar com a Universidade de Cornell, a Universidade de Michigan, a Penn State e a Virginia Tech objetivando o desenvolvimento e difusão de um método padrão de utilização do Standard Generalized Markup Language (SGML) para o alcance da disponibilização online das teses e dissertações. O aspecto de adoção de um padrão será aprofundado nas próximas seções. Fox, McMillan e Eaton (1999) informaram a respeito da aplicação do SGML que seguido da reunião entre as instituições, a Virginia Tech 
provided $\$ 5000$ to develop an SGML Document Type Definition (DTD), in conjunction with SoftQuad. Unfortunately, tools to help authors create SGML documents were expensive and harder to use than common word processors, so this approach had a low priority, and perhaps hindered the early development of this genre. In 1996, however, when the Southeastern Universities Research Association (SURA) provided about $\$ 90,000$ to Virginia Tech to explore ETDs further, project staff developed a Document Type Definition called ETD-ML, which is continually refined to be easier to use and powerful enough to capture the important metadata and structure of ETDs (FOX, MCMILLAN e EATON, 1999, p. 3).

Fox, McMillan e Eaton (1999, p. 1) apontaram para alguns fatores que fizeram parte, à época, das discussões iniciais quanto à iniciativa das teses e dissertações eletrônicas.

Figura 7: Fatores envolvidos com as teses e dissertações eletrônicas

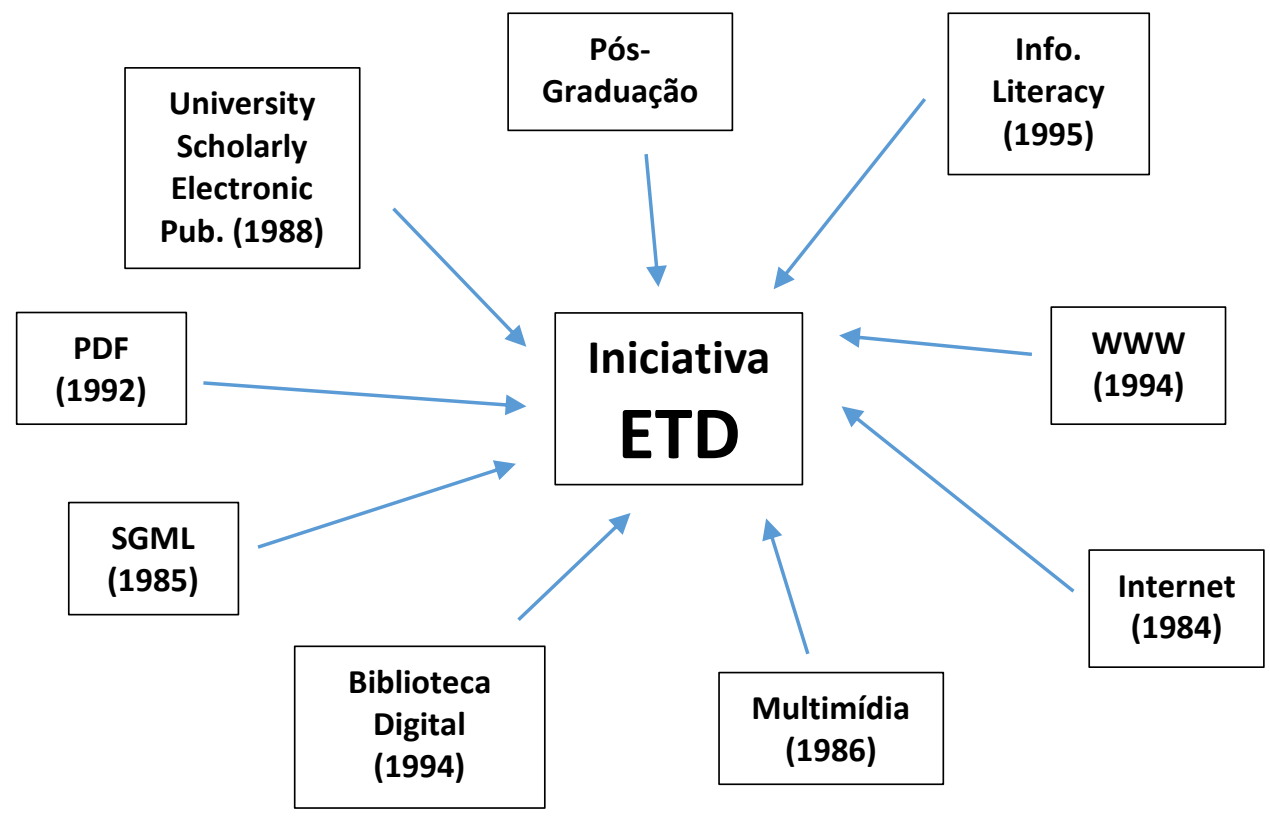

Fonte: Fox, McMillan e Eaton, 1999, p. 1, com adaptações.

A submissão da versão eletrônica das teses e dissertações em sistemas de informação foi também iniciada pela Virginia Tech, em 1997, à época que foi concretizado o projeto da Networked Digital Library of Theses and Dissertations (NDLTD). O desenvolvimento desta rede impulsionou a criação de inúmeras bibliotecas digitais semelhantes em todo o mundo. A iniciativa da NDLTD e as demais derivadas que correspondem ao desenvolvimento de bibliotecas digitais de teses e dissertações em todo o mundo serão tratadas com maior profundidade na seção 2.4.1. 
Embora os benefícios das ETDs estejam claros, Ramirez et al (2013) e Seamans (2003) alertaram para uma possível preocupação dos estudantes e orientadores quanto ao acesso irrestrito aos resultados dessas pesquisas pode provocar. A questão está relacionada com a possibilidade da diminuição de oportunidades para publicações futuras (RAMIREZ et al, 2013), como livros e artigos de periódicos.

Ao final do estudo realizado por Ramirez et al (2013) com editores de revistas científicas e diretores da editora em universidades nas áreas de ciências sociais, artes e humanidades, mostrou que manuscritos que correspondem às revisões de ETDs, totalmente acessíveis, são bem-vindos para a publicação ou são considerados caso a caso por $82,8 \%$ dos editores de revistas e $53,7 \%$ dos diretores entrevistados. Dalton, em 2003, e Moxley, em 2001, já haviam apresentado estudos que apontaram para resultados semelhantes. No trabalho de Joan Dalton (2003), aplicado na Universidade de Windsor, a autora contatou 200 editores e os questionou sobre o tema referido. Como resultados, Dalton descobriu que $94 \%$ dos participantes da pesquisa afirmaram que a revista tinha uma política explícita sobre publicação prévia, mas que $68 \%$ afirmaram que a política não se referia especificamente às obras que foram publicadas na web ou disponibilizadas eletronicamente. Na pesquisa apresentada por Moxley (2001), os resultados alcançados demonstram que $83 \%$ dos editores de periódicos ponderaram para o fato de que teses e dissertações eletrônicas, disponíveis em uma base web, não deveriam ser consideradas como uma publicação anterior, de acordo com as políticas existentes dos periódicos.

Em um estudo anterior, McMillan et al (2011), que conta com os mesmos autores do estudo realizado dois anos após (RAMIREZ et al, 2013), 616 editores científicos foram questionados sobre se consideram teses e dissertações como uma publicação anterior ao artigo. O questionário sobre o tema continha indagações do tipo, "como editor científico, você considera que uma ETD já é uma publicação anterior? Será que seu periódico ou publicação considera aceitável a submissão de um artigo derivado de uma dissertação eletrônica" (McMILLAN et al, 2011, p. 2). Como resposta para a questãochave do estudo, Manuscripts which are revisions derived from openly accessible electronic theses or dissertations (ETDS), $45 \%$ dos editores consideram que as submissões são bem-vindas, $27 \%$ afirmaram que considerariam caso a caso, $14 \%$ disseram que aceitaram somente se os conteúdos e conclusões fossem 
substancialmente diferentes da ETD, 3\% dos entrevistados aceitariam se a ETD tivesse acesso apenas da comunidade da universidade e $4 \%$ disseram que não aceitariam em nenhuma circunstância.

A preocupação relacionada com as percepções dos editores científicas e a disponibilização das teses e dissertações eletrônicas é interessante de ser mencionada, já que algumas ETDs passaram a incorporar também os artigos científicos já publicados. A ideia é que, sobretudo nos casos das teses, seus capítulos passam a serem os artigos publicados. Nesse contexto, Suber (2006) citou a desvalorização das teses e dissertação em razão de seu critério de avaliação. Questiona o porquê não se considera as teses e dissertações avaliadas por pares. De acordo com o autor, as teses e dissertações "passam por uma avaliação suficientemente rigorosa (...). Mas, ao mesmo tempo, a sua avaliação é suficientemente não convencional (ou suficientemente diferente de avaliação do periódico)" (SUBER, 2006, web).

Em 2014, Alemneh apresentou um estudo sobre o modelo de gestão do ciclo de vida das teses e dissertações eletrônicas. Neste modelo, o autor destaca as partes envolvidas na gestão do ciclo de vida das ETDs.

- Autores estudantes que criam e submetem as ETDs de acordo com as políticas determinadas;

- Membros da instituição que supervisionam e orientam o aluno no processo de desenvolvimento das ETDs;

- Processos das instituições para aprovar, embargar, lançar e atualizar as ETDs ao longo do tempo por meio dos sistemas de submissão online;

- Bibliotecas arquivam e disseminam as ETDs por meio de sistemas de repositórios institucionais e políticas de preservação;

- Estudiosos e pesquisadores usam e reutilizam as ETDs por meio de navegadores web, downloads de aplicativos e ferramentas de análise.

Wang (2014) discorre sobre as partes envolvidas em um projeto de gestão de ETDs, estando elas, uma parte, ativamente envolvidas no processo e outras, direta ou indiretamente, em um ou dois estágios. Segundo o autor, as partes interessadas podem ser divididas em dois grupos: internos e externos (Figura 8). 
- Partes interessadas internas: são os indivíduos ou unidades acadêmicas das instituições de ensino superior onde as ETDs são produzidas. Consistem, portanto, de administradores institucionais, instituições de pós-graduação, bibliotecas e indivíduos da área da tecnologia da informação.

- Partes interessadas externas: são entidades, com ou sem fins lucrativos, envolvidas nos programas de ETDs, mas que se encontram fora das instituições de ensino dos alunos.

Figura 8: Estágios para a implantação de um programa de ETD

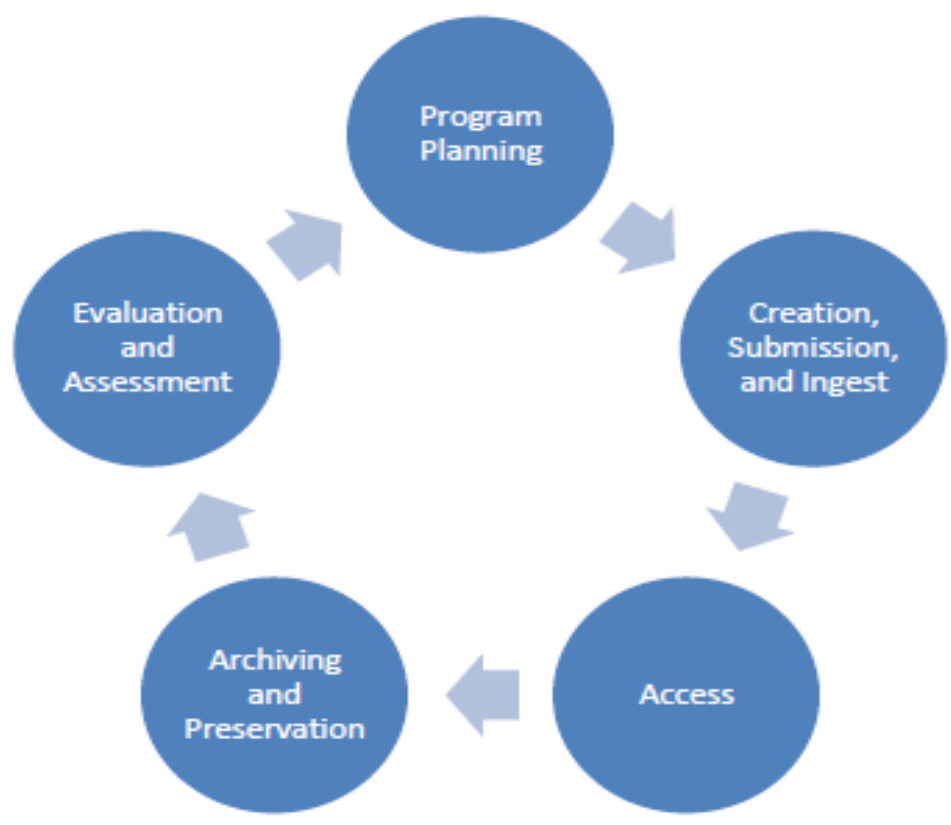

Fonte: Wang, 2014.

O autor também apresentou, o que chama de estágios para a implementação de um programa de ETD, alguns já mencionados aqui nesta pesquisa, como a NDLTD. Wang (2014) apresenta cinco estágios para a gestão da iniciativa de ETD, incluindo as etapas de planejamento, as formas de acesso e definição do modo de arquivamento e preservação da tese e dissertação. 
Figura 9: Partes interessadas em um programa de ETD

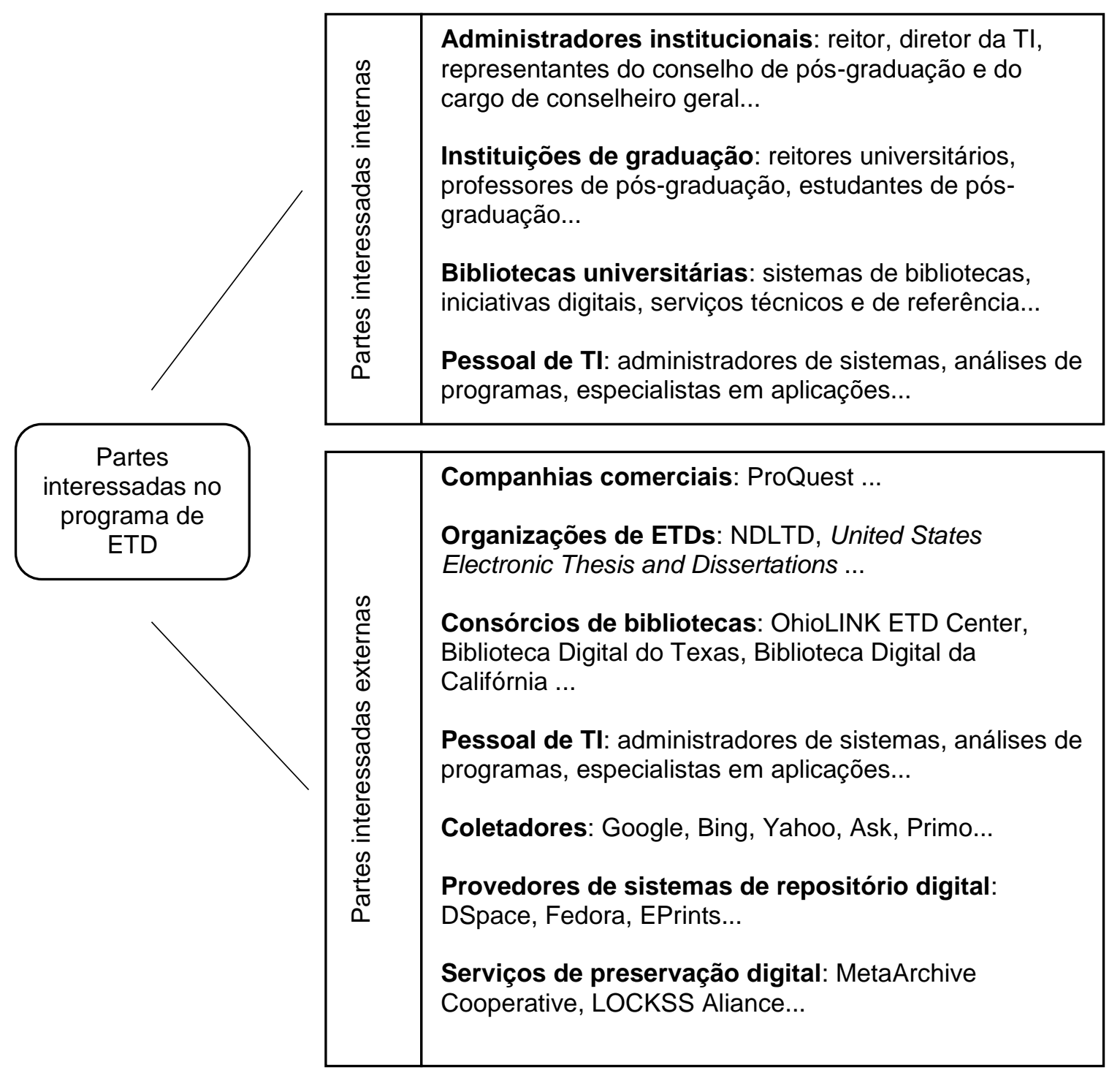

Fonte: Wang, 2014, com adaptações.

Não há dúvidas de que a produção das teses e dissertações em formato eletrônico já está consolidada e que é uma tendência que deve ser seguida. A disponibilização dos resultados de pesquisas desse material científico passa a incorporar, portanto, sistemas de informação das instituições de ensino e pesquisa. Tais sistemas de informação se tornam próprios locais para o armazenamento das teses e dissertações eletrônicas, e que em sua grande maioria, passam a ser denominados como bibliotecas digitais de teses e dissertações, que serão discutidas no contexto da Open Archives Initiative (OAi) na seção 2.4.1.1 desta dissertação. 


\subsection{Acesso Aberto à Informação Científica}

Esta seção tem como proposta discorrer sobre o Movimento do Acesso Aberto à Informação Científica. Nesta pesquisa optou-se por apresentar seus fundamentos e conceitos a partir do projeto dos Arquivos Abertos até a consolidação do Movimento de Acesso Aberto à Informação Científica.

A maximização do uso da internet pelos pesquisadores e a rapidez que o referido meio possibilita para a disseminação dos resultados da pesquisa, provocou profundas alterações no fluxo da comunicação científica. A morosidade do processo tradicional de comunicação científica tornou-se evidente frente à agilidade oferecida pelas tecnologias de informação. Correia (2001) destaca a insatisfação dos autores e outros atores envolvidos quanto ao papel dos periódicos científicos como um veículo privilegiado para a comunicação científica, designadamente: a morosidade (já citada na linha anterior) entre a submissão/apresentação de trabalhos para publicação e o seu efetivo aparecimento na literatura - incapacidade do sistema em responder à aceleração no aumento do volume de novos conhecimentos científicos; modelo tradicional de transferência dos direitos dos autores de artigos publicados para as editoras científicas impede os autores de promover a difusão dos resultados de pesquisa; modelo atual de implementação do processo de peer-review é demasiado rígido; agravamento do desequilíbrio entre os preços de assinaturas de publicações periódicos, estabelecidos pelos editores científicos, e os orçamentos das bibliotecas universitárias e de pesquisa.

A necessidade de algumas áreas do conhecimento, sobretudo as ciências exatas, de disseminar rapidamente os resultados de suas pesquisas, resultou em um crescente número de produções científicas disponibilizadas na web. Lagoze e Van de Sompel (2001, p. 55) apontaram que as disciplinas acadêmicas, especialmente as chamadas de "ciências duras" como, por exemplo, Física e a Ciência da Computação, estão produzindo resultados de pesquisa em um ritmo cada vez maior. Em consequência, a mudança na velocidade de produção exige mecanismos para relatar os estudos em um tempo de latência menor do aquele que o modelo tradicional de publicação proporciona. Entretanto, deve-se ressaltar que a tecnologia foi uma das condições que permitiu a reação dos pesquisadores frente à lógica do sistema de publicação da pesquisa 
científica. E, nesta pesquisa aponta que, outros fatores também influenciaram as mudanças no processo tradicional de publicação científica.

Van de Sompel e Lagoze (2000, web) enumeraram os desafios enfrentados pelo modelo tradicional de publicação:

- Crescimento explosivo da internet - permitindo aos pesquisadores o acesso, quase universal, a um meio de comunicação que facilita o compartilhamento imediato dos resultados;

- Rapidez dos avanços na maioria dos campos acadêmicos;

- Direitos de autor - a transferência total dos direitos para os editores científicos muitas vezes age como um impedimento para o acesso e divulgação para o pesquisador, cuja principal preocupação é a mais ampla divulgação dos resultados;

- Rigidez da revisão por pares - às vezes age para reprimir novas ideias, favorecendo artigos de instituições de prestígio e causar atrasos indevidos na publicação;

- Crise econômica das bibliotecas - desequilíbrio entre a disparada dos preços de assinatura dos periódicos científicos e o orçamento das bibliotecas.

Dawrs (2012) apresenta números relacionados com os valores gastos com as assinaturas de periódicos científicos. Segundo o autor, desde meados da década de 1980, os valores anuais das assinaturas institucionais das publicações científicas ultrapassaram as taxas da inflação. Entre 1986 e 2001, quando foi convocada a reunião de Budapeste, a despesa média anual das publicações seriadas das bibliotecas da Association of Research Libraries (ARL) subiu de 1.496.775 dólares para 4.660.349 dólares. Em 2009, esse número era de 7.193.291 dólares - um aumento de 381\% desde 1986 ou, em média, 7,4 por cento ao ano (KYRILLIDOU, MORRIS e ROEBUCK, 2011).

De acordo com os autores, os e-prints "exemplificam um modelo mais justo e eficiente para a disseminação dos resultados de pesquisa". De acordo com Warner 
(2003, p. 152), os e-prints incluem: artigos de periódicos, preprints ${ }^{12}$, relatórios técnicos, livros, teses e dissertações. Os e-prints são um modelo alternativo de comunicação para algumas áreas da pesquisa (SENA, 2000; VAN DE SOMPEL \& LAGOZE, 2000, web).

Uma característica fundamental dos sistemas de arquivos de e-prints, dentre outras, é o fato de ser dedicado para o que Harnad (1995) chama de "esoteric scholarly publication" ou publicação acadêmica esotérica. Neste caso, o termo "esotérico" é utilizado como sinônimo de não-comercial, viabilizando-se a vontade do autor de que haja a máxima distribuição dos resultados de sua pesquisa. Esta distribuição, livre de quaisquer custos, resguarda o direito do autor em publicar os resultados de sua pesquisa em qualquer lugar, permitindo que se estabeleçam endereços na web para que se possa localizar o trabalho. Desta forma, Harnad iniciou a propagação das ideias que diz em respeito à disseminação dos resultados de pesquisa na web, ao papel desempenhado pelos editores científicos e aos lucros exorbitantes que passaram a ter.

Uma das iniciativas mais bem-sucedidas quanto ao desenvolvimento de um sistema para o armazenamento e disseminação de arquivos e-prints é o arXiv. Mantido pelo Laboratório Nacional de Los Alamos, no Novo México, o desenvolvimento do sistema foi iniciado, em 1991, por Paul Ginsparg. Com os anos, o arXiv se tornou um repositório global de artigos não-revisados por pares, nas áreas de pesquisa da Física, que, posteriormente, começou a abrigar também produções da Matemática, Ciência da Computação e as Ciências Não-lineares. No início chamado de High Energy Physics Theory (hep-th), o sistema começou com o trabalho de 200 físicos e, em meses, se expandiu para mais de 1.000 usuários e, depois de poucos anos, para mais de 3.800 usuários (GINSPARG, 1996). A próxima figura apresenta, a título de verificação, a evolução do número de depósitos, por mês, no sistema do arXiv, entre os anos de 1991 e 2000. É importante esclarecer que, as versões iniciais das pesquisas não ficam apenas depositadas no arXiv. Posteriormente, esses trabalhos são publicados em revistas científicas.

\footnotetext{
12 Preprint: Versão do trabalho científico ainda não revisada pelos pares.
} 
Figura 10: Número de depósitos por mês no arXiv (1991-2000)

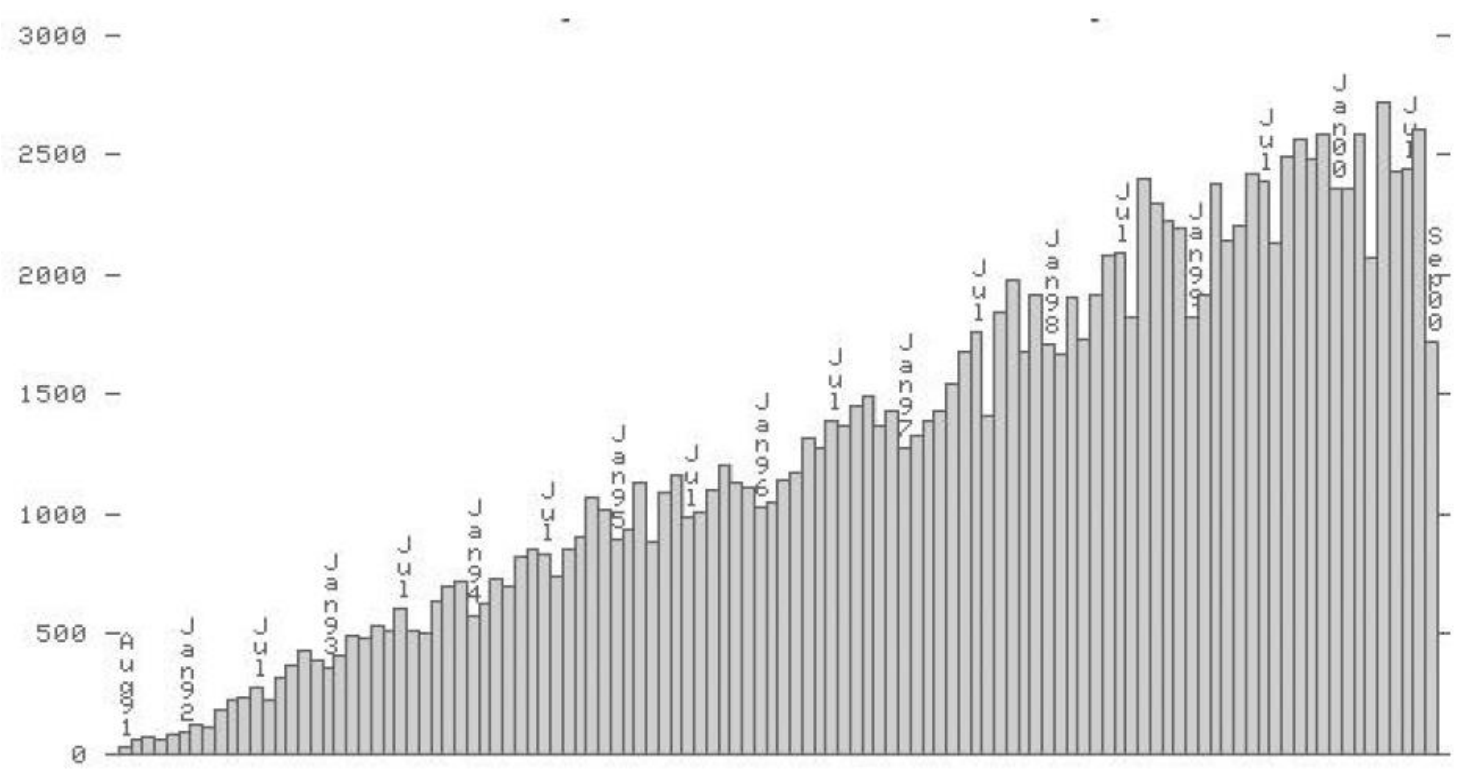

Fonte: arXiv.org apud Sena, 2000, p. 3.

Van de Sompel e Lagoze (2000) citaram outros esforços existentes no mundo para a criação de arquivos de e-prints:

- CogPrints $^{13}$ - organizado pela Universidade de Southampton, do Reino Unido. Criado de acordo com o modelo do arXiv, reúne produções das áreas da Psicologia, Linguística, Neurociências, Ciência da Computação, Filosofia e Biologia;

- NCSTRL (Networked Computer Science Technical Reference Library) ${ }^{14}$ - coleção internacional sobre relatórios de pesquisa em Ciência da Computação. O sistema foi criado formando uma rede, com um modelo descentralizado, no qual os documentos são armazenados em repositórios distribuídos e disponibilizados por serviços também distribuídos, via protocolo Dienst ${ }^{15}$;

- NDLTD (Networked Digital Library of Theses and Dissertations) - biblioteca digital de teses e dissertações das instituições membros da rede. As pesquisas desenvolvidas para a criação desta rede abordam assuntos como a criação de um fluxo de trabalho (workflow) para submissão de ETDs (Electronic Theses and

\footnotetext{
${ }^{13}$ CogPrints <http://cogprints.soton.ac.uk/>

${ }^{14}$ NCSTRL <http://www.ncstrl.org/>

15 Protocolo Dienst - Open Archives Dienst Subset
} 
Dissertations), o desenvolvimento de XML e de DTD (Document Type Definition) para ETDs e o suporte para a biblioteca digital de teses e dissertações eletrônicas;

- RePEc (Research Papers in Economics) - Da área de Economia, também opera em um modelo distribuído. O sistema fornece aos autores o envio dos trabalhos por meio do uso do protocolo de Guildford.

As instituições que passaram a desenvolver esses sistemas para disponibilizar os resultados das pesquisas na web entenderam que era importante haver comunicação entre os sistemas. Nesse sentido, há o surgimento de um protocolo que viria a viabilizar tal ação e que será apresentado na seção a seguir.

\subsubsection{Open Archives Initiative (OAi): a Convenção de Santa Fé}

Naquele contexto, em julho de 1999, Paul Ginsparg, Rick Luce e Herbert Van de Sompel enviaram convites para especialistas para que participassem de uma reunião que tinha o intuito de promover a discussão sobre a cooperação entre os arquivos acadêmicos de e-prints (VAN DE SOMPEL e LAGOZE, 2000). O encontro foi realizado em outubro do mesmo ano, no Novo México, sob as orientações do Council on Library and Information Resources (CLIR), da Digital Library Federation (DLF), da Scholarly Publishing \& Academic Resources Coalition (SPARC), da Association of Research Libraries (ARL) e do Los Alamos National Laboratory (LANL).

A reunião originalmente chamada de Universal Preprint Service (USP) levou à criação da Open Archives Initiative (OAi) ${ }^{1617}$. A razão apontada para a criação da OAi foi a crença de que a interoperabilidade entre os arquivos e-prints seria de fundamental importância para o aumento do impacto e o estabelecimento de alternativas viáveis para o modelo de comunicação científica (VAN DE SOMPEL e LAGOZE, 2000).

Sena (2000, p. 4) apontou que "as discussões sobre o assunto demonstraram que interoperabilidade é um termo bastante abrangente no universo dos sistemas de

\footnotetext{
${ }^{16}$ Em Português (Brasil), Iniciativa de Arquivos Abertos.

${ }^{17}$ Adota-se nesta dissertação a escrita da sigla para Open Archives Initiative como OAi, conforme utilizado por Van de Sompel e Lagoze (2000). Desta forma, distingue-se a sigla para a referida Iniciativa do Protocolo OAI.
} 
arquivo". Ainda, o fato relaciona-se com o que Lagoze e Van de Sompel (2000) citaram como

os formatos de metadados, a arquitetura de sistema que permanece subjacente a essas escolhas, a sua abertura à criação de serviços de bibliotecas digitais para terceiros, integração com o mecanismo estabelecido de comunicação científica/acadêmica, sua usabilidade em contextos transdisciplinares (cross-disciplinary context), sua habilidade em contribuir para um sistema métrico de uso e citação etc (LAGOZE e VAN DE SOMPEL, 2000, web).

Assim, a interoperabilidade se tornou a palavra-chave para a definição das estratégias e mecanismos de atuação da OAi. O objetivo central era o compartilhamento de informações entre os arquivos de e-prints e a possibilidade da busca centralizada em um arquivo considerado "global".

Desta forma, na mesma ocasião, segundo informações da própria Iniciativa (2000), foi aprovada pela maioria dos participantes do evento - representantes de organizações que mantinham e/ou que planejavam a criação de arquivos de e-prints - a Convenção de Santa Fé.

A Convenção de Santa Fé apresenta uma estrutura técnica e organizacional simples para suportar a interoperabilidade entre os arquivos de e-prints. Triska e Café (2001, p. 92) apontaram para três princípios básicos definidos na Convenção: o autoarquivamento, a revisão pela comunidade e a interoperabilidade.

- Autoarquivamento: é a possibilidade do próprio autor em realizar o processo de envio a sistemas na web de seus resultados de pesquisa sem intermédio de terceiros. Segundo os autores, "trata-se de um conceito inovador cujos objetivos são tornar o texto disponível o mais rápido possível e favorecer o acesso democrático e gratuito".

- Interoperabilidade: como já afirmado, a interoperabilidade é o aspecto central da OAi. Ou seja, a capacidade de um sistema se comunicar com outro sistema com protocolos abertos.

Alguns aspectos são assinalados como componentes cruciais de um arquivo de e-prints: mecanismo de submissão, sistema de armazenamento de longo prazo e 
possibilidade de realização de coleta automática por terceiros. Dois conceitos são de fundamental entendimento no modelo de comunicação de acordo com a OAi: a distinção entre provedores de dados e provedores de serviço.

Os provedores de dados são compreendidos como os sistemas que oferecem os dados para a coleta por parte de terceiros. O provedor de dados de um arquivo aberto deve conter, pelo menos, um mecanismo de submissão, um sistema de armazenamento a longo prazo e, ainda, o mecanismo de coleta. Já os provedores de serviço coletam as informações disponibilizadas pelos provedores de dados e criam serviços para os usuários finais.

Para a concretização da interoperabilidade, a Convenção de Santa Fé estabeleceu alguns mecanismos para a realização de tal processo:

- Definição de um conjunto mínimo de metadados, conhecidos como OAMS (Open Archives Metadata Set);

- Concordância do uso de uma sintaxe comum, expressa em XML (Extensible Markup Language), para representar e transportar tanto o OAMS como os conjuntos de metadados específicos de cada provedor de dados;

- Definição de um protocolo comum (Open Archives Dienst Subset) que possibilita a extração do OAMS e dos metadados específicos de cada provedor de dados.

Ressalta-se nas palavras de Lagoze e Van de Sompel (2000) que a Convenção de Santa Fé representa

\footnotetext{
uma abordagem pragmática, incremental e colaborativa para a interoperabilidade. Os percussores da OAi esperavam que esta abordagem prática se tornasse um catalisador para mudanças significativas dos mecanismos da comunicação científica (VAN DE SOMPEL \& LAGOZE, 2000, web).
}

Com o objetivo de garantir a interoperabilidade entre os sistemas, passou a ser utilizado o Protocolo Dienst que viabilizou o acesso aos arquivos de forma mais simples que o Protocolo Z39.5018. Em referência a este último Protocolo e a exemplo para

\footnotetext{
18 Protocolo Z39.50: É um protocolo de comunicação entre computadores desenhado para permitir pesquisa e recuperação de informação, baseado em arquitetura cliente/servidor (ROSETTO, 1997).
} 
demonstrar as dificuldades encontras pelas bibliotecas no uso do até então Protocolo Z39.50, Sayão e Marcondes (2008) observaram que

\begin{abstract}
as bibliotecas que compartilham registros de catálogos on-line usando o protocolo Z39.50, trabalham segundo o nível de federação. O ANSI/NISO39.50 (ISO 23950) é um protocolo de comunicação entre computadores que pode ser implementado sobre qualquer plataforma. Ele tem como propósito a pesquisa e a recuperação de informações. A implementação do protocolo permite que, por meio de uma única interface, seja possível o acesso uniforme a uma diversidade de fontes de informações heterogêneas de modo síncrono e transparente para o usuário-final (SAYÃO e MARCONDES, 2008, p. 138).
\end{abstract}

Tempos depois, o Protocolo Dienst passou a se chamar Protocolo OAl. Assim, a base da Iniciativa de Arquivos Abertos é o protocolo Open Archives Initiative Protocol for Metadata Harvesting (OAI-PMH), tendo sido a sua primeira versão lançada em 2001. O protocolo fornece uma interface simples para que os provedores de dados tornem seus metadados disponíveis para a coleta por parte dos provedores de serviços, com base no Protocolo HTTP (Hypertext Transport Protocol) e na linguagem XML. Assim, toda a comunicação entre os sistemas de acordo com a filosofia da OAi é realizada com base nesse protocolo de interoperabilidade. Para a realização da coleta de dados, portanto, basta que os sistemas tenham implementado o Protocolo OAI. É, nesse contexto de "pós-desenvolvimento" do protocolo OAI, que se consolida a interoperabilidade entre as bibliotecas digitais de teses e dissertações e o fortalecimento da Rede NDLTD e demais iniciativas.

Como exposto, o Protocolo OAI viabiliza a coleta automática dos metadados. Comumente definidos na literatura científica como "dados sobre dados", os metadados têm por função descrever o documento em um sistema de informação. Embora no início da definição do Protocolo OAl tenha sido recomendado o uso do esquema de metadados Dublin Core ${ }^{19}$, atualmente é possível identificar diferentes padrões de metadados que visam especificar a descrição de cada tipologia documental. Entretanto, o uso de diferentes esquemas de metadados exige "ajustes" para a interoperabilidade dos sistemas, devendo os sistemas que oferecem os metadados para a coleta automática atenderem os metadados mínimos exigidos pelo outro sistema.

\footnotetext{
19 O Padrão de Metadados Dublin Core objetiva descrever um objeto digital. Para tanto, contém em seu esquema 15 campos gerais para descrição, entre eles: autor, título e data.
} 
Baptista (2010, p. 72) afirma que o Protocolo OAl fornece uma base para a interoperabilidade, entretanto "deixa de fora as questões da interoperabilidade semântica". A autora apresenta a seguinte reflexão:

\footnotetext{
Como retirar informação com significado a partir de conjuntos de dados tão diversos, que utilizam a mesma roupagem (o protocolo OAI-PMH e as propriedades Dublin Core utilizadas no seu âmbito), mas com distintos e, por vezes incompatíveis, conteúdos? (BAPTISTA, 2010, p. 72).
}

Ainda, a autora justifica o questionamento ao apontar a dificuldade relacionada com a interpretação de um valor, como por exemplo no campo data, um sistema utiliza como valor de preenchimento "10-12-06", "o que significa? 10 de Dezembro de 2006, 12 de Outubro de 2006, 6 de Dezembro de 2010?" (BAPTISTA, 2010, p.77). Esta questão será retomada na discussão das próximas seções ao se falar da coexistência das bibliotecas digitais de teses e dissertações e os repositórios digitais de acesso aberto.

\subsubsection{As bibliotecas digitais de teses e dissertações}

Em mais um momento desta pesquisa, os avanços das tecnologias de comunicação e informação têm destaque no contexto das mudanças nos processos e produtos das bibliotecas. O impacto dessas tecnologias impulsionou uma alteração significativa quanto à demarcação de espaço e tempo da informação. As bibliotecas se viram de certo modo obrigadas à desenvolverem ferramentas e processos para o acompanhamento de tais avanços e buscando, sobretudo, atender às novas demandas de seus usuários cada vez mais inseridos na era da conectividade e inovação.

$\mathrm{O}$ acervo das bibliotecas que antes era apenas composto por obras em formato impresso, passou a incorporar também documentos no formato digital. Orera Orera (2007, p. 330) afirmou que desse novo modelo é apresentada a "nova biblioteca", denominada como biblioteca híbrida. Segundo a autora, a biblioteca híbrida é a "soma dos elementos tradicionais da biblioteca com outros novos que derivam da informação digital, das novas tecnologias e da telemática". Complementando a ideia, Orera Orera (2007) afirmou que a biblioteca híbrida exige uma formação mais qualificada e contínua para a sua gestão. 
Entretanto, outras denominações foram apresentadas na literatura científica para a qualificação da nova biblioteca. O termo mais comumente encontrado é o de biblioteca digital. Segundo a Digital Library Federation, as bibliotecas digitais são organizações que disponibilizam recursos (incluído o recurso humano) para a seleção, estruturação, interpretação, distribuição e disponibilização de objetos digitais de modo que estejam acessíveis à comunidade, a baixo custo. Toutain (2006) definiu a biblioteca digital como uma biblioteca que tem

\footnotetext{
como base informacional conteúdos em texto completo em formatos digitais - livros, periódicos, teses, imagens, vídeos e outros -, que estão armazenados e disponíveis para acesso, segundo processos padronizados, em servidores próprios ou distribuídos e acessados via rede de computadores em outras bibliotecas ou redes de bibliotecas da mesma natureza (TOUTAIN, 2006, p. 16).
}

Para Cunha (1999, p. 258), a biblioteca digital é também conhecida como "biblioteca eletrônica (termo preferido dos britânicos), biblioteca virtual (quando se utiliza os recursos da realidade virtual), biblioteca sem paredes e biblioteca conectada a uma rede". O mesmo autor, em 2008, afirmou que a biblioteca digital "combina a estrutura e a coleta da informação, tradicionalmente usada por bibliotecas e arquivos, com o uso da representação digital tornada possível pela informática". Segundo Tammaro e Saralelli (2008, p. 116) a biblioteca eletrônica é definida como sendo a "biblioteca informatizada que emprega todos os tipos de equipamento eletrônico necessários ao seu funcionamento". Os autores explicaram que o termo "eletrônico" define documentos que são inacessíveis sem um equipamento adequado. Tammaro e Saralelli (2008, p. 117) definiram a biblioteca virtual como sendo a biblioteca inexistente. Neste caso, a biblioteca virtual é formada por uma "coleção de documentos ligados em rede, constituídos por objetos digitais e páginas web produzidos por milhares de autores".

A gestão das publicações eletrônicas ${ }^{20}$ implica no desenvolvimento de novos padrões para o armazenamento, organização, preservação e disseminação de seus conteúdos. Cunha $(2008$, p. 5) afirma que, à semelhança da biblioteca tradicional, "a

\footnotetext{
${ }^{20}$ As publicações eletrônicas neste estudo são entendidas como uma (ou várias) tecnologia de distribuição de informação de modo que pode ser acessada e visualizada por meio do computador, de acordo com Sabatini (1999).
} 
biblioteca digital também inclui os princípios consagrados de como a informação é organizada". De acordo com esse raciocínio, Vidotti e Sant'Ana (2006) ponderaram para o fato de que o desenvolvimento de uma biblioteca digital

\begin{abstract}
se baseia no planejamento de uma biblioteca tradicional/convencional, desde o processo de aquisição (compra, digitalização, acesso a outros sites e autoarquivamento), o processamento técnico (catalogação, classificação, indexação - metadados e iniciativa de arquivos abertos), a recuperação (ferramentas de busca), a disseminação (boletins eletrônicos), o atendimento ao usuário (setor de referência digital - meios de comunicação digital e sistemas agentes), até a preservação (itens documentários e dos suportes informacionais). Neste sentido, torna-se necessário um estudo sobre as funcionalidades, as características e os serviços a serem oferecidos, bem como uma política de desenvolvimento de coleções baseada em tipos documentais, conteúdos informacionais e público-alvo, além de uma política de preservação (VIDOTTI e SANT'ANA, 2006, p. 78).
\end{abstract}

O conceito apresentado por Vidotti e Sant'Ana (2006) ilustra os processos envolvidos para o desenvolvimento de uma biblioteca digital e que pode ser também adaptado ao contexto das bibliotecas digitais de teses e dissertações, como será discutido no decorrer desta seção.

Nesse sentido, Davenport (1998) sinalizou para as novas funções das bibliotecas ao apontar que elas devem se adaptar aos modelos organizacionais e utilizarem as tecnologias a favor para a extração de substratos que visam a melhoria na prestação de serviços e uso das informações. Os processos apontados pelo autor e que se aplicam ao contexto desta pesquisa são os seguintes: aquisição, organização, recuperação, disseminação e política de preservação da informação em ambiente digital. No conjunto, todos os processos nomeados devem favorecer o acesso e disseminação dos conteúdos digitais que neste estudo são as teses e dissertações eletrônicas.

Como visto anteriormente, a geração das teses e dissertações eletrônicas impulsionou o armazenamento desses documentos, com o texto completo, em sistemas de informação. As ETDs têm sido um dos tipos de publicação eletrônica mais comuns e mais importante dos arquivos abertos, juntos aos eprints e os artigos de periódicos científicos (SCHÖPFEL, ZENDULKOVA e FATEMI, 2014; MARCONDES e SAYÃO, 2003). Estes sistemas, em sua grande maioria, passaram a ser denominados como bibliotecas digitais de teses e dissertações, já que no mesmo contexto há o surgimento da Networked Digital Library of Theses and Dissertations (NDLTD). Moxley, já em 2001, 
demarcou que "enquanto no passado a qualidade das universidades estava relacionada às bibliotecas, no futuro a qualidade das universidades estará relacionada com as bibliotecas digitais de teses e dissertações".

Considera-se que o surgimento da NDLTD foi a mola propulsora para a criação de inúmeras iniciativas similares e desenvolvimento de bibliotecas digitais de teses e dissertações em todo o mundo, no final dos anos de 1990. Destaca-se também o papel da UNESCO que, internacionalmente, desde o ano de 1999 patrocinou ações de capacitação e construção de bibliotecas digitais de teses e dissertações eletrônicas.

A NDLTD funciona em rede e tem por objetivo reunir em um só local as teses e dissertações eletrônicas já defendidas em diversas instituições de todos os países. A NDLTD é a maior iniciativa existente para tal propósito, uma vez que a partir de adesão contínua de novas instituições de ensino e pesquisa tem expandido o seu alcance. Segundo Suleman (2001), em agosto de 2001, a NDLTD contava com a participação de 120 membros $^{21}$ (52 universidades americanas, 52 universidades não-americanas e 16 instituições, centros regionais e organizações, como a Organização das Nações Unidas para a educação, a ciência e a cultura (UNESCO)). Os membros citados se encontram distribuídos em 23 países: África do Sul, Alemanha, Austrália, Brasil, Canadá, China, Colômbia, Coreia do Sul, Espanha, Estados Unidos, Grécia, Holanda, Hong Kong, Índia, Itália, México, Noruega, Reino Unido, Rússia, Singapura, Sudão, Suécia e Taiwan. Em janeiro de 2014, os números de sistemas de informação coletados pela NDLTD somavam o total de 109.

O funcionamento da NDLTD se dá por meio de coletas automáticas (harvesting) das teses e dissertações eletrônicas armazenadas nos diferentes sistemas de informação implantados nas instituições participantes. A coleta é viabilizada mediante o uso do Protocolo OAI-PMH desenvolvido no âmbito da Iniciativa de Arquivos Abertos. No entanto, mais um elemento é fundamental para a concretização do processo de coleta: a descrição da tese e dissertação eletrônica no sistema de informação, o que implica diretamente na definição dos metadados.

Segundo Canós et al (2000), uma ETD é caracterizada por uma série de atributos ou metadados que descrevem informações referentes ao autor, orientador ou

\footnotetext{
${ }^{21}$ O número representa o dobro de instituições que a Rede apresentava em 1999.
} 
orientadores e aspectos relacionados com o próprio documento (título, palavras-chave, resumo entre outros). Entretanto, o número de metadados que devem ser preenchidos para a descrição da ETD pode variar entre os documentos e entre as próprias instituições participantes da NDLTD, sendo necessária, portanto, a definição de um conjunto mínimo metadados requisitados pela Rede. Assim, são coletados para o servidor da Rede os metadados devidamente preenchidos pelas instituições, sendo referenciado o texto completo da ETD por meio de um link. A discussão sobre os padrões de metadados e aspectos relacionados serão abordados em um momento posterior desta seção.

As iniciativas que passaram a surgir em todo o mundo detinham do mesmo, ou muito semelhante, conhecimento aplicado para o funcionamento da NDLTD. No Brasil, o Instituto Brasileiro de Informação em Ciência e Tecnologia (IBICT) atento às mudanças ocorridas no cenário internacional no âmbito do Projeto da Biblioteca Digital Brasileira (BDB), com apoio da Financiadora de Estudos e Pesquisas (FINEP) (BLATTMAN e SANTOS, 2009), iniciou também discussões acerca da gestão das teses e dissertações. Marcondes e Sayão (2003) descreveram a importância da produção brasileira de teses e dissertações como

essencial neste contexto dada suas dimensões múltiplas: mecanismo de transferência e comunicação de conhecimentos e dos resultados da pesquisa científica; indicador multifacetado deste esforço por área do conhecimento, por autor, por orientador, por instituição, por região geográfica do país, por agência de fomento (MARCONDES e SAYÃO, 2003, p. 162).

O primeiro esforço relacionado com a integração de teses e dissertações em uma única base de dados data do ano de 1995, com o desenvolvimento do Sistema de Teses (SITE) (MARCONDES e SAYÃO, 2003). O SITE era de iniciativa e responsabilidade do IBICT. No entanto, diferentemente da NDLTD, o SITE contava em seu início com mais de 140.000 referências bibliográficas de teses e dissertações, alimentada por 15 universidades brasileiras (IBICT, 2005; MARCONDES e SAYÃO, 2003). Desta forma, o SITE formava uma base de dados somente referencial.

Ao longo dos anos, desde 1995, o IBICT passou a aprofundar as discussões para o alcance da disponibilização das teses e dissertações eletrônicas. Nesse sentido, no final dos anos de 1990 e início dos anos 2000, um grupo de instituições foi chamado para 
participar das discussões realizadas no Instituto e para formarem parte de um possível projeto-piloto, assim como relato por Marcondes e Sayão (2003).

O IBICT chamou instituições brasileiras que tinham, até o momento, experiências de desenvolvimento de bancos de teses e dissertações eletrônicas, para se articularem no que vem sendo chamado de Consórcio Brasileiro de Teses Eletrônicas, com o objetivo de montar um catálogo coletivo de teses eletrônicas e torna-las disponíveis através de um único portal na internet. As instituições que inicialmente formaram o Consórcio foram a BIREME, que opera como experiência-piloto, o banco de teses eletrônicas da FIOCRUZ, a PUC-RIO, a UFSC, a USP e o CNPq (MARCONDES e SAYÃO, 2003, p. 163).

Assim, no mês de dezembro de 2002 surge a Biblioteca Digital Brasileira de Teses e Dissertações (BDTD). Baseada no modelo de operacionalização da NDLTD e com uso do Protocolo OAI-PMH, o Portal da BDTD reúne as teses e dissertações eletrônicas defendidas nas instituições brasileiras de ensino e pesquisa e por brasileiros no exterior e as disponibiliza para a sociedade de modo gratuito e acesso aos seus textos completos passíveis de downloads.

No período da sua concepção também foi desenvolvido um sistema de informação para atender às instituições brasileiras que não detinham de uma tecnologia para o gerenciamento das teses e dissertações. Nesse sentido, o referido sistema chamado Sistema de Publicação Eletrônica de Teses e Dissertações (TEDE). Segundo dados do IBICT (2014), o TEDE foi implantado em 78 instituições brasileiras, embora seu uso não tenha sido continuado em todas as instituições até os dias atuais. Este aspecto, bem como o sistema como um todo, será discutido com maior profundidade na seção 2.4.3 desta dissertação. 
Figura 11: Funcionamento da BDTD

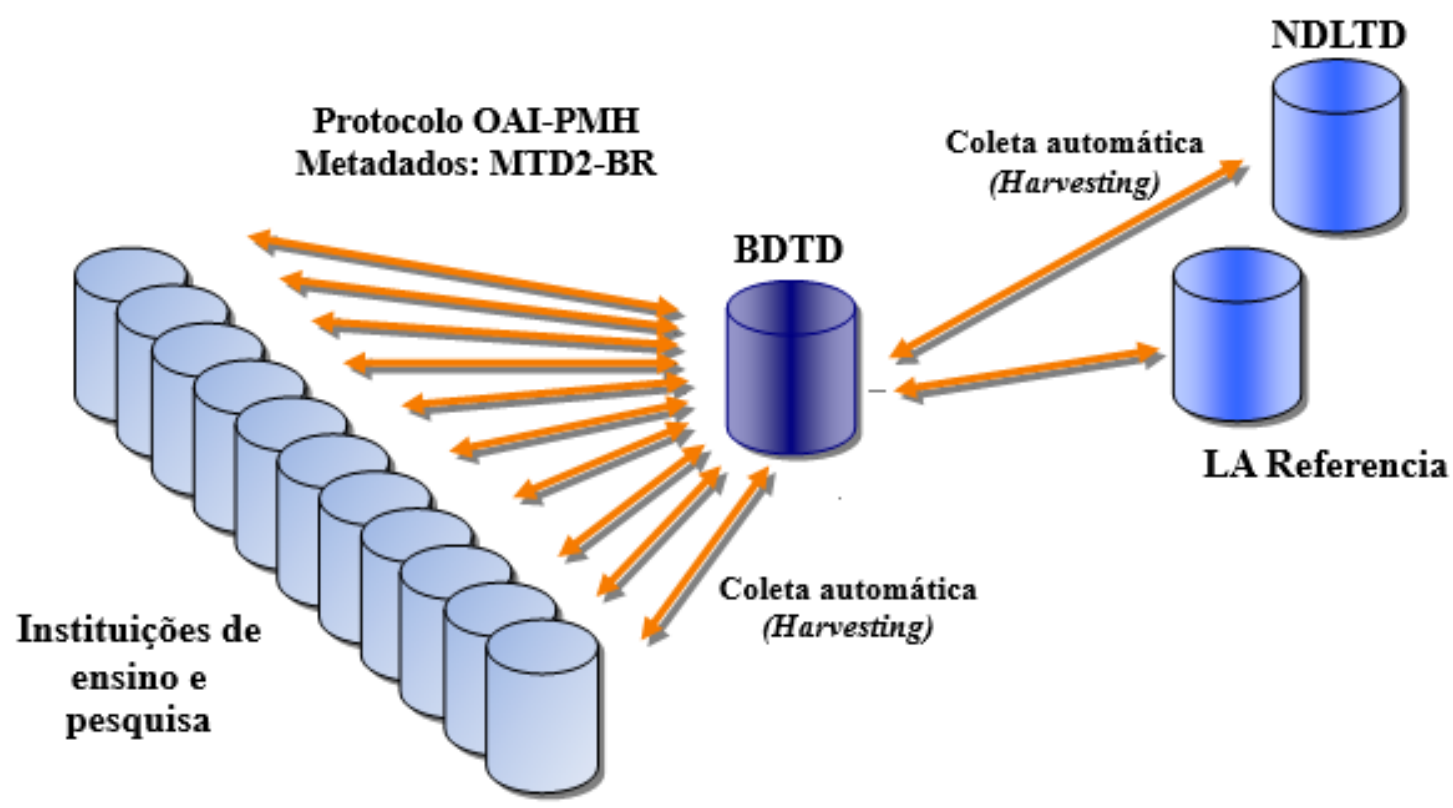

Fonte: IBICT, 2014.

Treze anos após a sua criação, a BDTD conta com a parceria de 111 instituições brasileiras de ensino e pesquisa, concentrando um total de aproximadamente 300.000 teses e dissertações eletrônicas (IBICT, 2015). Este número faz da BDTD figurar entre as cinco maiores bibliotecas digitais de teses e dissertações em todo o mundo (NDLTD, 2015). O número representativo dessa tipologia documental disponível para acesso e uso da comunidade científica brasileira e de todo o cenário internacional, reforça o papel do IBICT como órgão responsável pela ampla disseminação desse importante conhecimento científico e pelo apoio às instituições brasileiras de ensino e pesquisa para que disseminem a sua produção abertamente.

Figura 12: Distribuição das instituições participantes da BDTD por regiões geográficas

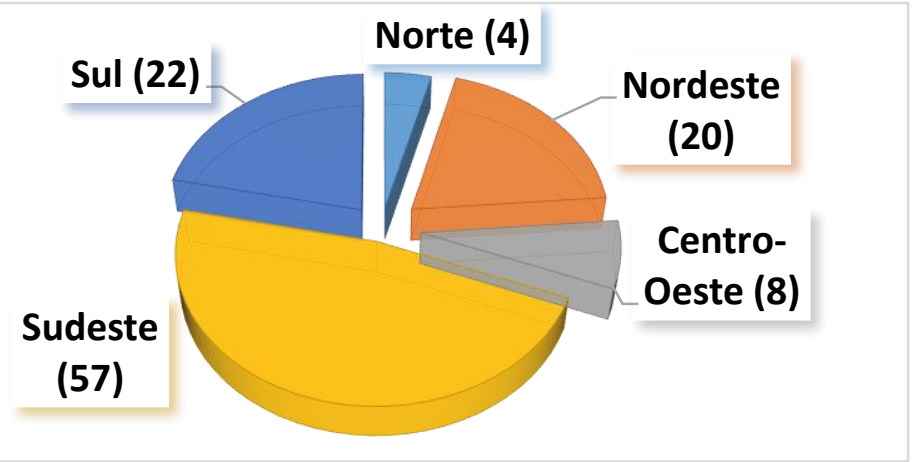

Fonte: IBICT, 2015. 
Padrões de metadados

Os metadados são classicamente definidos como "dados sobre dados". Tem por função descrever o documento a ser inserido em um sistema de informação, promovendo assim a sua recuperação. De acordo com De Marchi e Costa (2004, p. 3-4) "podem ser comparados a um sistema de rotulagem que descreve o recurso, seus objetivos e características, mostrando como, quando e por quem o recurso foi armazenado, e como está formatado". Ainda segundo os autores, "são dados descritivos que podem informar sobre o título, autor, data, publicação, palavras-chave, descrição, localização do recurso, entre outros". Para a descrição dos recursos eletrônicos e com vistas a facilitar a padronização e a interoperabilidade entre os sistemas são definidos padrões de metadados ou esquemas de metadados. A National Information Standards Organization (NISO) (2004, p. 2) aponta que os esquemas de metadados são conjuntos de elementos definidos para atender a uma determinada finalidade.

Desta forma, diversos padrões de metadados passaram a ser desenvolvidos para atender diferentes áreas e sistemas, como as bibliotecas digitais de teses e dissertações, os repositórios digitais, os sistemas de arquivos, dentre outros.

Para esta pesquisa são apresentados três esquemas de metadados: Dublin Core, o ETD-MS e o próprio MTD2-BR que é objeto de discussão deste trabalho.

\section{- $\quad \underline{\text { Dublin Core }}$}

De maneira informal, a discussão sobre a Dublin Core Metadata Initiative se por meio de um workshop interdisciplinar. O debate ganhou maiores proporções fazendo com que fossem desenvolvidos processos formais para a iniciativa (WEIBEL, 1999, p. 19). O Dublin Core Metadata Element Set, chamado comumente como Dublin Core, é uma recomendação derivada dessas discussões. Weibel et al $(1998$, p. 2) apontam que os objetivos que nortearam o desenvolvimento do Dublin Core foram: simplicidade na criação e manutenção; semântica comumente entendida; conformidade com os padrões já existentes e emergentes; alcance e aplicabilidade internacional; extensibilidade; e, interoperabilidade entre coleções e sistemas de indexação. 
Desta forma, o padrão de metadados Dublin Core é constituído por um conjunto de 15 elementos genéricos que possibilitam a descrição de uma vasta gama de documentos eletrônicos de diferentes áreas do conhecimento.

\section{Quadro 3: Padrão de metadados Dublin Core}

\begin{tabular}{|c|c|c|}
\hline $\mathbf{1}$ & Elementos & Aplicação \\
\hline $\mathbf{2}$ & Title & $\begin{array}{c}\text { Átulo dado ao documento } \\
\text { Geralmento do documento. }\end{array}$ \\
\hline $\mathbf{3}$ & Subject & $\begin{array}{c}\text { Descrição do documento. Podem } \\
\text { ser o resumo e abstract }\end{array}$ \\
\hline $\mathbf{4}$ & Description & Tipo do documento \\
\hline $\mathbf{5}$ & Type & Origem ou fonte do documento \\
\hline $\mathbf{6}$ & Source & $\begin{array}{c}\text { Relação do documento com outro } \\
\text { recurso }\end{array}$ \\
\hline $\mathbf{7}$ & Relation & $\begin{array}{c}\text { Localização espacial, temporal do } \\
\text { documento }\end{array}$ \\
\hline $\mathbf{8}$ & Coverage & Autor do documento \\
\hline $\mathbf{9}$ & Creator & $\begin{array}{c}\text { Publicador ou editor. Responsável } \\
\text { por publicar o documento }\end{array}$ \\
\hline $\mathbf{1 0}$ & Publisher & Contribuidor \\
\hline $\mathbf{1 1}$ & Contributor & Informações sobre direitos \\
autorais
\end{tabular}

Fonte: Da autora, 2015.

Além dos 15 elementos apresentados, o padrão de metadados Dublin Core possibilita a utilização de qualificadores para maior especificação dos campos. Baptista e Machado (2001, p. 2) apontam que "a quase todos os elementos do Dublin Core estão associados qualificadores de refinamento de elemento e/ou de esquema de codificação". Ainda segundo os autores, "os qualificadores de refinamento de elemento são, como o próprio nome sugere, outros termos associados ao elemento que 
especificam com mais precisão o significado desse mesmo elemento". Como exemplo é citado o campo Date ou Data que tem como qualificadores Issued, Created, Available, Modified e Valid.

Pelos objetivos que nortearam a definição do Dublin Core, este padrão de metadados é um dos mais utilizados para a organização da informação na Internet. Por estar presente em diversos sistemas digitais e com vistas à interoperabilidade, o Dublin Core é utilizado como base no processo de definição de outros padrões de metadados. Assim, a seguir é apresentado o padrão ETD-MS.

\section{$\underline{E T D-M S}$}

O Interoperability Metadata Standard for Theses and Dissertations (ETD-MS) é uma extensão do padrão de metadados Dublin Core, contendo campos adicionais para a descrição de teses e dissertações. No cenário internacional é o padrão de metadados utilizado em sistemas de informação que armazenam teses e dissertações, como é o caso da NDLTD.

\section{Quadro 4: Padrão de metadados ETD-MS}

\begin{tabular}{|c|c|c|}
\hline & $\begin{array}{c}\text { Metadata about thesis or } \\
\text { dissertation }\end{array}$ & Elements of ETD-MS format \\
\hline $\mathbf{1}$ & Author & dc.contributor \\
\hline $\mathbf{2}$ & Advisor & dc.contributor \\
\hline $\mathbf{3}$ & Chair & dc.contributor \\
\hline $\mathbf{4}$ & Committee member & dc.title \\
\hline $\mathbf{5}$ & Title & dc.title.alternative \\
\hline $\mathbf{6}$ & Alternative title & dc.subject \\
\hline $\mathbf{7}$ & Keywords & dc.description.abstract \\
\hline $\mathbf{8}$ & Abstract & dc.description.note \\
\hline $\mathbf{9}$ & Note & dc.language \\
\hline $\mathbf{1 0}$ & Language & dc.publisher \\
\hline $\mathbf{1 1}$ & Publisher & dc.date \\
\hline $\mathbf{1 2}$ & Publication date & \\
\hline
\end{tabular}




\begin{tabular}{|c|c|c|}
\hline $\mathbf{1 3}$ & Record type & dc.type \\
\hline $\mathbf{1 4}$ & Content format & dc.format \\
\hline $\mathbf{1 5}$ & URI & dc.rights \\
\hline $\mathbf{1 6}$ & Access rights & thesis.degree.name \\
\hline $\mathbf{1 7}$ & Name of author's degree after \\
defence & Level of education & thesis.degree.level \\
\hline $\mathbf{1 8}$ & Scientific field & thesis.degree.discipline \\
\hline $\mathbf{1 9}$ & Institution & thesis.degree.grantor \\
\hline $\mathbf{2 0}$ & &
\end{tabular}

Fonte: Ivanóvic, Ivanóvic e Surla, 2012, p. 556, com adaptações.

Portanto, o padrão ETD-MS é um conjunto de metadados desenvolvido para a descrição de teses e dissertações e que pode ser interoperável com vários sistemas de informação junto com a utilização do protocolo OAI-PMH (IVANÓVIC, IVANÓVIC e SURLA, 2012).

\section{$\underline{M T D-B R \text { e } M T D 2-B R}$}

O IBICT, em conjunto com o comitê técnico-consultivo (CTC) formado pelo IBICT, CNPq, MEC (Capes e Secretaria de Educação Superior (SESU)), FINEP e de três universidades do projeto-piloto da BDTD (Universidade de São Paulo (USP), Pontifícia Universidade Católica do Rio de Janeiro (PUC-Rio) e Universidade Federal de Santa Catarina (UFSC)), instalado em 2002, aprovou o Padrão Brasileiro de Metadados de Teses e Dissertações (MTD-BR) no início do projeto da BDTD. No processo de definição do padrão brasileiro de metadados foram observados os padrões de metadados já definidos no cenário internacional: o Dublin Core e o ETD-MS.

A criação de um padrão de metadados brasileiros objetivou garantir a interoperabilidade entre os sistemas de informação que armazenam teses e dissertações e a BDTD. Em outras palavras, a definição de um conjunto mínimo de metadados obrigatórios presentes no MTD-BR viabilizaria a coleta automática de metadados nas instituições de ensino e pesquisa, fazendo com que, na busca centralizada na BDTD, fossem recuperadas as teses e dissertações com o mínimo de informações que atendam às necessidades dos usuários. Molossi (2008) apontou que 
a principal finalidade desse padrão de metadados é tornar disponíveis os meios que a comunidade brasileira de Ciência e Tecnologia possa publicar seus trabalhos diretamente na rede, aumentando a visibilidade do seu trabalho em âmbito nacional e internacional, otimizando o fluxo da comunicação científica e reduzindo a frustação de resultados ineficientes nas buscas de documentos digitais (MOLOSSI, 2008, p. 17).

O próprio Instituto - IBICT - justifica o desenvolvimento de um padrão de metadados brasileiro:

(...) foi desenvolvido o Padrão Brasileiro de Metadados de Teses e Dissertações (MTD-BR) para atender aos objetivos da BDTD de oferta de produtos e serviços de informação com vistas à identificação e localização das teses e dissertações eletrônicas (TDEs), como também para a coleta de informação com vistas à geração de indicadores e integração com outros repositórios nacionais e internacionais (IBICT, 2003, web).

Desta forma, a relação do padrão de metadados MTD-BR com os outros padrões, Dublin Core e o ETD-MS, é representada na figura a seguir.

Figura 13: A relação entre o MTD-BR, ETD-MS e o Dublin Core

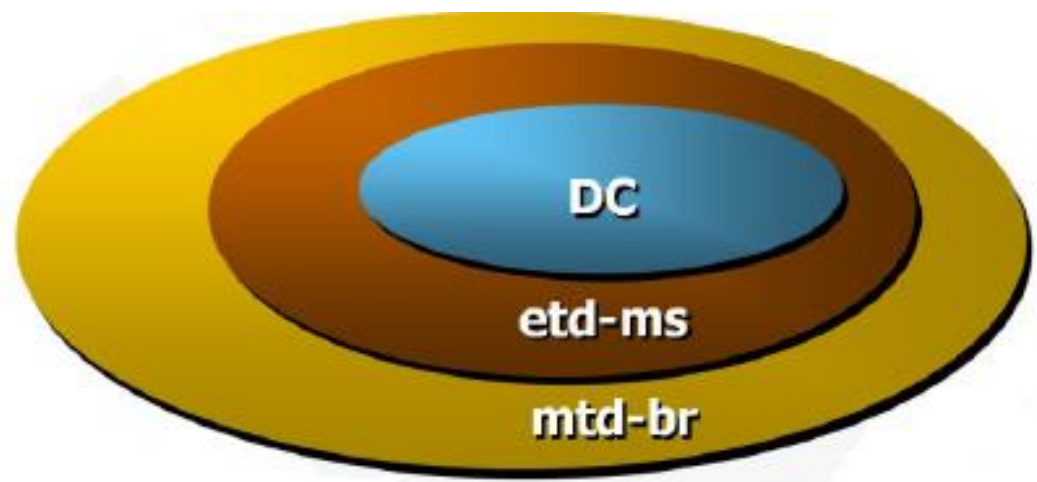

Fonte: Molossi, 2012.

Entretanto, após a divulgação do padrão MTD-BR e a sua implantação nos sistemas de informação das instituições de ensino e pesquisa, o IBICT observou a necessidade de realizar "alterações significativas no padrão com objetivo de melhorar a qualidade e controle sobre o conteúdo alimentado na BDTD" (IBICT, 2013, web). Ainda, o Instituto (2013) apontou que 
o aspecto de interoperabilidade previsto para a integração entre as instituições cooperantes fornecedoras de metadados e o sistema BDTD tornou-se preponderante para a reconstrução do sistema atual a partir das novas premissas de consistência e qualidade dos dados, frisando o aspecto de interoperabilidade como fator incondicional para atingir os objetivos do sistema BDTD (IBICT, 2013, web).

Assim, o IBICT reestruturou a tecnologia utilizada na BDTD, bem como o padrão de metadados, passando a ser chamado de MTD2-BR. A definição da nova versão foi homologada na 3ạ Reunião do comitê técnico-consultivo (CTC) da BDTD que ocorreu no ano de 2005.

Após as mudanças ocorridas e definido o MTD2-BR, o padrão passou a ser composto por 19 metadados que são qualificados. No total, somando-se os metadados e seus qualificadores tem-se o número de 80 campos disponíveis para a descrição das teses e dissertações na BDTD utilizando-se o padrão de metadados MTD2-BR. Abaixo são apresentados os metadados principais ${ }^{22}$.

Quadro 5: Padrão de metadados MTD2-BR

\begin{tabular}{|c|c|c|}
\hline & Nome do elemento & Explicação do metadado \\
\hline 1 & Controle & Dados de controle do registro de teses e dissertações \\
\hline 2 & Biblioteca Digital & $\begin{array}{l}\text { Nome da instituição responsável pela publicação digital } \\
\text { da tese ou dissertação }\end{array}$ \\
\hline 3 & Biblioteca Depositária & $\begin{array}{c}\text { Biblioteca onde o exemplar físico da tese ou dissertação } \\
\text { está arquivada }\end{array}$ \\
\hline 4 & Título & Título da tese ou dissertação \\
\hline 5 & Arquivo & $\begin{array}{l}\text { Endereço eletrônico dos arquivos da tese ou dissertação } \\
\qquad \text { na Biblioteca Digital }\end{array}$ \\
\hline 6 & Idioma & Idioma da tese ou dissertação \\
\hline 7 & Grau & Grau acadêmico associado à tese ou dissertação \\
\hline 8 & Titulação & $\begin{array}{l}\text { Nome do grau acadêmico associado à tese ou } \\
\text { dissertação }\end{array}$ \\
\hline 9 & Resumo & Resumo da tese ou dissertação \\
\hline 10 & Cobertura & Escopo espacial ou temporal da tese ou dissertação \\
\hline 11 & Assunto & $\begin{array}{l}\text { Tópicos tratados na tese ou dissertação e a tabela de } \\
\text { onde estes tópicos foram extraídos, quando for o caso }\end{array}$ \\
\hline
\end{tabular}

${ }^{22} \mathrm{O}$ padrão completo de metadados pode ser encontrado no Anexo I. 


\begin{tabular}{|c|c|c|}
\hline 12 & Local de defesa & Local de defesa da tese ou dissertação \\
\hline 13 & Data de defesa & Data em que foi defendida a tese ou dissertação \\
\hline 14 & Autor & Autor da tese ou dissertação \\
\hline 15 & Contribuidor & $\begin{array}{c}\text { Contribuidor da tese ou dissertação e forma de } \\
\text { participação (papel) }\end{array}$ \\
\hline 16 & Instituição de defesa & Instituição onde a tese foi defendida \\
\hline 17 & Agência de Fomento & $\begin{array}{c}\text { Agência de financiamento que apoiou financeiramente } \\
\text { o autor }\end{array}$ \\
\hline
\end{tabular}

Fonte: IBICT, 2014, com modificações.

Entretanto, há que se dizer que o preenchimento do padrão MTD2-BR não tem sido feito de forma correta pelas instituições implicando nas questões relacionadas à padronização e na coleta automática.

\subsubsection{O Movimento de Acesso Aberto à Informação Científica}

O cenário, caracterizado pela explosão e compartilhamento dos resultados de pesquisa por meio da internet e o crescente número de arquivos de eprints, impulsionou o surgimento do Movimento de Acesso Aberto à Informação Científica. Pode-se dizer que a origem partiu de reações da própria comunidade científica: a crise dos periódicos científicos, impulsionada pelos preços exorbitantes para a assinatura dessas publicações e a insatisfação dos pesquisadores quanto ao lento processo de publicação dos resultados da pesquisa em periódicos científicos. Com relação aos altos preços impostos e monopólio dos editores científicos, Abadal (2012) destaca que o processo de controle de mercado teve seu crescimento depois da 2a Guerra Mundial, quando surgiu um grande número de revistas científicas e quando também foram criadas e potencializada a influência dos índices de citação (Citation Index) do Institute of Scientific Information (atualmente Thomson Reuters). Seguindo a discussão com relação aos custos, o estudo realizado pela Association of Research Libraries (ARL) apontou que no período de 19862006 houve um aumento de $321 \%$ no valor das assinaturas de revistas científicas acadêmicas. 
Figura 14: Custos da Association of Research Libraries

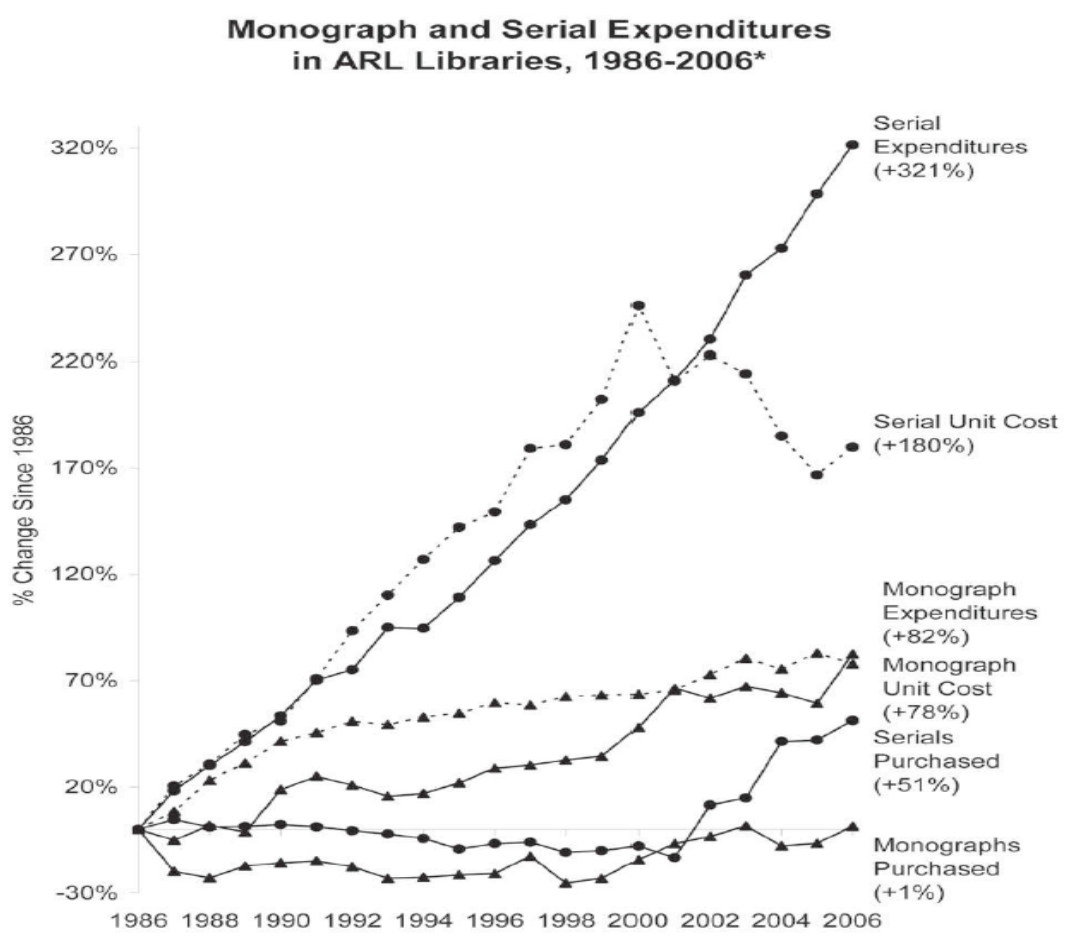

Fonte: Association of Research Libraries (ARL) Statistic 2005-6, 2006.

Abadal (2012) cita dois fatores importantes para a viabilização do Movimento: a internet e a digitalização dos documentos. Segundo o autor, "la edición digital e internet, por tanto, han posibilitado la aplicación y extensión del modelo" (ABADAL, 2012, p. 10).

As discussões que se iniciaram, ainda durante o desenvolvimento da OAi, sobre alternativas para a maximização do acesso às publicações científicas, levaram à criação de uma série de iniciativas e eventos relacionados com o tema. A reunião realizada em Budapeste, no ano de 2001, convocada pela Open Society Foundations (OSF), tornou-se o marco do Movimento de Acesso Aberto, que segue os ditames presentes na Budapest Open Access Initiative (BOAl). Lançada em 2002, a BOAl é apontada como uma "declaração de princípio, uma declaração de estratégia e uma declaração de compromisso" (BOAl, 2014). Segundo informações da própria Iniciativa, a BOAI “procurou deliberadamente reunir projetos já existentes para explorar como poderiam "trabalhar em conjunto para conseguir o mais amplo, profundo e rápido sucesso"”". A declaração da BOAl após 10 anos de criação enumera os feitos alcançados pela Iniciativa: a primeira a utilizar o termo acesso aberto para tal propósito; a primeira a articular uma definição pública; a primeira a propor estratégias complementares para atingir o Acesso Aberto; a primeira a generalizar o apelo ao acesso aberto a todas as 
disciplinas e países e; a primeira a ser acompanhada por financiamento significativo (BOAI, 2014).

Segundo a Declaração da BOAl, o Acesso Aberto significa a disponibilização livre e irrestrita, por meio da internet, permitindo a qualquer pessoa ler, baixar, copiar, distribuir e imprimir, salvaguardando os direitos de autor. Para a concretização do Acesso Aberto, a Iniciativa recomenda duas estratégias: o autoarquivamento e a publicação em periódicos de acesso aberto.

- Autoarquivamento: consiste em um processo no qual os próprios autores realizam o processo de depósito da cópia de suas publicações, devidamente revisadas por pares, em sistemas de acesso aberto. Esses arquivos devem estar de acordos com os padrões da OAi. Esta primeira estratégia ficou conhecida posteriormente como Via Verde;

- Periódicos de acesso aberto: a segunda estratégia aponta para a necessidade de mudança no modelo de negócio dos periódicos científicos. Há o incentivo para a criação de periódicos de acesso aberto e para aqueles já existentes, a transição para o novo modelo onde não haja cobrança pelo acesso ao seu conteúdo. Mais tarde, esta estratégia passou a ser chamada de Via Dourada.

Desta forma, a BOAI convoca a todos os pesquisadores e instituições a disponibilizarem as pesquisas científicas no modelo do acesso aberto.

Abadal (2012) reforça a importância do Movimento na área da Comunicação Científica. Segundo o autor, o acesso aberto, é uma mudança do modelo de funcionamento da comunicação científica, já que hoje, não é nem grátis e nem livre. De acordo com Abadal (2012, p. 8), "el acceso abierto es en realidad un cambio de paradigma, una revolución que quiere modificar de pies a cabeza el sistema de comunicación de la ciencia".

Seguindo com o estudo de Abadal (2012), o autor apresenta um quadro que sintetiza a ideia do "novo" sistema de comunicação científica com a inclusão dos elementos do acesso aberto em todo o processo. 
Quadro 6: Funcionamento do processo de comunicação científica

\begin{tabular}{|l|l|l|}
\hline \multicolumn{1}{|c|}{ Agente } & \multicolumn{1}{|c|}{ Função } & \multicolumn{1}{c|}{ Produto } \\
\hline Autor & $\begin{array}{l}\text { Pesquisa } \\
\text { Elaboração de originais }\end{array}$ & Texto original \\
\hline Revisor & Revisão ou avaliação (peer review) & Aviso de revisão \\
\hline Editor & Publicação & Artigo de revista \\
\hline Distribuidor/Agregador & Agregar & $\begin{array}{l}\text { Portal de revistas } \\
\text { comerciais } \\
\text { acesso aberto }\end{array}$ \\
\hline Autor & Autoarquivo & Repositório \\
\hline Indexador & $\begin{array}{l}\text { Indexação (referência ou texto } \\
\text { completo) }\end{array}$ & $\begin{array}{l}\text { Base de dados científica, motor } \\
\text { de busca acadêmico, } \\
\text { coletadores etc }\end{array}$ \\
\hline Biblioteca & Seleção, submissão, acesso & Catálogo de revistas \\
\hline
\end{tabular}

Fonte: Abadal, 2012, p. 11, com alterações.

A ideia central do Movimento é tornar disponíveis para acesso e consulta, livres de custos e restrições, por meio da internet, principalmente os artigos científicos. Para isso, considera-se como o processo ideal a publicação por meio de revistas científicas de acesso (Via Dourada). No entanto, na realidade ainda não é possível ter todas as revistas científicas de acordo com o idealizado. Desta maneira, o depósito dos resultados de pesquisa materializados em artigos científicos e nas demais publicações científicas é realizado nos repositórios digitais.

\subsubsection{Os repositórios digitais de acesso aberto}

Como já exposto, o Movimento de Acesso Aberto à Informação Científica recomenda duas estratégias para a promoção do acesso aberto: a Via Dourada e a Via Verde. Como as teses e dissertações passaram a também integrar os repositórios institucionais discute-se nesta dissertação o contexto da Via Verde.

Leite (2009, p. 21) afirmou que "todo repositório institucional de acesso pode ser considerado um tipo de biblioteca digital, mas nem toda biblioteca digital pode ser considerada um repositório institucional". O autor apresentou algumas diferenciações importantes entre os dois sistemas. O primeiro aspecto refere-se ao conteúdo a ser armazenado no sistema. Os repositórios institucionais lidam exclusivamente com a produção científica de uma instituição. O segundo aspecto diz respeito às características 
relacionadas à filosofia do movimento de acesso aberto à informação científica: o autoarquivamento e a interoperabilidade. Por fim, o terceiro aspecto citado pelo autor é a proposta do software, que no caso dos repositórios institucionais há "peculiaridades que envolvem os processos de gestão da informação científica e, sobretudo, nas características dos processos de comunicação científica" (LEITE, 2009, p. 21).

Observa-se que o termo utilizado nesta seção, até o momento, refere-se aos repositórios institucionais. Nesta pesquisa, considera-se que os repositórios institucionais são um tipo de repositório digital. Os repositórios institucionais destinamse à captura, armazenamento, organização, preservação, recuperação, disseminação e uso da informação científica produzida por uma instituição. Diferem-se, portanto, dos repositórios temáticos os quais têm por objetivo reunir a produção científica relacionada com uma determinada área do conhecimento. Nesse contexto, pelo fato de que as instituições passaram a armazenar as teses e dissertações também em repositórios institucionais, este trabalho dará enfoque à Via Verde. Esta relação, a coexistência entre as bibliotecas digitais de teses e dissertações e os repositórios de acesso aberta, será discutida com maior profundidade na próxima seção.

Na região da América Latina e Caribe também foram elaborados documentos que visam à promoção do acesso aberto à informação científica. O IBICT lançou, em 2005, o Manifesto Brasileiro de Apoio ao Acesso Livre à Informação Científica. O Manifesto é baseado nos termos presentes na Declaração de Berlim, que trata das políticas de informação para o acesso aberto. No cenário legislativo, o Brasil apresentou, em 2007, uma proposta de Projeto de Lei (PL 1.120/2007), para a determinação da obrigatoriedade de criação de repositórios institucionais em todas as instituições brasileiras públicas de ensino e pesquisa. Entretanto, essa proposta foi arquivada em 2011 em razão do esgotamento do tempo de tramitação no Congresso Nacional Brasileiro. Em substituição a essa primeira tentativa, em 2011 foi lançado no Senado Federal o Projeto de Lei 387 (PLS 387/2011) que ainda se encontra em tramitação nas comissões da Casa.

Seguindo o exemplo do Brasil, outros países da região lançaram também propostas nacionais, tais como, o Peru e a Argentina. O Peru teve aprovada a Lei 30.035 de 2013, que regulamenta o Repositorio Nacional Digital de Ciencia, Tecnología y Inovación de Acceso Abierto. Na Argentina, em 2012, foi sancionada a Lei que também 
visa a criação de repositórios institucionais nas instituições pesquisa que recebem financiamento público. O México publicou, no início de 2013, um projeto, direcionada por uma senadora da república, que objetiva estabelecer que qualquer pesquisa realizada em instituições públicas, com recursos públicos ou ainda com a infraestrutura financiada por recursos públicos, esteja disponível em formato de acesso aberto por meio de plataformas online. O projeto tomou por base um estudo realizado, em 2011, pela Universidad Nacional Autónoma de México (UNAM) e o Centro de Estudios Imanol Ororika que para cada dez pesquisas realizadas por instituições de ensino superior, apenas uma foi realizada em uma instituição privada.

As ações supracitadas são notadamente importantes para o fortalecimento do acesso aberto na região. Neste cenário, tem sido uma prática a formação de redes entre os países para a concentração das publicações científicas originadas na região e redes nacionais para melhor gestão e promoção das iniciativas de acesso aberto. Considerase que a Red Federada Latinoamericana de Repositorios Institucionales de Documentación Científica en América Latina (LA Referencia) uma iniciativa extremamente relevante.

A LA Referencia ${ }^{23}$, estabelecida em 2012, conta com a participação de nove países latino-americanos (Argentina, Brasil, Chile, Colômbia, Equador, México, Peru e Venezuela). O objetivo da Rede é "compartilhar e dar visibilidade à produção científica gerada nas instituições de educação superior e de pesquisa científica na América Latina" (LA REFERENCIA, 2014). A Rede disponibiliza, hoje, aproximadamente 500 mil artigos científicos, mais de 90 mil teses de doutorado e mais de 200 mil dissertações de mestrado ${ }^{24}$.

A LA Referencia reúne as teses e dissertações de nove países da América Latina. Segundo dados da Rede, a região dissemina 618.145 teses e dissertações em formato eletrônico e em texto completo. Dentre os países, o Brasil é o que mais se destaca pela quantidade de teses e dissertações disseminadas, com um total de cerca de 556.768, o que corresponde a $90 \%$ destes documentos na Rede. Para efeitos de comparação, o número de publicações indexadas no Science Citation Index $(\mathrm{SCl})^{25}$, em 2011, foi de

\footnotetext{
${ }^{23}$ LA Referencia <http://lareferencia.redclara.net>.

${ }^{24}$ Fonte: <http://www.lareferencia.info/vufind/>.

25 Dados apresentados pela RICYT <http://www.ricyt.org/indicadores>.
} 
70.084 documentos. Segundo o Directory of Open Access Journals (DOAJ) ${ }^{26}$ dos dez primeiros países com maior número de artigos científicos, três são da América Latina (Brasil, Colômbia e Chile), sendo o Brasil o país com o maior número de publicações de todos os dez países (329.176).

Observa-se que no contexto atual há uma maior integração entre as bibliotecas digitais de teses e dissertações e os repositórios digitais de acesso aberto. Ou seja, as teses e dissertações passaram também a estar presentes nos repositórios digitais, em conjunto com as demais produções científicas da instituição. As instituições têm optado em adotar um ou os dois sistemas para o gerenciamento de suas teses e dissertações eletrônicas. Desta forma, a apresentação dos conceitos e, consequentemente, a distinção dos dois sistemas, será importante para a análise dessa junção de sistemas.

\subsubsection{A coexistência das bibliotecas digitais de teses e dissertações e os repositórios institucionais no contexto do Acesso Aberto à informação científica}

Para a discussão proposta nesta seção, a coexistência das bibliotecas digitais de teses e dissertações e os repositórios institucionais no contexto do Acesso Aberto à informação científica, faz-se necessária uma nova análise nas definições para os dois sistemas de informação. Para isto, recorre-se às definições apresentadas por Alma Swan (2011?), extraídas do Online Dictionary for Library \& Information Science (ODLIS).

Segundo o dicionário, as ETDs são definidas como "the Master's theses and Ph.D. dissertations submitted in digital from rather than in print on paper, as opposed to those submitted in hard copy and subsequently converted tom machine-readable format". Assim sendo, entende-se que as bibliotecas digitais de teses e dissertações são sistemas de informação que se destinam, única e exclusivamente, para a gestão das teses e dissertações eletrônicas.

O repositório institucional é definido, como apresentado pelo dicionário,

um conjunto de serviços oferecidos por uma universidade ou grupo de universidades para membros de sua comunidade para o gerenciamento e disseminação de materiais acadêmicos em formato digital criado pela instituição e seus membros, como eprints, relatórios técnicos, teses e

\footnotetext{
${ }^{26}$ Directory of Open Accecss Journals (DOAJ) <http://doaj.org/>.
} 
dissertações, conjuntos de dados e materiais de ensino. (....) Repositórios institucionais são uma parte do grande esforço para mudar a comunicação acadêmica e frear o monopólio dos editores de periódicos (...) (ONLINE DICTIONARY FOR LIBRARY \& INFORMATION SCIENCE (ODLIS)).

Ressalta-se desse conceito a referência às teses e dissertações como documentos eletrônicos armazenados em repositórios institucionais. No entanto, novamente é necessário fazer outras ponderações.

Como apresentado nas seções anteriores desta dissertação, o fenômeno do surgimento das bibliotecas digitais de teses e dissertações ocorreu no final dos anos de 1990, consolidando-se nos primeiros anos de 2000. Por sua vez, a criação dos repositórios institucionais de acesso aberto ocorre a partir das orientações da BOAl, em 2002, no contexto do Movimento de Acesso Aberto à informação científica, como pertencentes à estratégia da Via Verde apresentada em tal iniciativa. Considera-se nesta pesquisa que, a estruturação do Protocolo $\mathrm{OAI}-\mathrm{PMH}$, e as experiências da troca de informações entre as bibliotecas digitais de teses e dissertação no seu uso, podem ser consideradas como sementes que viabilizam a concretização do ideal estabelecido pelo Movimento de Acesso Aberto. Nesse contexto, as teses e dissertações por prescindirem da figura dos editores científicos e, portanto, não exigirem uma negociação de direitos autorais entre os possíveis atores, os pesquisadores-autores das ETDs e a universidade, passaram a ser os documentos mais fáceis para a alimentação dos repositórios institucionais. Desta forma, as ETDs passaram a figurar entre o rol de documentos científicos presentes nos repositórios.

De acordo com Schöpfel, Zendulkova e Fatemi (2014), as teses e dissertações eletrônicas são conteúdos que correspondem a mais da metade de todos os repositórios institucionais do Diretório OpenDOAR. Segundo os dados estatísticos do OpenDOAR, 1.488 repositórios cadastrados declaram conter teses e dissertações. Comparando esse número com o número de repositórios com conteúdo formado por artigos presentes no OpenDOAR, há 378 repositórios que contém teses e dissertações a mais.

Em sua pesquisa da análise das características e contribuições da Via Verde para - Acesso Aberto na América Latina, Costa (2014, p. 130) aponta que as teses e dissertações têm uma significativa importância para o desenvolvimento dos repositórios 
institucionais. Esta conclusão confirma o estudo de Leite (2011) que afirma que as teses e dissertações são o "carro-chefe" no povoamento dos repositórios institucionais.

\section{Figura 15: Abrangência dos tipos de documentos dos repositórios}

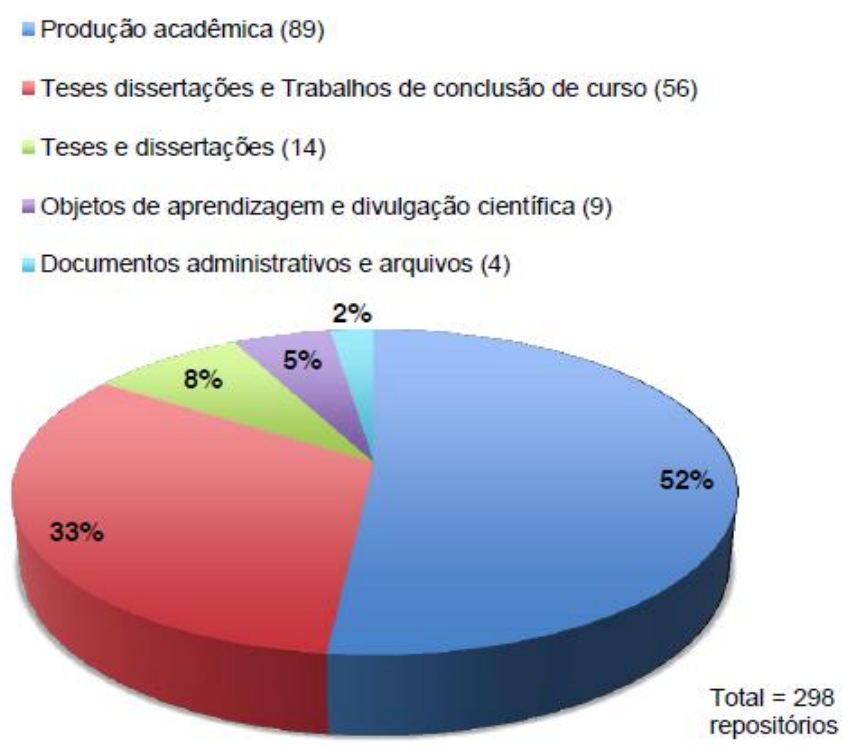

Fonte: Costa, 2014, p. 130.

Costa (2014) também destaca que as teses, dissertações e os trabalhos de conclusão de curso são o segundo tipo de documento mais presente nos repositórios institucionais da América Latina, ficando atrás apenas dos artigos científicos.

\section{Figura 16: Tipos de documentos nos repositórios institucionais da América Latina}
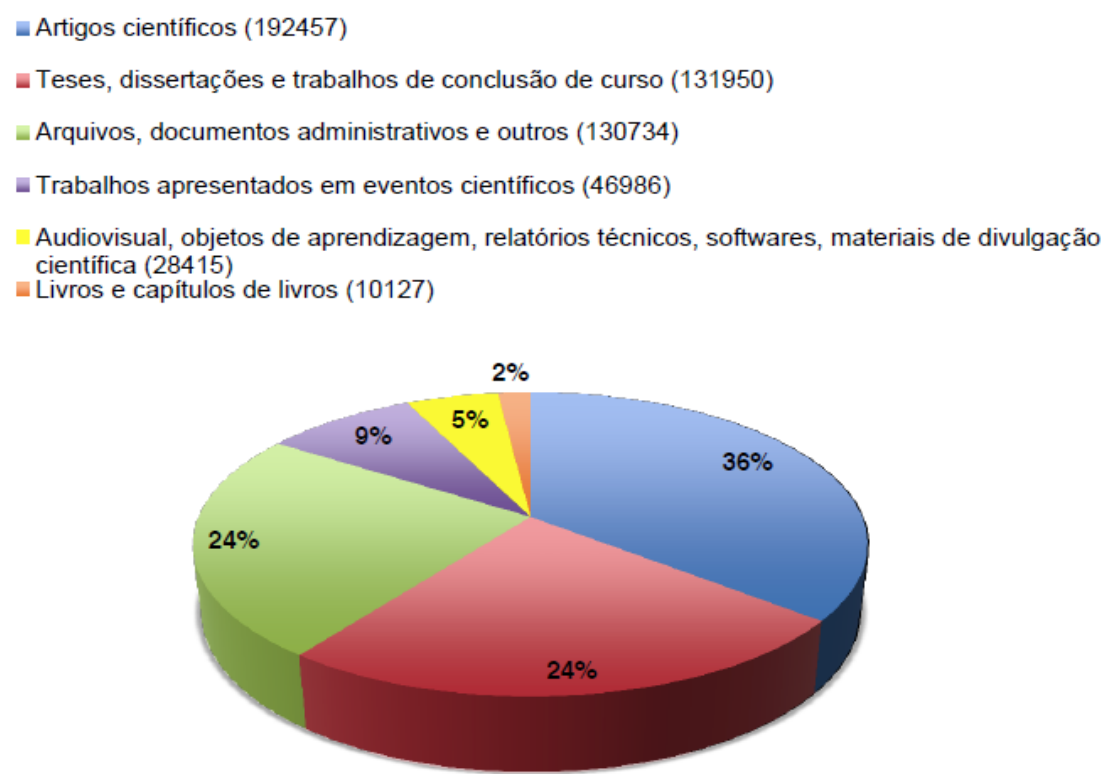

Fonte: Costa, 2014, p. 147. 
Observa-se, portanto, que a integração das teses e dissertações como conteúdos gerenciados pelos repositórios institucionais tem sido uma prática frequente. Entretanto, a junção dos dois sistemas de informação - bibliotecas digitais de teses e dissertações e os repositórios institucionais - implica em uma decisão política da própria instituição. Cabe aos gestores de informação decidirem se desejam manter em conjunto os dois sistemas ou a sua integração. De todo o modo, as questões relacionadas com a interoperabilidade devem ser observadas nesse cenário de coexistência de sistemas de bibliotecas digitais de teses e dissertações e repositórios institucionais. Tais questões se relacionam, sobretudo, com a definição do esquema de metadados a ser utilizado para a descrição das teses e dissertações. O repositório institucional que, por gerir outras tipologias documentais além das teses e dissertações, deve ter formulários para

descrição específicos para cada tipo de documento. Por meio da aplicação dos instrumentos de pesquisa esta dissertação buscou identificar os meios adotados e as razões pelas quais os gestores têm optando para o gerenciamento das teses e dissertações eletrônicas. Estas questões podem ser claramente identificadas no contexto da gestão da Biblioteca Digital Brasileira de Teses e Dissertações (BDTD), e com isso, nas universidades do País.

A relação entre a BDTD e os repositórios institucionais brasileiros pode ser explicada brevemente a partir de três aspectos: a atualização do padrão de metadados exigido pela BDTD, a atualização do processo de coleta automática da BDTD e a atualização do Sistema de Publicação Eletrônica de Teses e Dissertações (TEDE).

\section{Atualização do Padrão de Metadados da BDTD}

De acordo com o IBICT (2014), no ano de 2012, o Instituto iniciou junto às instituições participantes da BDTD, a discussão sobre a definição de um novo padrão brasileiro de metadados para a descrição de teses e dissertações eletrônicas. As instituições participantes na discussão do Novo Padrão Brasileiro de Metadados de Teses e Dissertações foram: Universidade Estadual de Campinas (UNICAMP), Universidade de São Paulo (USP), Universidade Federal do Rio Grande do Sul (UFRGS), Pontifícia Universidade Católica do Rio de Janeiro (PUC-Rio), Universidade Federal de Minas Gerais (UFMG), Universidade de Brasília (UnB), Universidade Federal de Viçosa 
(UFV), Universidade Católica de Brasília (UCB), Universidade do Estado do Rio de Janeiro (UERJ), Universidade Federal do Estado do Rio de Janeiro (UNIRIO), Universidade Federal do Ceará (UFC), Instituto Nacional de Pesquisas Espaciais (INPE), Universidade Federal de Goiás (UFG), Universidade Federal do Rio Grande do Norte (UFRN), Pontifícia Universidade Católica de São Paulo (PUC-SP), Pontifícia Universidade Católica do Rio Grande do Sul (PUC-RS), Universidade Federal de São Carlos (UFSCAR) e a Universidade Federal da Paraíba (UFPB). A escolha dessas instituições se deu em razão do número de teses e dissertações que possuem disponibilizadas na BDTD.

Entre os principais fatores para a tomada de decisão, estava o fato de que, o padrão, MTD2-BR, não estava sendo preenchido conforme o desejado, o que implicava diretamente nos processos de coleta e recuperação dos documentos no portal da BDTD. Nesse sentido, a definição de um novo padrão contou com a participação de uma consultora externa ${ }^{27}$ ao IBICT que apresentou, por meio de estudos, os padrões de metadados adotados internacionalmente para a descrição das ETDs. As discussões junto às instituições se estenderam até o ano de 2014 quando foi oficialmente apresentado o Novo Padrão Brasileiro de Metadados no XVIII Seminário Nacional de Bibliotecas Universitárias (SNBU) (IBICT, 2014).

O Novo Padrão de Metadados da BDTD utiliza os mesmos descritores adotados por outros sistemas internacionais, tendo sido necessária a realização de pequenas inclusões diferenciadas para atender às demandas nacionais de interoperabilidade, como o caso da determinação do campo para informação do Currículo Lattes. Ao final, o Novo Padrão de Metadados da BDTD conta ao todo com 53 campos, obrigatórios e opcionais, disponíveis para a descrição das teses e dissertações brasileiras. Os metadados que devem ser necessariamente preenchidos pelas instituições para que tenham a efetiva interoperabilidade com a BDTD e, por esta razão são caracterizados como obrigatórios são:

\footnotetext{
${ }^{27}$ Professora Doutora Fernanda P. Moreno.
} 
Figura 17: Metadados obrigatórios no Novo Padrão de Metadados da BDTD

\begin{tabular}{|c|}
\hline METADADOS OBRIGATÓRIOS \\
\hline dc.creator \\
\hline dc.contributor.advisor1 \\
dc.date.accessioned \\
dc.date.issued \\
\hline dc.description.abstract \\
\hline dc.description.sponsorship \\
dc.publisher \\
dc.publisher.country \\
\hline dc.publisher.department
\end{tabular}

METADADOS OBRIGATÓRIOS
dc.publisher.program
dc.publisher.initials
dc.type
dc.title
dc.language
dc.rights
dc.subject
dc.subject.cnpq

Fonte: IBICT, 2014.

Atualização da ferramenta de coleta automática da BDTD

Com a modificação no padrão de metadados da BDTD foi necessário realizar ajustes na ferramenta de coleta automática da BDTD. Foi levado em conta para tal processo: a possibilidade de coleta dos metadados de ETDs armazenadas em outros sistemas de informação, como os repositórios institucionais e os catálogos OPAC das bibliotecas (IBICT, 2014). Nesse sentido, há uma maior integração entre a BDTD e os repositórios institucionais.

Atualização do Sistema de Publicação Eletrônica de Teses e Dissertações (TEDE)

Este último processo abordado se apresenta como de maior impacto na discussão desta seção. O TEDE é um software livre desenvolvido pelo IBICT no ano de 2002 e vem sendo repassado às instituições desde o início do funcionamento da BDTD. Segundo Pereira (2011), o TEDE foi desenvolvido em PHP com auxílio de dois softwares para a sua execução, Apache e MySQL, e conforme as diretrizes dos arquivos abertos. Considera-se que até o ano de 2005 (data da sua atualização até então) (IBICT, 2013), o TEDE atendia efetivamente às demandas das instituições que o utilizavam. No entanto, 
com a rapidez das mudanças provocadas pelas tecnologias de informação e a não atualização por um período longo de tempo, implicaram em problemas relacionados ao seu funcionamento. Nesse sentido, o IBICT deu início também, em 2012, a atualização do sistema como um todo.

Observado o novo contexto em que as instituições brasileiras de ensino e pesquisa estavam inseridas, já consolidados os pressupostos do Acesso Aberto e as ações também impulsionadas pelo IBICT para a criação de repositórios institucionais, optou-se realizar a nova versão do TEDE a partir do uso da plataforma livre DSpace. Segundo dados do OpenDOAR (2014), o DSpace é o software livre mais utilizado em todo o mundo para a criação de repositórios institucionais. Aliado a esta informação, visto que os gestores de informação já estavam habituados com o funcionamento de uma ferramenta especificamente destinada ao gerenciamento de teses e dissertações e identificada a tendência em utilizar o DSpace como software para as teses e dissertações eletrônicas, o novo TEDE foi desenvolvido com a citada tecnologia e tem sido repassado às instituições interessadas (IBICT, 2014).

Observados os elementos destacados para a construção do cenário para o gerenciamento das teses e dissertações eletrônicas no Brasil, conclui-se que tais medidas adotadas contribuem para o estreitamento entre as relações das bibliotecas digitais de teses e dissertações e os repositórios institucionais.

Entretanto não se pode esquecer que, embora os diretórios, como o Registry of Open Access Repository Mandates and Policies (ROAR) e o OpenDOAR, o ranking Webometrics ${ }^{28}$, por exemplo, e demais mecanismos de gestão e avaliação de sistemas de informação de acesso aberto considerem as bibliotecas digitais de teses e dissertações em suas bases de dados, deve-se levar em conta o aspecto quanto à finalidade desse sistema. Os repositórios digitais, criados no contexto do Movimento de Acesso Aberto, são espaços que têm como objetivo o depósito da produção científica como um todo, sobretudo os artigos científicos. Já as bibliotecas digitais de teses e dissertações são destinadas à gestão de somente desses documentos. No resultado de seu estudo, Costa (2014, p. 183) destacou que as teses e dissertações são tipologias

\footnotetext{
${ }^{28}$ O ROAR, o OpenDOAR e o Ranking Webometrics são sistemas desenvolvidos no âmbito do Movimento de Acesso Aberto que têm por objetivo registrar e pontuar repositórios de acesso aberto, sendo assim, os dois primeiros Diretórios e o último um ranking que a partir de uma metodologia pontua os repositórios digitais de acesso aberto desenvolvidos em todo o mundo.
} 
documentais importantes na constituição de repositórios institucionais na região da América Latina e que, em conjunto com documentos administrativos, apontam para uma "forte distorção na compreensão do papel dos RIs no contexto do acesso aberto e da comunicação científica". 


\section{CAPÍTULO 3}

\section{METODOLOGIA DA PESQUISA}

Este capítulo tem por objetivo apresentar o referencial teórico e os procedimentos metodológicos que orientaram o desenvolvimento da pesquisa. 0 referencial teórico apresentado é resultado da extração dos principais conceitos abordados na revisão de literatura e estabelecimento de relações entre eles. Sua função é orientar tanto aos procedimentos metodológicos, explicitados no desenho da pesquisa, quanto à análise e discussão dos resultados do estudo. Espera-se obter como resultados desta pesquisa a identificação das características dos sistemas de informação que gerenciam teses e dissertações eletrônicas no contexto das universidades brasileiras, bem como a análise do quanto esses sistemas estão de acordo com os pressupostos do Acesso Aberto à Informação Científica.

\subsection{Referencial teórico}

O referencial teórico apresentado tem como intenção evidenciar o filtro por meio do qual o problema da pesquisa passa a ser visualizado. De acordo com o objetivo desta pesquisa - identificar características dos sistemas de gestão de teses $e$ dissertações eletrônicas brasileiros no contexto do Acesso Aberto - o referencial teórico concentra a relação entre os elementos relevantes para a pesquisa: i) comunicação científica; ii) teses e dissertações eletrônicas; iii) acesso aberto à informação científica; iv) sistemas de informação de acesso aberto: bibliotecas digitais de teses e dissertações/repositórios institucionais.

\subsubsection{Relação entre os elementos relevantes para a pesquisa}

O processo de comunicação entre pesquisadores é uma atividade antiga. A troca de informações era realizada por meio de cartas. Ao longo do tempo, o volume de cartas teve um crescimento considerável impulsionando o surgimento do periódico científico 
(MEADOWS, 1999). Nesse sentido, a comunicação científica é entendida nesta pesquisa como o conjunto de atividades que envolvem a troca de informações entre os pesquisadores. Estas informações são os resultados de pesquisas científicas materializadas, por exemplo, em livros, relatórios de pesquisa, artigos científicos, teses e dissertações. Estas últimas, objetos de estudo nesta pesquisa, foram fortemente afetadas em razão da adoção de tecnologias de informação no ciclo da comunicação científica. Neste sentido, surgem as teses e dissertações eletrônicas, nascidas digitalmente ou digitalizadas, que oferecem uma série de benefícios tanto para usuários da informação científica quanto para as instituições.

O Movimento de Acesso Aberto à Informação Científica, tendo como atores principais os próprios pesquisadores, e também as bibliotecas, tem provocado a mudanças significativas no sistema e nos processos de comunicação científica, ao incluir, sobretudo, novas estratégias para disseminação dos resultados de pesquisa. Vessuri (2011) sintetiza em duas frases a mudança ocorrida nas últimas décadas.

\footnotetext{
La tecnologia abierta, el contenido abierto y el conocimiento abierto son rasgos de la actualidad que están transformando nuestro paisaje del aprendizaje y de la producción del conocimiento. La evolución reciente de Internet, la llamada Web 2.0, borra la línea divisoria entre productores y consumidores de contenido y traslada la atención del acceso a la información al acceso a otras personas (VESSURI, 2011, web).
}

Assim, o Acesso Aberto promovido por meio de duas estratégias, a Via Dourada e a Via Verde, provoca uma alteração e a implantação de novos modelos de negócio de revistas científicas e a criação de sistemas de informação de acordo com os princípios da Iniciativa dos Arquivos Abertos (OAi) e do Acesso Aberto. Considera-se, com base na revisão de literatura desta dissertação, que a OAi estabeleceu, do ponto de vista tecnológico, meios para a operacionalização do Acesso Aberto. Ou seja, a definição do conceito de interoperabilidade e apresentação do Protocolo OAl no contexto da comunicação científica, viabilizou a concretização do Acesso Aberto em todo o mundo.

Nesse cenário novos sistemas de informação foram desenvolvidos, com destaque para dois tipos que têm sido utilizados para o gerenciamento das teses e dissertações eletrônicas: as bibliotecas digitais de teses e dissertações e os repositórios institucionais de acesso aberto. As primeiras, desenvolvidas e fortalecidas no contexto 
dos Arquivos Abertos ganharam destaque pela quantidade de documentos que gerenciavam e disseminavam em texto completo para a comunidade científica. Os segundos, criados já no contexto do Acesso Aberto, têm a intenção de servir ambientes digitais para o armazenamento, organização, disseminação e preservação da produção científica como um todo, principalmente os artigos científicos. Em razão dessas duas modalidades de gerenciar a produção científica gerada em uma instituição, as universidades têm enfrentado dilemas decorrentes da coexistência dos dois tipos de sistemas de informação. O primeiro, bibliotecas digitais exclusivas para teses e dissertações. E o segundo, repositórios institucionais, dedicados à gestão da produção científica como um todo, incluindo a teses e dissertações. Os dilemas estão relacionados a decisão sobre manter ou não os dois tipos de sistemas, visto um claramente incorpora as funções do outro e as implicações decorrentes de qualquer que seja a decisão para a gestão da informação científica em nível institucional. Isso inclui a gestão de teses e dissertações em ambiente digital.

O gerenciamento das teses e dissertações eletrônicas, seja por meio das bibliotecas digitais de teses e dissertações ou repositórios institucionais de acesso aberto, requer que sejam levados em consideração processos específicos. Ou seja, os gestores desses sistemas devem estar atentos aos processos necessários ao funcionamento dos sistemas de informação. Dessa maneira, para auxiliar a busca da compreensão do problema desta pesquisa e nortear sua realização, adota-se a ideia exposta no estudo de Leite (2011), o qual aponta que a comunicação da informação científica é possibilitada mediante os processos da gestão da informação. Para efeitos desta dissertação, a gestão da informação é representada pelo conjunto de processos de aquisição, organização, recuperação, disseminação e preservação de teses e dissertações eletrônicas. Considera-se, portanto, que na medida em que esses processos são realizados de modo efetivo por bibliotecas digitais de teses e dissertações e repositórios institucionais, a comunicação científica é positivamente afetada.

\subsubsection{Modelo conceitual da pesquisa}

A teoria embutida no modelo conceitual que norteou a realização da presente pesquisa considera que a efetividade da comunicação da informação científica, 
entendida nesta dissertação como as trocas de informação entre produtores e usuários, está diretamente atrelada à efetividade dos processos de gestão de teses e dissertações.

O modelo conceitual da pesquisa é constituído de elementos que foram extraídos da revisão de literatura e das relações estabelecidas entre eles. Esses elementos são: produtores, usuários, teses e dissertações eletrônicas, sistemas de informação, processos de gestão de teses e dissertações eletrônicas, comunicação científica. Nesse sentido, no modelo é estabelecido que estudantes dos programas de pós-graduação exercem, ao mesmo tempo, as funções de produtores e de usuários de resultados de pesquisa registrados em teses e dissertações. São usuários, pois, em decorrência do projeto de pesquisa que necessitam executar, têm necessidades de informação. Na medida em que, têm acesso e utilizam informação para alimentar sua atividade de pesquisa, reúnem condições para produzir novos conhecimentos. 0 conhecimento científico produzido a partir de pesquisas de mestrado e doutorado é, primeiramente, registrado em forma de teses e dissertações, as quais, como canais de comunicação científica, alimentarão novos ciclos de produção do conhecimento. Desse modo, em decorrência de projetos de pesquisa que necessitam executar, outros estudantes de programas de pós-graduação e demais pesquisadores, têm necessidades de informação que poderão ser, em parte, supridas por teses e dissertações anteriormente geradas. A circulação de teses e dissertações entre produtores e usuários somente será efetiva se promovida por sistemas de informação que as gerencie levando em considerações a perspectiva do Acesso Aberto à Informação Científica. Para tanto, os sistemas de informação necessitam sistematizar os processos de obtenção, organização, armazenamento, preservação, recuperação e disseminação de teses e dissertações segundo os pressupostos preconizados pelas estratégias do Acesso Aberto. A representação gráfica do modelo conceitual da pesquisa é apresentada na figura 18. 
Figura 18: Modelo conceitual da pesquisa

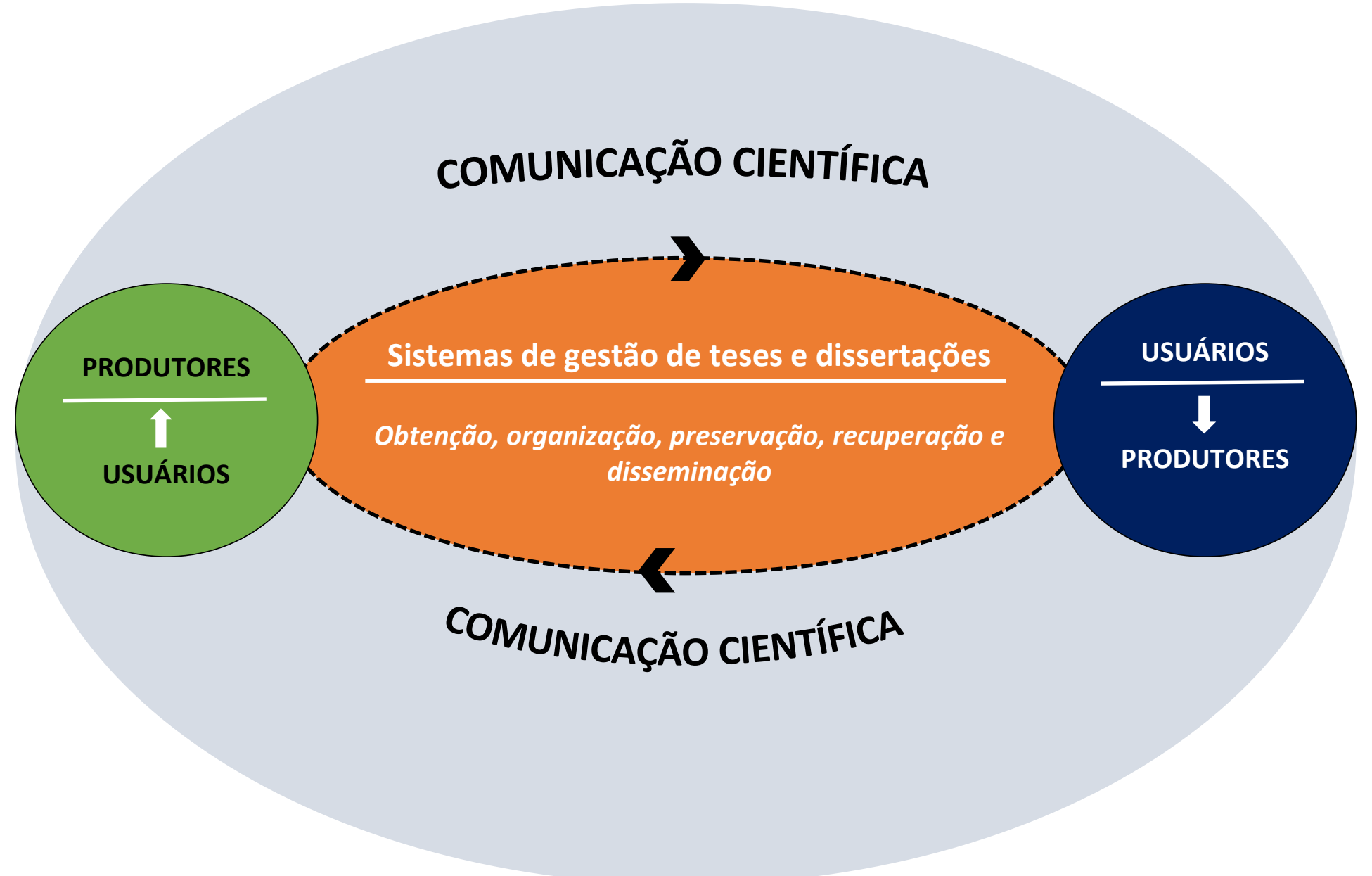


Definições operacionais do modelo conceitual da pesquisa

Produtores: No contexto do modelo conceitual da pesquisa, os produtores são os alunos dos programas de pós-graduação que finalizaram suas pesquisas de mestrado e/ou doutorado, tendo os seus resultados de pesquisa materializados em dissertações e teses, respectivamente. Estes documentos, entregues em formato digital ao setor responsável da instituição, são armazenados em sistemas de informação que gerenciam teses e dissertações.

Usuários: Considera-se que os usuários também são os alunos dos programas de pósgraduação e outros pesquisadores, já que para o desenvolvimento de seus projetos de pesquisa necessitam de fontes de informação. Por serem pesquisas mais detalhadas e extensas, as teses e dissertações são comumente utilizadas como fonte de informação para a geração de novas pesquisas (UNESCO, 2001). Uma vez que novos conhecimentos são produzidos pelos usuários farão parte de novos ciclos de informação tornando-se assim fontes para a geração de novos resultados de pesquisa.

Comunicação científica: No modelo conceitual a comunicação científica é entendida como o conjunto de processos que envolvem as trocas de informação entre os pesquisadores para a geração de pesquisas científicas. Entende-se que a comunicação científica das teses e dissertações, no âmbito das universidades e programas de pósgraduação brasileiros, é viabilizada mediante o uso de sistemas de informação que gerenciam tais documentos.

Sistemas de gestão de teses e dissertações: Os sistemas de gestão de teses e dissertações são considerados ambientes digitais dedicados ao gerenciamento desses resultados de pesquisa. Considera-se que para a maior promoção e uso das teses e dissertações, esses sistemas de informação devem ser desenvolvidos de acordo com os pressupostos do Acesso Aberto. Ainda, esses sistemas devem adotar processos sistematizados que viabilizam a circulação das teses e dissertações entre produtores e usuários. No âmbito do modelo conceitual, os sistemas de gestão citados fazem referências, sobretudo, às bibliotecas digitais de teses e dissertações e os repositórios 
institucionais de acesso aberto. Os processos considerados para uma gestão efetiva dos sistemas de informação são obtenção, organização, preservação, recuperação e disseminação.

\subsection{Caracterização da pesquisa}

No que concerne ao propósito do estudo, esta pesquisa se caracteriza como de natureza descritiva. De acordo com Sekaran (2003, p. 121), o estudo descritivo tem por objetivo verificar e ser capaz de descrever as características das variáveis de interesse em uma situação. Segundo o autor, esses estudos ajudam a pensar sistematicamente os aspectos de uma determinada situação e/ou a tomar certas decisões simples. Khotari (2004) conceitua a pesquisa descritiva como a que inclui pesquisas e inquéritos investigativos de diferentes tipos. A finalidade deste tipo de pesquisa, de acordo com o autor, é a descrição do estado de assuntos, caracterizando-se principalmente pelo fato do pesquisador não ter controle sobre as variáveis. Assim sendo, justifica-se a adoção da pesquisa descritiva neste estudo, uma vez que foram descritas as características dos sistemas de informação que gerenciam as teses e dissertações eletrônicas, bem como a análise do quanto esses sistemas estão de acordo com os pressupostos do Acesso Aberto.

Outra dimensão que caracteriza a atividade de pesquisa é sua abordagem metodológica. Para discussão desse aspecto, adotou-se as orientações de Creswell (2010). O autor apresenta de forma clara três "componentes" necessários para a realização de um projeto de pesquisa e que são orientados de acordo com a abordagem escolhida (qualitativa, quantitativa ou de métodos mistos): a concepção filosófica, a estratégia de investigação e os métodos utilizados (Figura 21). A seguir são discutidas as decisões sobre os três componentes no âmbito da presente pesquisa.

As concepções filosóficas orientam para a escolha da abordagem que será adotada na pesquisa (qualitativa, quantitativa ou de métodos mistos). Esta pesquisa se orientará pela concepção pragmática, na qual a preocupação se concentra no problema e não nos métodos. Creswell (2010, p. 34) enfatiza que o pragmatismo dá maior liberdade de escolha dos métodos, técnicas e procedimentos de pesquisa aos pesquisadores. Não há, portanto, uma única forma de coletar dados ou uma abordagem 
absoluta. A adoção do pragmatismo se justifica pela pluralidade de perspectivas tanto na coleta de dados quanto na análise de dados, de modo que os resultados possam contribuir para uma mais completa descrição do fenômeno investigado.

As estratégias de investigação, segundo Creswell (2010, p. 35), "são os tipos de projetos ou modelos de métodos qualitativos, quantitativos e mistos que proporcionam uma direção específica aos procedimentos". Orientada pela concepção pragmática, esta pesquisa adotará como estratégia de investigação a de métodos mistos.

A pesquisa de métodos mistos, também conhecida como "multi-métodos" ou "terceiro movimento", agrupa elementos tanto da abordagem qualitativa quanto da quantitativa. Creswell (2010, p. 40) afirma que os métodos mistos adotam métodos predeterminados e emergentes: questões abertas e fechadas; formas múltiplas de dados baseadas em todas as possibilidades; análise estatística e de texto. A escolha pela pesquisa de métodos mistos dá a possibilidade de ampliação da interpretação dos dados, uma vez que faz uso das duas abordagens. Entretanto, deve-se estar atento aos desafios que se encontra na adoção dessa estratégia: o uso das duas abordagens implica na necessidade de uma coleta de dados mais extensa e de um tempo maior para a análise dos dados (CRESWELL, 2010).

Figura 19: Estrutura para o projeto (interconexão das concepções, estratégias de investigação e métodos de pesquisa)

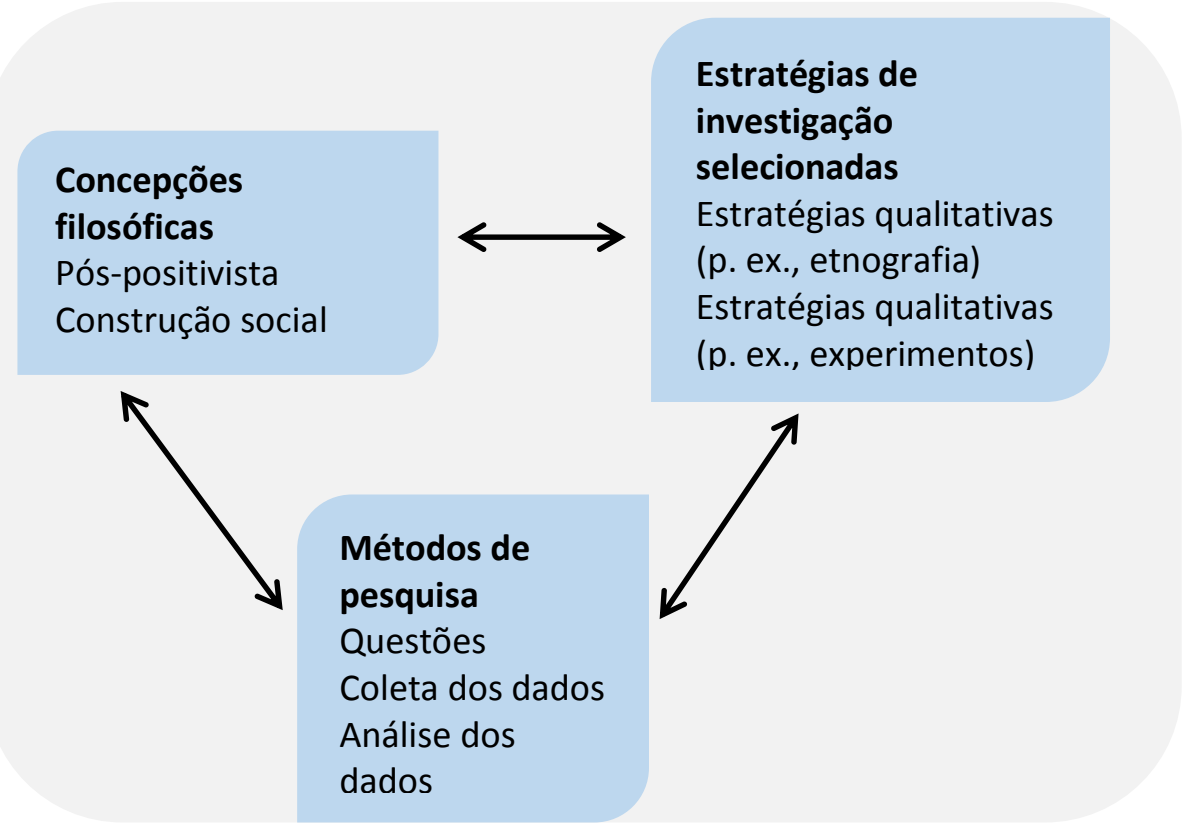

Fonte: Creswell, 2010, com adaptações. 
Tréz (2012, p. 1.140) aponta que tanto para a abordagem qualitativa quanto para quantitativa existem estratégias específicas. Segundo o autor, "na abordagem mista existe uma variedade de desenhos específicos que atendem as necessidades das questões de pesquisa".

Os modelos visuais dos desenhos da pesquisa de métodos mistos têm notações específicas que facilitam a interpretação da informação. Creswell (2010, p. 245) explica os seus significados:

- A notação "+" indica a forma concomitante para a coleta dos dados, assim os dados qualitativos e quantitativos são coletados simultaneamente;

- A notação " $\rightarrow$ " indica uma forma sequencial de coleta dos dados;

- As letras maiúsculas indicam peso ou prioridade dos dados, de sua análise e interpretação, sendo qualitativos ou quantitativos. Entretanto, há que se considerar que as abordagens podem ser igualmente enfatizadas ou uma pode ser mais enfatizada do que a outra. Para isso, as letras maiúsculas indicam a ênfase a uma abordagem;

- "Quan" e "Qual" significam, respectivamente, quantitativo e qualitativo, e o mesmo número de letras indica a igualdade entre as formas dos dados.

Ainda, Creswell (2010) identifica três estratégias gerais de métodos mistos: sequenciais, concomitantes e transformativos. Segundo as orientações do autor e considerando o já exposto, para efeitos da proposta desta pesquisa opta-se por utilizar a estratégia de triangulação concomitante, levando assim, a inclusão aos projetos concomitantes. Por meio desta estratégia, os dados quantitativos e os dados qualitativos são coletados ao mesmo tempo e depois são comparados para a identificação de convergências, diferenças ou combinações. Segundo o autor (2010, p. 250), "esse modelo geralmente utiliza os métodos quantitativos e qualitativos separadamente, como meio de compensar os pontos fracos inerentes a um método com os pontos fortes do outro (ou inversamente $(\ldots)$ )". É atribuído peso igual às duas abordagens, mas podendo, na prática, a atribuição de um peso maior a um ou outro (CRESWELL, 2010). 
Figura 20: Estratégia de triangulação concomitante

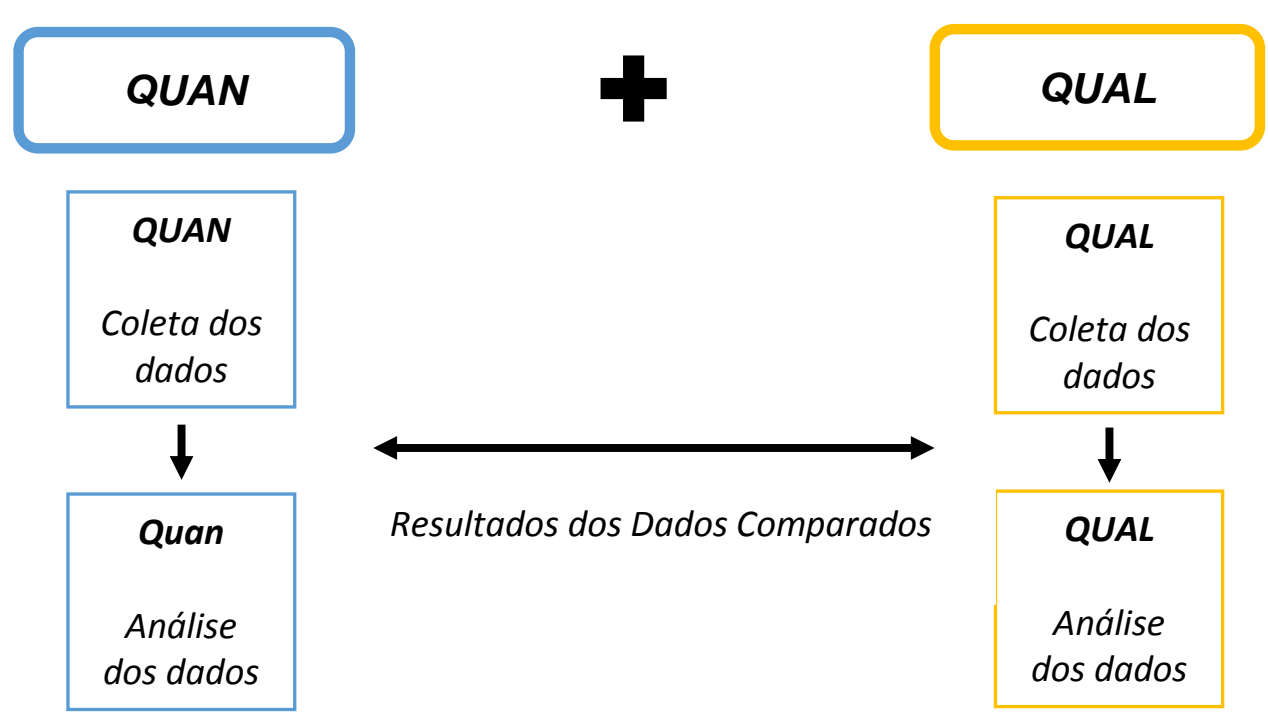

Fonte: Creswell, 2010, com adaptações.

Portanto, esta pesquisa se caracteriza como de métodos mistos em razão da diversidade de técnicas que foram utilizadas para a coleta e análise dos dados. A interpretação de toda a análise desta pesquisa combinou as estratégias apontadas nas etapas das pesquisas qualitativa e quantitativa de forma a responder o problema deste estudo.

Tendo em vista o problema deste estudo - Quais são as características dos sistemas de gestão de teses e dissertações eletrônicas brasileiros e o quanto estão de acordo com os pressupostos do Acesso Aberto? - é apresentado, a seguir, o desenho da pesquisa.

\subsection{Desenho da pesquisa}

Nesta seção é apresentado o desenho da pesquisa. Para a sua construção foram tomados como base os objetivos específicos deste estudo para a definição do universo da pesquisa, amostra, fonte de coleta dos dados, técnica de coleta e análise dos dados.

A partir do projeto sugerido por Creswell (2010), tem-se a aplicação do modelo visual para o contexto dos elementos desta pesquisa. 
Figura 21: Modelo visual detalhado aplicado à pesquisa

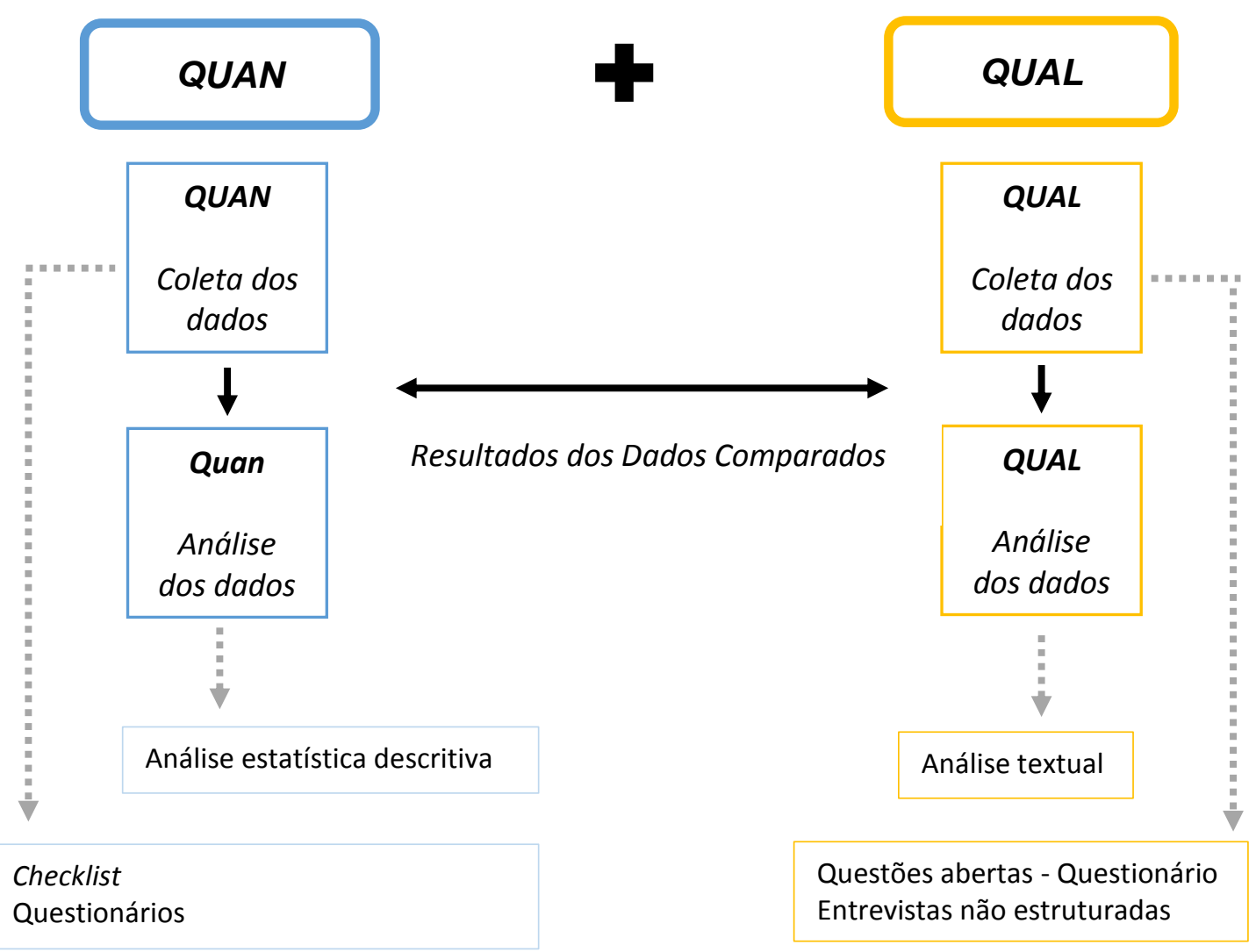

Fonte: Da autora, 2015.

Com relação aos instrumentos de coleta dos dados, tanto quantitativos quanto qualitativos, foram utilizados o checklist (ou lista de verificação), o questionário e a entrevista (entrevista não estruturada). A aplicação destes instrumentos de coletadas de dados será detalhada com maior profundidade nas próximas seções.

O quadro 8 apresenta a relação entre os instrumentos utilizados para as coletas dos dados para o alcance dos objetivos específicos, bem como a fonte e a análise dos dados.

Quadro 7: Relação entre os instrumentos de coletas de dados, os objetivos específicos, a fonte e o modo de análise dos dados

\begin{tabular}{|llccc|}
\hline \multicolumn{2}{|c}{ Objetivo específico } & Fonte & Coleta de dados & Análise de dados \\
\hline $\mathbf{1}$ & $\begin{array}{l}\text { Mapear os sistemas de } \\
\text { informação utilizados } \\
\text { para a gestão das teses }\end{array}$ & $\begin{array}{c}\text { Universidades } \\
\text { brasileiras }\end{array}$ & Checklist - Itens 1 a 4 & Análise estatística \\
\hline
\end{tabular}




\begin{tabular}{|c|c|c|c|c|}
\hline & $\begin{array}{l}\text { e dissertações } \\
\text { eletrônicas no Brasil }\end{array}$ & & & \\
\hline 2 & $\begin{array}{l}\text { Identificar } \\
\text { características e } \\
\text { processos realizados } \\
\text { pelos sistemas de } \\
\text { informação utilizados } \\
\text { para a gestão de teses } \\
\text { e dissertações } \\
\text { eletrônicas no Brasil }\end{array}$ & $\begin{array}{l}\text { Sistemas de } \\
\text { informação }\end{array}$ & $\begin{array}{c}\text { Checklist - Itens } 5 \text { a } 12 \\
\text { Questionários } \\
\text { - Tipo I - Itens 3, 4, } 5 \text { e } 7 \text { a } \\
19 \\
\text { - Tipo II - Itens 4, } 5 \text { e } 6\end{array}$ & Análise estatística \\
\hline 3 & $\begin{array}{l}\text { Identificar, com base } \\
\text { na percepção de } \\
\text { gestores dos sistemas } \\
\text { de informação de } \\
\text { acesso aberto, fatores } \\
\text { que influenciam a } \\
\text { gestão de teses e } \\
\text { dissertações } \\
\text { eletrônicas }\end{array}$ & $\begin{array}{l}\text { Gestores de } \\
\text { informação }\end{array}$ & $\begin{array}{c}\text { Questionário } \\
\text { - Tipo I - Itens 6, 20, } 21 \text { e } 22 \\
\text { - Tipo II - Itens 3, } 7 \text { e } 8 \\
\text { Entrevista- Todos os itens } \\
\text { de todos os tipos de } \\
\text { entrevista }\end{array}$ & $\begin{array}{c}\text { Análise estatística } \\
\text { Análise textual }\end{array}$ \\
\hline
\end{tabular}

Fonte: Da autora, 2015.

\subsubsection{Universo, amostra e fontes de dados}

As decisões relacionadas com universo, amostra e as fontes de dados desta dissertação variam em razão dos objetivos específicos anteriormente estabelecidos. Nesse sentido, no intuito de melhor explicitar as decisões estabelecidas, optou-se por apresentar separadamente o universo, amostra e fontes de dados de acordo com cada objetivo específico.

Para o alcance do Objetivo Específico 1, que corresponde ao mapeamento dos sistemas de informação utilizados para a gestão das teses e dissertações eletrônicas no Brasil, o universo foi constituído das universidades brasileiras. Para identificar o conjunto de universidades brasileiras utilizou-se como fonte o Portal e-MEC ${ }^{29}$.

O Portal e-MEC é de responsabilidade do Ministério da Educação (MEC), do Brasil, que é órgão responsável pelo credenciamento das instituições de ensino superior no País. Por meio da busca avançada do Portal é possível, entre outras opções, buscar por instituições de ensino superior, curso de graduação e curso de especialização e, ainda, por sua categoria administrativa, como pública municipal, pública federal, pública estadual, privada sem fins lucrativos, privada com fins lucrativos e privada beneficente (Figura 25). Por meio do Portal foram identificadas 196 universidades brasileiras. No

\footnotetext{
${ }^{29}$ Portal e-MEC - <http://emec.mec.gov.br/>.
} 
entanto, do total de 196 universidades foi observado que em quatro delas, apesar de serem caracterizadas como universidades, não foram identificados programas de pósgraduação, de onde são originadas as teses e dissertações. Desse modo, essas quatro universidades foram desconsideradas do estudo. Portanto, para o alcance do objetivo específico 1 adotou-se todo o conjunto das 192 universidades brasileiras.

Figura 22: Busca avançada do Portal e-MEC

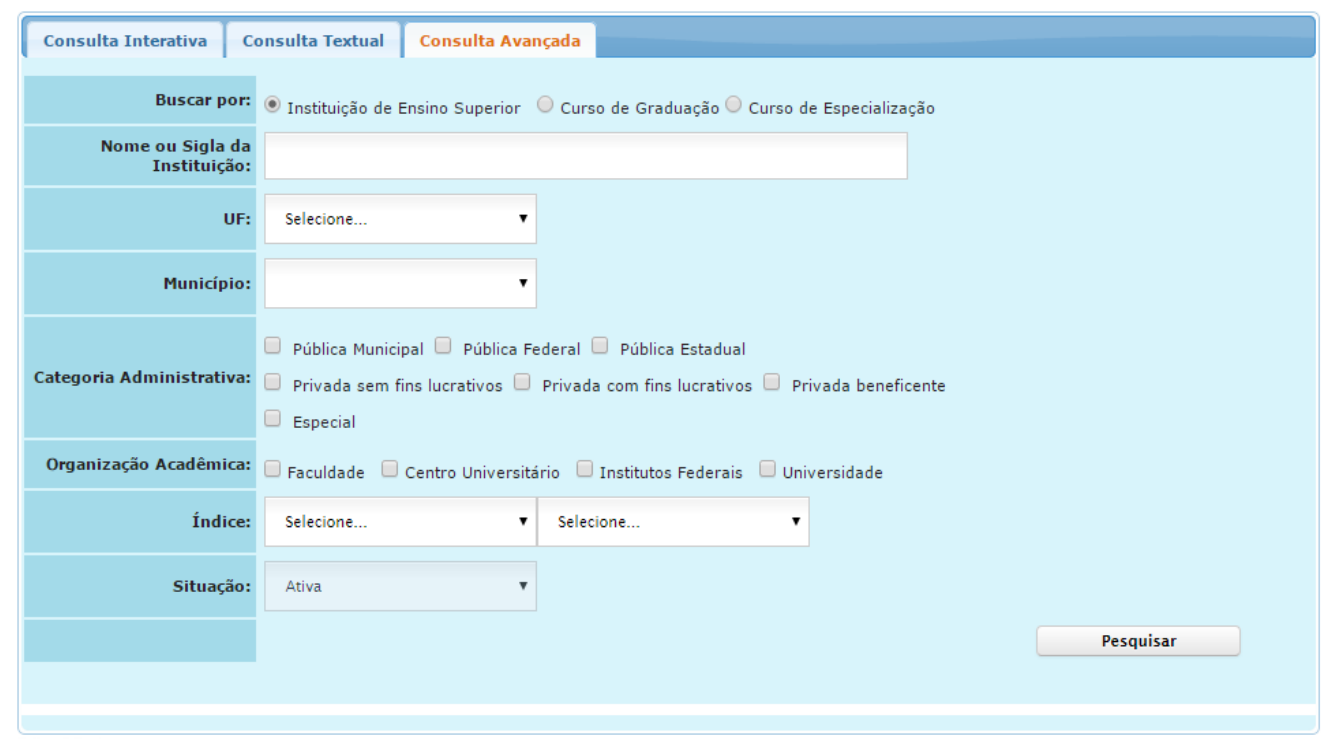

Fonte: Portal e-MEC, 2015.

Esse universo possui as seguintes características:

- 86 universidades privadas (45\%) e 106 universidades públicas (municipais, estaduais e federais);

- As universidades estão distribuídas geograficamente nas seguintes proporções: 76 instituições na região Sudeste; 45 instituições na região Sul; 39 instituições na região Nordeste; 17 instituições na região Norte e; 15 instituições na região Centro-Oeste;

- Os programas de pós-graduação estão distribuídos geograficamente nas seguintes proporções: 411 programas na região Sudeste (32,4\%); 272 programas na região Sul (21,5\%); 349 programas na região Nordeste (37,5\%); 98 programas na região Norte $(7,7 \%)$ e; 137 programas na região Centro-Oeste (11\%). 
O Objetivo Específico 2, por sua vez, que é a identificação das características e processos realizados pelos sistemas de informação utilizados para a gestão de teses $e$ dissertações eletrônicas no Brasil, teve o universo formado pelos sistemas de informação das universidades brasileiras identificados a partir do primeiro objetivo específico. Ou seja, uma vez que as universidades brasileiras e seus respectivos sistemas de informação de gestão das teses e dissertações eletrônicas foram identificados, foi possível caracterizá-los. Por esta razão, o universo do Objetivo Específico 2 dependeu do resultado da análise do objetivo específico anterior. Das 192 universidades brasileiras foi possível identificar que 125 universidades (aproximadamente 65\%) apresentam sistemas de gestão de teses e dissertações eletrônicas e fizeram parte da investigação. Tal como no objetivo específico anterior, não foi necessário definir amostra, pois optouse investigar o conjunto total de sistemas identificados. Nesta etapa, por apresentarem problemas quanto à exibição de suas páginas web, não foi possível a análise em seis universidades. Esse total de universidades possui as seguintes características:

- 66 universidades públicas e 59 universidades privadas possuem sistemas de gestão de teses e dissertações;

- As universidades e seus respectivos sistemas estão distribuídos geograficamente nas seguintes proporções: 18 públicas e 29 privadas na região Sudeste; 13 públicas e 18 privadas na região Sul; 18 públicas e 5 privadas na região Nordeste; 8 públicas e 1 privada na região Norte e; 8 públicas e 5 privadas na região Centro-Oeste.

Por fim, para o cumprimento do Objetivo Específico 3, que corresponde à identificação, com base na percepção de gestores dos sistemas de informação, fatores que influenciam a gestão de teses e dissertações eletrônicas, o universo de pesquisa é formado pelos gestores dos sistemas que gerenciam as teses e dissertações eletrônicas. Entretanto, como este terceiro objetivo específico demandou a aplicação de instrumentos de coleta de dados houve a necessidade da definição de amostras. Richardson (1999) ponderou que a amostra é considerada um subconjunto de indivíduos de uma população ou universo. Essa definição é necessária uma vez que o estudo de todo o universo se tornaria inviável. Como o alcance do Objetivo Específico 3 dependeu 
da aplicação de duas técnicas de coleta de dados (questionário e entrevista), como será visto na próxima seção, fez-se necessário definir dois grupos de amostras, em função das técnicas adotadas, baseados em critérios igualmente diferentes.

A amostra para aplicação dos questionários foi constituída dos gestores dos sistemas de teses e dissertações, sendo probabilística, em que os sujeitos tiveram a mesma probabilidade de serem escolhidos, do tipo estratificada. Segundo Babbie (2003), uma amostragem estratificada é entendida como um

\footnotetext{
método para obter maior grau de representatividade, reduzindo o provável erro amostral. (...) em vez de selecionar a amostra da população total em geral, você garante que quantidades apropriadas de elementos sejam tirados de subconjuntos homogêneos da população. (...) Portanto, a função última da estratificação é organizar a população em subconjuntos homogêneos (com heterogeneidade entre os subconjuntos) e selecionar o número apropriado de elementos de cada subconjunto (BABBIE, 2003, p. 72).
}

Após esta definição, partiu-se para o cálculo de quantos respondentes, no mínimo, para cada estrato, seriam necessários para manter a proporcionalidade do universo da pesquisa. Dessa maneira, os critérios para a definição da amostra probabilística estratificada foram:

- Considerando o universo formado pelas 192 universidades:

i. Tem-se o total de universidades por região: Centro-Oeste (15); Nordeste (39); Norte (17); Sul (45) e; Sudeste (76);

ii. Tem-se a porcentagem do número de universidades por região em relação ao total de universidades: Centro-Oeste (8\%); Nordeste (20\%); Norte (9\%); Sul (23\%) e; Sudeste (40\%).

- Considerando o universo formado pelas 186 universidades:

i. Tem-se o percentual do número de universidades por região em relação ao total de universidades, agora consideradas as 186 universidades: Centro-Oeste (8\%); Nordeste (20\%); Norte (9\%); Sul (24\%) e; Sudeste (41\%);

ii. Tem-se o total de universidades de acordo com o porcentual que representam no universo, exemplo: região Centro-Oeste tem 15 universidades ao todo, o que corresponde a $100 \%$. Assim, o número de universidades que representa o 
porcentual identificado anteriormente, $8 \%$, corresponde a aproximadamente duas (2) universidades. Aplicando a regra do cálculo para as demais regiões, tem-se: Nordeste (8); Norte (2); Sul (11) e; Sudeste (31).

Assim sendo, apresentam-se os resultados consolidados na tabela a seguir.

Tabela 6: Definição da amostra de acordo com a sua proporção ao universo da pesquisa

\begin{tabular}{lcccc}
\hline Região & $\begin{array}{c}\text { Total de } \\
\text { universidades }\end{array}$ & $\begin{array}{c}\text { \% do total de } \\
\text { universidades }\end{array}$ & $\begin{array}{c}\text { \% do total de 186 } \\
\text { universidades }\end{array}$ & $\begin{array}{c}\text { Total mínimo de } \\
\text { universidades para a } \\
\text { amostra }\end{array}$ \\
\hline Centro-Oeste & 15 & 8 & 8 & 2 \\
Norte & 17 & 9 & 9 & 2 \\
Nordeste & 39 & 20 & 20 & 8 \\
Sudeste & 76 & 40 & 41 & 31 \\
Sul & 45 & 24 & 24 & 11 \\
\hline TOTAL & $\mathbf{1 9 2}$ & $\mathbf{1 0 0}$ & $\mathbf{1 0 0}$ & $\mathbf{5 4}$ \\
\hline
\end{tabular}

Fonte: Da autora, 2015.

Definidos os valores mínimos considerados para a composição das amostras para posterior aplicação do questionário, partiu-se para a definição da amostra para a realização das entrevistas. As entrevistas, segundo Richardson (1999), visam obter do entrevistado o que se considera como aspectos mais relevantes de determinado problema. A amostra, neste caso, foi definida como não probabilística intencional. Neste caso, a definição da amostra é baseada "no próprio conhecimento da população e dos seus elementos, e da natureza das metas da pesquisa" (BABBIE, 2003, p. 80). Portanto, a amostra estabelecida para a aplicação das entrevistas visou à participação de gestores que atuam em diferentes cenários. São eles: i. universidades que possuem apenas repositório institucional; ii. universidades que possuem apenas biblioteca digital de teses e dissertações; iii. universidades que possuem biblioteca digital de teses e dissertações e repositório institucional; iv. universidades que possuem sistema próprio e; v. universidades que não possuem sistema de informação que gerencie teses e dissertações eletrônicas. A amostra foi constituída por um participante, no mínimo, de cada um desses cenários, ou seja, cinco entrevistados.

A próxima seção apresenta o detalhamento das decisões sobre os métodos e técnicas adotados para a realização do estudo. 


\subsubsection{Métodos, técnicas e instrumentos da pesquisa}

Nesta seção são apresentados o método adotado para a realização da pesquisa, as técnicas e os instrumentos para a coleta de dados assim como as técnicas para a análise dos dados coletados. É importante lembrar que a elaboração dos instrumentos de coleta de dados foi norteada pelo modelo conceitual da pesquisa.

A pesquisa utilizou o método de levantamento (survey), tendo adotado três técnicas para a coleta de dados: checklist, questionário e entrevista. O uso das técnicas variou em função dos objetivos específicos da pesquisa, conforme a descrição a seguir.

Para a coleta de dados do objetivo específico 1 e parte do objetivo específico 2 adotou-se o checklist. Segundo Andrews (2008), essa técnica se operacionaliza é um instrumento utilizado para a verificação da adoção de propostas, passos ou ações específicas. $O$ instrumento elaborado para coletar dados a partir dessa técnica encontrase no Apêndice A e foi utilizado em dois momentos: primeiro, para o mapeamento dos sistemas de informação utilizados pelas universidades brasileiras para a gestão de teses e dissertações eletrônicas. Segundo, para identificar as características dos processos realizados pelos sistemas brasileiros de informação que gerenciam as teses e dissertações eletrônicas. Conforme dito na seção anterior, 186 universidades fizeram parte dessa etapa do levantamento.

A técnica do questionário, por sua vez, foi adotada para coleta de dados para satisfazer ao Objetivo Específico 2. É oportuno afirmar que, conforme Richardson (1999) chama a atenção, os questionários, em sua maioria, têm pelo menos duas finalidades: a descrição das características e a mensuração de determinadas variáveis de um grupo social. Nesta pesquisa a técnica foi operacionalizada com base em dois instrumentos (Apêndice B): i. questionário aplicado às universidades que possuem teses e dissertações eletrônicas identificadas por meio do checklist (tipo I) e; ii. questionário aplicado às universidades que não possuem teses e dissertações eletrônicas por meio do checklist (tipo II).

Ambos os questionários foram elaborados e aplicados com o uso da ferramenta SurveyMonkey. Ao todo, foram enviados 238 questionários eletrônicos, sendo que 175 foram do tipo I e 63 enviados do tipo II. No total, 83 questionários foram respondidos, 
sendo que 5 deles foram eliminados do conjunto de respostas ( 3 inválidos e 2 respondidos mais de uma vez pela mesma instituição). Foram considerados, portanto, 78 questionários respondidos, o que corresponde a $33 \%$ do universo investigado. Desse total, foram 58 respostas ao questionário do tipo I e 19 respostas ao questionário do tipo II. Considerando a amostra estratificada e a quantidade mínima de respondentes para sua validade, as respostas ficaram distribuídas conforme descrito na tabela 7.

Tabela 7: Retorno de respostas dos questionários e os valores da amostra estratificada

\begin{tabular}{lcc}
\hline \multicolumn{1}{c}{ Região } & $\begin{array}{c}\text { Total mínimo de universidades para a } \\
\text { amostra válida }\end{array}$ & $\begin{array}{c}\text { Total de respostas do } \\
\text { questionário }\end{array}$ \\
\hline Centro-Oeste & 2 & 6 \\
Norte & 2 & 7 \\
Nordeste & 8 & 17 \\
Sudeste & 31 & 32 \\
Sul & 11 & 16 \\
\hline
\end{tabular}

Fonte: Da autora, 2015.

Para a análise dos dados coletados por meio de checklist e questionários adotouse a estatística descritiva, especialmente a contagem de frequências. De acordo com Babbie (2003, p. 195) a estatística descritiva "é um método de apresentar descrições quantitativas de modo manejável". Isso significa que o uso desse tipo de estatística oferece de modo sintetizado as principais características dos dados coletados. Ao todo, foram realizadas nove entrevistas. Embora o número represente um número menor quando comparado ao questionário, Babbie (2003) apontou que as taxas de respostas são mais elevadas, devendo alcançar 80 a $85 \%$ quando aplicada adequadamente. Segundo o autor, uma possível razão para tal êxito e que pode ser considerada uma entre as principais vantagens da entrevista, é o fato de que há a redução de dúvidas quanto ao entendimento do que está sendo questionado. Ou seja, caso a pessoa entrevistada não entenda a pergunta há a possibilidade do entrevistador, de modo controlado, clarear o assunto (BABBIE, 2003).

Algumas regras gerais foram ser seguidas para a realização adequada das entrevistas, conforme recomendações de Babbie (2003; 2008):

i. familiaridade com o roteiro das entrevistas: perguntas foram feitas inequivocamente (o entrevistador deve ser capaz de fazer as perguntas sem 
erros, devendo também estar familiarizado com todas as instruções, no intuito de não tomar mais tempo do que o necessário);

ii. seguir exatamente a redação da questão (uma pequena mudança de redação pode modificar a resposta do entrevistado);

iii. registrar a maneira de forma exata (o entrevistado deve tomar nota de toda a resposta e não deve tentar resumir, parafrasear ou corrigir erros de gramática).

Nessa linha, Richardson (1999, p. 216) também apontou aspectos para a realização de uma entrevista, dos quais dois foram adotados nesta pesquisa: i. explicação do objetivo e natureza do trabalho, informando ao entrevistado como foi escolhido; ii. o entrevistador deve solicitar autorização para gravar a entrevista, explicando o motivo da gravação.

As entrevistas foram feitas por telefone e contaram com o auxílio de um roteiro de entrevista (Apêndice C), elaborado com base no modelo conceitual da pesquisa e utilizado para nortear sua realização.

Atentando às recomendações, as nove entrevistas foram realizadas com gestores de diferentes universidades, selecionados conforme a representação dos seguintes cenários:

i. universidades que possuem apenas biblioteca digital de teses e dissertações;

ii. universidades que possuem apenas repositório institucional;

iii. universidades que possuem biblioteca digital de teses e dissertações e repositório institucional;

iv. universidades que possuem sistemas de informação próprio que gerenciam teses e dissertações eletrônicas;

v. universidades que não possuem nenhum sistema de informação que gerencia de teses e dissertações eletrônicas.

Desse modo, as instituições selecionadas para as entrevistas foram: Universidade Tecnológica Federal do Paraná (UTFPR), Universidade Católica de Brasília (UCB), Universidade Estadual do Rio Grande do Norte (UERN), Universidade Federal do 
Recôncavo Baiano (UFRB), Universidade Federal de Goiás (UFG), Universidade Federal de Campina Grande (UFCG), Pontifícia Universidade Católica do Rio de Janeiro (PUC Rio), Universidade Estadual de Santa Catarina (UDESC) e Universidade Federal de São Carlos (UFSCAR). Todos os entrevistados permitiram que as entrevistas fossem gravadas. 0 passo seguinte foi a transcrição das entrevistas, a partir da qual foram gerados textos fiéis às falas dos entrevistados, mas com a supressão de aspectos próprios da expressão oral.

Tanto os dados coletados por meio de entrevistas quanto os dados coletados a partir das questões abertas dos questionários foram submetidos à análise textual. A análise textual é o processo que "consiste em extrai sentido dos dados de texto e imagem" (CRESWELL, 2007, p. 194). Assim, a técnica de análise textual empregada neste estudo teve como intenção extrair e interpretar os dados coletados.

Após as devidas explicações sobre a definição do universo, amostra e as atividades de coleta e análise dos dados, segue para a próxima fase e seção desta pesquisa: a análise e discussão dos dados. 
Quadro 8: Síntese das estratégias e procedimentos desta pesquisa

\begin{tabular}{|c|c|c|c|c|c|c|}
\hline Objetivo específico & $\begin{array}{c}\text { Universo da } \\
\text { pesquisa }\end{array}$ & Amostra & Fonte de dados & Método & $\begin{array}{c}\text { Técnica de coleta } \\
\text { dos dados }\end{array}$ & $\begin{array}{c}\text { Técnica de análise } \\
\text { dos dados }\end{array}$ \\
\hline $\begin{array}{l}\text { Mapear os sistemas de } \\
\text { informação utilizados para a } \\
\text { gestão das teses e } \\
\text { dissertações eletrônicas no } \\
\text { Brasil }\end{array}$ & \multicolumn{2}{|c|}{ Universidades brasileiras } & $\begin{array}{l}\text { Páginas das } \\
\text { universidades e de } \\
\text { suas bibliotecas }\end{array}$ & \multirow{3}{*}{ 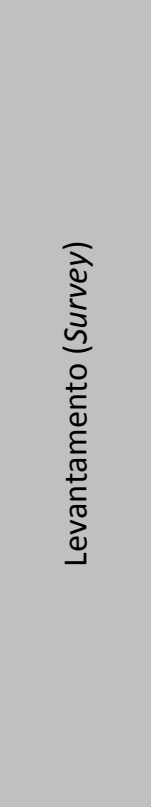 } & Checklist & Análise estatística \\
\hline $\begin{array}{l}\text { Identificar características e } \\
\text { processos realizados pelos } \\
\text { sistemas de informação } \\
\text { utilizados para a gestão de } \\
\text { teses e dissertações } \\
\text { eletrônicas no Brasil }\end{array}$ & $\begin{array}{l}\text { Gestores dos } \\
\text { sistemas }\end{array}$ & $\begin{array}{c}\text { Amostra } \\
\text { probabilística } \\
\text { estratificada } \\
\text { Amostra não } \\
\text { probabilística } \\
\text { intencional } \\
\end{array}$ & Gestores dos sistemas & & $\begin{array}{l}\text { Questionário } \\
\text { Entrevista }\end{array}$ & $\begin{array}{l}\text { Análise estatística } \\
\text { descritiva } \\
\text { Análise textual }\end{array}$ \\
\hline $\begin{array}{l}\text { Identificar, com base na } \\
\text { percepção de gestores dos } \\
\text { sistemas de informação de } \\
\text { acesso aberto, fatores que } \\
\text { influenciam a gestão de } \\
\text { teses e dissertações } \\
\text { eletrônicas }\end{array}$ & $\begin{array}{l}\text { Gestores dos } \\
\text { sistemas }\end{array}$ & $\begin{array}{l}\text { Amostra } \\
\text { probabilística } \\
\text { estratificada } \\
\text { Amostra não } \\
\text { probabilística } \\
\text { intencional }\end{array}$ & Gestores dos sistemas & & $\begin{array}{l}\text { Questionário } \\
\text { Entrevista }\end{array}$ & $\begin{array}{l}\text { Análise estatística } \\
\text { descritiva } \\
\text { Análise textual }\end{array}$ \\
\hline
\end{tabular}

Fonte: Da autora, 2015. 


\section{CAPÍTULO 4}

\section{ANÁLISE E DISCUSSÃO DOS RESULTADOS}

Este capítulo apresenta a análise dos dados coletados e discussão dos resultados obtidos por meio do checklist, dos questionários e das entrevistas. Para cada aspecto objetivo da investigação primeiramente são apresentados e discutidos os dados de natureza quantitativa e a esses são integrados os dados qualitativos, de modo que possa ser efetivada a complementação das duas abordagens, conforme a lógica da execução de projeto concomitante no âmbito dos métodos mistos, definida na metodologia desta dissertação.

Este capítulo é dividido em duas grandes seções: análise e discussão dos resultados das universidades que possuem gerenciamento de teses e dissertações eletrônicas e análise e discussão dos resultados das universidades que não possuem gerenciamento de teses e dissertações eletrônicas. As subseções, por seu turno, correspondem aos processos de gestão de teses e dissertações eletrônicas (Figura 23), conforme modelo conceitual da pesquisa, extraído da revisão de literatura e apresentado na metodologia.

Figura 23: Definição das seções para análise e discussão dos resultados

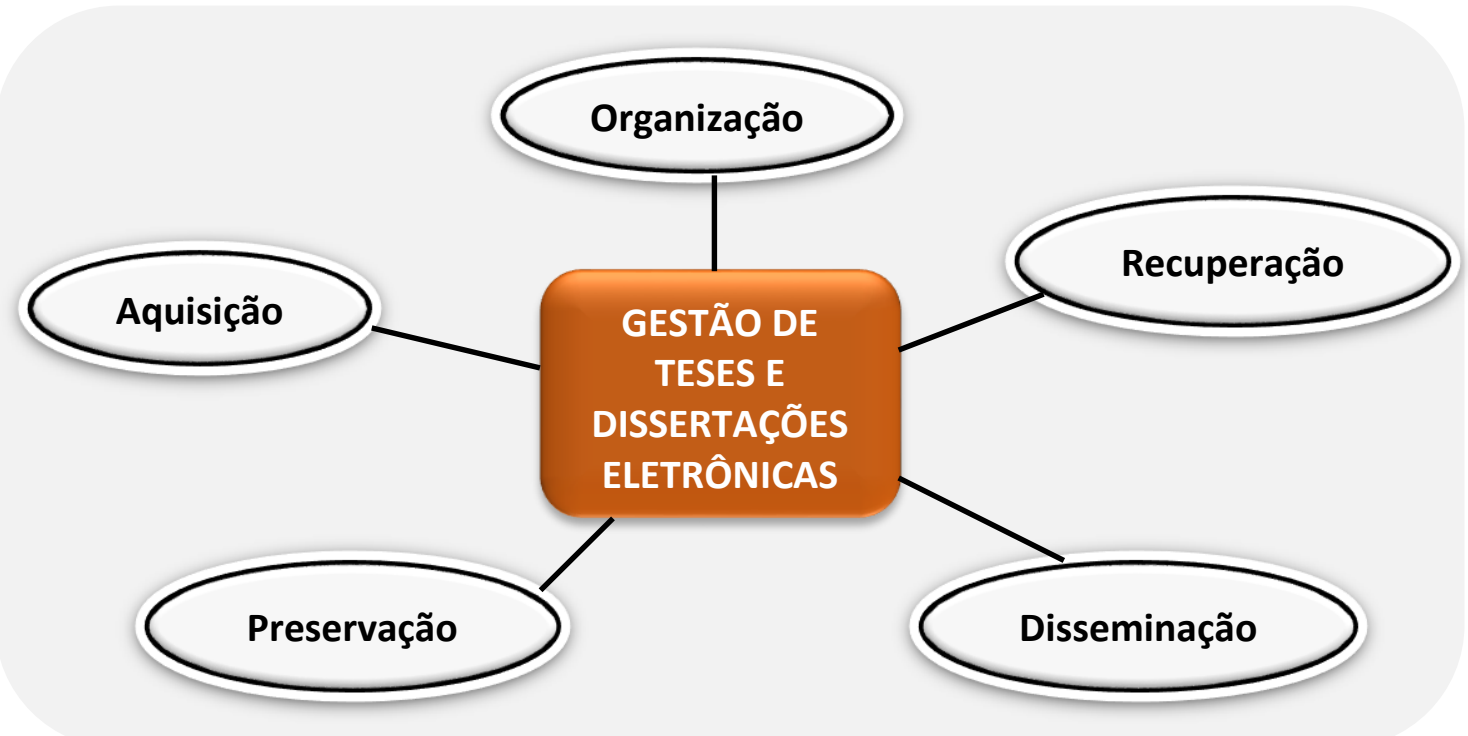

Fonte: Da autora, 2015. 
Ao final da apresentação das duas grandes seções apresenta-se a terceira e última seção que objetiva fazer uma breve análise comparativa das demais e ressaltar os principais aspectos ora identificados.

Cada seção foi dividida em seis tópicos de acordo com cada processo apontado. No entanto, a primeira linha é voltada para a apresentação da caracterização das universidades respondentes.

\subsection{Universidades que possuem gerenciamento de ETDs}

\subsubsection{Caracterização das universidades respondentes}

O primeiro aspecto avaliado se refere à caracterização das universidades respondentes. O referido aspecto se relaciona com elementos do tipo, região geográfica, categoria (pública/privada) e a equipe responsável pelo gerenciamento das teses e dissertações eletrônicas.

Observa-se que no contexto das universidades que possuem gerenciamento de teses e dissertações eletrônicas, das 58 respondentes, 40 são públicas e 18 privadas. Em valores porcentuais correspondem a aproximadamente $69 \%$ e $31 \%$, respectivamente. Quanto à distribuição geográfica das universidades tem-se a maior concentração na região Sudeste obedecendo a proporção da distribuição das universidades em todo o País, 28 universidades. 0 gráfico 1 ilustra os primeiros valores obtidos. 
Gráfico 1: Caracterização das universidades que possuem ETDs

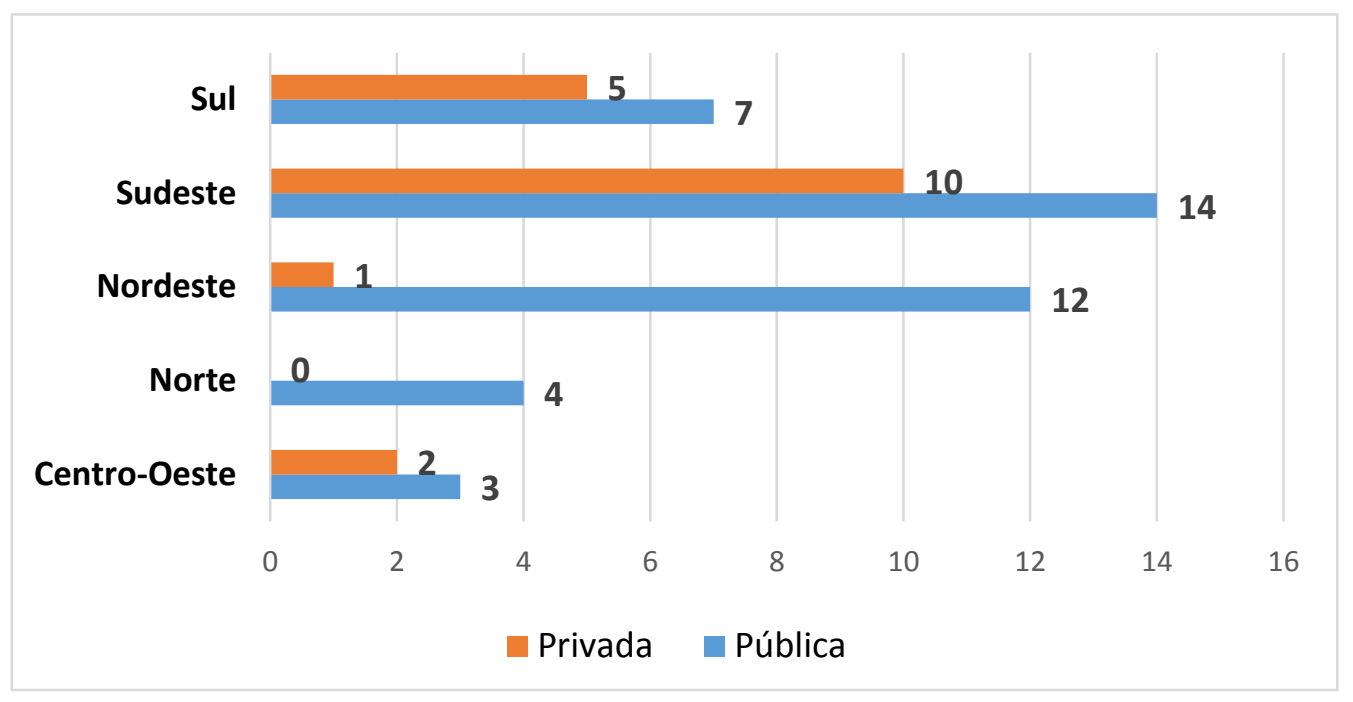

Fonte: Da autora, 2015.

Segundo dados do Portal e-MEC (2015) e do GeoCapes (2015), a região Sudeste oferta o maior número de programas de mestrado e doutorado no País, um total de 411 programas, tendo o maior número de universidades em relação às outras regiões. Entretanto, embora o resultado apresente o maior número na região Sudeste, os dados apresentados no balanço social pelo MEC mostraram que entre os anos de 2003 e 2013 as regiões Norte e Nordeste apresentaram significativa expansão de oferta na educação superior. Segundo o MEC (2014),

\footnotetext{
o percentual de crescimento das matrículas na região Nordeste, de $94 \%$, correspondeu ao dobro do registrado para o Sudeste e mais do triplo daquele registrado na região Sul. A região Norte teve a segunda maior taxa de crescimento (76\%) entre as regiões do país. Tais resultados são consequências dos investimentos na interiorização da universidade pública e nas políticas de democratização do acesso desenvolvidas pelo governo federal (MEC, 2014, p. 19).
}

Quando observados também os números da ampliação das universidades federais em todo o País, tem-se que a região Sudeste não apresentou os maiores crescimentos entre os anos de 2003 e 2013, de acordo com o MEC (2014). 
Tabela 8: Expansão das universidades federais por região

\begin{tabular}{|c|c|c|c|c|c|c|c|c|c|}
\hline \multirow[b]{2}{*}{ REGIÃO } & \multicolumn{3}{|c|}{ CURSOS } & \multicolumn{3}{|c|}{ VAGAS } & \multicolumn{3}{|c|}{ MATRÍCULAS } \\
\hline & 2002 & 2013 & $\begin{array}{c}\% \text { de } \\
\text { crescimento }\end{array}$ & 2002 & 2013 & $\begin{array}{c}\% \text { de } \\
\text { crescimento }\end{array}$ & 2002 & 2013 & $\begin{array}{c}\% \text { de } \\
\text { crescimento }\end{array}$ \\
\hline Norte & 478 & 714 & $49 \%$ & 16.755 & 30.094 & $80 \%$ & 76.779 & 128.228 & $67 \%$ \\
\hline Nordeste & 583 & 1.299 & $123 \%$ & 33.587 & 75.052 & $123 \%$ & 147.464 & 281.421 & $91 \%$ \\
\hline Sul & 286 & 951 & $233 \%$ & 17.152 & 42.241 & $146 \%$ & 75.985 & 157.206 & $107 \%$ \\
\hline Sudeste & 430 & 1.332 & $210 \%$ & 32.509 & 71.502 & $120 \%$ & 139.641 & 275.687 & $97 \%$ \\
\hline $\begin{array}{l}\text { Centro- } \\
\text { Oeste }\end{array}$ & 270 & 571 & $111 \%$ & 13.260 & 27.044 & $104 \%$ & 60.590 & 89.721 & $48 \%$ \\
\hline
\end{tabular}

Fonte: MEC, 2014.

Entretanto, a região Sudeste apresentou maior número de universidades criadas em regiões não metropolitanas, no período entre 2003 e 2007, correspondendo a 40\% das universidades criadas dentre os anos (MEC, 2014).

Ao analisar apenas a distribuição das universidades públicas de acordo com a sua categoria tem-se a maior presença das universidades federais.

\section{Gráfico 2: Universidades: federal x estadual}

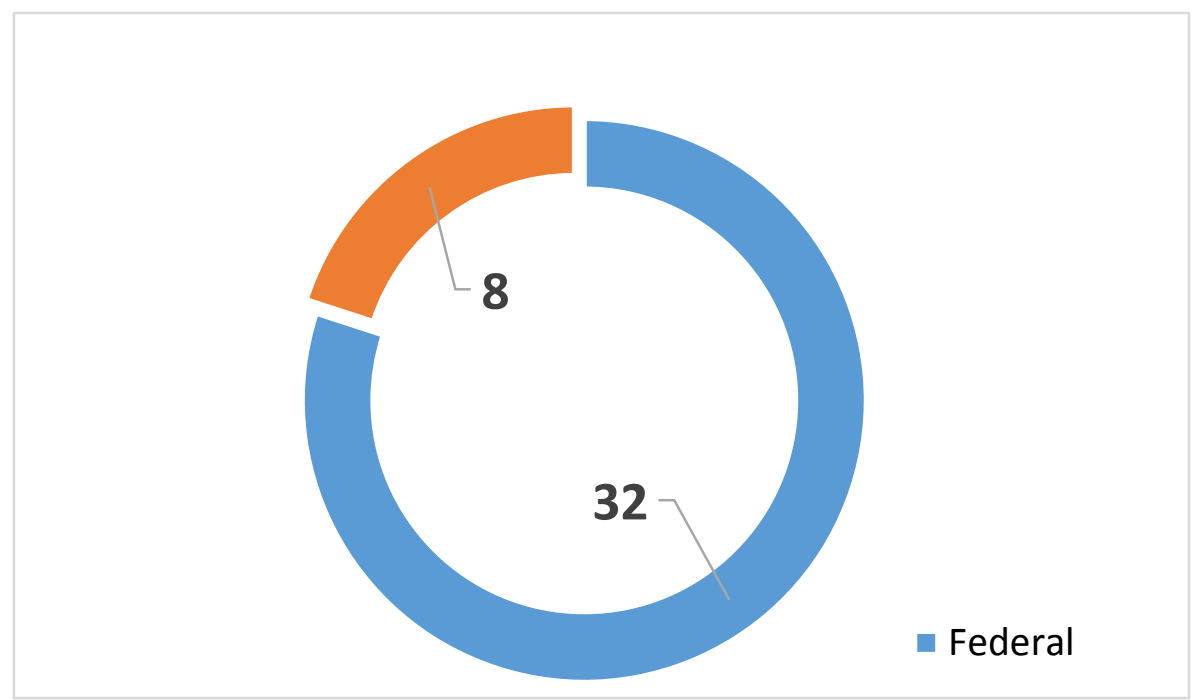

Fonte: Da autora, 2015.

O maior número de universidades federais apresentadas nesta etapa da pesquisa e que possuem gerenciamento de teses e dissertações eletrônicas pode se relacionar com o fato de que nessas instituições se encontra maior parte dos programas de pósgraduação. Segundo informações do GeoCapes (2014), as federais ofertam aproximadamente $57 \%$ dos programas de pós-graduação no Brasil. Relacionando-se 
com esse dado, a Biblioteca Digital Brasileira de Teses e Dissertações (BDTD) tem em sua rede a maior participação das universidades públicas, aproximadamente 65 instituições públicas de ensino e pesquisa, do total de 111 instituições. Desta forma, os resultados obtidos parecem ilustrar o cenário da BDTD.

Com relação à equipe responsável pelo gerenciamento das teses e dissertações eletrônicas nas universidades, destaca-se o número reduzido de pessoas envolvidas no projeto de gestão das ETDs, de 1 a 3 responsáveis. O valor corresponde a aproximadamente $70 \%$ das universidades entrevistadas.

Gráfico 3: Quantidade de pessoas que formam parte da equipe de gestão das ETDs

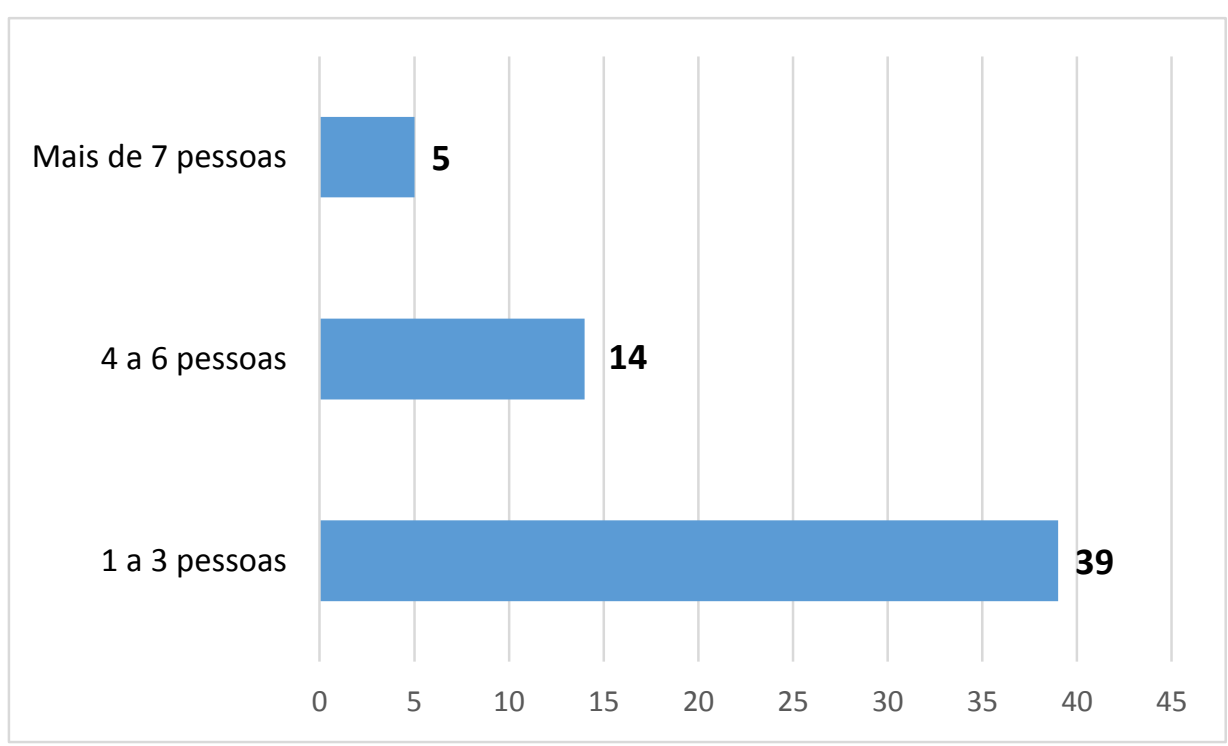

Fonte: Da autora, 2015.

Al Salmi (2014) aponta que para criar e manter um sistema de informação que gerencia teses e dissertações varia entre universidades, no entanto, a quantidade de pessoas envolvidas não é tão numerosa. Para justificar, o autor cita o exemplo da biblioteca da Virginia Tech que criou seu sistema com um bibliotecário e um programador.

Entretanto, os dados coletados a partir da resposta à questão aberta do questionário, sobre fatores internos ou externos à universidade que favorecem ou dificultam a gestão de teses e dissertações eletrônicas, apontaram que a falta de recursos humanos na própria universidade é um dos fatores principais que dificultam a gestão de ETDs, conforme evidenciado nas respostas. 
Internos: definição de equipe de TI (não dispomos de um técnico exclusivo para o sistema). (UNIVERSIDADE 1).

Internos: quadro deficitário de $R H$, entraves nos processos decisórios e no processo de depósito. Externos: apoio do IBICT (treinamentos e suporte técnico). (UNIVERSIDADE 2).

Dificuldades: pessoal técnico com conhecimento em biblioteconomia, especificamente em bibliotecas digitais; falta pessoal técnico na área de departamento informática; (...) (UNIVERSIDADE 3).

Utilizamos apenas o sistema de gestão de teses e dissertações por não haver pessoal disponível para gerenciar um repositório (...) (UNIVERSIDADE 4).

A resistência da equipe diante da falta de pessoal. 1 bibliotecário por campus trabalhando com terceirizados sem formação na área. (UNIVERSIDADE 5).

No que tange a questões internas, temos poucos profissionais para trabalhar com o Repositório, isso dificulta o autoarquivamento (...) (UNIVERSIDADE 6).

O fator que dificulta a gestão das teses e dissertações é falta de pessoal da área de informática mais ativo nessa área (...) (UNIVERSIDADE 7).

Todavia, o resultado encontrado no âmbito das universidades brasileiras vai de encontro ao resultado encontrado no estudo de Al Salmi (2014). Ao realizar o estudo sobre os programas de ETDs no Estado do Golfo Árabe, o pesquisador obteve como resposta que a disponibilidade para pessoal qualificado não pode ser classificada como uma das principais barreiras para a adoção de programas de ETDs na região. Em seu estudo, os fatores tecnológicos, como a adoção de uma nova tecnologia, são apontados como um dos fatores negativos para a implantação de sistemas de informação de ETDs.

Os mesmos dados que indicam dificuldades dos recursos humanos ressaltam, também, que esta dificuldade é mais significativa em relação a pessoal de tecnologias de informação. A gestão de sistemas de informação de teses e dissertações eletrônicas e que, em sua maioria, se inicia com o desenvolvimento do próprio sistema, exige maior interação de bibliotecários e informáticos (tecnologias de informação). Isto porque considera-se que são esses últimos que são responsáveis pela instalação, customização e posteriores atualizações nos sistemas. Nesse sentido, os bibliotecários recorrem a esses profissionais sempre que necessário realizar quaisquer mudanças técnicas nos sistemas de informação de ETDs. 
Orera Orera (2002) sinalizou para a necessidade do profissional de Biblioteconomia em se manter atualizado das inovações do contexto digital. De acordo com a autora, à medida que a biblioteca foi se tornando um sistema mais complexo, os conhecimentos profissionais para atendê-la evoluíram na mesma direção. Assim sendo, foi necessário que o bibliotecário, com um perfil científico e profissional definido, tivesse a oportunidade de adquirir a formação necessária para desempenhar suas funções (ORERA ORERA, 2002). Assim sendo, considera-se que os bibliotecários devem buscar compreender alguns conhecimentos de outras formações, sobretudo, das áreas relacionadas às tecnologias de informação.

\subsubsection{Tipo de sistema e tecnologia adotados para a gestão de ETDs}

O modelo conceitual da pesquisa considera que a gestão das teses e dissertações (aquisição, organização, preservação, recuperação e disseminação) é realizada por sistemas de informação que normalmente são de três tipos: bibliotecas digitais de teses e dissertações, repositórios institucionais e sistemas próprios. Tendo em vista este norteamento oferecido pelo modelo conceitual, os sistemas assim como as motivações que levaram a adotá-lo foram investigados a partir do checklist, questionário e entrevistas.

No que se refere ao tipo de sistemas, os dados do questionário indicaram que há equilíbrio entre instituições que adotaram exclusivamente repositórios institucionais, sendo 18 casos, e instituições que possuem tanto repositórios institucionais quanto bibliotecas digitais de teses e dissertações, com 17 instituições dos casos. Tão expressivo quanto esses resultados foi a quantidade de instituições que afirmaram gerenciar as teses e dissertações exclusivamente a partir de bibliotecas digitais de teses e dissertações, com 14 casos de ocorrências.

Além dessas três situações os respondentes também puderam indicar outros sistemas, que correspondeu a dez casos. As respostas a essa alternativa foram acompanhadas da especificação dos outros sistemas, sendo que em sua maioria se referiram aos catálogos de bibliotecas gerados a partir de sistemas de gestão de bibliotecas, como o Pergamum e Sophia. Dessa forma, os resultados que ilustram o 
cenário da gestão de teses e dissertações nas universidades são apresentados no gráfico 4 a seguir.

Gráfico 4: Cenário da gestão das ETDs nas universidades

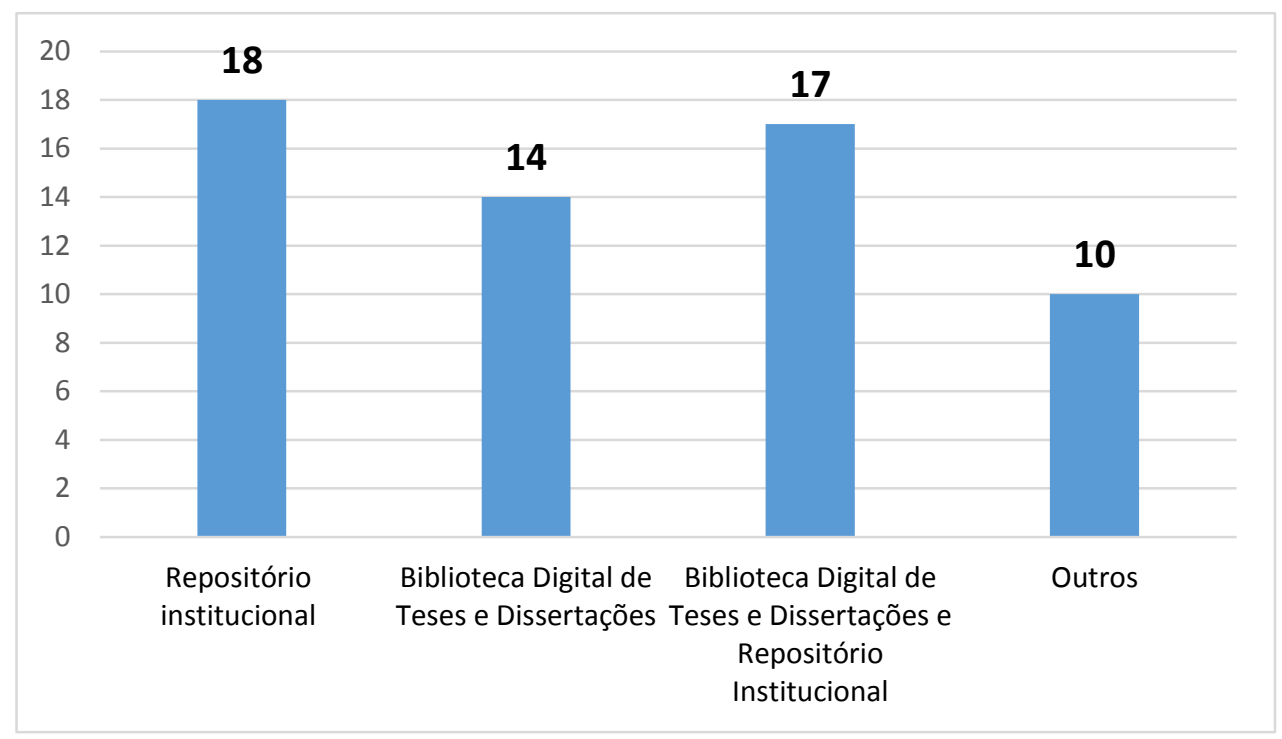

Fonte: Da autora, 2015.

A coleta de dados por meio do checklist também contemplou a questão do tipo de sistema de informação adotado (Tabela 9). Nesse caso, todos os sistemas de informação identificados foram analisados, e não apenas uma amostra, o que explica a diferença quantitativa dos dados. Os sistemas predominantes são as bibliotecas digitais de teses e dissertações. Do total de 125 instituições, 46 possuem esse tipo de sistema. Em seguida, tornar as teses e dissertações em alguma medida acessíveis por meio de páginas na internet, especialmente por meio das páginas dos programas de pósgraduação, são uma segunda estratégia mais frequente, com 32 casos identificados. Os repositórios institucionais figuram como a terceira mais frequente com 20 casos. É interessante notar que a quantidade de repositórios institucionais identificada por meio do questionário é muito próxima da quantidade de repositórios institucionais identificadas por meio do checklist. Como se trata do universo como um todo, seria natural uma quantidade maior desse último tipo de sistema, como sugerem dados do próprio IBICT (2015). O Brasil tem 41 repositórios de acesso aberto apoiados pelo IBICT, ou seja, que receberam kits tecnológicos para a criação dos sistemas de acesso aberto. Segundo dados do OpenDOAR (2015), o País conta com aproximadamente 90 
repositórios criados. É possível que esse fato tenha ocorrido, pois as fontes adotadas para a localização dos sistemas foram as páginas da instituição e de sua biblioteca. Ou seja, na medida em que essas páginas não remetiam aos sistemas não foi possível identificá-los.

Os dados coletados demonstram que o fenômeno ocorrido em todo o mundo também aconteceu no Brasil com a criação de inúmeras bibliotecas digitais de teses e dissertações em todo o País. A partir das ações do IBICT para a promoção da criação desses sistemas nas instituições brasileiras de ensino e pesquisa, como por exemplo, a distribuição de servidores (máquinas) e do sistema de gestão de teses e dissertações, o TEDE, sem dúvidas é um dos fatores mais importantes nesse contexto. Gubiani (2005) apontou que o IBICT antes do desenvolvimento e repasse do TEDE estudou outros softwares para buscar uma solução final. No estudo de Costa (2014), a autora identificou no universo de 172 repositórios institucionalmente definidos em sua pesquisa, o total de 14 sistemas dedicados somente para o armazenamento de teses e dissertações e outros 56 destinados para teses, dissertações e trabalhos de conclusão de curso. Outro aspecto que deve ser ressaltado e que se relaciona com os números apresentados é que, o surgimento de tecnologias de bibliotecas digitais para a gestão de teses e dissertações eletrônicas está inserido em um contexto anterior ao dos repositórios institucionais de acesso aberto, tendo, portanto, um período de tempo maior para a sua consolidação nas universidades brasileiras. Por essa razão os sistemas denominados como bibliotecas digitais expressam um grande conjunto no contexto brasileiro. O uso de bibliotecas digitais para o gerenciamento das teses e dissertações decorre por influência da rede internacional NDLTD, uma vez que foi por meio desse tipo de sistema que se teve início a gestão das teses e dissertações eletrônicas (ALLARD, 2003; FOX, EATON e MCMILLAN, 1997).

No entanto, a presença de outros sistemas de informação que passaram a gerenciar também os textos completos das teses e dissertações eletrônicas tem impulsionado o IBICT a desenvolver novas estratégias para a gestão desses documentos, principalmente na Biblioteca Digital Brasileira de Teses e Dissertações (BDTD). Segundo informações do IBICT, o armazenamento das teses e dissertações em repositórios institucionais e nos catálogos de biblioteca tem exigido a adoção de novas tecnologias para a coleta automática desses metadados para a base da BDTD. Até o ano de 2014, a 
BDTD só era capaz de coletar os metadados quando registrados em bibliotecas digitais de teses e dissertações e/ou em sistemas próprios desenvolvidos pelas instituições e que obedecem às solicitações técnicas para a interoperabilidade. Ainda, as instituições que gerenciam as teses e dissertações por meio de repositórios institucionais de acesso aberto adotaram soluções em seus ambientes para que o efetivo processo de envio dos metadados à BDTD (IBICT, 2014). Dessa forma, observa-se que em razão do número expressivo de repositórios institucionais identificados nesta pesquisa, o número de teses e dissertações presentes na BDTD tende a alcançar valores bem maiores que o se apresenta até o momento.

Destaca-se também o número de páginas web identificadas para a gestão das teses e dissertações eletrônicas nas universidades brasileiras. Tais páginas foram observadas, em sua totalidade, nas páginas dos programas de pós-graduação. Verificouse que não há um padrão estabelecido para a disseminação das teses e dissertações entre os programas das universidades e, até mesmo, entre os programas de pósgraduação de uma mesma universidade. Também foi possível constatar que nem todas as teses e dissertações defendidas nos programas estavam livremente acessíveis, sendo necessária a identificação por meio de login em alguns casos.

Tabela 9: Dados coletados pelo checklist em relação ao sistema de informação

\begin{tabular}{lc}
\hline \multicolumn{1}{c}{ Tipo de sistema de informação ${ }^{30}$} & Quantidade \\
\hline Biblioteca Digital de Teses e Dissertações & 46 \\
Repositório Institucional & 23 \\
Catálogo da Biblioteca & 8 \\
Página web & 38 \\
Biblioteca Digital de produção da instituição & 7 \\
Biblioteca Digital de Teses e Dissertações e Repositório & 4 \\
Institucional & 4 \\
Banco/ Repositório de Teses & 4 \\
Página web e Repositório Digital & $\mathbf{1}$ \\
Não identificado & 3 \\
\hline
\end{tabular}

Fonte: Da autora, 2015.

\footnotetext{
30 Os tipos de sistemas de informação listados obedecem a forma como foram nomeados nas próprias universidades.
} 
Ao relacionar os dados identificados por meio do checklist com a natureza das universidades (privadas e públicas) chama atenção para o fato de que nenhuma universidade privada apresenta um repositório institucional de acesso aberto e para o equilíbrio entre instituições públicas e privadas quando observados os números de bibliotecas digitais de teses e dissertações e as páginas web (Tabela 10). Para a apresentação dos dados adotou-se as seguintes referências:
(A) Biblioteca Digital de Teses e Dissertações
(B) Repositório Institucional
(C) Catálogo da biblioteca
(D) Página web
(E) Biblioteca digital de produção da instituição
(F) Biblioteca Digital de Teses e Dissertações e Repositório Institucional
(G) Banco / Repositório de Teses
(H) Página web e repositório digital
(I) Não identificado

Tabela 10: Tipo de sistema de informação x natureza da universidade

\begin{tabular}{lccccccccc}
\hline Natureza & (A) & (B) & C & (D) & (E) & (F) & (G) & (H) & (I) \\
\hline Pública & 25 & 20 & 2 & 12 & 4 & 4 & - & 1 & 1 \\
Privada & 21 & - & 5 & 20 & 3 & - & 4 & - & 2 \\
\hline
\end{tabular}

Fonte: Da autora, 2015.

Ao confrontar os sistemas de informação das universidades com a presença delas na BDTD tem-se que a maioria das instituições participantes, entre públicas e privadas, são cooperantes por meio de suas bibliotecas digitais de teses e dissertações (Gráfico 5). Este fato confirma as informações apresentadas anteriormente referentes à criação desses sistemas de informação impulsionada pelas ações do IBICT.

Outros dois aspectos contemplados nesta pesquisa, sobre a dimensão tecnológica dos sistemas, referem-se ao software adotado (Tabela 11) e às motivações que levaram a sua escolha (Gráfico 5). De acordo com Vicentini (2006, p. 242), para a construção de bibliotecas digitais, o uso de softwares livres (código aberto) se torna um mecanismo viável para que "instituições desenvolvam soluções (serviços e produtos) 
com maior velocidade a custo muito baixo". Desta forma, a construção de bibliotecas digitais, em sentido amplo, depende fortemente da dimensão tecnológica (ROSETTO, 2008; VICENTINI, 2006; CUNHA, 1999).

Conforme a tabela 11, os dados revelaram que o software mais adotado para a gestão de teses e dissertações, no Brasil, é o TEDE. Das 125 instituições que possuem teses e dissertações eletrônicas foi possível identificar que 43 adotam o uso dessa ferramenta. Essa ampla adoção não foi por acaso. Reforça-se, mais uma vez, o papel desempenhado pelo IBICT quanto ao suporte dados às universidades para a criação de seus ambientes digitais de teses e dissertações. Como visto, o TEDE foi desenvolvido e é mantido pelo IBICT. Segundo Dudziak e Villela (2006, p. 6), o TEDE "automatiza os procedimentos de publicação eletrônica". No estudo de Benítez de Vendrell (2011) identifica-se que o TEDE é também usado no cenário internacional. Segundo a autora, o TEDE é utilizado pela Universidad Nacional del Sur, na Argentina, na criação de sua biblioteca digital de teses e dissertações. Dada a sua recente atualização e disponibilização às instituições de ensino e pesquisa, a versão atualizada do TEDE, denominada até o momento como TEDE 2 (IBICT, 2014), está em uso em apenas uma universidade.

As páginas web apresentam-se em um segundo lugar como uma forma de sistema para a gestão das teses e dissertações eletrônicas. No entanto, a gestão desses documentos nessa modalidade gera obstáculos para a interoperabilidade com demais sistemas de informação e com a BDTD. As dificuldades são ocasionadas uma vez que as páginas web podem não armazenar o conteúdo da forma desejada, ou seja, podem não conter o padrão mínimo de metadados desejado para a interoperabilidade e ainda, não possuir as infraestruturas tecnológicas necessárias para que esse processo ocorra como a adoção do Protocolo OAI-PMH. As implicações disso são, portanto, uma limitação para a visibilidade da produção de teses e dissertações da universidade. Por sua vez, a baixa visibilidade pode acarretar um número reduzido de acessibilidade e citação dos autores e pesquisas, como por exemplo.

Em terceiro, destaca-se o uso do software DSpace. Com base nos dados coletados pode-se afirmar que o DSpace é utilizado em sua totalidade para a criação dos repositórios institucionais brasileiros. O DSpace é um software livre desenvolvido pela Massachusetts Institute of Technology (MIT) e mantido, atualmente, pela organização 
DuraSpace. Segundo dados do Diretório OpenDOAR, o DSpace é o software mais utilizado em todo o mundo para a criação de repositórios institucionais de acesso aberto correspondendo a $43 \%$ do total de 2.845 repositórios registrados no Diretório. No estudo sobre os repositórios institucionais presentes na América Latina, o DSpace também se destaca como o mais utilizado na região com a predominância de $82 \%$ (COSTA, 2014). Demonstrando a sua internacionalização, no contexto de repositórios criados na região da Ásia, o DSpace também figura como o software mais utilizado (SENGUPTA, 2012).

Infere-se que o uso do DSpace, no Brasil, para a criação de repositórios institucionais relaciona-se com as ações do IBICT também para a promoção desses espaços digitais para o gerenciamento da produção científica de uma instituição como um todo, o que inclui as teses e dissertações. Nesse sentido, os 23 casos identificados na coleta de dados são repositórios institucionais de acesso aberto.

Tabela 11: Dados coletados pelo checklist em relação ao software do sistema de informação

\begin{tabular}{lc}
\hline \multicolumn{1}{c}{ Tipo de sistema de informação } & Quantidade \\
\hline Sistema de Publicação Eletrônica de Teses e Dissertações (TEDE) & $\mathbf{4 3}$ \\
Sistema de Publicação Eletrônica de Teses e Dissertações atualizado (TEDE2) & $\mathbf{1}$ \\
DSpace & $\mathbf{2 3}$ \\
Página web de cada programa de pós-graduação & $\mathbf{3 5}$ \\
Catálogo de Biblioteca (Sophia, Pergamum, por exemplo) & $\mathbf{8}$ \\
Software próprio & $\mathbf{5}$ \\
Não identificado & $\mathbf{6}$ \\
\hline
\end{tabular}

Fonte: Da autora, 2015.

A compreensão das motivações que influenciaram a escolha do software para a gestão de teses e dissertações eletrônicas foi importante para o estudo, uma vez que permitiu identificar as razões que estiveram relacionadas ao software em si (funcionalidades) e razões circunstanciais. De acordo com o gráfico 5, a principal razão apontada pelos respondentes dos questionários é ser um software distribuído gratuitamente e que tem suporte do IBICT. Infere-se que o apoio do IBICT é uma variável diferencial para a escolha do software, já que a opção de software distribuído gratuitamente teve uma taxa menor. A adoção de um software livre mostra-se como um fator importante para a escolha entre as universidades brasileiras. Hoe-Lian Goh et al (2006) apontaram que os softwares livres tendem a ter mais funções quando 
comparados aos distribuídos comercialmente, isso porque dá liberdade à comunidade de programadores desenvolverem novas funcionalidades ao sistema.

Gráfico 5: Escolha do software para gestão de ETDs

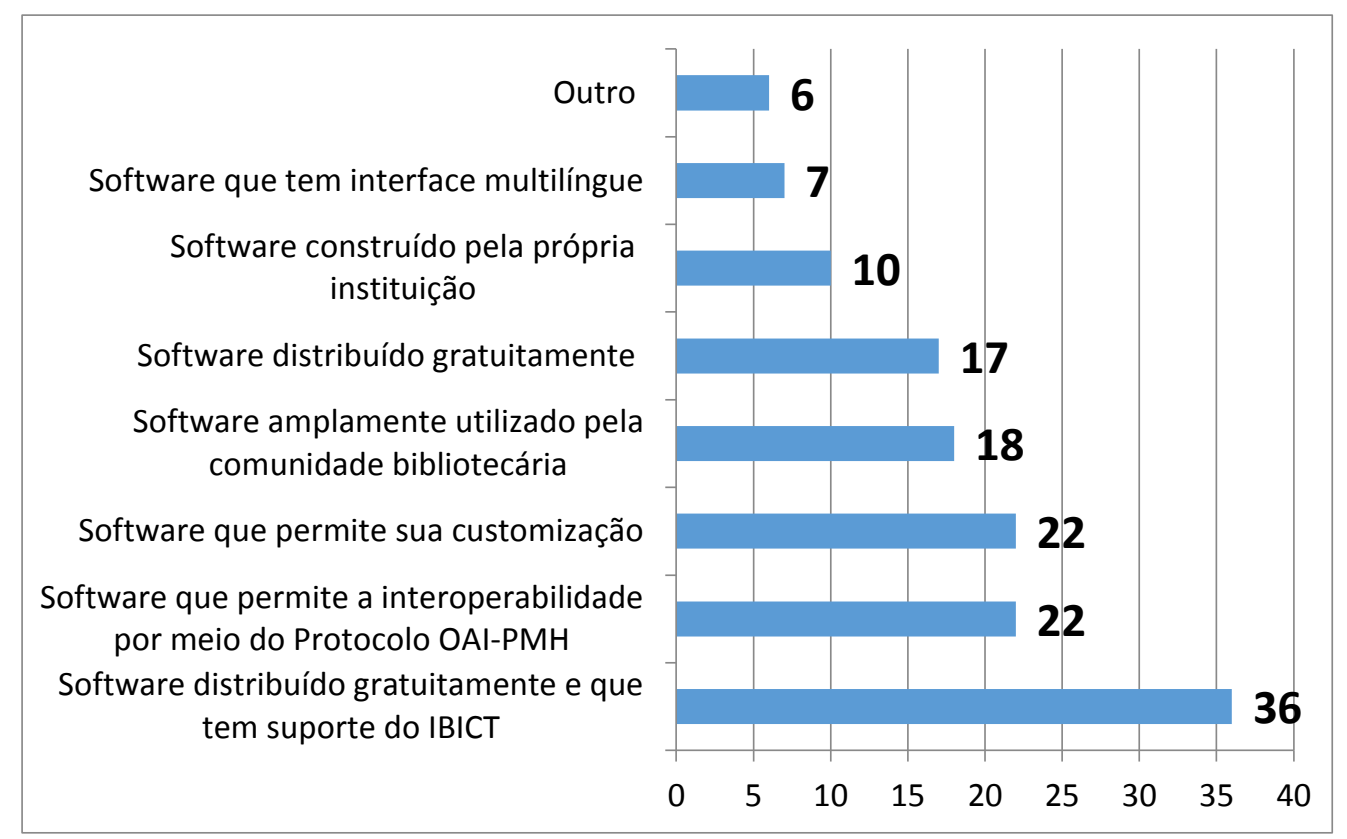

Fonte: Da autora, 2015.

A dimensão tipo de conteúdo foi levada em consideração no levantamento realizado. A relevância desta questão reside no fato de que, no contexto do Acesso Aberto e da comunicação científica, teses e dissertações são gerenciadas de duas maneiras principais: bibliotecas digitais ou repositórios digitais de teses e dissertações (que lidam exclusivamente com esse tipo de material) e repositórios institucionais (que lidam com a totalidade da produção científica). Pickton e Mecknight (2006) apresentaram em seu estudo que o acesso às teses e dissertações eletrônicas foi um dos serviços mais atrativos nos repositórios para estudantes, como pesquisadores e autores.

O gráfico 6 mostra a frequência dos tipos de conteúdo nos sistemas gerenciados pelos respondentes. Note-se que em 30 universidades teses e dissertações são gerenciadas exclusivamente. Entretanto, 26 respondentes informaram que também gerenciam teses e dissertações, ou seja, esse tipo de conteúdo é gerenciado com conteúdos de outra natureza. Nesses últimos casos, como é possível perceber, os conteúdos mais frequentes que acompanham as teses e dissertações são os artigos de 
periódicos científicos, trabalhos apresentados em conferências, livros e capítulos de livros, representantes legítimos da literatura científica.

Os dados reforçam a tendência de que repositórios institucionais incorporam as funções bibliotecas ou repositórios digitais de teses e dissertações na medida em que lidam também com esse tipo de conteúdo.

Gráfico 6: ETDs e outros tipos de conteúdos nos sistemas de informação

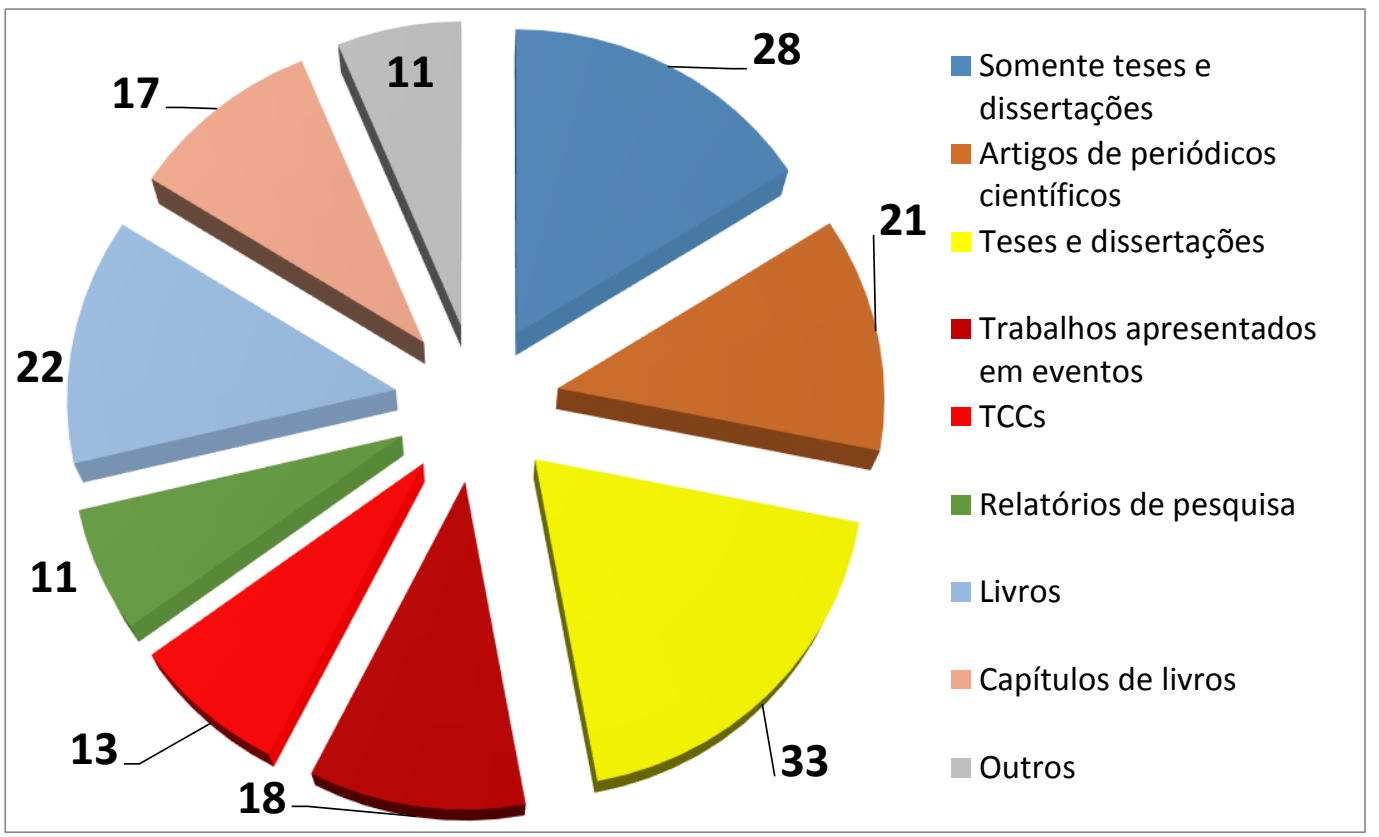

Fonte: Da autora, 2015.

Ao verificar os outros tipos de documentos citados pelos respondentes tem-se:

i. Documentos da Coleção da Verdade, referente a documentos do período da Ditadura Militar da (nome da universidade);

ii. $\quad$ Patentes, Programas da (nome da universidade) TV, Acervo fotográfico;

iii. Monografias de especialização;

iv. Vídeos;

v. Materiais educacionais;

vi. Documentos administrativos.

Quando os observados os sistemas que são utilizados para o gerenciamentos das demais produções científicas identificam-se os repositórios institucionais com maior 
expressão nesse contexto. Justifica-se o fato em virtude do apontamento aos artigos de periódicos científicos, juntamente com as teses e dissertações. Di Giusti (2013) confirma que, com base nos repositórios institucionais de acesso aberto em todo o mundo, teses e dissertações são documentos que mais estão inseridos nos repositórios, com 17,2\%, ficando atrá apenas dos artigos científicos, 21,8\%.

\subsubsection{Obtenção das ETDs nos sistemas de informação}

O processo de aquisição das teses e dissertações eletrônicas é entendido como a etapa que envolve as decisões relacionadas ao modo como as ETDs são incorporadas ao sistema. Nesse sentido, foram considerados aspectos relacionados como a adoção de autoarquivamento (ou depósito realizado pelos próprios autores), depósito mediado (realizado por bibliotecários ou outros), por coleta automática de ETDs pertencentes a em outros sistemas de informação. Esse processo inicial realizado pelo sistema de gestão de teses e dissertações foi contemplado na questão 14 do questionário, assim como no item 7 do roteiro de entrevistas.

O gráfico 7 apresenta as modalidades de obtenção de teses e dissertações mais frequentes nos sistemas investigados. Percebe-se a predominância do depósito mediado por bibliotecário que pode ser explicada pelo fato de que os sistemas de informação de ETDs são responsabilidades das bibliotecas universitárias, o que torna natural, portanto, que bibliotecários conduzam essa atividade.

Gráfico 7: Modalidade de depósito das ETDs no sistema

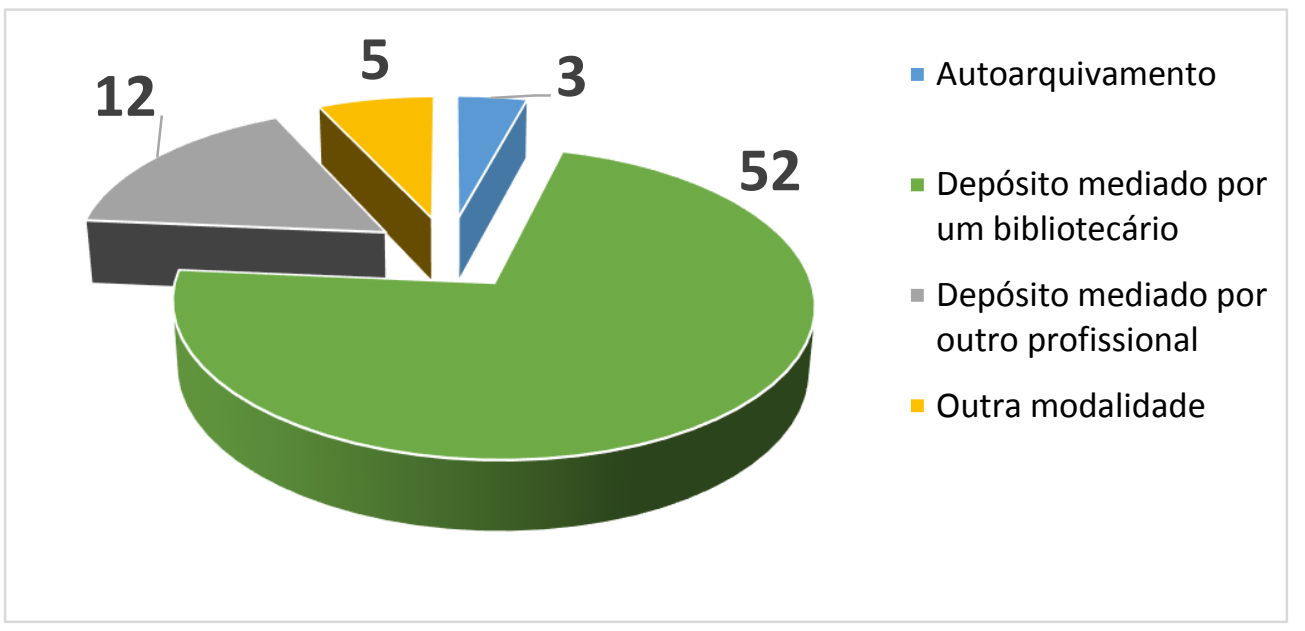

Fonte: Da autora, 2015. 
Essa questão também foi levada em consideração nas entrevistas realizadas com as universidades selecionadas. Segundo a percepção dos entrevistados sobre essa questão, o depósito mediado por bibliotecários consiste na principal estratégia de obtenção de teses e dissertações, conforme trechos a seguir:

os programas encontraram como saída a disponibilização em páginas web. Então, eles começaram a disponibilização das dissertações e teses nas páginas dos programas e a biblioteca ficava apenas com o armazenamento físico daquele material. Quando nós implantamos o repositório, lógico já depois das fases de teses e projeto-piloto, nós fizemos reuniões com esses programas de pós-graduação para que nós começássemos a cultura do depósito desse material na biblioteca, no repositório. Para isso definimos um documento institucional, que a gente chama aqui de Instrução Normativa, que saiu em 2011, e que objetiva então que o depósito das dissertações e teses é obrigatório no repositório da instituição. $O$ que nós adotamos como fluxo é que a partir da entrega desse material à biblioteca é que esse depósito não é feito nem pelo aluno, nem pelo programa, mas é feito direto pela biblioteca porque nós precisamos também institucionalmente de um documento que a biblioteca emita, um memorando de recebimento, para gerar o diploma (...) (UNIVERSIDADE 1).

O depósito é feito pela biblioteca, feita por bibliotecários, porque inicialmente, antes de existirem as teses e dissertações eletrônicas, as dissertações vinham no formato impresso, somente, e elas eram catalogadas no sistema de automação da biblioteca que era o Tesauro, hoje se usa o Pergamum. Elas ainda são catalogadas no Pergamum, no sistema de automação da biblioteca, para o aluno buscar no catálogo, assim como ele pesquisa os livros e, posteriormente, é feito o depósito na bdtd. Mas tudo é feito pelo bibliotecário. (UNIVERSIDADE 2)

Pela Biblioteca. (...). E nós estamos em dia, tudo que a gente recebe a gente coloca disponível. (UNIVERSIDADE 3)

(...) toda a entrada de dados é feita pela equipe de Biblioteconomia. Ninguém entra dados aqui, eu não autorizo o professor a colocar dados aqui no sistema porque o professor não conhece a informação e eu sou super chata. Então tudo é feito via (nome da pessoa) que é bibliotecária, por ela e toda a equipe dela. Ela que designa, distribui as responsabilidades, verifica etc (...) (UNIVERSIDADE 4)

(...) os programas [programas de pós-graduação] encaminham para a gente [biblioteca] as teses dissertação e nós que colocamos no sistema. (...) a gente tem uma bibliotecária aqui que faz só a parte de catalogação de teses e dissertações (UNIVERSIDADE 5)

Estudos similares sobre a gestão da produção científica de universidades também revelaram resultados semelhantes. Ubogu (2006) apontou que a maioria dos sistemas desenvolvidos nos países africanos são gerenciados pelas bibliotecas. Em concordância com Ubogu (2006), Al Salmi (2014) afirmou que as bibliotecas universitárias são usualmente responsáveis pela reunião e organização das teses e dissertações e torna-las acessíveis para a comunidade universitária e outras comunidades por meio dos serviços da biblioteca. 
Os respondentes do questionário puderam indicar outras modalidades de aquisição de teses e dissertações praticadas, explicitadas nas respostas a seguir. Ao todo, o questionário recebeu cinco respostas relacionadas ao aspecto. Quatro delas foram selecionadas para serem apresentadas.

A versão do software adotado na (nome da universidade) é o TEDE Modular e são atores: $O$ Secretário do Programa, o Autor e o Bibliotecário (UNIVERSIDADE 1)

O autoarquivamento está em processo de implementação, no entanto, sem uma data de início prevista (UNIVERSIDADE 2)

Depósito na Pró-reitoria de Pesquisa e Pós-Graduação (UNIVERSIDADE 3)

O depósito é feito pelo autor, através de conta gerada pelo Serviço de Pós-Graduação da unidade a qual o aluno está vinculado. Após a submissão, é respeitado um workflow de revisão (SPG) e catalogação (Bibliotecas) (UNIVERSIDADE 4)

Neste estudo, considerou-se que a aquisição de teses e dissertações também está relacionada com a existência ou não de normas que obriguem ou recomendem o depósito desse tipo de material. Esse aspecto foi abordado na coleta de dados por meio do questionário. Algumas respostas foram:

O que favorece é a exigência da CAPES, para que seja publicado. (UNIVERSIDADE 1)

O que favorece é o apoio da PPG - Pró-reitoria de Pós-graduação, Portaria CAPES, incentivos de produção para Pós-graduação. (UNIVERSIDADE 2)

Fatores externos que favorecem: Suporte e orientações do IBICT; Portaria no 013, de 15 de fevereiro de 2006 da CAPES. (UNIVERSIDADE 3)

Como já apresentado, no Brasil há estabelecida a Portaria no 13, de 2006, da Capes, que obriga o depósito das teses e dissertações em formato digital, na internet, a partir de 2006. No entanto, não é claramente definido em qual sistema de informação elas devem ser gerenciadas. Alguns respondentes consideraram que essa Portaria contribui para a aquisição das teses e dissertações. Considerando que esta Portaria foi emitida pela Capes, órgão responsável pela avaliação e credenciamento dos programas de pós-graduação no Brasil e que a maior iniciativa de gestão de teses e dissertações em nível nacional é responsabilidade do IBICT, um dos respondentes apontou para a 
necessidade de uma maior e melhor diálogo entre estas instituições para a definição de processos quanto à gestão das ETDs, especialmente no que se refere ao depósito desses materiais e geração de metadados. O não efetivo diálogo entre as duas instituições foi considerado um fator que dificulta o processo de gestão das ETDs, conforme ilustra a opinião do respondente.

Falta de integração entre os planos do governo. A CAPES possui uma plataforma SUCUPIRA ${ }^{31}$ onde funcionários da PROPG precisam cadastrar os metadados das teses e dissertações, e no final do processo a biblioteca faz o mesmo trabalho em outro sistema, com outro objetivo. $O$ Ibict e a CAPES poderiam conversar mais nesse sentido. (UNIVERSIDADE 4)

Além da Portaria da Capes, os respondentes dos questionários indicaram normas institucionais como instrumentos que favorecem o depósito das teses e dissertações eletrônicas em seus sistemas. As seguintes respostas chamam a atenção para essas normas:

Ato Administrativo da Pró-Reitoria de Pesquisa e Pós-Graduação (nosso mandato de entrega da dissertação e tese nos Repositórios); Revolução do Conselho de Ensino Pesquisa e Extensão que 5.525/2013 Regulamenta a política de informação do Repositório Institucional da (nome da universidade) Recomenda; Espaço físico e equipe exclusiva para trabalhar no Repositório Institucional. (UNIVERSIDADE 1)

Fatores favoráveis que contribuem para a cultura organizacional e favorecem o depósito das Teses e Dissertações da Universidade na BDTD e no RI/(nome da universidade): A Biblioteca Universitária é a gestora da BDTD + o software TEDE versão Modular (a responsabilidade é coletiva) + POLITICA DE INFORMAÇÃO DA (nome da universidade) - RESOLUÇÃO No 02/CONSUNI, DE 29 DE ABRIL DE 2011 + As "Normas Exigências para Obtenção do Título" da PróReitoria de Pesquisa e Pós-Graduação da Universidade. Soma-se ainda, a consciência de que este é um indicador de avaliação institucional e a responsabilidade social da Universidade. (UNIVERSIDADE 2)

A criação de uma resolução pela PRPG/(nome da universidade) que obriga o autor a entregar a versão digital da tese ou dissertação favorece o recebimento do arquivo digital. (UNIVERSIDADE 3)

No questionário aplicado foi contemplada uma questão específica sobre a existência de uma política formal que serve de estímulo para o depósito das teses e dissertações eletrônicas. Os dados indicaram que maior parte das instituições inquiridas (46) (Gráfico 8), afirmou possuir algum tipo de política formal. Esses dados confirmam a

\footnotetext{
${ }^{31}$ A Plataforma SUCUPIRA apresenta-se como uma tecnologia que visa a melhor gestão do Sistema Nacional de Pós-Graduação (SNPG), no Brasil.
} 
percepção de que normas que obriguem ou recomendem o depósito de teses e dissertações constituem fatores que estimulam a aquisição desse tipo de material. Ao investigar as motivações para a institucionalização do depósito por meio de políticas formais, as mais citadas foram: exigência da Capes, avaliação do MEC, deliberação da Reitoria e o regimento dos programas de pós-graduação da universidade.

Gráfico 8: Existência de política formal para estimular o depósito de ETDs

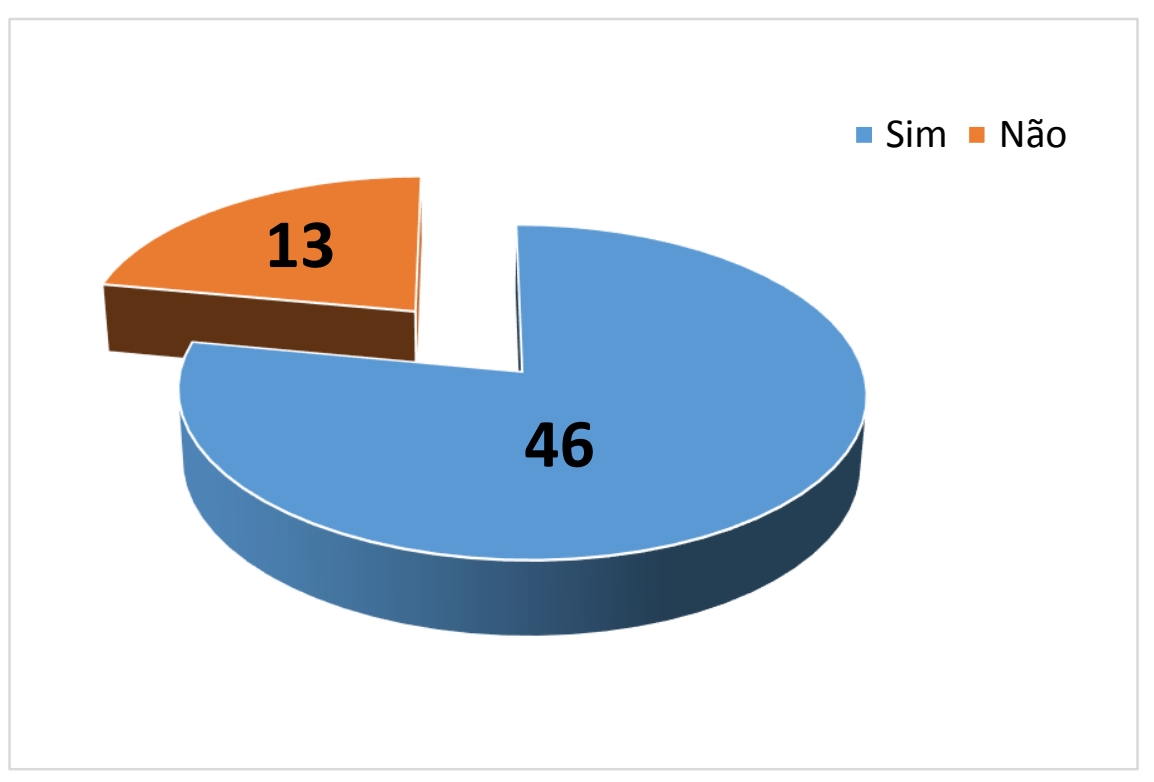

Fonte: Da autora, 2015.

Políticas formais de depósito foram apontadas por diversos autores como um fator que estimula o recrutamento da produção científica para sistemas de informação de acesso aberto. Benítez de Vendrell (2011) destaca que a implementação de repositórios institucionais deve se sustentar em políticas fortemente estabelecidas que contemplam e respeitam o direito de cada um dos autores. Suber (2010) e Harnad (2006) também identificaram que as políticas institucionais também influenciam positivamente o depósito em sistemas de informação de acesso aberto, uma vez que impulsionam o depósito nesses sistemas. Xia et al (2012) e Melero (2007) ressaltam que as políticas institucionais também tendem a assegurar o processo de autoarquivamento (ou depósito realizado pelos próprios autores) nos sistemas de acesso aberto contribuindo, assim, para o aumento de documentos nesses ambientes. Ainda, de acordo com o estudo de Xia et al (2012) o segundo maior grupo de políticas de mandato 
correspondem ao depósito de teses, o que colabora para o fato de que teses e dissertações são os documentos mais facilmente depositados em sistemas de informação de acesso aberto.

Ao serem questionados sobre o tipo de política estabelecida, 36 dos respondentes afirmaram serem políticas que obrigam o depósito. Uma política de caráter obrigatório deve exigir o depósito imediato do documento, salvo aquele com restrições referentes aos direitos autorais (HARNAD, 2006). Assim sendo, quando perguntado às universidades que tinham respondido SIM sobre a existência de uma política de depósito de teses e dissertações o caráter de suas políticas a grande maioria respondeu que é obrigatória.

Gráfico 9: Caráter da política de depósito de ETDs

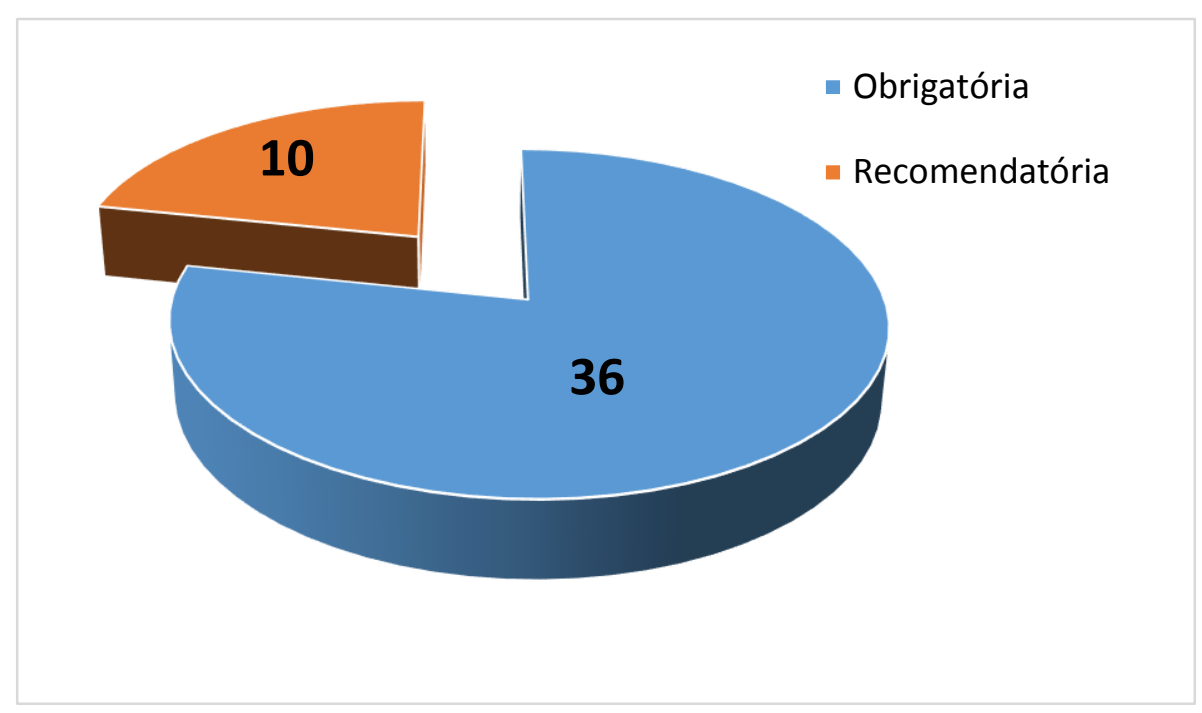

Fonte: Da autora, 2015.

Os resultados confirmam o ponto de vista ou descobertas de outros autores. De um modo geral, a literatura considera que quando o depósito é voluntário, as taxas de depósito são consideradas baixas ou menores que o desejado (FOSTER e GIBBONS, 2005; JONES e ANDRÉ, 2005; KIM, 2007; PIORUN et al, 2007; VENDA, 2006).

Ainda relacionado com a aquisição, outro aspecto relevante considerado no levantamento realizado é sobre o embargo das teses e dissertações. Os gestores foram questionados sobre a existência da possibilidade de embargo, além dos períodos permitidos. Conforme ilustrado no gráfico 10, 44 respondentes afirmaram existir a 
possibilidade do embargo. Daquelas instituições que permitem o embargo, aproximadamente $70 \%$ o fazem por um por um período de até dois anos.

Gráfico 10: Período de embargo para ETDs

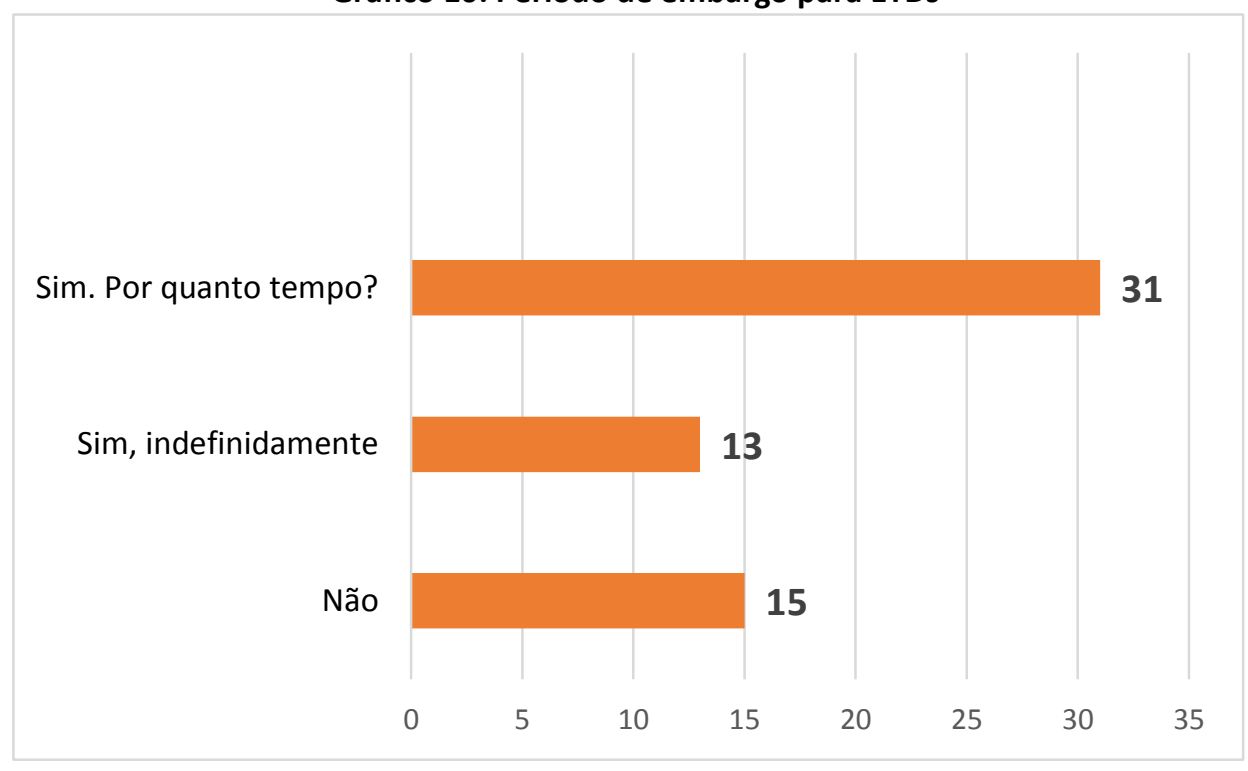

Fonte: Da autora, 2015.

Al Salmi (2014) chama a atenção para a necessidade do sistema de gestão de teses e dissertações lidar com essa questão. Segundo o autor, quando um aluno de pósgraduação hesitar em concordar com o depósito da sua tese ou dissertação em um sistema de informação, devem ser oferecidas opções para restrições de acesso por um período de tempo, o chamado período de embargo. Este recurso é utilizado, tanto no contexto das ETDs, quando as pesquisas tiverem gerado conhecimentos sensíveis ou patenteáveis, quanto a produção científica que está submetida às restrições decorrentes de direitos autorais.

Por meio da entrevista foi possível a identificação de um contexto relatado por uma universidade com relação ao período de embargo.

Mas o aluno tem opção, em deixa-la disponível ou não. Ele pode reter o conteúdo por dois anos, sendo prorrogável por igual período, mas após quatro anos essa dissertação pode ficar com o acesso full, o acesso completo em nossa bdtd. Até porque algumas dissertações acontecem muito no programa de biotecnologia, muita pesquisa inédita, direito também acontece bastante, às vezes aquela dissertação vai virar um livro, então esse material fica retido a pedido do aluno por até quatro anos. (UNIVERSIDADE 1). 
De modo que fosse possível compreender as condições em que teses e dissertações pudessem ser embargadas, os respondentes foram convidados a responder questão sobre os motivos que levam à decisão pelo embargo (Gráfico 11).

Gráfico 11: Motivos para embargos de ETDs

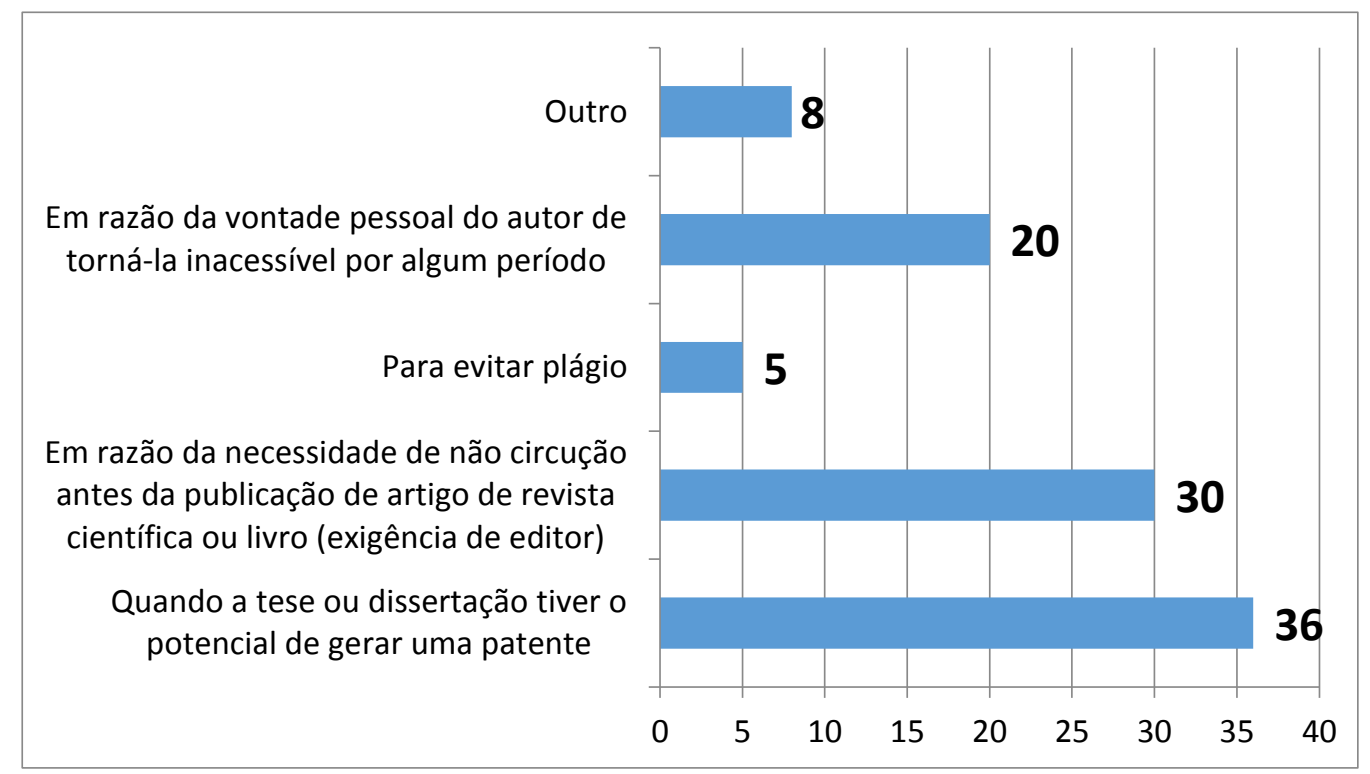

Fonte: Da autora, 2015.

Foram duas as principais motivações por trás da decisão pelo embargo. Em primeiro lugar, com $92 \%$ das respostas, a proteção do conhecimento gerado por meio de patente, o que requer que a tese ou dissertação não circule anteriormente. Em segundo lugar, quase tão importante quanto a primeira motivação, está a necessidade de impedir a distribuição dos resultados de pesquisa antes de sua publicação formal. Esta normalmente é uma exigência feita por editores de periódicos científicos.

Como discutido na revisão de literatura desta dissertação, o segundo motivo apontado para o embargo é uma preocupação que afeta autores e orientadores, uma vez que consideram que o acesso aos resultados da pesquisa nas teses ou dissertações interferirem na aceitação de artigos derivados desses documentos em periódicos científicos. No entanto, como visto, o resultado da pesquisa feita por Ramirez et al (2013) apontou que a maioria dos editores científicos entrevistados (45\%) consideram que essas submissões são aceitas.

Pekala (2015) apontou para diferentes razões para o embargo e o não-embargo. Entre os motivos pró-embargo estão: i. caso o documento contenha propriedade 
intelectual patenteável que o autor ainda não tenha recebido o certificado; ii. o documento tenha dados sensíveis; iii. caso um editor que tenha interesse em publicar o resultado da pesquisa como livro e por esta razão determina que só será feito caso o documento não esteja disponível online. No caso de não-embargo, Pekala (2015) ressalta que: i. uma dissertação mais acessível é mais facilmente citada; ii. ter a tese ou dissertação disponível ajuda o ensino de futuros acadêmicos. Desta forma, considera-se que o uso do embargo deve ser aplicado nos casos, principalmente, de possibilidade de patentes.

O último aspecto abordado que possui relação com a Obtenção, embora impacte todos os processos de gestão de teses e dissertações, é o da transformação de um dos requisitos para a obtenção de títulos de mestre ou doutor. Parece constituir tendência em algumas áreas do conhecimento que cursos de mestrado, e, especialmente, doutorado, passem a exigir a publicação de artigos científicos em periódicos bem avaliados em vez da produção de teses e dissertações. Conforme destacado a seguir, tanto por meio do questionário (questão aberta) quanto por meio das entrevistas, os respondentes puderam expressar sua opinião acerca dos impactos possíveis dessa transformação para os sistemas de gestão de teses e dissertações. Os dados revelam aspectos que sinalizam transformações no processo de comunicação de resultados de pesquisa por meio de teses e dissertações assim como necessidades de modificações nos sistemas de gestão.

Teríamos que inovar adequando o sistema às novas demandas, alterando se necessário, sua arquitetura (UNIVERSIDADE 1)

Teriam um novo propósito. Assim que o artigo fosse publicado, poderia ser inserido no RI com endereçamento para o periódico (UNIVERSIDADE 2)

A resposta dada pela Universidade 2 aponta para uma possível relação mais direta entre os repositórios institucionais e os sistemas de gestão de periódicos científicos online.

Essa tendência já está presente na Universidade em alquns Programas de Pós-graduação, entretanto, ficou deliberado pelas coordenações que o aluno submeterá o artigo para as revistas científicas e construirá uma versão do artigo para ser depositado na BDTD, em conformidade de uma dissertação e/ou tese (páginas pré-textuais + artigos) para ser depositado (UNIVERSIDADE 3) 
Basicamente nenhum impacto, pois, havendo possibilidade de inclusão da publicação, independente do formato, sistema continuaria a fornecer a informação que o usuário deseja (UNIVERSIDADE 4).

Reavaliação de metadados do sistema e das políticas de depósito (questões de direito autoral), alteração nos padrões de apresentação dos trabalhos.(UNIVERSIDADE 5)

Entendo que os impactos no sistema de gestão seriam principalmente de ordem política $e$ cultural e, em segundo plano, com menor intensidade, ficaram os impactos de ordem tecnológica. Os impactos de ordem política e cultural implicariam: (1) na necessidade de alcançar um equilibrio entre os programas de pós-graduação e a pró-reitoria de pós-graduação, de modo que as especificidades da comunicação científica de cada área possam ser respeitadas e, ao mesmo tempo, sejam estabelecidos procedimentos/normas mínimos aplicáveis a todos os programas da universidade; (2) na necessidade de capacitar os envolvidos nos fluxos de trabalho relacionados às teses e dissertações, o que inclui os funcionários das seções de pós-graduação, os bibliotecários, a Coordenadoria Geral de Bibliotecas e, obviamente, os próprios alunos; (3) na necessidade de regulamentar as decisões, as obrigações, os direitos e o novo fluxo de trabalho; e (4) na necessidade de discutir e conscientizar a todos os envolvidos sobre direitos autorais no âmbito das publicações científicas. Sobre os impactos tecnológicos, entendo que seriam poucos, pois o sistema utilizado no repositório institucional, para o qual as teses e dissertações estão sendo migradas, tem condições de armazenar, preservar, disponibilizar e disseminar tal material.(UNIVERSIDADE 6)

(...) isso é uma tendência que já começou a acontecer aqui. Alguns mestrados estão a adquirir esse formato. Não são muitos, dos programas que nós temos, eu creio que dois ou três estão com essa ideia, mas, assim, tendo um aluno ali, outro lá. $\underline{O}$ impacto inicial seria primeiramente a não-exclusividade do artigo. $O$ artigo pode ir para outro periódico, pode ir para mais dois ou três periódicos. Então acho que o impacto inicial seria a exclusividade. Aquele material produziu dentro da universidade e não vai ser um conteúdo exclusivo da universidade. Alguns professores estão relutando, alguns professores exigem que esse material pertença à universidade, que deve ser pesquisado aqui dentro, mas eu creio que o maior impacto seja a não-exclusividade daquele conteúdo. Mas o impacto mais positivo que eu acho seria a disseminação maior daquele conteúdo. Eu creio que outros periódicos que têm aquele foco como tema, como abordagem, acho que merecem ter esses conteúdos inéditos também divulgados (UNIVERSIDADE 7)

(...) isso é um problema (...) isso já foi discutido em reuniões da NDLTD. Um dos problemas são as co-autorias dos artigos. Porque pensa bem: eu estou fazendo um doutorado, estou trabalhando junto com aluno de mestrado e outro de iniciação científica. Eu coloco o nome deles lá. Em outro artigo seguinte, estou trabalhando com outro mestrando. Então isso tem uma discussão grande de como é que fica a atribuição de quem fez o quê. (...) outra coisa, os artigos entram com formatos diferentes (...) cada um submete o artigo para um periódico diferente. (UNIVERSIDADE 8)

\subsubsection{Organização das ETDs nos sistemas de informação}

De acordo com o modelo conceitual elaborado para a pesquisa, a organização da informação constitui um dos processos embutidos na gestão das teses e dissertações 
eletrônicas. Para efeitos dessa pesquisa, o processo de organização da informação diz respeito às definições e atividades que estão relacionadas com a representação tanto descritiva quanto temática das teses e dissertações, discutidas sob a ideia geral de geração de metadados.

O primeiro aspecto considerado na perspectiva da organização da informação foi o padrão de metadados adotado pelo sistema. Essa foi uma característica observada na totalidade dos sistemas por meio do checklist. Como o TEDE se apresenta em maior número como sistema para a gestão de teses e dissertações eletrônicas, também a maior parte dos sistemas adota o MTD2-BR (43), padrão de metadados desenvolvido e disseminado pelo IBICT. Em razão dos repositórios institucionais identificados o padrão internacional Dublin Core está presente nesses sistemas de modo qualificado, o que atende às necessidades e realidade das universidades brasileiras.

O segundo aspecto contemplado no levantamento sobre organização da informação foi a responsabilidade sobre a geração dos metadados. Essa questão evidencia a operacionalização da geração de metadados e também está relacionada com o processo de obtenção das teses e dissertações uma vez que, na modalidade do autoarquivamento, são os próprios autores, ou pessoas por ele designadas, que inserem os metadados.

Dados coletados por meio do questionário indicaram que na maioria dos casos (51 universidades respondentes) os metadados são gerados pelos próprios bibliotecários. Como discutido na revisão de literatura desta dissertação, as bibliotecas têm maior autonomia quanto ao gerenciamento das teses e dissertações. Isso significa que, no que se refere às teses e dissertações, a prática do autoarquivamento ain da não constitui uma realidade, assim como no contexto dos repositórios institucionais. 
Gráfico 12: Atribuição do preenchimento dos metadados às ETDs

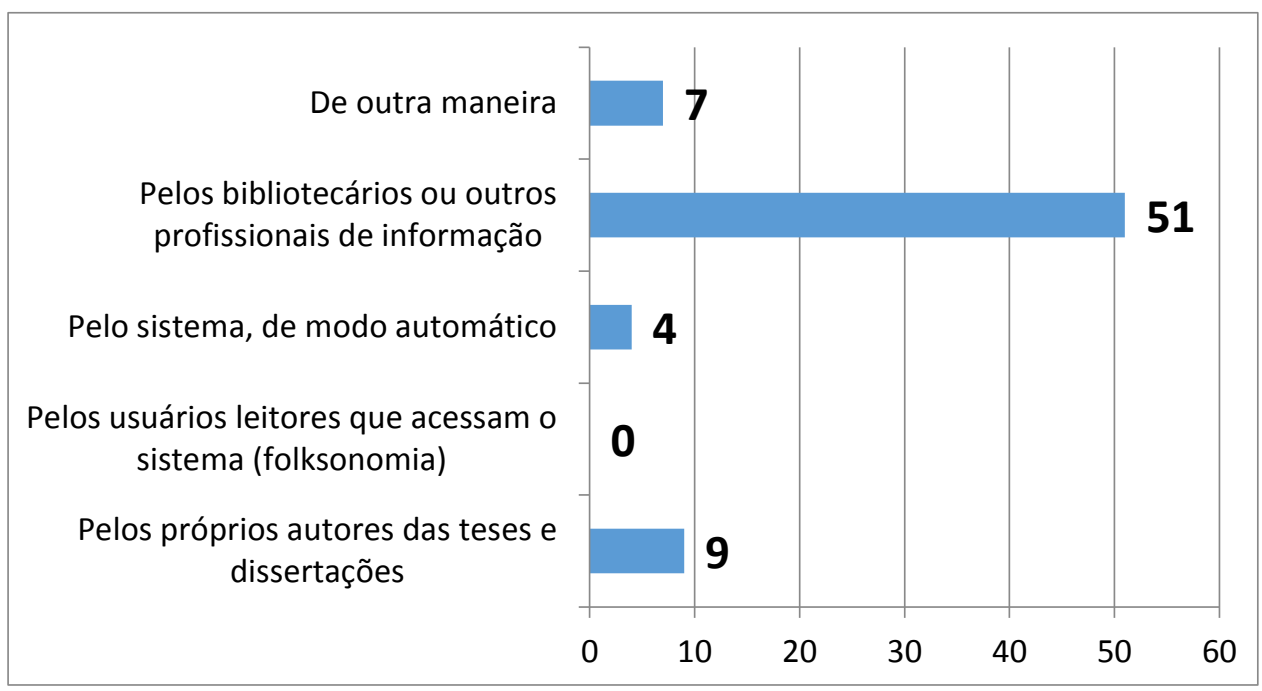

Fonte: Da autora, 2015.

A geração automática de metadados pelo próprio sistema foi uma alternativa de respostas escolhida por quatro respondentes. Essa modalidade de geração de metadados significa que o sistema pode ter um tipo de vocabulário controlado embutido no sistema. Considera-se que o uso desse mecanismo é positivo, uma vez que oferece maior padronização para a descrição dos documentos.

Ainda na perspectiva da geração de metadados, foi relevante considerar no levantamento se o sistema prevê a criação de metadados em outros idiomas. Esta é uma questão relacionada com a organização da informação, mas que incide diretamente na recuperação, e, sobretudo, na visibilidade das teses e dissertações. Isso porque a representação tanto descritiva quanto temática em outros idiomas, especialmente o inglês, aumenta consideravelmente a possibilidade dos recursos de informação serem encontrados. Portanto, quando questionados sobre a geração de metadados em outros idiomas, 45 respondentes afirmaram que sim, enquanto que 15 afirmaram que não. Resumo, título e palavras-chave foram os campos indicados como aqueles que recebem metadados em outros idiomas neste estudo com as universidades brasileiras. 
Gráfico 13: Preenchimento de metadados em outro idioma

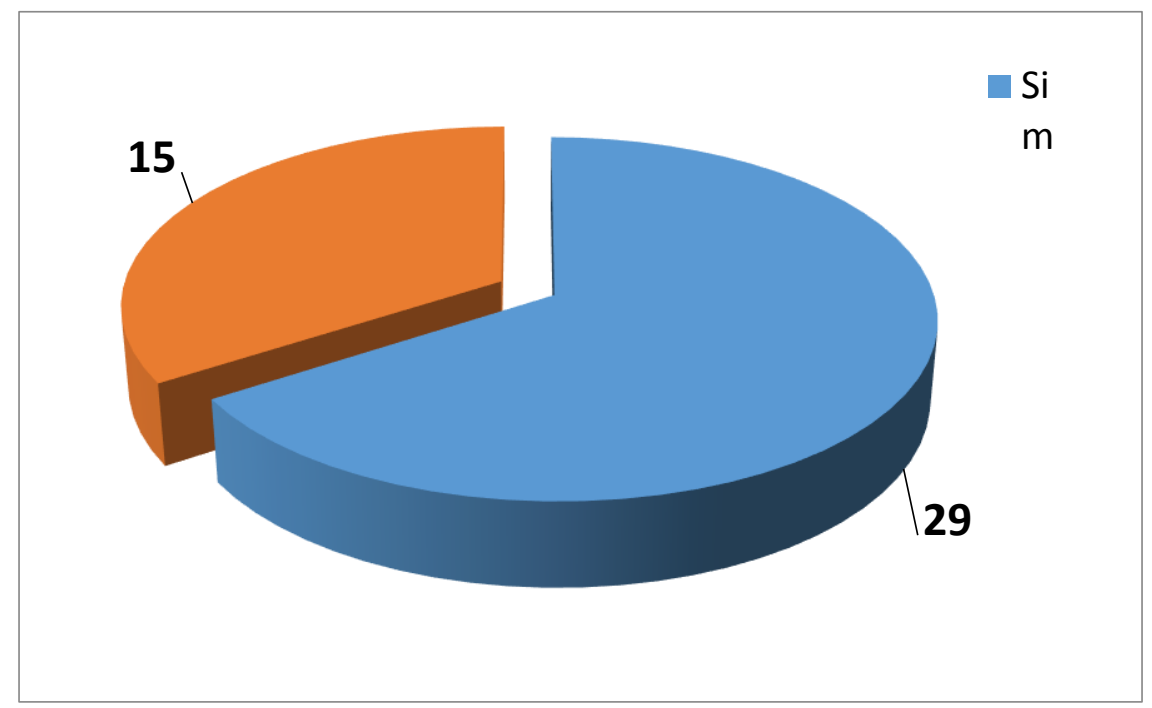

Fonte: Da autora, 2015.

\subsubsection{Preservação das ETDs nos sistemas de informação}

Com relação aos formatos, em sua grande maioria, senão todas, as universidades apresentam as suas ETDs em formato Portable Document Format (PDF). Tal formato é usualmente utilizado para geração de um arquivo eletrônico (AL SALMI, 2014; ALLARD, 2003). Segundo Sayão (2007), o PDF se notabilizou como um formato utilizado como padrão no que concerne às bibliotecas digitais.

De acordo com Santhanagopalan, Fox e McMillan (2006), a preservação digital tem por objetivo maior a preservação digital visando assegurar o acesso e reutilização no futuro do arquivo digital. O PDF como apresentado é considerado o formato padrão a ser usado nas teses e dissertações eletrônicas. Visto o seu largo uso no contexto da informação científica e também em outros cenários que envolvem objetos digitais, a empresa desenvolvedora do PDF viu a necessidade de atribuir mecanismo ao software objetivando oferecer a preservação digital a longo prazo. Dessa motivação surgiu o formato PDF/A-1 que deu origem ao formato de arquivo PDF/A que objetiva, portanto, a preservação dos documentos digitais por um período de tempo mais extenso.

Outro mecanismo adotado visando assegurar a integridade e acesso aos documentos digitais é o uso dos identificadores persistentes, como apontado por Sayão (2007). Nesse sentido, por meio do questionário foi perguntado às universidades sobre a adoção de um serviço de identificação persistente nos sistemas de informação. 
Gráfico 14: Uso de identificadores persistentes

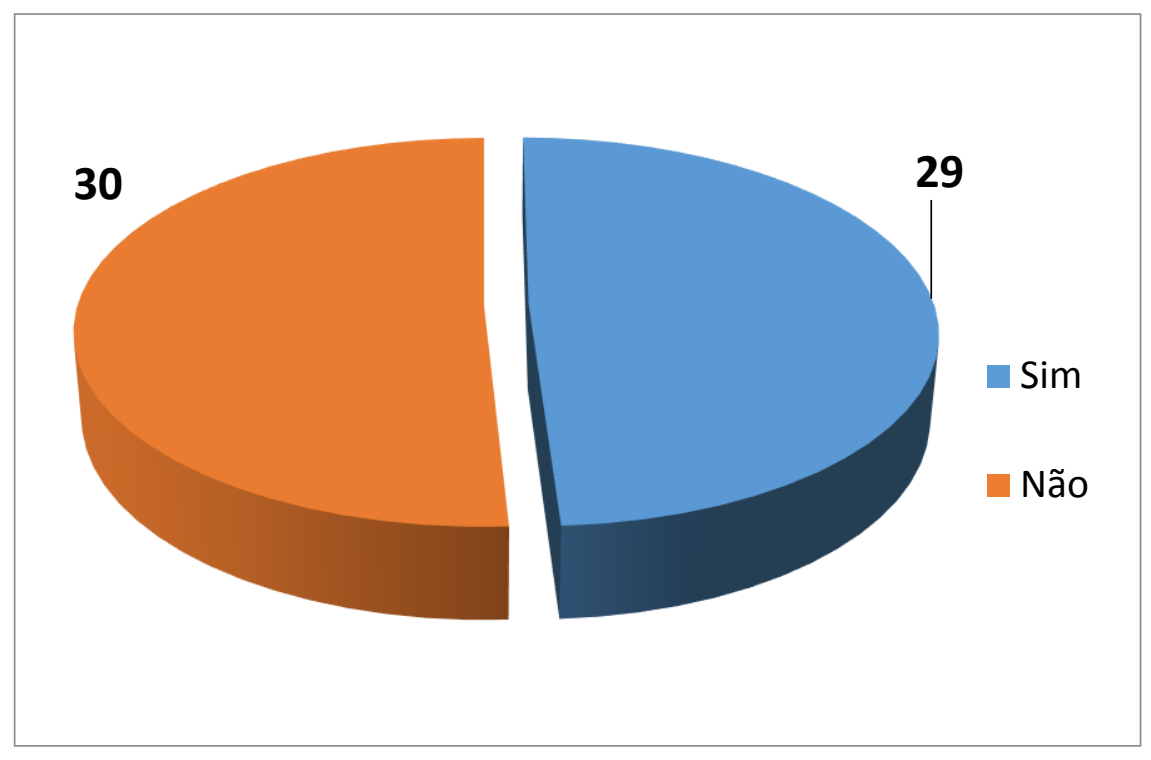

Fonte: Da autora, 2015.

Observa-se a diferença de apenas uma universidade entre as duas possibilidades de resposta: sim (29) e não (30). Ao analisar as respostas das universidades que afirmaram não utilizarem identificadores persistentes há a identificação de uma alta taxa de respondentes que desconheciam do assunto ou por utilizarem o TEDE não fazem do mecanismo.

Não sei informar. (UNIVERSIDADE 1)

Não sei responder (UNIVERSIDADE 2)

Não sei informar (UNIVERSIDADE 3)

Não tínhamos conhecimento do assunto (UNIVERSIDADE 4)

Desconheço. Utilizamos o software TEDE desenvolvido pelo Ibict ((UNIVERSIDADE 5)

Fazemos conforme TEDE (UNIVERSIDADE 6)

TEDE não dá suporte (UNIVERSIDADE 7)

Relacionado com o tema de preservação das teses e dissertações, Santhanagopalan, Fox e McMillan (2006) desenvolveram um estudo sobre o uso da 
ferramenta LOCKSS para a preservação de coleções de ETDs nos sistemas de informação por meio da aplicação de um plug-in.

\subsubsection{Recuperação das ETDs nos sistemas de informação}

De acordo com o modelo conceitual que norteou a realização desta pesquisa, a recuperação da informação significa ter acesso à informação desejada por meio de diferentes estratégias de busca (ARAÚJO JR., 2007; LOPES, 2002). Nesse sentido, as possibilidades de recuperação da informação são diretamente relacionadas com os processos e padrões adotados para a organização da informação. Foi possível caracterizar essa dimensão por meio da aplicação do checklist.

A primeira característica observada diz respeito aos mecanismos de busca à disposição dos usuários. Conforme a tabela 13, entre os 125 sistemas analisados, 87 apresentam possibilidade de busca simples e busca avançada. Essa característica está diretamente relacionada com o software adotado. Considerando que 80 dos sistemas adotaram os softwares, DSpace, TEDE, TEDE2 e catálogo web, o resultado não poderia ser diferente, pois, essas ferramentas dispõem dessa funcionalidade.

Os respondentes que afirmaram não possuir uma busca avançada em seus sistemas são exatamente aqueles cujas ferramentas são desenvolvidas na própria instituição ou são páginas em que as teses e dissertações estão listadas. Essas soluções não são apropriadas visto que, especialmente do ponto de vista da recuperação, não possibilitam que usuários consigam encontrar exatamente aquilo que necessitam mediante a correspondência de sua estratégia de busca e a descrição dos recursos de informação.

Tabela 12: Possibilidades de recuperação das ETDs nos sistemas identificados

\begin{tabular}{lcc}
\hline \multicolumn{1}{c}{ Tipo de sistema de informação } & Tipos de busca & $\begin{array}{c}\text { Refinamento dos } \\
\text { resultados da busca }\end{array}$ \\
\hline $\begin{array}{l}\text { Sistema de Publicação Eletrônica de Teses e } \\
\text { Dissertações (TEDE) }\end{array}$ & $\begin{array}{c}\text { Busca simples } \\
\text { Busca avançada }\end{array}$ & Não \\
$\begin{array}{l}\text { Página web de cada programa de pós- } \\
\text { graduação* }\end{array}$ & Busca simples & Não \\
Catálogo da Biblioteca & $\begin{array}{c}\text { Busca simples } \\
\text { Busca avançada }\end{array}$ & Sim \\
Software próprio & Busca simples & Não \\
\hline
\end{tabular}




\begin{tabular}{lcc}
\hline & Busca avançada & Sim \\
Sistema de Publicação Eletrônica de Teses e & Busca simples & \\
Dissertações atualizado (TEDE2) & Busca avançada & \\
& Busca facetada & \\
\hline
\end{tabular}

Fonte: Da autora, 2015.

Outra característica investigada nesta dimensão foram as possibilidades de "navegação" (browsing) oferecida aos usuários de modo que possam percorrer os recursos de informação. Nos sistemas de informação identificados por meio do checklist há possibilidade de navegação em todos por título, autor, assunto e ano. O processo de refinamento de busca está disponível em 35 sistemas de informação. Tal com a configuração dos mecanismos de busca, as possibilidades de navegação são decorrências dos metadados estabelecidos.

\subsubsection{Disseminação das ETDs}

A disseminação constitui uma importante dimensão dos sistemas de informação. No contexto dessa dissertação, a disseminação diz respeito ao conjunto de esforços para "tornar público a produção de conhecimentos gerados ou organizados por uma instituição", conforme afirmaram Lara e Conti (2003). Nesse sentido, engloba, portanto, às ações e serviços oferecidos pelo sistema de gestão de teses e dissertações aos seus usuários com a finalidade de maximizar tanto a entrega quanto à ampla difusão dos conteúdos. Assim, foram investigados: alertas, integração com redes sociais, estatísticas de acesso informadas aos usuários, integração por outros sistemas (indexação por buscadores).

Uma vez que a integração dos sistemas analisados com os principais buscadores (provedores de serviços) foi investigada, foi possível conhecer o quanto tais sistemas estão expostos aos sistemas de busca integrada. Essa integração é possível graças aos padrões de interoperabilidade estabelecidos para bibliotecas e repositórios digitais, como a adoção do Protocolo OAI-PMH e se torna indispensável no contexto do Acesso Aberto, pois permite que as informações armazenadas em um sistema possam compor outro sistema que por sua vez pode ser coletado por outro e assim por diante. Esses dados foram obtidos por meio do questionário. 
Quando questionados sobre quais buscadores coletam ou indexam o sistema de gestão de teses e dissertações de informação que gerencia ETDs na universidade, observa-se que a BDTD é a mais mencionada no universo das universidades brasileiras. No entanto, pode-se inferir duas conclusões a respeito deste dado. A primeira corresponde ao fato de que uma universidade que faz parte da BDTD já será, automaticamente coletada também pela NDLTD e o Portal Brasileiro de Acesso Aberto à Informação Científica (oasisbr), uma vez que a BDTD integra a essas duas iniciativas. A segunda é justamente o não conhecimento por parte das universidades da integração que o IBICT faz por meio da BDTD aos dois sistemas citados.

Gráfico 15: Sistemas coletadores

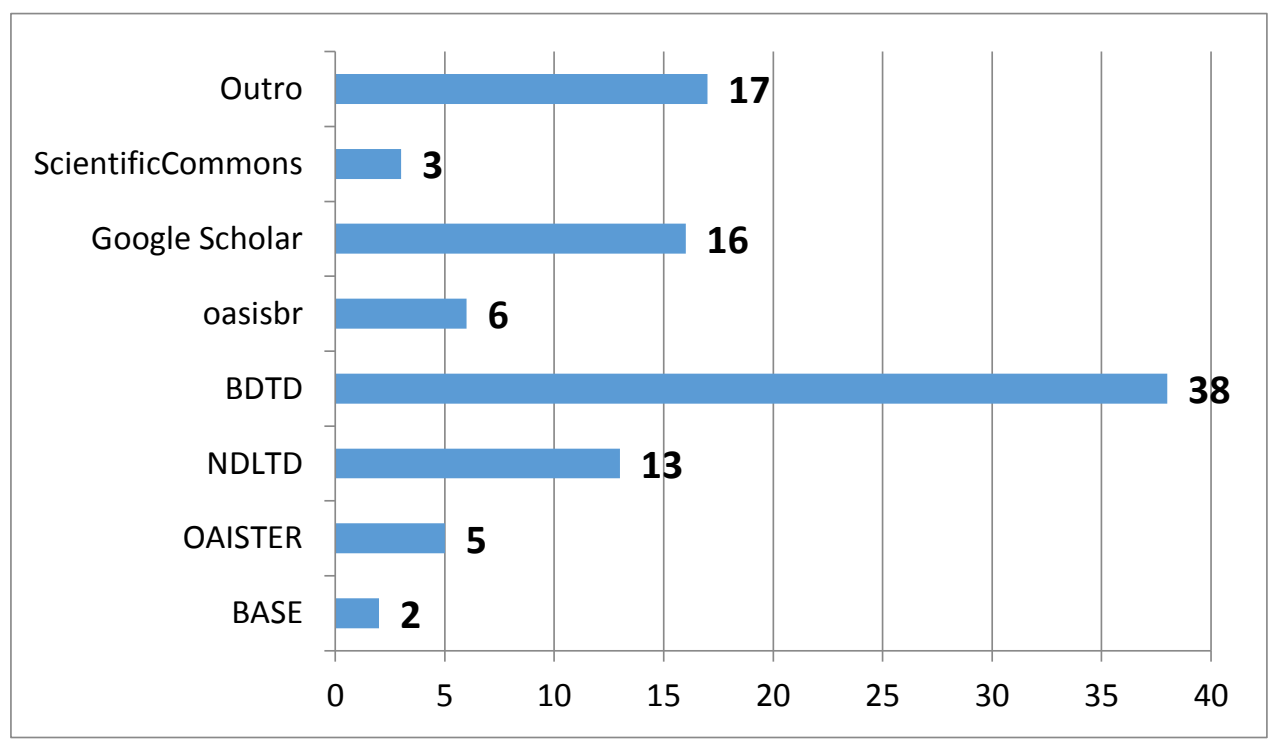

Fonte: Da autora, 2015.

\subsection{Universidades que não possuem gerenciamento de ETDs}

Assim como iniciada a discussão na seção anterior que corresponde às universidades que possuem gerenciamento de teses e dissertações eletrônicas, em um primeiro momento apresenta-se a caracterização das universidades que não possuem gerenciamento de teses e dissertações eletrônicas.

\subsubsection{Caracterização das universidades que não gerenciam ETDs}


Esta pesquisa identificou universidades brasileiras que não gerenciam suas teses e dissertações de modo digital. Estes documentos estão presentes catalogados na base dos catálogos das bibliotecas sendo disponibilizados de modo impresso e presentes fisicamente nas prateleiras das bibliotecas universitárias. Pereira e Lima (2011, p. 2.614) argumentam que apesar dos benefícios, a ideia ainda não foi aceita por "todas as instituições de ensino e superior do País. Mas a tendência é que, vendo os benefícios trazidos, as instituições venham a participar desse compartilhamento".

Por meio do checklist observou-se que há um equilíbrio entre as universidades privadas e públicas que não gerenciam teses e dissertações eletrônicas, sendo, respectivamente, 27 e 33 instituições.

Gráfico 16: Universidades que não possuem ETDs x Natureza da instituição

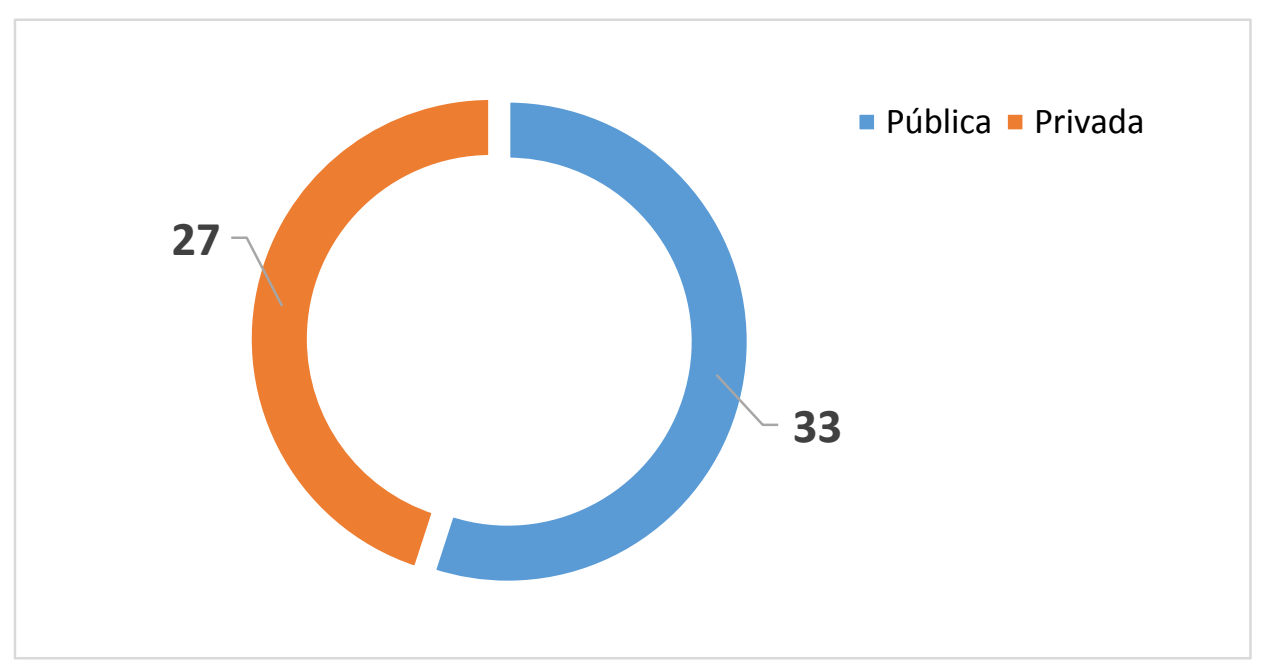

Fonte: Da autora, 2015.

\subsubsection{Identificação dos motivos para o não gerenciamento das ETDs}

A identificação dos motivos que levam às universidades não gerenciarem suas teses e dissertações em formato eletrônico é importante uma vez que dá margem para o entendimento das dificuldades que se apresentam no processo. Nesse sentido, os dados apresentados foram coletados por meio dos questionários. As opções de respostas nesse caso foram: 
(A) Em razão de dificuldades relacionadas com recursos humanos, tecnológicos, financeiros ou de outro tipo.

(B) Em razão de decisão institucional por considerar não ser necessário até o momento.

(C) Em razão de não conhecermos a finalidade desse tipo de sistema de informação.

(D) Em razão do fato de que as teses e dissertações já serem gerenciadas em formato impresso.

(E) Minha instituição possui um sistema de informação para gerenciar teses e dissertações. Qual?

Gráfico 17: Identificação dos motivos para o não gerenciamento das ETDs

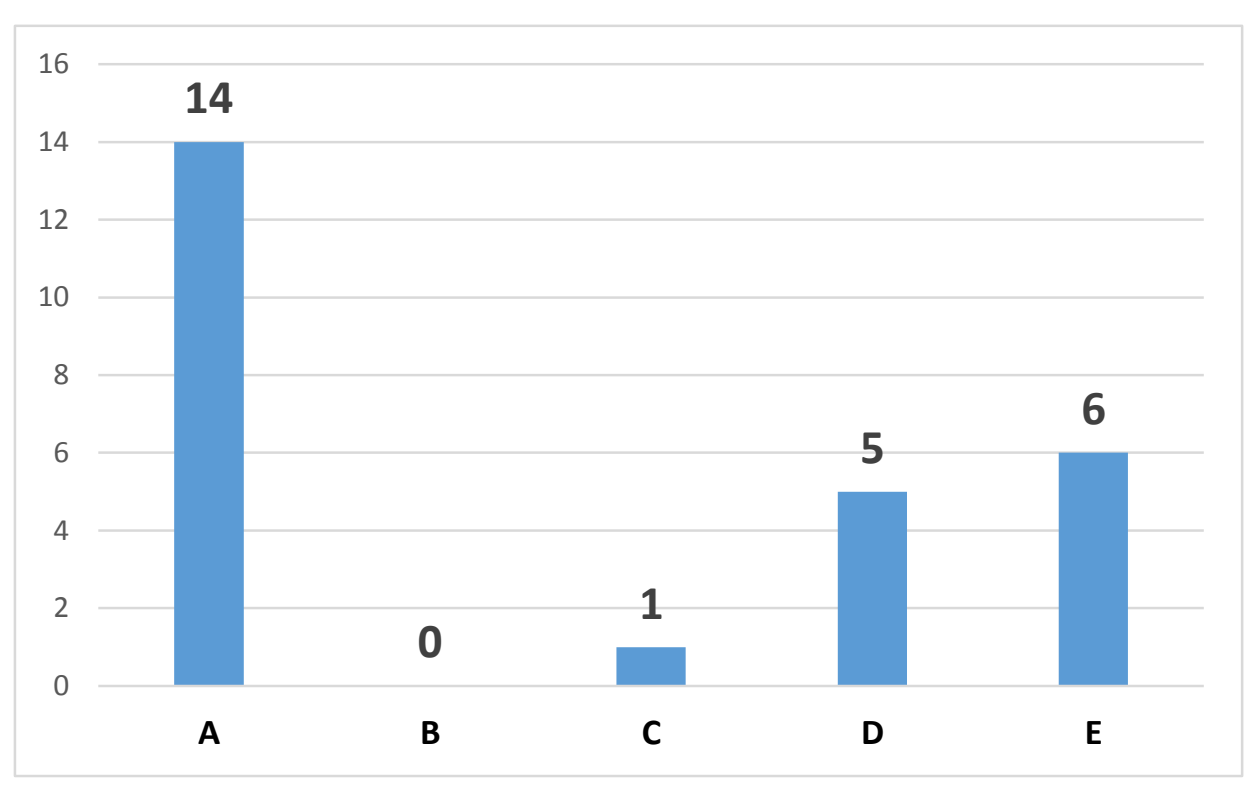

Fonte: Da autora, 2015.

Como observado no gráfico 18, o principal fator que impede a gestão das teses e dissertações eletrônicas na opinião dos respondentes de cada universidade está relacionado com os recursos humanos, tecnológicos, financeiros ou de outro tipo. Assim, como no contexto das universidades que possuem gerenciamento de teses e dissertações eletrônicas, os recursos humanos têm sido apontados mais uma vez como um elemento importante para a viabilização da gestão das teses e dissertações eletrônicas. 
Quando analisadas as entrevistas realizadas com universidades que não possuem a gestão de teses e dissertações eletrônicas, observa-se questões que até então não tinham sido consideradas na pesquisa, tal como o crescimento da própria universidade e a criação de novos programas de pós-graduação.

Ao longo dos anos, nós tivemos um setor de recursos muito voltado para a graduação, principalmente notadamente, às licenciaturas. No entanto, nos últimos anos a nova gestão da universidade vem inovando essa perspectiva de romper com aquela limitação da graduação $e$ da licenciatura. Nós estamos agora com um salto muito expressivo na pós-graduação e isso requer algumas soluções para que a nossa produção científica venha a ser divulgada. $O$ repositório, a sua dificuldade de criação, ela perpassa justamente as dificuldades que a universidade vem enfrentando no decorrer do ano pela a sua construção e o novo desafio que se apresenta em um momento em que se dá um salto enorme na pós-graduação, você tem que acompanhar as soluções de informação e a instituição tem que acompanhar esse passo largo que a instituição está dando. Então assim, no modo geral é isso. E do fato que nós termos novos cursos, novos programas a serem criados reivindica da gente essa dedicação especial. Aí é onde está o desafio e a perspectiva de crescimento (UNIVERSIDADE 1).

(...) nós somos uma universidade relativamente nova (...) e nós encontramos aqui pessoas que são muito resistentes às mudanças (UNIVERSIDADE 2).

Observa-se que essas questões exigem das universidades um maior amadurecimento e esforço para o desenvolvimento de um sistema de gestão das teses e dissertações relacionadas, no intuito de que anteriormente ao passo de implantação do sistema, os gestores dessas universidades devem ser capazes de criar e repassar o conhecimento sobre a cultura de gestão teses e dissertações eletrônicas.

Ao trazer para este tópico também as respostas apresentadas na questão aberta do questionário (item 7) relacionada com a identificação de fatores internos e externos que favorecem ou dificultam a gestão das teses e dissertações, destacam-se as respostas a seguir:

Ausência de profissionais bibliotecários para dividir mais de uma tarefa de extrema importância. (UNIVERSIDADE 1)

Falta de pessoal para este serviço (UNIVERSIDADE 2).

Não é o foco da reitoria e direção no atual momento (UNIVERSIDADE 3). 
Embora não tenha sido foco nesta pesquisa a percepção dos próprios autores quanto à disponibilização das teses e dissertações eletrônicas, tal questão foi apresentada em diversos estudos em todo o mundo (AL SALMI, 2014; VIJAYAKUMAR et al, 2007; SEAMANS, 2003). Observa-se que o ponto principal das discussões está relacionado com a percepção de que teses e dissertações podem ser consideradas primeiras publicações o que interferiria no aceite de artigos científicos derivados dessa pesquisa. No entanto, como discutido na revisão de literatura desta dissertação, a grande maioria dos editores científicos aceitam as submissões de artigos derivados das teses ou dissertações mesmo que estas estejam já em Acesso Aberto (RAMIREZ et al, 2013; SEAMANS, 2003). Assim, o estudo de Brown (2010) apresenta consolidadas as principais preocupações dos estudantes de pós-graduação.

Figura 24: Percepções dos estudantes quanto à disponibilização das ETDs

\section{Times cited}

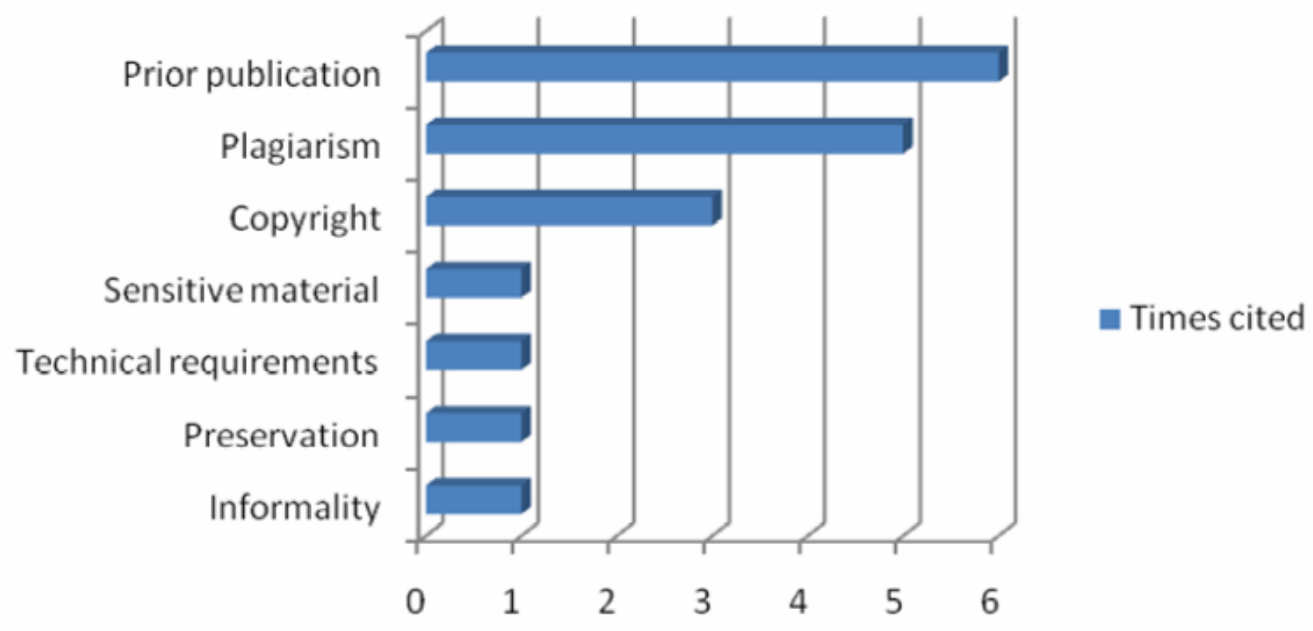

Fonte: Brown, 2010.

\subsubsection{Existência de experiência com a gestão de ETDs}

Embora não apresentem sistemas de gestão de teses e dissertações eletrônicas atualmente, oito universidades apontaram que já tiveram alguma experiência no passado com as teses e dissertações eletrônicas. No entanto, no período de aplicação desta pesquisa essas instituições não apresentaram em nenhum sistema de informação ou menção às teses e dissertações em formatos eletrônicos. 
Gráfico 18: Identificação de alguma experiência relacionada com ETDs

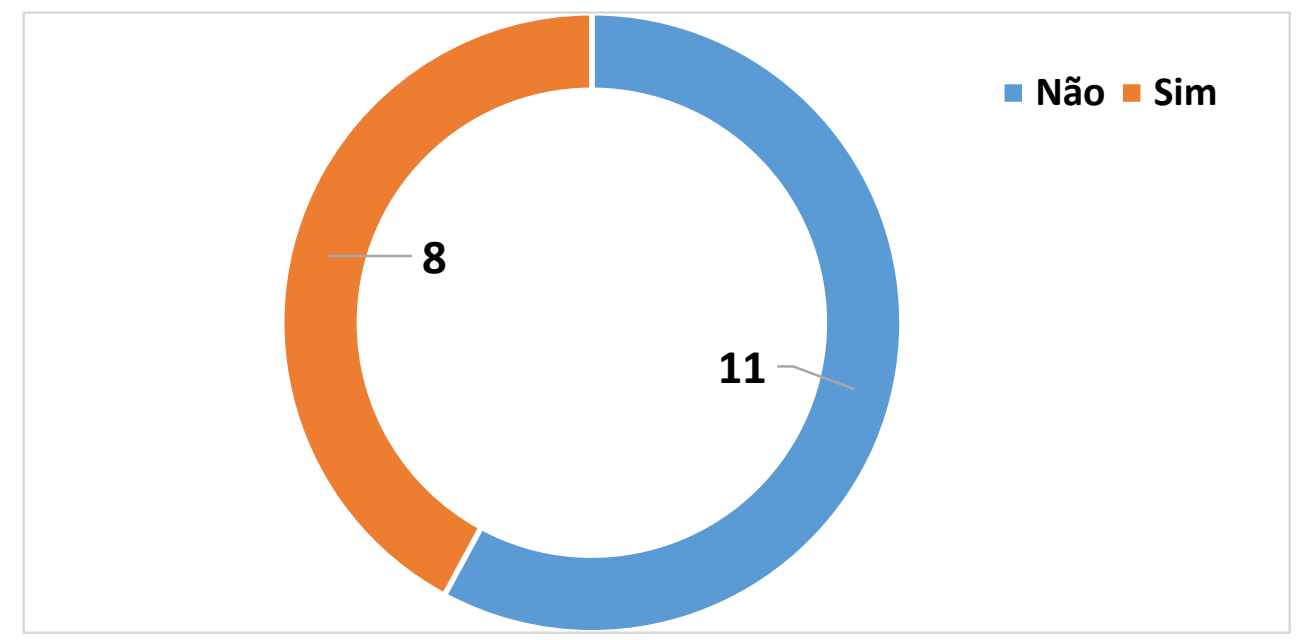

Fonte: Da autora, 2015.

Assim, como relatos das experiências foram apontados:

i. TEDE; (UNIVERSIDADE 1)

ii. No próprio sistema de materiais Gnuteca e uma biblioteca digital de Teses, e de monografias; (UNIVERSIDADE 2)

iii. Nossas teses e dissertações estão incluídas no Sistema Pergamum. Já tentamos inclui-las na BDTD IBICT, mas não obtivemos sucesso; (UNIVERSIDADE 3)

iv. Sistema próprio; (UNIVERSIDADE 4)

v. Software DSpace em um servidor de teste. (UNIVERSIDADE 5)

Entre as respostas observa-se a referência ao sistema desenvolvido pelo IBICT e repassado às institucionais de ensino e pesquisa que desejam gerenciar suas teses e dissertações eletrônicas, o TEDE. Segundo informações do IBICT (2014), o TEDE, desenvolvido no início do projeto da BDTD, em 2002, com o passar dos anos ficou defasado tecnologicamente, o que provocou impacto negativo quanto ao seu uso causando dificuldades de gestão pelas instituições. Ainda de acordo com o Instituto, tal fato ocasionou a impossibilidade de algumas instituições em continuar com o projeto de gestão das teses e dissertações eletrônicas e sua efetiva participação na Biblioteca Digital Brasileira de Teses e Dissertações (BDTD). 


\subsubsection{Sobre o sistema de informação mais apropriado para a gestão de ETDs}

Quando questionadas quanto, hipoteticamente, a escolha de um sistema de informação para a gestão de teses e dissertações eletrônicas na universidade, as instituições apontaram, em sua grande maioria, para a criação de um repositório institucional.

Gráfico 19: Escolha do sistema de informação para a gestão de ETDs

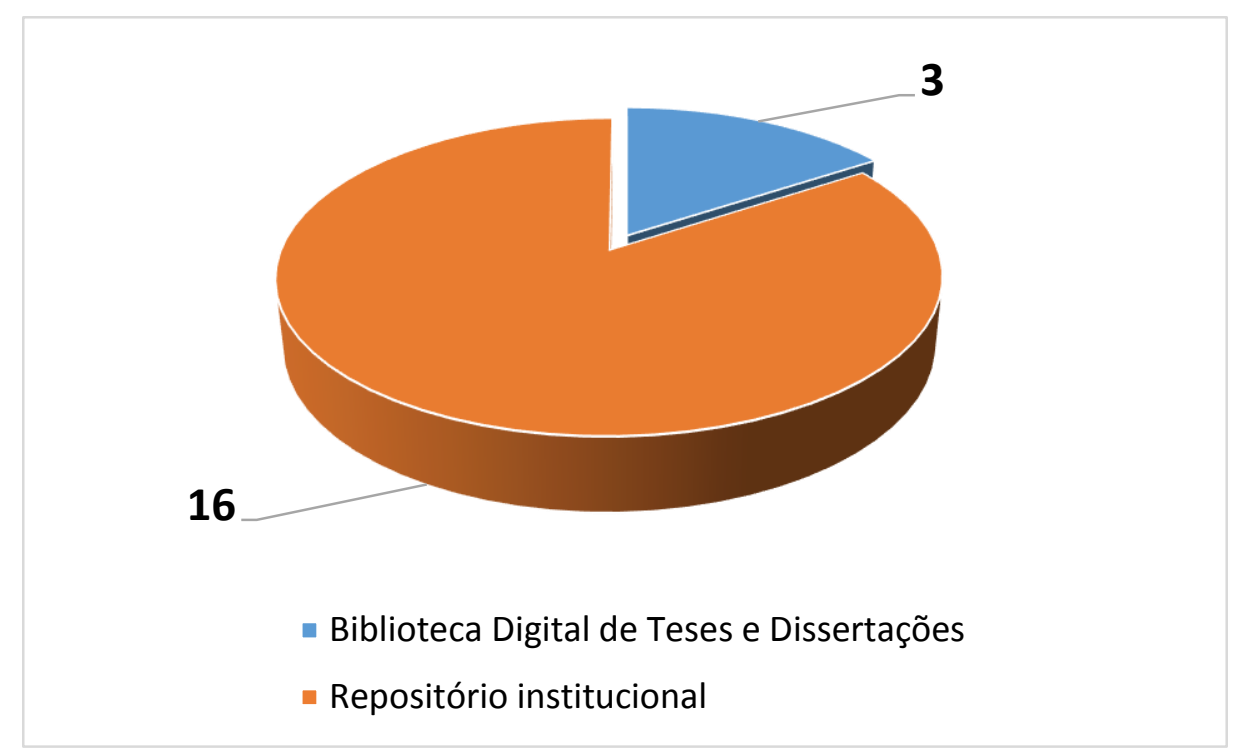

Fonte: Da autora, 2015.

No entanto, os relatos obtidos por meio das entrevistas realizadas apontaram ideias distintas para esse cenário.

Assim, nós queremos que esse repositório seja o ponto central, o ponto de encontro da nossa produção e não ter que dividir teses e dissertações para um lado, os artigos científicos, anais para o outro. Então o nosso objetivo é integrar tudo. (UNIVERSIDADE 1)

Como nós reconhecemos que estamos um pouco atrasados com relação à disponibilização das teses e dissertações em rede, nós optamos primeiramente em consolidar com a criação de uma biblioteca digital de teses e dissertações. Para isso nós escolhemos o software já pensando no futuro na formação do repositório da universidade (...) (UNIVERSIDADE 2)

Três conclusões podem ser inferidas diante das respostas expostas: i. teses e dissertações devem ser gerenciadas em conjunto com as demais produções científicas produzidas na universidade; ii. teses e dissertações são documentos mais fáceis de 
serem gerenciados e; iii. a gestão anterior de teses e dissertações em sistemas de informação de acesso aberto possibilidade o desenvolvimento de capacidade técnica e o desenvolvimento de um comportamento cultural na instituição para o compartilhamento dos reduzidos de pesquisa. Embora os relatos sejam distintos tem-se um ponto comum nas duas experiências: o desejo em tornar acessíveis os resultados de pesquisa materializados em teses e dissertações. Texier (2013), Castro, Ferreira e Andrade (2011) e Xia e Opperman (2010) corroboram ao afirmarem que esses sistemas de informação assumem papel fundamental na formação de futuros mestres e doutores, sendo que aproximadamente $50 \%$ dos documentos depositados pertencem a trabalhos estudantis, convertendo-os em atores principais no desenvolvimento de novos trabalhos disponíveis nos repositórios.

No questionário (questão aberta), quando indagadas pela decisão que levaram à escolha da resposta da questão anterior, buscou-se ter o levantamento desses motivos. Assim tem-se a relação de respostas.

Pela possibilidade de gerenciar toda a produção institucional (UNIVERSIDADE 1)

O compartilhamento da informação científica, tratamento e acondicionamento dos acervos digitais para melhor disseminação da informação aos usuários (UNIVERSIDADE 2)

Por entender que é mais diversificado (não limitando apenas para as Teses) e porque seria muito bom para os professores/pesquisadores poderem compartilhar seus estudos (UNIVERSIDADE 3).

Pelo aumento na produção de tais trabalhos em nossa Instituição. (UNIVERSIDADE 4)

Inicialmente para dissertações e teses, em seguida outros documentos científicos produzidos na instituição já que, como órgão público, estaríamos compromissados com a transparência e a disseminação de toda informação gerada e financiada pelo governo. (UNIVERSIDADE 5)

Porque amplia possibilidade de reunir todos os tipos publicação cientifica produzida pela instituição. (UNIVERSIDADE 6)

Porque já engloba um maior número de documentos. (UNIVERSIDADE 7)

Porque já possuímos um servidor e software instalado para esta finalidade. Não temos no momento uma pessoa que possa se dedicar a este serviço, em breve teremos. (UNIVERSIDADE 8)

Para disponibilizar todos os conteúdos em único ambiente para que fiquem amplamente acessiveis proporcionado maior visibilidade e impacto da produção científica da instituição. (UNIVERSIDADE 9) 
Por abranger mais tipo de materiais informacionais além de teses e dissertações. (UNIVERSIDADE 10)

Um repositório institucional tem uma abrangência de publicações maior já que temos consciência de que na universidade existem outros tipos de publicação para divulgação dos conhecimentos produzidos além das teses e dissertações. No primeiro momento estamos lutando para implementar o nosso repositório institucional de teses e dissertações na plataforma DSpace. Futuramente quando estivermos consolidados com o formato contemplado iremos expandir o repositório para outras mídias. (UNIVERSIDADE 11)

Considera-se que a partir dos relatos dos gestores nas universidades há a preocupação quanto à disponibilização dos resultados de pesquisa em Acesso Aberto.

\subsubsection{Apoio do IBICT}

Entendido que o IBICT é o órgão nacional responsável pelas orientações e disseminação das práticas a serem adotadas para a disponibilização em Acesso Aberto da produção científica institucional, a quinta pergunta do questionário tinha o intuito de identificar esse papel para as universidades. Assim, diante da pergunta "Caso sua instituição tenha interesse em criar um sistema de informação para gerenciar teses $e$ dissertações eletrônicas, seria útil receber suporte/orientação do IBICT (Instituto Brasileiro de Informação em Ciência e Tecnologia)?" as dezenove universidades entrevistadas responderam, de forma unânime, que sim. O resultado apresentado pelas universidades que não gerenciam teses e dissertações eletrônicas comprova, mais uma vez, que o IBICT desempenha papel fundamental quanto às orientações para a disponibilização desses documentos em Acesso Aberto.

Em outros países observa-se que institutos nacionais também têm promovido a disseminação de teses e dissertações eletrônicas. Sheeja e Cherukodan (2011) apontaram o projeto desenvolvido, na Índia, pelaa Coachin University of Science and Technology e Mahtma Gandhi University. Segundo os autores, essas instituições realizam workshops, orientações para adoção de software de código aberto para teses e dissertações eletrônicas e treinamentos de pessoal. Na China, Jin (2004) apontou que

a China Academic Library and Information System (CALIS) que é uma federação de bibliotecas acadêmicas chinesas com pouco mais de 150 membros desenvolveu ações 
que visam apoiar e atender às demandas da China Networked Digital Library of Theses and Dissertations (CNDLTD).

\subsection{Análise da opinião das universidades quanto às ETDs}

As duas últimas questões dos questionários aplicados às universidades que possuem gerenciamento de teses e dissertações eletrônicos se tornam importantes para o entendimento e importância que é dada a essas produções científicas.

Ao longo da construção da revisão de literatura deste estudo foram vistas as diversas definições e contextos que estão inseridas as teses e dissertações eletrônicas. A pergunta apresentada neste momento às universidades se relaciona com os materiais que são produzidos pelos programas de mestrados e doutorados que vão além de teses e dissertações - Além de teses e dissertações, mestrados e doutorados podem produzir como resultado de suas pesquisas materiais não textuais complementares associados, como, por exemplo, áudio, vídeo, simulações e imagens. Sobre a gestão desses materiais juntamente com as teses e dissertações, qual sua opinião a respeito das afirmações a seguir?

Schöpfel et al (2014) apresentaram um estudo que tinha por objetivo explorar os dados de pesquisa relacionados com as teses e dissertações eletrônicas, como uma parte específica emergente de pesquisa. De acordo com Borgman et al (2007), os dados de pesquisa têm se tornado um produto final importante que complementam o papel tradicional das publicações científicas.

Segundo Schöpfel et al (2014), uma pesquisa informal realizada entre 92 bibliotecas universitárias norte-americanas que exigem a entrega de ETDs, mostrou que aproximadamente $40 \%$ permitia o depósito de material suplementar. Entretanto, os autores chamam a atenção para o fato de que não existem modelo de padrão a ser seguido para a disseminação dos dados de pesquisa, o que dificulta o seu tratamento. Como um exemplo, os autores relatam uma possível situação: uma tese de 2012 contém dois anexos, um com questionários e seus dados brutos e outro com tabelas do resultado de pesquisa, mais de cinquenta páginas. A tese está disponível sem qualquer restrição no repositório. Os conjuntos de dados são gravados com um único 
identificador, mas como são parte do arquivo de texto em PDF, eles não podem ser reutilizados - estão abertos, mas não explorados (SCHÖPFEL et al, 2014).

Assim, considerando esse contexto de dados de pesquisa, foram apresentadas seis afirmações que a elas deveria ser atribuído um grau de concordância. Desta forma, os resultados se resumem na tabela (Tabela 13).

Tabela 13: Sobre materiais não textuais complementares às ETDs

\begin{tabular}{|c|c|c|c|}
\hline & Discordo & Não tenho opinião & Concordo \\
\hline $\begin{array}{l}\text { É algo necessário aos autores que } \\
\text { produzem esse tipo de material }\end{array}$ & 1 & 4 & 52 \\
\hline É algo necessário aos usuários & 4 & 7 & 46 \\
\hline $\begin{array}{l}\text { É uma iniciativa desejável, mas temos } \\
\text { dificuldades de ordem tecnológica, cultural, } \\
\text { organizacional ou de outro tipo para } \\
\text { implementá-la }\end{array}$ & 17 & 11 & 29 \\
\hline $\begin{array}{l}\text { É algo necessário para algumas áreas do } \\
\text { conhecimento e para outras não }\end{array}$ & 19 & 8 & 31 \\
\hline Depende do tipo de material & 16 & 7 & 35 \\
\hline $\begin{array}{l}\text { Dados de pesquisa de mestrado e } \\
\text { doutorado poderiam ser gerenciados } \\
\text { juntamente com suas teses e dissertações }\end{array}$ & 3 & 11 & 43 \\
\hline
\end{tabular}

Fonte: Da autora, 2015.

Por fim, a última questão do questionário mencionado diz respeito aos sistemas de informação institucionais e suas possíveis formas de gerenciamento. Assim, por meio da pergunta "Considerando que as afirmações a seguir dizem respeito aos sistemas de informação institucionais, qual a sua opinião a respeito das afirmações a seguir?". Embora esta questão tenha sido abordada em outros momentos do levantamento, por meio da atribuição de um grau para resposta pode ampliar o seu entendimento.

De acordo com Araújo (1995), os sistemas de informação, de um modo mais amplo, objetivam a realização do processo de comunicação. Aplicando o conceito para o tema tratado nesta pesquisa, a construção de sistemas de informação que gerenciam teses e dissertações viabilizam a comunicação desses documentos para a comunidade interna da universidade e para a comunidade científica de um modo geral. Nesse sentido foram apresentadas quatros questões que deveriam ser analisadas: 
i. É preferível gerenciar teses e dissertações em sistema de informação próprio, separadas de outros tipos de produção científica da instituição;

ii. É preferível gerenciar teses e dissertações juntamente com outros tipos de produção científica, tal como é possível em repositórios institucionais;

iii. Manter dois sistemas de informação em separado, uma biblioteca digital para teses e dissertações e um repositório institucional para os demais tipos de produção científica, é uma solução apropriada para uma instituição;

iv. Repositórios institucionais incorporaram ou podem incorporar as funções das bibliotecas digitais de teses e dissertações das instituições.

Tabela 14: Formas para o gerenciamento de ETDs

\begin{tabular}{|c|c|c|c|}
\hline & Discordo & Não tenho opinião & Concordo \\
\hline $\begin{array}{l}\text { É preferível gerenciar teses e } \\
\text { dissertações em sistema de informação } \\
\text { próprio, separadas de outros tipos de } \\
\text { produção científica da instituição }\end{array}$ & 41 & 5 & 11 \\
\hline $\begin{array}{l}\text { É preferível gerenciar teses e } \\
\text { dissertações juntamente com outros } \\
\text { tipos de produção científica, tal como é } \\
\text { possível em repositórios institucionais }\end{array}$ & 4 & 8 & 45 \\
\hline $\begin{array}{l}\text { Manter dois sistemas de informação em } \\
\text { separado, uma biblioteca digital para } \\
\text { teses e dissertações e um repositório } \\
\text { institucional para os demais tipos de } \\
\text { produção científica, é uma solução } \\
\text { apropriada para uma instituição }\end{array}$ & 38 & 5 & 14 \\
\hline $\begin{array}{l}\text { Repositórios institucionais incorporaram } \\
\text { ou podem incorporar as funções das } \\
\text { bibliotecas digitais de teses e } \\
\text { dissertações das instituições }\end{array}$ & 4 & 7 & 48 \\
\hline
\end{tabular}

Fonte: Da autora, 2015.

Os resultados apresentados confirmam os outros dados obtidos anteriormente e discutidos nas seções anteriores desta dissertação. No entanto, são muito importantes por apresentar as opiniões dos gestores nas universidades e que devem ser observados para a tomada de decisão das ações do IBICT quanto ao gerenciamento das teses e dissertações eletrônicas. 


\section{CAPÍTULO 5}

\section{CONCLUSÕES}

Esta pesquisa teve como objetivo central a identificação de características dos sistemas brasileiros de informação que gerenciam teses e dissertações eletrônicas no contexto do Acesso Aberto. Nesse sentido, para o alcance do objetivo maior proposto nesta pesquisa foram determinados também objetivos menores para que uma vez concluídos viabilizassem a concretização do objetivo principal. Foram estabelecidos, portanto, quatro objetivos específicos: 1. Mapear os sistemas de informação utilizados para a gestão das teses e dissertações eletrônicas no Brasil; 2. Identificar características e processos realizados pelos sistemas de informação utilizados para a gestão de teses e dissertações eletrônicas no Brasil; 3. Identificar, com base na percepção de gestores dos sistemas de informação de acesso aberto, fatores que influenciam a gestão de teses e dissertações eletrônicas; 4. Identificar características, com base na percepção dos gestores de informação, fatores que impedem a gestão de teses e dissertações eletrônicas. Nesta ordem, serão apresentadas as conclusões obtidas para cada objetivo específico proposto, e ao final, apresenta-se uma breve análise dos resultados conseguidos para a comprovação do alcance do objetivo geral.

\section{Mapeamento dos sistemas de informação utilizados para a gestão das teses e dissertações eletrônicas no Brasil}

O primeiro objetivo específico proposto para esta pesquisa correspondia o mapeamento dos sistemas de informação utilizados pelas universidades para o gerenciamento das suas teses e dissertações eletrônicas. Tal objetivo foi alcançado a partir da aplicação do checklist. Assim, os resultados obtidos possibilitaram o seguimento da pesquisa e a aplicação dos demais instrumentos de coleta de dados. Os principais pontos deste objetivo específicos são relacionados a seguir. 
- No total 125 universidades brasileiras, entre públicas e privadas, possuem teses e dissertações eletrônicas;

- A maior parte das universidades que possuem teses e dissertações eletrônicas são de natureza pública;

- A quantidade de teses e dissertações eletrônicas correspondem a aproximadamente $84 \%$ dos documentos científicos presentes nos sistemas de informação;

- Com relação aos sistemas de informação, estes se apresentam diversificados, no entanto, destacam-se as bibliotecas digitais de teses e dissertações que lidam exclusivamente com essa tipologia documental; os repositórios institucionais de acesso aberto; os catálogos de biblioteca e; as páginas web de programas de pós-graduação;

- Quando analisados os softwares utilizados para o desenvolvimento dos sistemas de informação, destacam-se: o Sistema de Publicação Eletrônica de Teses e Dissertações (TEDE), desenvolvido, mantido e distribuído pelo IBICT, o DSpace, software livre mais comumente utilizado para a criação de repositórios institucionais e os softwares para o gerenciamento de catálogo de biblioteca, como o Pergamum e o Sophia.

\section{Identificação das características e processos realizados pelos sistemas de informação utilizados para a gestão das teses e dissertações eletrônicas no Brasil}

O segundo objetivo específico parte-se dos sistemas de informação identificados no passo anterior. A ideia central era identificar as suas características e os processos que são realizados para a gestão das teses e dissertações eletrônicas. Assim, destaca-se:

- Definição dos macros processos envolvidos na gestão das bibliotecas digitais de teses e dissertações: aquisição; organização; disseminação; recuperação e; preservação;

- Número reduzido de pessoas envolvidas nas universidades com as atividades relacionadas com a gestão das ETDs (1 a 3 pessoas); 
- Principais dificuldades apontadas para a gestão das ETDs - falta de recurso humano e apoio dos profissionais das áreas de tecnologias de informação;

- As ETDs são depositadas pelos bibliotecários ou profissionais de informação na grande maioria dos sistemas de informação das universidades;

- A existência de uma política definida na universidade assegura o depósito das teses e dissertações eletrônicas no sistema de informação.

Identificação, com base na percepção dos gestores dos sistemas de informação, fatores que influenciam a gestão de teses e dissertações eletrônicas

O terceiro objetivo específico definido nesta pesquisa trata da identificação, a partir de dados coletados diretamente dos gestores dos sistemas de informação por meio dos questionários e entrevistas, de fatores que influenciam a gestão das teses e dissertações eletrônicas. O objetivo foi concluído na medida que os outros dados já tinham sido coletados (ou grande parte) e as entrevistas possibilitaram o aprofundamento e melhor entendimento de algumas questões abordadas na pesquisa. Nesse sentido, considera-se que as entrevistas foram importantes mecanismos para a descrição mais próxima da realidade encontrada nas universidades brasileiras, sejam elas públicas ou privadas. Desta forma, destaca-se deste objetivo específico que:

- O apoio e orientações do Instituto Brasileiro de Informação em Ciência e Tecnologia (IBICT) é um fator que influencia diretamente para a gestão das teses e dissertações eletrônicas nas universidades brasileiras;

- Por meio dos questionários observou-se que: 18 universidades usam somente os repositórios institucionais para a gestão das ETDs, 14 usam as bibliotecas digitais de teses e dissertações e 17 universidades utilizam os dois tipos sistemas separadamente.

Identificação, com base na percepção dos gestores dos sistemas de informação, fatores que impedem a gestão de teses e dissertações eletrônicas 
O quarto e último objetivo específico foi alcançado, uma vez que foi observado que o fator apontado como maior impeditivo para a gestão de teses e dissertações eletrônicas nas universidades brasileiras é a falta de recursos humanos das próprias instituições.

\section{Contribuições da pesquisa}

Considera-se que o estudo realizado para a concretização desta dissertação apresenta contribuições para as discussões relacionadas com a gestão das teses e dissertações eletrônicas no Brasil. Embora circunscrita a este País, a metodologia adotada neste estudo pode ser reaplicada para o conhecimento da gestão das teses e dissertações eletrônicas em diversos outros contextos. Ainda, o estudo pode oferecer insumos para a Biblioteca Digital Brasileira de Teses e Dissertações (BDTD), coordenada pelo IBICT, na definição de novas ações ou revisões das estratégias já adotadas.

\section{Apontamentos para novos estudos}

A pesquisa sobre a gestão de teses e dissertações eletrônicas nas universidades brasileiras aponta para alguns campos passíveis de estudo e que assim possam também contribuir para a discussão dessa temática no País. Assim, sugerem-se os temas para estudos futuros:

- Identificar com base nos autores de teses e dissertações, ou seja, os alunos de pós-graduação, a conscientização quanto à importância e aplicações da disseminação de seus resultados de pesquisa de modo amplo em sistemas de informação de acesso aberto;

- Identificar com base nos editores científicos brasileiros se há implicações diretas ao processo de submissão de artigos científicos derivados de teses e dissertações;

- Analisar o impacto do uso de teses e dissertações eletrônicas para a geração de outras produções científicas no contexto brasileiro. 


\section{REFERÊNCIAS}

ABADAL, Ernest. Acceso abierto a la ciencia. Barcelona: Editorial UOC, 2012. Coleção EI profesional de la información. Disponível em: <http://eprints.rclis.org/16863/1/2012-accesoabierto-epi-uoc-vfinal-autor.pdf>. Acesso em: jun. 2013.

AGUIAR, A. C. A. Informação e atividades de desenvolvimento científico, tecnológico e industrial: tipologia proposta com base em análise funcional. Ciência da Informação, v. 20, n. 1, 1991. p. 7-17.

AL SALMI, Jamal Mattar Yousuf. Electronic theses and dissertations programmes in the Arab Gulf States: exploring factors affecting their adoption and development. 2014. $316 \mathrm{f}$. Tese (Doctor of Philosophy in Information Systems - Victoria University of Wellington), Wellington, 2014. Disponível em: <http://hdl.handle.net/10063/3319>. Acesso em: jun. 2014.

ALBERANI, Vilma; DE CASTRO, Paola. Grey Literature from the York Seminar (UK) of 1978 to the year 2000. INSPEL, v. 35, 2000, p. 236-247.

ALEMNEH, Daniel et al. Guindance Documents for Lifecycle Management of ETDs. Atlanta: Educopia Institute, 2014.

ALLARD, Suzanne L. Innovation in a university social system: the adoption of electronic theses and dissertations digital libraries. 2003. $188 \mathrm{f}$. Tese (Doctor of Philosophy in the College of Communications and Information Studies - University of Kentucky), Kentucky, 2003.

Disponível em: <http://uknowledge.uky.edu/gradschool_diss/316/>. Acesso em: jul. 2012.

ALMEIDA, Maria do Rosário Guimarães. Literatura cinzenta: teoria e prática. São Luís: UFMA, 2000. 173 p.

ALVAREZ ARAGÓN, Virgilio. Situação e desafios da pós-graduação na América Latina. Cad. Pesq., n. 105, p. 11-51, 1998. Disponível em:

<http://www.fcc.org.br/pesquisa/publicacoes/cp/arquivos/169.pdf>. Acesso em: set. 2013.

ÁLVAREZ-OSSORIO, J. R. P. Introducción a la información y documentación científica. Madri: Editorial Alhambra, 1988.

ANDREWS, Gavin. Checklist. In: GIVEN, L. M. The SAGE Encyclopedia of Qualitative Research Methods. SAGE Publications, 2008. p.78-79.

ARAUJO, Vania Maria Rodrigues Hermes de. Sistema de informação: nova abordagem teóricoconceitual. Ciência da Informação, v. 24, n. 1, 1995. Disponível em:

<http://revista.ibict.br/ciinf/index.php/ciinf/article/view/532/484>. Acesso em: 2014.

ARTUS, H. M. A. Grey Literature and the author/respondant relantioship. In: INTERNACIONAL CONFERENCE ON GREY LITERATURE, 1., 1993. Proceedings... Amsterdã: TransAtlantic, 1994.

ASSIS, Tainá Batista de. Biblioteca Digital Brasileira de Teses e Dissertações (BDTD): um panorama geral de 2002 a 2013. Brasília: IBICT, 2013. (Relatório técnico). 
BABBIE, Earl. Métodos de pesquisa de survey. Belo Horizonte: UFMG, 2003.

. The basics of social research. 4.ed. Estados Unidos: Thomson Wadsworth, 2008.

BABINI, Dominique. Acceso abierto a la producción científica de América Latina y el Caribe: identificación de principales instituciones para estrategias de integración regional. Revista Iberoamericana de Ciencia, Tecnología y Sociedade CTS, v. 6, n. 17, 2011. Disponível em: <http://papers.ssrn.com/sol3/papers.cfm?abstract_id=1821582>. Acesso em: 2013.

BANDRA, S. Digitization of theses: Possible international collaboration-a discussion paper. 2002. Disponível em:

<http://dspace.mona.uwi.edu/bitstream/123456789/349/1/Digitization\%20of\%20Theses.brief .pdf>.

BAPTISTA, Ana Alice. A falar nos entendemos: a interoperabilidade entre repositórios digitais. In: GOMES, Maria João; ROSA, Flávia (Orgs.). Repositórios institucionais: democratizando o acesso ao conhecimento. Salvador: EDUFBA, 2010. p. 71-90. Disponível em:

<http://repositorium.sdum.uminho.pt/handle/1822/11517>. Acesso em: 2012.

BARDIN, L. Análise de conteúdo. Lisboa: Edições 70, 2006.

BARRETO, Aldo. Uma quase história da Ciência da Informação. DataGramaZero, v. 9, n. 2, 2008. Disponível em: <http://eprints.rclis.org/17637/>. Acesso em: 2013.

BATOMÉ, Sílvio Paulo; KUBO, Olga Mitsue. Responsabilidade social dos programas de PósGraduação e formação de novos cientistas e professors de nível superior. Interação em Psicologia, v. 6, n. 1, p. 81-110, 2002. Disponível em: <www.isac.psc.br/wpcontent/uploads/formacao/Botome,_Kubo_(2002)>. Acesso em: jan. 2013.

BELL, J. Doing your research project: a guide for first-time researchers in education and social science. 3. ed. Buckingham: Open University Press, 1999.

BENÍTREZ DE VENDRELL, Belarmina. Repositorios de tesis: capacidad del Sistema académico NEA para la generación de depósitos digitales de acceso libre. In: JORNADAS VIRTUALES IBEROAMERICANAS DE CIENCIAS DE LA INFORMACIÓN Y LA DOCUMENTACIÓN. 2011.

BERAZA GARMENDIA, José María; RODRÍGUEZ CASTELLANOS, Arturo. La evolución de la misión de la universidad. Revista de Dirección y Administración de Empresas, n. 14, 2007, p. 25-56.

BERENDT, B.; BRENSTEIN, E.; LI, Y.; WENDLAND, B. Marketing for participation: how can electronic dissertation services win authors? Proceedings... 2002. Disponível em:

<http://edoc.huberlin.de/etd2003/berendt-bettina>. Acesso em: 2012.

BEST, David P. The future of information management. Records Management Journal, v. 2, n. 2, p. 50-60, 1990. Disponível em:

<http://www.sciencedirect.com/science/article/pii/0268401288900047>. Acesso em: 17 jul. 2014.

BHAT, Mohd Iqbal; MUDHOL, Mahesh V. Importance of electronic theses and dissertations (ETDs) on Internet: a survey of Indian ETD Repository Shodganga. International Journal of Library and Information Studies, v. 4, n. 2, 2014. 
BJÖRK, Bo-Christer. A model of scientific communication of a global distributed information system. Proceedings... 2007. Disponível em:

<http://docs.lib.purdue.edu/iatul/2007/papers/3>. Acesso em: 2013.

BLATTMAN, U.; SANTOS, R. N. M. dos. Acesso e uso de tecnologias em teses e dissertações: o caso BDTD. 2009.

BOAI. Budapest Open Access Initiative. Budapeste. Disponível em:

<http://www.opensocietyfoundations.org/openaccess/read>. Acesso em: mar. 2014.

BORGMAN, Christine L. Scholarship in the Digital Age: information, infrastructure and the Internet. London: MIT Press, 2007. 363 p. Disponível em: <http://books.google.com.br/>. Acesso em: 2014.

BORKO, H. Information Science: what is it? American Documentation, v. 19, n. 1, p. 3-5. Jan. 1968. Disponível em: <DOI: 10.1002/asi.5090190103>. Acesso em: nov. 2012.

BOYER, Calvin James. The doctor of Philosophy dissertation: an analysis of the Doctoral dissertation as an Information source. 1972. 123 f. Tese (Doctor of Philosophy - University of Texas at Austin), Texas, 1972.

BRASIL. CNPq. Conselho Nacional de Desenvolvimento Científico Tecnológico. Indicadores de pesquisa. 2014. Disponível em: <www.cnpq.br/web/guest/indicadores1>. Acesso em: 2014.

CAPES. Coordenação de Aperfeiçoamento de Pessoal de Nível Superior. Disponível em: <http//www.capes.gov.br/>. Acesso em: 2014.

. IBICT. Instituto Brasileiro de Informação em Ciência e Tecnologia. Biblioteca Digital Brasileira de Teses e Dissertações (BDTD). In: SEMINÁRIO NACIONAL DE BIBLIOTECAS UNIVERSITÁRIAS (SNBU), 18., Belo Horizonte, 2014. (Apresentação em slide).

IBICT. Biblioteca Digital Brasileira de Teses e Dissertações (BDTD): revisão, atualização e modernização. Brasília, 2014. (Apresentação em slide).

. INEP. Instituto Nacional de Estudos e Pesquisas Educacionais Anísio Teixeira. Censo da Educação Superior. Disponível em: <http://portal.inep.gov.br/web/censo-da-educacaosuperior>. Acesso em: 2014.

. Lei no 9.394, de 20 de dezembro de 1996. Disponível em:

<http://www.planalto.gov.br/ccivil_03/leis/19394.htm>. Acesso em: 2014.

. Lei no 11.892, de 29 de dezembro de 2008.

. Ministério da Educação. 2015. Disponível em: <http://mec.gov.br>.

Portaria no 13, de 15 de fevereiro de 2006. Disponível em:

<https://www.capes.gov.br/images/stories/>. Acesso em: 2012.

BROWN, Josh. Literature review of research into attitudes towards electronic theses and dissertations (ETDs). 2010. Disponível em: <discovery.ucl.ac.uk>. Acesso em: set. 2014. 
BRUGNOLLO FILHO, Cláudio et al. Literatura cinzenta: teses. Eventos. Relatórios. São Paulo: 2006.

BRUNNER, José Joaquín. Educación superior en América Latina: cambios y desafíos. Chile: Fondo de Cultura Económica, 1990. Disponível em:

<http://www.terras.edu.ar/biblioteca/7/SIST-Brunner\%20-\%20Unidad\%205.pdf>. Acesso em: jun. 2014.

CAMPELLO, Bernadete Santos. Teses e dissertações. In: CAMPELLO, Adete Santos; CENDÓN, Valadares; KREMER, Ette Marguerite (Orgs.). Fontes de informação para pesquisadores e profissionais. Belo Horizonte: UFMG, 2000. p. 121-129.

CANÓS et al. NDLTD: una biblioteca digital global de tesis doctorales y de licenciatura. 2000.

CARVALHO, E. M. R. La literature gris y su contribución a la sociedad del conocimiento.

Proceedings... In: IFLA COUNCIL AND GENERAL CONFERENCE, 67., 2001. Disponível em: $<$ http://www.ifla.org/>.

CASE, M. M. Igniting change in scholarly communication: SPARC, present and future. Advances in Librarianship, v. 26, 2002. Disponível em: <http://indigo.uic.edu/handle/10027/74>. Acesso em: ago. 2013.

CASTELLS, Manuel. A sociedade em rede. 2. ed. São Paulo: Paz e Terra, 1999. v. I. Disponível em:

<http://www.ige.unicamp.br/site/aulas/134/Castells,M.\%20A\%20sociedade\%20em\%20rede.\% 20Prol\%F3go.pdf>. Acesso em: maio 2014.

CASTRO, C.; FERREIRA, S. A.; ANDRADE, A. Repositories of Digital Educational Resources in Portugal in the elementary and secondary education. 2011.

$\mathrm{CHOO}, \mathrm{C}$. W. Information management for the intelligent organization: the art of scanning the enviroment. 2. ed. Medford: ASIS/Information Today, 1998.

CHRISTOVÃO, H. T. Da comunicação informal à comunicação formal: identificação da frente de pesquisa através de filtros de qualidade. Ciência da Informação, Rio de Janeiro, v. 8, n. 1, p. 336, 1979.

CHU, S.; LAW, N. Development of information search expertise: research students knowledge of source types. Journal of Librarianship and Information Science, v. 39, n. 1, p. 27-40.

COATES, Mildred. Search engine queries used to locate electronic theses and dissertations: diferences for local and non-local users. Emerald, v. 32, 2014. Disponível em: <http://dx.doi.org/10.1108/LHT-02-2014-0022>. Acesso em: jan. 2015.

COMBEROUSSE, M. Les Nouvelles technologies au service de la litteráture grise, BBF, tome 40, n. 2, 1995.

CORREIA, Ana Maria Ramalho. O papel das bibliotecas digitais de literatura cinzenta - os repositórios de eprints - na comunicação científica. In: SEGUNDAS JORNADAS DE BIBLIOTECAS DIGITAIS, 2001. 
CÔRTES, Pedro Luiz. A importância da Literatura Cinzenta disponível na internet para as áreas de Ciências Contábeis e Administração de Empresas. RBGN, São Paulo, v. 8, n. 20, p. 13-22, jan./abr. 2006.

Revistas científicas eletrônicas on-line e a dinâmica da publicação, divulgação e comunicação científica: um quadro conceitual. 2004. Tese (Doutorado - Universidade de São Paulo), São Paulo, 2004.

COSTA, Michelli Pereira da. Características e contribuições da Via Verde para o Acesso Aberto à Informação Científica na América Latina. 2014. 226 f. Dissertação (Mestrado em Ciência da Informação - Universidade de Brasília), Brasília, 2014. Disponível em: <repositorio.unb.br/handle/10482/15687>. Acesso em: 2014.

COSTA, Sely Maria de Souza. The impact of computer usage on scholarly communication amongst academic social scientists. 1999. $318 \mathrm{f}$. Tese (Doctor of Philosophy - Loughborough University), Inglaterra, 1999.

CRANE, D. Invisible colleges: diffusion of knowledge in scientific communities. Chicago, London: University of Chicago Press, 1972. 213p.

CRESWELL, John W. Projeto de pesquisa: métodos qualitativo, quantitativo e misto. 2. ed.Porto Alegre: Artmed, 2007. 248 p.

Projeto de pesquisa: métodos qualitativos, quantitativos e misto. 3. ed.Porto Alegre: Artmed, 2010. 296 p.

CUNHA, Murilo Bastos da. Das bibliotecas convencionais às digitais: diferenças e convergências. Perspectivas em Ciência da Informação, v. 13, n. 1, p. 2-17, jan./abr. 2008. Disponível em: <www.brapci.ufpr.br/download.php?dd0=14318>. Acesso em: nov. 2013.

Desafios na construção de uma biblioteca digital. Revista Ciência da Informação, v. 28, n. 3, p. 257-268, 1999. Disponível em: <www.scielo.br/pdf/ci/v28n3/v28n3a3.pdf>. Acesso em: nov. 2013.

DARWS, Stuart. Virtually there: Open Access and the online growth of Pacific Dissertations and Theses. The Contemporary Pacific, v. 24, n. 2, 2012. Disponível em: $<$ http://muse.jhu.edu/journals/contemporary_pacific/v024/24.2.dawrs.html>. Acesso em: jul. 2014.

DAVENPORT, T. H. Ecologia da informação: por que só a tecnologia não basta para o sucesso na era da informação. São Paulo: Futura, 1998. 316 p.

Process innovation: reegineering work through information technology. Boston: Harvard Business School Press, 1993.

DETLOR, Brian. Information management. International Journal of Information Management, v. 30 , n. 2, p. 103-108, abr. 2010.

DI GIUSTI, Marisa de. Hacia la construcción de un Repositorio Institucional. Semana del Acceso Abierto, Montevideo, 2013. (Apresentação em slide). 
DIDRIKSSON, Axel. Contexto global y regional de la educación superior en América Latina y el Caribe. In: GAZZOLA, Ana Lúcia; DIDRIKSSON, Axel (Ed.). Tendencias de la educación superior en América Latina y el Caribe. Caracas: IESALC-UNESCO, 2008. p. 21-54. Disponível em: $<200.6 .99 .248 / . . . /$ files/CAPITULO_01_Didriksson.pdf>. Acesso em: 2014.

DUDZIAK, Elisabeth Adriana; VILLELA, Maria Cristina Olaio. Bibliotecas digitais de dissertações e teses - a comunidade politécnica da Universidade de São Paulo - Brazil. In: SIMPÓSIO INTERNACIONAL DE BIBLIOTECAS DIGITAIS, 4., Málaga, Espanha.

FARACE, D. J.; FRANTZEN, J. Perspectives on the design and transfer of scientific and technical information. In: INTERNATIONAL CONFERENCE ON GREY LITERATURE, 3., Amsterdam, 1998.

FINEMAN, Yale. Electronic theses and dissertations. Libraries and the Acadmy, v. 3, n. 2, 2003. p. 219-227. Disponível em:

<http://muse.jhu.edu/journals/pla/summary/v003/3.2fineman.html>. Acesso em: dez. 2012.

FLICK, Uwe. Qualidade na pesquisa qualitativa. Porto Alegre: Artmed, 2009. 191 p.

FOX, E. A.; MCMILLAN, G.; EATON, J. L. The evolving genre of electronic theses and dissertations.In: HAWAII INTERNATIONAL CONFERENCE ON SYSTEM SCIENCES, 1999.

FREIRE, Gustavo Henrique. Ciência da Informação: temática, histórias e fundamentos. Perspect. ciênc. inf., Belo Horizonte, v. 11, n. 1, p. 6-19, jan./abr. 2006.

FREITAS NETO, José Alves de. A reforma universitária de Córdoba (1918): um manifesto por uma universidade latino-americana. Revista Ensino Superior Unicamp, 2011. Disponível em: <http://www.gr.unicamp.br/ceav/revistaensinosuperior/ed03_junho2011/pdf/10.pdf>. Acesso em: jun. 2014.

FUNDORA HERRERA, Gilberto. La educación superior avanzada: calidad-equidad-pertinencia: tasas de coberturas terciarias en América Latina y el Caribe. Revista Pedagogía Universitaria, v. XV, n. 1, 2010. Disponível em:

<http://cvi.mes.edu.cu/peduniv/index.php/peduniv/article/view/521>. Acesso em: jun. 2014.

GARVEY, W.; GRIFFITH, B. Communication and information processing within scientifc disciplines: empirical findings for psychology. In: GARVEY, D. Communication: the essence of Science. Oxford: Pergamon Press, 1979.

GIBBONS, Michael et al. The new production of knowledge: the dynamics of science and research in contemporary societies. Sweden: SAGE, 1994. Disponível em:

$<$ http://books.google.ca/books?id=KS_caFqMFoMC\&printsec=frontcover\&hl=pt-

BR\&source=gbs_ge_summary_r\&cad=0\#v=onepage\&q\&f=false>. Acesso em: maio 2014.

GINSPARG, P. Electronic publishing in science. 1996. Disponível em:

<http://arXiv.org/blurb/pg96unesco.html>. Acesso em: jan. 2012.

GODIN, B.; GRINGAS, Y. The place of universities in the system of knowledge production.

Research Policy, n. 29, 2000, p. 273-278. Disponível em:

<http://EconPapers.repec.org/RePEc:eee:respol:v:29:y:2000:i:2:p:273-278>. Acesso em: mar. 2013. 
GOFFMAN, W. Information Science: discipline or disappearance. Aslib Proceedings, v. 22, n. 12, p. 589-596, 1970.

GOLDSMITH, U. I. A. A first research work: thesis and dissertations. 2010.

Perceptions of active graduate faculty at a research extensive university regarding electronic submission of theses and dissertations (ETDs). 2002. $208 \mathrm{f}$. Dissertação (Doctor of Philosophy - Louisiana State University), Louisiana, 2002.

GREIG, M. Implementing electronic theses at the University of Glasgow: cultural challenges. Library Collections, Acquisitions \& Technical Services, v. 29, n. 3, p. 326-335, 2005. Disponível em: <http://eprints.gla.ac.uk/2295/>. Acesso em: 2011.

GUBIANI, Juçara Salete. Biblioteca digital: uma proposta para publicação e disseminação do conhecimento produzido através das teses e dissertações. 2005. 124 f. Dissertação (Mestrado em Engenharia de Produção - Universidade Federal de Santa Maria), Santa Maria, 2005.

HARNAD, Stevan. Electronic scholarly publication: quo vadis. Serials Review, v. 21, n. 1, 1995, p. 70-72. Disponível em:

<http://eprints.soton.ac.uk/253356/2/harnad95.quo.vadis.html>. Acesso em: 2012.

HARNAD, Stevan. Research access, impact and assessment. Times higer education supplement, n. 18, maio 2001a. Disponível em: http://eprints.soton.ac.uk/255950/>. Acesso em: 2012.

HAWKINS, Ann R.; KIMBALL, Miles A.; IVES, Maura. Mandatory Open Access Publishing for Electronic Theses and Dissertations: ethics and enthusiasm. Elsevier, 2013. Disponível em: <http://dx.doi.org/10.1016/j.acalib.2012.12.003>. Acesso em: Jun. 2013.

HOE-LIAN GOH, Dio et al. A checklist for evaluating open source digital library software. Online Information Review, v. 30, n. 4, 2006, p. 360-379. DOI: 10.1108/14684520610686283.

HURD, J. M. Models of scientific communication systems. In: CRAWFORD, S. Y.; HURD, H. M.; WELLER, A. C. From print to electronic: the transformation of scientific information. Medford: Asis, p. 9-33, 1996.

ISMAIL, M. A.; KAREEM, S. A. Identifying how novice researches search, locate, choose and use web resources at the early stage of research. Malaysian Journal of Library \& Information Science, v. 16, n. 3, 2011, 67-85.

JEWELL et al. Required Open Access to ETDs: technical, logistical and philosophical implications. Proceedings... 2006. Disponível em: <lib.uwaterloo.ca>. Acesso em: dez. 2012.

JIN, Yi. The development of the China Networked Digital Library of Theses and Dissertations. Online Information Review, v.28, n. 5, 2004, p. 367-370. DOI: 10.1108/14684520410564299.

JOHNSON, R. Burke; ONWUEGBUZIE, Anthony J.; TURNER, Lisa A. Toward a definition of mixed methods research. Journal of Mixed Methods Research, v. 1, n. 2, Apr. 2007, p. 112-133.

KHOTARI, C. R. Research methodology: methods \& techniques. New Delhi: New Age International, 2004. $401 \mathrm{p}$. 
KYRILLIDOU, Martha; MORRIS, Shaneka; ROEBUCK, Gary (Comp.). ARL Statistics 2010-2011. Washington: ARL, 2011. Disponível em:

<http://comminfo.rutgers.edu/ tefko/Courses/e553/Readings/ARL\%20Statistics\%2020102011.pdf>. Acesso em: jan. 2013.

LA Referencia. Red Federada de Repositorios Institucionales de Publicaciones Científicas. Disponível em: <http://lareferencia.redclara.net/rfr/>. Acesso em: 2014.

LAGOZE, Carl et al. The Open Archives Initiative Protocol for Metadata Harvesting. Disponível em: <http://www.openarchives.org/OAl/openarchivesprotocol.html>. Acesso em: 2014.

LAGOZE, Carl; VAN DE SOMPEL, Herbert. The making of the Open Archives Initiative Protocol for Metadata Harvesting. Emerald, v. 21, n. 2, p. 118-128, 2003. Disponível em: < http://www.emeraldinsight.com/doi/pdfplus/10.1108/07378830310479776>. Acesso em: jul. 2012.

LAGOZE, C.; VAN DE SOMPEL, H. The Open Archives Initiative: Building a low-barrier interoperability framework. 2001. Proceedings... Roanoke VA: jun. 24-28, 2001, p. 54-62. Disponível em: <http://www.openarchives.org/documents/jcdl2001-oai.pdf>. Acesso em: fev. 2013.

LAGOZE, Carl; VAN DE SOMPEL, Herbert. The Santa Fe Convention of the Open Archives Initiative. D-Lib Magazine, v. 6, n. 2, 2000. Disponível em: <http://www.dlib.org/dlib/february00/vandesompel-oai/02vandesompeloai.html?iframe=true\&width=95\%\&height=95\%>. Acesso em: fev. 2013.

LE COADIC, Y. F. A Ciência da Informação. Brasília: Briquet de Lemos, 1996. 199 p.

LEITE, Fernando César Lima. Como gerenciar e ampliar a visibilidade da informação científica brasileira: repositórios institucionais de acesso aberto. Brasília: Ibict, 2009. 120 p.

Modelo genérico de gestão da informação científica para instituições de pesquisa na perspectiva da comunicação científica e do acesso aberto. 2011. $262 \mathrm{f}$. Tese (Doutorado em Ciência da Informação - Universidade de Brasília), Brasília, 2011. Disponível em: <http://hdl.handle.net/10482/9753>. Acesso em: mar. 2013.

LEYDESDORFF, Loet; ETZKOWITZ, Henry. The transformation of university-industrygovernment relations. Electronic Journal of Sociology, v. 5, n. 2, 2001. Disponível em: <http://arizona.openrepository.com/arizona/bitstream/10150/106531/3/th.html>. Acesso em: 2014.

LOPES, Maria Immacolata Vassallo de; ROMANCINI, Richard. Teses e dissertações: estudo bibliométrico na área da comunicação. In: POBLACIÓN, Dinah; WITTER, Geraldina Porto; SILVA, José Fernando Modesto da (Org.). Comunicação e produção científica: contexto, indicadores e avaliação. São Paulo: Angellara, 2006.

LYNCH, C. Institutional repositories: essential infrastructure for scholarship in the digital age. ARL: A Bimonthly Report, v. 226, 2003. Disponivel em: <http://www.arl.org/resources/pubs/br/br226ir.shtml>. Acesso em: nov. 2012.

MACDONALD, Stuart; HEADLAM, Nicola. Research Methods Handbook: introductory guide to research methods for social research. Manchester: CLES, 2009. Disponível em: 
<http://www.cles.org.uk/wp-content/uploads/2011/01/Research-Methods-Handbook.pdf>. Acesso em: jul. 2014.

MCCUTHEON, Angela. Are ETD alumni reporting publisher rejections to ETD personnel within the United States? In: ETD, 2010.

MCMILLAN, Gail et al. An investigation of ETDs as prior publications: findings from the 2011 NDLTD Publisher's Survey. Proceedings... In: INTERNATIONAL SYMPOSIUM ON ELECTRONIC THESES AND DISSERTATIONS, 14., Cape Town (África do Sul), 2011.

MEADOWS, J. A comunicação científica. Brasília: Briquet de Lemos, 1999. . Communication in science. London: Butterworths, 1974. 248 p.

MENZEL, H. Scientific communication: five themes from social science research. American Psychologist, v.21, n.10, p.999-1004, 1966. Disponível em:

<http://psycnet.apa.org/journals/amp/21/11/999/>. Acesso em: mar. 2014.

The flow of information among scientists: problems, opportunities and research questions - Unpublished Manuscript, Columbia Univ., Bureau Of Applied Social Research. 1958.

MOLOSSI, Sinara. Inserção da biblioteca digital de teses e dissertações no contexto da web semântica: construção e uso da ontologia. 2008. 228 f. Dissertação (Mestrado em Ciência da Informação - Universidade Federal de Santa Catarina), Florianópolis, 2008.

MOREIRA, Walter. Os colégios virtuais e a nova configuração da comunicação científica. Revista Ciência da Informação, v. 34, n. 1, p. 57-63, jan./abr. 2005. Disponível em: <http://www.scielo.br/pdf/ci/v34n1/a07v34n1.pdf>. Acesso em: dez. 2012.

MORLES, Victor. Educación de postgrado o educación avanzada en Venezuela: ¿para qué? Investigación y Postgrado, v. 20, n. 2, 2005. Disponível em: <www.redalyc.org/articulo.oa?id=65820203>. Acesso em: 2014.

MORLES, V.; LEÓN, J.R. La educación de postgrado en Iberoamérica en La gestión del postgrado en Iberoamérica: experiencias nacionales. Asociación Universitaria Iberoamericana de Postgrado, Salamanca, 2003.

MOXLEY, Joseph M. American universities should require Electronic Theses and Dissertations. Educause Quarterly, n. 3, 2001. Disponível em: <scholarcommons.usf.edu>. Acesso em: ago. 2012.

MUELLER, Suzana Pinheiro Machado. O periódico científico. In: CAMPELLO, B. S.; CENDÓN, B. V.; KREMER, J. M. (Org.). Fontes de informação para pesquisadores e profissionais. Belo Horizonte: UFMG, 2000. cap. 5, p. 73-95.

MUELLER, Suzana Pinheiro Machado; CAMPELLO, Bernadete Santos; DIAS, Eduardo José Wense. Disseminação da pesquisa em Ciência da Informação e Biblioteconomia no Brasil. Ciência da Informação, v. 25, n. 3, 1996. Disponível em: <http://revista.ibict.br/ciinf/index.php/ciinf/article/view/453/1644>. Acesso em: maio 2013.

ODDONE, Nanci. O IBBD e a informação científica: uma perspectiva histórica para a ciência da informação no Brasil. Ci. Inf., Brasília, v. 35, n. 1, p. 45-56, jan./abr. 2006. 
OLIVEIRA, Dalila Andrade; AZEVEDO, Mário Luiz Neves de. A atualidade dos ensinamentos da Reforma de Córdoba (1918): ou qual a herança de Córdoba nas reformas atuais? In: SADER, Emir; GENTILI, Pablo; ABOITES, Hugo. La reforma universitária: desafios y perspectivas noventa años después. Buenos Aires: CLACSO, 2008. p. 66-79. Disponível em: $<$ http://biblioteca.clacso.edu.ar/ar/libros/grupos/reforAboit/08oliaze.pdf >. Acesso em: jun. 2014.

OPENDOAR. Directory of Open Access Repositories. 2014. Disponível em: <www.opendoar.org>. Acesso em: 2014.

ORERA ORERA, Luisa. Bibliotecas digitales de tesis doctorales: metodologia para su planificación. Boletín de la Asociación Andaluza de Bibliotecarios, n. 72, p. 55-72, set. 2003. Disponível em: <dialnet.unirioja.es>. Acesso em: maio 2012.

. La biblioteca universitaria ante el nuevo modelo social y educativo. El profesional de la información, v. 16, n. 4, p. 329-337, 2007. Disponível em:

<http://elprofesionaldelainformacion.metapress.com/>. Acesso em: maio 2012.

La edición digital de tesis doctorales: hacia la resolución de los problemas de accesibilidad. Ver. Interam. Biblot. Medellín, v. 26, n. 1, enero-junio 2003. Disponível em: <aprendeenlinea.udea.edu.co>. Acesso em: maio 2012.

PANDO, Daniel Abraão. A comunicação científica a partir da WEB 2.0: os blogs como repositórios de informações científicas. FIRB Editora, 2013. Disponível em: <www.firb.br/editora/index.php/teste/article/download/29/35>. Acesso em: mar. 2014.

PEREIRA, Fernanda. Estudo de usabilidade em bibliotecas digitais: um estudo de caso. 2011. 123 f. Dissertação (Mestrado em Ciência da Informação - Universidade Federal de Minas Gerais), Belo Horizonte, 2011.

PICKTON, M.; MCKNIGHT, C. Research Students and the Loughborough institutional repository. Journal of Librarianship and Information Science, v. 38, n. 4, p. 206-223, 2006.

PINHEIRO, Lena Vania Ribeiro. Comunidades científicas e infra-estrutura tecnológica no Brasil para uso de recursos eletrônicos de comunicação e informação na pesquisa. Revista Ciência da Informação, v. 32, n. 3, 2003. Disponível em:

<http://revista.ibict.br/ciinf/index.php/ciinf/article/view/27/23>. Acesso em: jul. 2012.

POBLACIÓN, Dinah. Literatura cinzenta: presente e future. INTERCOM - Rev. Bras. de Com., v. 20, n. 1, p. 153-160, jan./jun. 1997. Disponível em:

<http://www.portcom.intercom.org.br/revistas/index.php/revistaintercom/article/view/935>. Acesso em: maio 2011.

Literatura cinzenta ou não convencional: um desafio a ser enfrentado. Ci. Inf., Brasília, v. 21, n. 3, p. 243-246, set./dez. 1992.

POBLACIÓN, Dinah; NORONHA, Daisy Pires. Produção das literaturas "branca" e "cinzenta" pelos docents/doutores dos programas de pós-graduação em Ciência da Informação no Brasil. Revista Ciência da Informação, v. 31, n. 2, p. 98-106, maio/ago. 2002. Disponível em: $<w w w . s c i e l o . b r / s c i e l o . p h p$ ?pid=S0100-19652002000200011\&script=sci_abstract $>$. Acesso em: maio 2012. 
POBLACIÓN, Dinah; NORONHA, Daisy Pires; CURRÁS, Emilia. Literatura cinzenta versus literatura branca: transição dos autores das comunicações dos eventos para produtores de artigos. Revista Ciência da Informação, v. 25, n. 2, 1995. Disponível em: <brapci.inf.br>. Acesso em: out. 2012.

RAMA, Claudio. La tercera reforma de la educación superior en América Latina. Buenos Aires: Fondo de cultura económica, 2006. Disponível em: <rsu.uninter.edu.mx>. Acesso em: 2014.

RAMIREZ et al. Do open access electronic theses and dissertations dimish publishing opportunities in the social sciences and humanities? 2013.

REEP, Joan M.; GLAVINO, Cliff. Dissertations: a study of scholar's approach. College \& Research Libraries, 1987. Disponível em: <ideals.illinois.edu>. Acesso em: fev. 2014.

RICHARDSON, Roberto Jarry. Pesquisa social: métodos e técnicas. 3. ed. São Paulo: Atlas, 1999. $334 \mathrm{p}$.

ROOSENDAAL, Hans E.; GEURTS, Peter A. Th. M. Forces and functions in scientific communication: an analysis of their interplay. 1999.

ROSETTO, Márcia. Uso do Protocolo Z39.50 para recuperação de informação em redes eletrônicas. Revista Ciência da Informação, v. 26, n.2, Brasília, maio/ago. 1997. Disponível em: $<w w w . s c i e l o . b r / s c i e l o . p h p$ ?script_sci_arttext\&pid=S0100-19651997000200004>. Acesso em: maio 2012.

ROWLEY, J. Towards a framework for information management. International Journal of Information Management, v. 8, n. 5, p. 359-369, 1998. Disponível em: <http://www.sciencedirect.com/science/article/pii/S0268401298000255>. Acesso em: fev. 2013.

RUSSELL, Jane M. La comunicación científica a comienzos del siglo XXI. Revista internacional deficiencias sociales, 2001. Disponível em: <http://oei.es/salactsi/rusell.pdf >. Acesso em: jan. 2014.

SABATINI, M. Publicações científicas eletrônicas na Internet: modelos, padrões e tendências. 1999. 256 f. Dissertação (Mestrado em Comunicação Social - Universidade Metodista de São Paulo), São Paulo, 1999.

SANTOS, Boaventura S. Pela mão de Alice: o social e o político na pós-modernidade. São Paulo: Cortez, 1995.

SAYÃO, L. F. Padrões para bibliotecas digitais abertas e interoperáveis. Pesq. Bras. em Ci. Info. e Biblio, v.2, n.2, 2007. Disponível em:

<http://revista.ibict.br/pbcib/index.php/pbcib/article/view/794>. Acesso em: set. 2013.

SAYÃO, Luis Fernando; MARCONDES, Carlos Henrique. O desafio da interoperabilidade e as novas perspectivas para as bibliotecas digitais. TransInformação, Campinas, v. 20, n. 2, maio/ago. 2008. p. 133-148. Disponível em: <http://periodicos.puccampinas.edu.br/seer/index.php/transinfo/article/view/530>. Acesso em: jan. 2012. 
SCHÖPFEL, Joachim et al. Open Access to research data in electronic theses and dissertations: an overview. Emerald, v. 34, 2014. Diponível em: <http://dx.doi.org/10.1108/LHT-06-20140058>. Acesso em: jan. 2015.

SEAMANS, Nancy $\mathrm{H}$. Electronic theses and dissertations as prior publications: what the editors say. Emerald, v. 21, n. 1, 2003. p. 56-61. Disponível em: <http://www.emeraldinsight.com/doi/abs/10.1108/07378830310467409>. Acesso em: fev. 2012.

SEKARAN, Uma. Research methods for business: a skill building approach. 4. ed. New York: John Wiley \& Sons, 2003.

SENA, Nathália Kneipp. Open Archives: caminho alternativo para a comunicação científica. Ciência da Informação, Brasília, v. 29, n. 3, p. 71-78, set./dez. 2000. Disponível em: <http://www.scielo.br/pdf/ci/v29n3/a07v29n3.pdf>. Acesso em: maio 2012.

SENGUPTA, Shantashree. E-thesis repositories: the Asian scenario. Chinese Librarianship: an International Electronic Journal, v. 33.

SGUISSARDI, Valdemar. Modelo de expansão da educação superior no Brasil: predomínio privado/mercantil e desafios para a regulação e a formação universitária. Educ. Soc., Campinas, v. 29, n. 105, p. 991-1022, set./dez. 2008.

SHEARER, K.; BIRDSALL, B. The transition of scholarly communication in Canada. 2002.

SHEEJA, N.K.; CHERUKODAN, S. The development and promotion of ETDs in Kerala. 2011. Disponível em:

<http://shodhganga.inflibnet.ac.in/dxml/bitstream/handle/1944/1606/16.pdf?sequence=1>

SUBER, Peter. Open Access to electronic theses and dissertations (ETDs). SPARC Open Access Newsletter, 2006. Disponível em:

$<$ http://dash.harvard.edu/bitstream/handle/1/4727443/suber_theses.htm?sequence=1 $>$. Acesso em: maio 2013.

SULEMAN, H. et al. Building digital libraries from simple building blocks. Emerald, v. 27, n. 5, 2003. Disponível em: <http://www.emeraldinsight.com/1468-4527.htm>. Acesso em: fev. 2013.

TAMMARO, Anna Maria; SALARELLI, Alberto. A biblioteca digital. Brasília: Briquet de Lemos, 2008. 378 p.

TARGINO, Maria das Graças. Comunicação científica: uma revisão de seus elementos básicos. Informação \& Sociedade: Estudos, 2000. Disponível em:

<http://www.biblionline.ufpb.br/ojs2/index.php/ies/article/viewFile/326/248>. Acesso em: maio 2012.

. O óbvio da informação científica: acesso e uso. TransInformação, Campinas, v. 19, n. 2, maio/ago. 2007.

TAVARES, Marcelo. Estatística aplicada à Administração. Sistema Universidade Aberta do Brasil, 2007. $142 \mathrm{p}$. 
TEN years on from the Budapest Open Access Initiative: setting the default to open. Budapeste, 2012. Disponível em: <http://www.opensocietyfoundations.org/openaccess/boai10-recommendations>. Acesso em: jun. 2013.

TEXIER, Jose. Los repositórios institucionales y las bibliotecas digitales: una somera revisión bibliográfica y su relación en la educación superior. In: LATIN AMERICAN AND CARIBBEAN CONFERENCE FOR ENGINEERING AND TECHNOLOGY, 11., 2013.

TRÉZ, Thales de Astrogildo e. Caracterizando o método misto de pesquisa na educação: um continuum entre a abordagem qualitativa e quantitativa. Atos de Pesquisa em Educação, v. 7, n. 4, p. 1.132-1.157, de. 2012. Disponível em: <http://gorila.furb.br/ojs/index.php/atosdepesquisa/article/view/1132/2235>. Acesso em: set. 2013.

TRISKA, Ricardo; CAFÉ, Lígia. Arquivos Abertos: subprojeto da Biblioteca Digital Brasileira. Ciência da Informação, Brasília, v. 30, n. 3, p. 92-96, set./dez. 2001. Disponível em: <http://www.scielo.br/pdf/ci/v30n3/7291.pdf>. Acesso em: jan. 2012.

UBOGU, F. N. Copyright and thesis in Africa. In: CONFERENCE ON OPEN ACCESS AND CREATING KNOWLEDGE SOCIETY, 2006, Harare.

UNESCO. The guide for electronic theses and dissertations. 2001. Disponível em: <www.etdguide.org/content>. Acesso em: 10 set. 2013.

VAN DE SOMPEL, H.; LAGOZE, C. The Santa Fe convention of the Open Archives Iniciative. Dlib Magazine, v. 6, n. 2, Feb. 2000. Disponível em: <http://www.dlib.org/dlib/february00/vandesompel-oai/02vandesompel-oai.html>. Acesso em: jul. 2012.

VELLOSO, Jacques. Universidade na América Latina: rumos do financiamento. Cadernos de Pesquisa, n. 110, p. 39-66, jul. 2000.

VESSURI, Hebe. Impacto del Acceso Abierto (Open Access) en la Educación Superior en América Latina y el Caribe. Revista Educación Superior y Sociedad, v. 16, n. 2, 2011. Disponível em: <http://ess.iesalc.unesco.org.ve/index.php/ess>. Acesso em: 2014.

VICKERS, Peter. Information management: selling a concept. In: CRONIN, Blaise. Information management: from strategies to action. London: Aslib, 1985. p.149-160.

VIDOTTI, Silvana Aparecida Borsetti Gregorio; SANT'ANNA, Ricardo Gonçalves . Infra-estrutura tecnológica de biblioteca digital: elementos básicos. In: MARCONDES, C. H. et al. (Org.). Bibliotecas digitais: saberes e práticas. 2 ed. Brasília: Instituto Brasileiro de Informação em Ciência e Tecnologia, 2006, p. 77-93.

VIEIRA, Sonia. Como elaborar questionários. São Paulo: Atlas, 2009. 159 p.

VITALE, Claudio Rama. Los nuevos estudiantes en circuitos diferenciados de educación. In: RODRÍGUEZ ORTÍZ, Gisela (Ed.). Educación superior en América Latina y el Caribe: sus estudiantes hoy. México: UDUAL, 2007. Disponível em: <http://www.udual.org/CIDU/Colldea/EducSuperiorALEstudiantesHoy.pdf>. Acesso em: 2014. 
WANG, X. Guidelines for implementing ETD programs - roles and responsabilities. In: SCHULTZ, M; KRABBENHOEFT, N.; SKINNER, K. Guidance documents for lifecycle management of ETDs (v.1.0). Atlanta: Educopia Institute, 2014.

WARNER, Simeon. E-prints and the Open Archives Initiative. Emerald, v. 21, n. 2, p. 151-158, 2003. Disponível em:

<http://www.emeraldinsight.com/doi/abs/10.1108/07378830310479794>. Acesso em: mar. 2012.

WEBSTER, Janet. Theses and dissertations for the next millennium. International Association of Aquatic and Marine Science Libraries and Information Centers, p. 75-86, 1999. Disponível em:

<http://ir.library.oregonstate.edu/xmlui/handle/1957/318>. Acesso em: maio 2014.

WEITZEL, Simone da Rocha. Iniciativa de arquivos abertos como nova forma de comunicação científica. In: SEMINÁRIO INTERNACIONAL LATINO-AMERICANO DE PESQUISA EM

COMUNICAÇÃO, 3., São Paulo, 2005.

WILSON, T. D. Information management. In: FEATHER, J.; STURGES, P. (Ed.). International Encyclopedia of Information and Library Science. Londres: Rout leg, 2002.

WOOD, D. N. Management of grey literature. In: DURANCE, C. J. (Comp.). Management of record information. Munich: 1990.

WOODMAN, Lynda. Information management in the large organisations. In: CRONIN, Blaise. Information management from strategies to action. London: Aslib, 1985. 95-114 p. Disponível em: <http://books.google.com.br/>. Acesso em: dez. 2013.

YIOTIS, Kristin. Electronic theses and dissertation (ETD) repositories: what are they? Where do they come from? How do they work? Emerald, v. 24, n. 2, 2008, p. 101-115. Disponível em: <http://www.emeraldinsight.com/doi/abs/10.1108/10650750810875458>. Acesso em: nov. 2013.

ZIMAN, J. M. The paradoxical conventionality of the tadicional scientific paper. In:

CONFERENCE ON QUALITY-BASED INFORMATION SYSTEMS. New York: Pocantico Hills, 1978. 


\section{Apêndice A - Checklist}

i. Software utilizado para o gerenciamento das teses e dissertações eletrônicas;

ii. Tipo de sistema (exemplo, biblioteca digital de teses e dissertações ou repositório institucional);

iii. Quantidade total de outras produções científicas identificadas no sistema, quando houver;

iv. Vinculação institucional do sistema de informação;

v. Acesso ao texto completo da tese ou dissertação;

vi. Possibilidade de refinamento do resultado da busca;

vii. Participação na Biblioteca Digital Brasileira de Teses e Dissertações (BDTD). 


\section{Apêndice B - Questionários}

Questionário tipo I-Aplicado somente para as universidades que possuem teses e dissertações eletrônicas.

1. Instituição a que pertence

2. Cargo que ocupa na instituição

3. Quantas pessoas formam a equipe responsável pelo sistema de gestão de teses e dissertações?

- 1 a 3 pessoas

- 4 a 6 pessoas

- Mais de 7 pessoas

4. Quais as áreas de formação dos profissionais envolvidos com o sistema de gestão de teses e dissertações? (Caso necessário, marque mais de uma alternativa).

○ Biblioteconomia

- Arquivologia

- Informática / Tecnologia da informação

- Administração

○ Comunicação

- Outro (especifique)

5. No que diz respeito à gestão de teses e dissertações, em qual das seguintes situações sua instituição se encaixa?

- Minha instituição possui repositório institucional e nele também são gerenciadas as teses e dissertações, além dos outros tipos de produção científica.

- Minha instituição possui uma biblioteca digital de teses e dissertações e ainda não possui um repositório institucional para gerenciar a totalidade da produção científica.

- Minha instituição possui uma biblioteca digital e teses e dissertações e um repositório institucional separadamente.

- Minha instituição não possui biblioteca digital de teses e dissertações e nem repositório institucional, mas sim um outro sistema para gerenciar as teses e dissertações.

○ Outra situação. Qual?

6. Quais fatores influenciaram a decisão de adoção do software para a criação do sistema de gestão de teses e dissertações de sua instituição? (Caso necessário, marque mais de uma alternativa).

○ É um software distribuído gratuitamente.

- É um software que permite sua customização para atender necessidades de minha instituição.

- É um software distribuído gratuitamente e que tem suporte do IBICT.

- É um software que tem interface multilíngue.

- É um software amplamente utilizado pela comunidade bibliotecária.

- É um software que permite a interoperabilidade por meio do Protocolo OAIPMH.

- É um software construído pela própria instituição.

- Outro (especifique) 
7. O sistema de gerenciamento das teses e dissertações está integrado com algum outro sistema da instituição? Exemplo: OPAC, sistema de gestão de recursos humanos, sistema de gestão de pós-graduação etc.

○ Não, não há necessidade

○ Não, mas há necessidade

- Sim. Qual?

8. Há alguma política formal para estimular o depósito de teses e dissertações?

○ Não. Por quê?

- Sim. Qual?

9. Caso tenha respondido SIM na questão 8, a política existente:

- Torna obrigatório o depósito.

- Recomenda o depósito.

10. Caso tenha respondido SIM na questão 8 , há a previsão de sanção para o não cumprimento dessa política?

○ Não
○ Sim. Qual?

11. Sua instituição permite o embargo de teses e dissertações? (Entende-se por embargo o período de tempo em que o documento fica com acesso ao texto completo restringido).

○ Não

- Sim. Indefinidamente.

- Sim. Por quanto tempo?

12. Caso tenha respondido SIM na questão 10 , em quais situações a seguir sua instituição permite o embargo de teses e dissertações? (Caso necessário, marque mais de uma alternativa).

- Quando a tese ou dissertação tiver o potencial de gerar uma patente.

- Em razão da necessidade de não circulação antes da publicação de artigo de revista científica ou livro (exigência de editor)

- Para evitar plágio

- Em razão da vontade pessoal do autor de torna-la inacessível por algum período

- Outro (especifique)

13. Quais os tipos de conteúdos são permitidos no sistema adotado para a gestão de teses e dissertações? (Caso necessário, marque mais de uma alternativa).

- Somente teses e dissertações

- Artigos de periódicos científicos

- Teses e dissertações

- Trabalhos apresentados em conferências

- TCCs

- Relatórios de pesquisa

- Livros

- Capítulos de livros

○ Outro(s) tipo(s). Qual(is)?

14. Qual a modalidade de depósito das teses e dissertações no sistema? (Caso necessário marque mais de uma opção).

- Autoarquivamento (Depósito da tese ou dissertação no sistema realizado pelo próprio autor). 
- Depósito mediado (Depósito da tese ou dissertação no sistema realizado por um bibliotecário).

- Depósito mediado (Depósito da tese ou dissertação no sistema realizado por um outro profissional).

- Outra modalidade. Qual?

15. Os metadados que descrevem os documentos são preenchidos por quem? (Caso necessário marque mais de uma opção).

- Pelos próprios autores das teses e dissertações.

- Pelos usuários leitores que acessam o sistema (folksonomia).

- Pelo sistema, de modo automático.

- Pelos bibliotecários ou outros profissionais da informação.

- De outra maneira. Qual?

16. Na descrição dos documentos, há metadados que são preenchidos em outros idiomas diferentes que o idioma oficial de seu país?

○ Não. Por quê?

- Sim. Qual?

17. No sistema de gestão de teses e dissertações foi adotado o serviço de identificação persistente dos documentos? (Exemplo, uso do handle).

o Sim.

○ Não. Por quê?

18. O sistema de gestão de teses e dissertações é coletado (metadata harvesting) ou indexado por quais dos sistemas abaixo? (Caso necessário, marque mais de uma alternativa).

$\begin{array}{ll}\circ & \text { BASE (Bielefeld Academic Search Engine) } \\ \circ & \text { OAISTER } \\ \circ & \text { NDLTD } \\ \circ & \text { BDTD } \\ \circ & \text { oasisbr } \\ \circ & \text { Google Scholar } \\ \circ & \text { ScientificCommons } \\ \circ & \text { Outro. Qual? }\end{array}$

19. Além de teses e dissertações, mestrados e doutorados podem produzir como resultado de suas pesquisas materiais não textuais complementares associados, como, por exemplo, áudio, vídeo, simulações e imagens. Sobre a gestão desses materiais juntamente com as teses e dissertações, qual sua opinião a respeito das afirmações a seguir? (Discordo / Não tenho opinião / Concordo)

○ É algo necessário aos autores que produzem esse tipo de material.

- É algo necessário aos usuários.

- É uma iniciativa desejável, mas temos dificuldades de ordem tecnológica, cultural, organizacional ou de outro tipo para implementá-la.

- É algo necessário para algumas áreas do conhecimento e para outras não.

- Depende do tipo de material.

- Dados de pesquisa de mestrado e doutorado poderiam ser gerenciados juntamente com suas teses e dissertações.

*20. Considerando que as afirmações a seguir dizem respeito aos sistemas de informação institucionais, qual a sua opinião a respeito das afirmações a seguir? (Discordo / Não tenho opinião / Concordo) 
- É preferível gerenciar teses e dissertações em sistema de informação próprio, separadas de outros tipos de produção científica da instituição.

- É preferível gerenciar teses e dissertações juntamente com outros tipos de produção científica, tal como é possível em repositórios institucionais.

- Manter dois sistemas de informação em separado, uma biblioteca digital para teses e dissertações e um repositório institucional para os demais tipos de produção científica, é uma solução apropriada para uma instituição.

- Repositórios institucionais incorporaram ou podem incorporar as funções das bibliotecas digitais de teses e dissertações das instituições.

21. É sabido que em alguns países e instituições não há mais a exigência de teses e dissertações como requisitos para a conclusão de mestrados e doutorados mas sim artigos publicados em periódicos científicos bem avaliados. Caso essa transformação se torne tendência, de acordo com sua opinião, quais impactos isso traria para seu sistema de gestão de teses e dissertações? (Questão aberta).

22. Quais fatores, internos ou externos à sua instituição, favorecem ou dificultam a gestão de teses e dissertações eletrônicas? (Questão aberta). 
Questionário tipo II - Aplicado somente para as universidades que não possuem teses e dissertações eletrônicas.

1. Instituição a que pertence

2. Cargo que ocupa na instituição

3. Por quais motivos sua instituição não possui um sistema de informação para gerenciar teses e dissertações eletrônicas? (Caso necessário, marque mais de uma alternativa).

- Em razão de dificuldades relacionadas com recursos humanos, tecnológicos, financeiros ou de outro tipo.

- Em razão de decisão institucional por considerar não ser necessário até o momento.

- Em razão de não conhecermos a finalidade desse tipo de sistema de informação.

- Em razão do fato de que as teses e dissertações já serem gerenciadas em formato impresso.

- Minha instituição possui um sistema de informação para gerenciar teses e dissertações. Qual?

4. Sua instituição já teve uma experiência de gerenciamento de teses e dissertações?

○ Não.

- Sim. Qual?

5. Caso sua instituição tenha interesse em criar um sistema de informação para gerenciar teses e dissertações eletrônicas, seria útil receber suporte/orientação do IBICT (Instituto Brasileiro de Informação em Ciência e Tecnologia)?

○ Não.

○ Sim.

6. Caso sua instituição tenha interesse em criar sistemas de informação para gerenciar teses e dissertações eletrônicas, qual seria o sistema mais apropriado?

- Biblioteca digital de teses e dissertações (para gerenciar exclusivamente teses e dissertações eletrônicas).

- Repositório institucional (para gerenciar teses e dissertações eletrônicas e demais tipos de produção científica como, por exemplo, artigos de periódicos, livros, capítulos de livro, artigos de conferências etc).

- Outro tipo de sistema. Qual?

7. Por quais razões você escolheu esse tipo específico de sistema na questão 6? (Questão aberta).

8. Quais fatores, internos ou externos à sua instituição, favorecem ou dificultam a gestão de teses e dissertações eletrônicas? (Questão aberta). 


\section{Apêndice C - Roteiro das entrevistas}

Roteiro de entrevista tipo I - Somente universidades com biblioteca digital de teses e dissertações

1. Sabemos que sua instituição gerencia teses e dissertações por meio de uma biblioteca digital de teses e dissertações. Quais foram as razões que levaram à decisão pela utilização desse tipo sistema para a gestão de teses e dissertações?

2. Repositórios institucionais gerenciam a totalidade da produção científica, incluindo teses e dissertações. Considerando que em sua universidade há essa diversidade de produção científica, por quais motivos vocês têm gerenciado apenas as teses e dissertações?

3. Considerando hipoteticamente que sua universidade apresente a demanda de um repositório institucional, das soluções as seguir, qual seria a mais apropriada? Por quê?

- Manter a biblioteca digital de teses e dissertações e criar um repositório institucional separadamente;

- Incorporar a biblioteca digital de teses e dissertações ao novo RI, já que ele pode contemplar teses e dissertações.

4. Qual software sua instituição adotou para gerenciar teses e dissertações? Por quais razões?

5. Você enxerga demandas específicas relacionadas com a gestão de teses e dissertações que não são atendidas por este software?

6. O sistema de gerenciamento das teses e dissertações está integrado com algum outro sistema da instituição? Em quais aspectos essa integração é/seria útil?

7. Quem realiza o depósito das teses e dissertações em sua instituição? 0 autoarquivamento seria útil? Por quais motivos você acha que ele tem/não tem funcionado?

8. Sua biblioteca digital de teses e dissertações faz parte da BDTD? Há algo que queira falar respeito disso?

9. É sabido que em alguns países e instituições não há mais a exigência de teses e dissertações como requisitos para a conclusão de doutorado e mestrado, respectivamente, mas sim artigos publicados em periódicos científicos bem avaliados. Caso essa transformação se torne tendência, quais impactos isso traria para a gestão de teses e dissertações em sua instituição?

10. Quais fatores, internos ou externos à sua instituição, favorecem ou dificultam a gestão de teses e dissertações eletrônicas? 


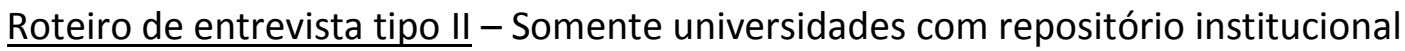

1. Sabemos que sua instituição gerencia teses e dissertações por meio de um repositório institucional. Quais foram as razões que levaram à decisão pela utilização desse tipo sistema para a gestão de teses e dissertações?

2. Repositórios institucionais gerenciam a totalidade da produção científica, incluindo teses e dissertações. É possível considerar que repositórios institucionais incorporaram a função das bibliotecas digitais de teses e dissertações? Ou você enxerga necessidade de gerenciar teses e dissertações separadamente?

3. Considerando hipoteticamente que sua universidade apresente demanda de gerenciar $100 \%$ de todas as teses e dissertações. Das soluções as seguir, qual seria a mais apropriada? Por quê?

- Manter o RI para demais tipos de produção científica e criar uma biblioteca digital de teses e dissertações;

- Gerenciar $100 \%$ das teses e dissertações diretamente no repositório institucional.

4. Qual software sua instituição adotou para gerenciar a produção científica? Por quais razões?

5. Você enxerga demandas específicas relacionadas com a gestão de teses e dissertações que não são atendidas por este software?

6. O repositório institucional está integrado com algum outro sistema da instituição? Em quais aspectos essa integração é/seria útil?

7. Quem realiza o depósito das teses e dissertações em sua instituição? 0 autoarquivamento seria útil? Por quais motivos você acha que ele tem/não tem funcionado?

8. Seu repositório institucional, especificamente suas coleções de teses e dissertações, fazem parte da BDTD? Há algo que queira falar respeito disso?

9. É sabido que em alguns países e instituições não há mais a exigência de teses e dissertações como requisitos para a conclusão de doutorado e mestrado, respectivamente, mas sim artigos publicados em periódicos científicos bem avaliados. Caso essa transformação se torne tendência, quais impactos isso traria para a gestão de teses e dissertações em sua instituição?

10. Quais fatores, internos ou externos à sua instituição, favorecem ou dificultam a gestão de teses e dissertações eletrônicas? 
Roteiro de entrevista tipo III - Somente universidades com biblioteca digital de teses e dissertações e repositório institucional

1. Sabemos que sua instituição possui tanto uma BD de T\&D quanto um repositório institucional. Quais foram as razões que levaram à decisão pela manutenção desses dois sistemas?

2. Repositórios institucionais gerenciam a totalidade da produção científica, incluindo teses e dissertações. É possível considerar que repositórios institucionais incorporaram a função das bibliotecas digitais de teses e dissertações? Ou quais razões justificam a necessidade de gerenciar teses e dissertações separadamente?

3. Considerando hipoteticamente que sua universidade apresente demanda de acesso unificado à totalidade da produção científica. Das soluções as seguir, qual seria a mais apropriada para sua instituição? Por quê?

- Migrar de modo automático todas as teses e dissertações para o repositório institucional;

- Criar um mecanismo de busca OAI para coletar metadados e permitir acesso aos dois sistemas;

- Implementar um sistema de descoberta em todos os sistemas de recuperação da informação da instituição (biblioteca).

4. Quais softwares sua instituição adotou para gerenciar as teses e dissertações e para o repositório institucional? Por quais razões?

5. Você enxerga demandas específicas relacionadas com a gestão de teses e dissertações e do restante da produção científica que não são atendidas por este software?

6. No que concerne ao depósito de teses e dissertações, há integração entre biblioteca digital de teses e dissertações e o repositório institucional? Os dois sistemas são alimentados? Há integração desses dois sistemas com algum outro sistema da instituição? Em quais aspectos essa integração é/seria útil? Há dificuldades ou facilidades decorrentes da manutenção dos dois sistemas? Quais?

7. Quem realiza o depósito das teses e dissertações em sua instituição? 0 autoarquivamento seria útil? Por quais motivos você acha que ele tem/não tem funcionado?

8. Seu RI, especificamente suas coleções de teses e dissertações, fazem parte da BDTD? E sua biblioteca digital de teses e dissertações? Há algo que queira falar respeito disso?

9. É sabido que em alguns países e instituições não há mais a exigência de teses e dissertações como requisitos para a conclusão de doutorado e mestrado, respectivamente, mas sim artigos publicados em periódicos científicos bem avaliados. Caso essa transformação se torne tendência, quais impactos isso traria para a gestão de teses e dissertações em sua instituição? 
10. Quais fatores, internos ou externos à sua instituição, favorecem ou dificultam a gestão de teses e dissertações eletrônicas?

Roteiro de entrevista tipo IV - Somente universidades com outro tipo de sistema de informação 
1. Sabemos que sua instituição gerencia teses e dissertações pelo sistema $X X$, que não é nem uma BD de T\&D e nem um repositório institucional. Quais foram as razões que levaram à decisão pela adoção desse tipo de sistema?

2. Repositórios institucionais gerenciam a totalidade da produção científica, incluindo teses e dissertações. É possível considerar que repositórios institucionais incorporam a função das do seu sistema de gestão de teses e dissertações? Ou quais razões justificam a necessidade de gerenciar teses e dissertações da forma como fazem?

3. Considerando hipoteticamente que sua universidade apresente demanda de gerenciar $100 \%$ de todas as teses e dissertações de que elas pudessem ser encontradas por meio de uma interface de recuperação da informação. Das soluções as seguir, qual seria a mais apropriada? Por quê?

- Implementar um RI, que poderia ser utilizado para demais tipos de produção científica;

- Implementar uma BD de T\&D, e futuramente um RI separadamente.

4. Qual software sua instituição adotou para gerenciar as teses e dissertações? Por quais razões?

5. Você enxerga demandas específicas relacionadas com a gestão de teses e dissertações que não são atendidas por este software?

6. O sistema de gestão de teses e dissertações está integrado com algum outro sistema da instituição? Em quais aspectos essa integração é/seria útil?

7. Quem realiza o depósito das teses e dissertações em sua instituição? 0 autoarquivamento seria útil? Por quais motivos você acha que ele tem/não tem funcionado?

8. Seu sistema de gestão de teses e dissertações não faz parte da BDTD? Ser coletado pela BDTD seria útil? Há algo que queira falar respeito disso?

9. É sabido que em alguns países e instituições não há mais a exigência de teses e dissertações como requisitos para a conclusão de doutorado e mestrado, respectivamente, mas sim artigos publicados em periódicos científicos bem avaliados. Caso essa transformação se torne tendência, quais impactos isso traria para a gestão de teses e dissertações em sua instituição?

10. Quais fatores, internos ou externos à sua instituição, favorecem ou dificultam a gestão de teses e dissertações eletrônicas?

Roteiro de entrevista tipo $\mathrm{V}$ - Somente universidades que não possuem sistema de informação que gerencia teses e dissertações eletrônicas 
1. Quais os fatores que você poderia apontar que dificultam ou impedem a criação desse sistema de informação e quais fatores você poderia apontar que favorecem a criação de um sistema?

2. Considerando que a universidade não possui ainda implantado um sistema de informação para o gerenciamento de teses e dissertações eletrônicas, hipoteticamente das soluções as seguir, qual seria a mais apropriada? Por quê?

- Implementar um repositório institucional, que poderia ser utilizado para demais tipos de produção científica;

- Implementar uma biblioteca digital de teses e dissertações, e futuramente um repositório institucional separadamente.

3. Com relação ao depósito das teses e dissertações eletrônicas, há alguma política da instituição ou da região ou do estado que oriente para esse depósito?

4. Questão aberta para comentários e sugestões. 


\section{Anexo I - Padrão Brasileiro de Metadados de Teses e Dissertações (MTD2-BR)}

\begin{tabular}{|c|c|c|c|c|c|c|}
\hline № & NomedoElemento & Atributos & Conteúdo & R / NR & $\mathbf{O} / \mathrm{F}$ & Padrão \\
\hline 1 & $<$ Controle $>$ & & Dados de controle do registro de Teses e Dissertações & NR & $\mathbf{0}$ & \\
\hline 1.1 & $<$ Sigla $>$ & & Sigla da Instituição Consorciada & NR & $\mathrm{O}$ & \\
\hline 1.2 & $<$ DataAtualizacao > & & Data em que foi realizada a última atualização do registro da tese ou dissertação & NR & $\mathrm{O}$ & $\begin{array}{c}\text { Protocolo } \\
\text { OAI }\end{array}$ \\
\hline 1.3 & $<$ ldentificacaoDocumento $>$ & & Código que identifica a tese ou dissertação na base de dados da biblioteca & NR & $\mathrm{O}$ & -- \\
\hline 1.4 & $<$ <Tipo $>$ & & Tipo da fonte de informação. & $\mathrm{R}$ & $\mathrm{O}$ & $\begin{array}{l}\text { DCMI Type } \\
\text { Vocabulary }\end{array}$ \\
\hline 2 & <BibliotecaDigital> & & Nome da Instituição responsável pela publicação digital da tese ou dissertação & NR & $\mathbf{F}$ & \\
\hline 2.1 & $<$ Nome $>$ & & Nome da Biblioteca Digital & NR & $\mathrm{O}$ & -- \\
\hline 2.2 & $<$ Sigla $>$ & & Sigla da Biblioteca Digital & NR & $\mathrm{O}$ & -- \\
\hline 2.3 & $<U R L>$ & & Endereço eletrônico do site da Biblioteca Digital & NR & $\mathrm{O}$ & Padrão URI \\
\hline 2.4 & <ProvedorServico $>$ & & Instituição que abriga a Biblioteca Digital & NR & $\mathrm{F}$ & -- \\
\hline 2.4 .1 & $<$ Nome $>$ & & Nome da Instituição & NR & $\mathrm{O}$ & -- \\
\hline 2.4 .2 & $<$ Sigla $>$ & & Sigla da Instituição & NR & $\mathrm{F}$ & -- \\
\hline 2.4 .3 & <País> & & País da Instituição & NR & $\mathrm{F}$ & ISO 3166 \\
\hline
\end{tabular}




\begin{tabular}{|c|c|c|c|c|c|c|}
\hline № & NomedoElemento & Atributos & Conteúdo & R/NR & $0 / \mathrm{F}$ & Padrão \\
\hline 2.4 .4 & $<U F>$ & & UF da Instituição & NR & $\mathrm{F}$ & $\begin{array}{l}\text { Unidade da } \\
\text { Federação }\end{array}$ \\
\hline 2.4 .5 & $\langle$ CNPJ $>$ & & CNPJ da Instituição & NR & $\mathrm{F}$ & $\begin{array}{l}\text { Padrão MF } \\
14 \text { dígitos }\end{array}$ \\
\hline 3.1 & $<$ Nome $>$ & & Nome da Biblioteca Depositária & NR & $\mathrm{F}$ & -- \\
\hline 3.2 & $<$ Sigla $>$ & & Sigla da Biblioteca Depositária & NR & 0 & $\begin{array}{c}\text { Cadastro } \\
\text { CCN/COMU } \\
\text { T }\end{array}$ \\
\hline 4 & $\langle$ Titulo> & Idioma & Título da tese ou dissertação & $\mathbf{R}$ & 0 & -- \\
\hline 5 & <Arquivo> & & Endereço eletrônico dos arquivos da tese ou dissertação na Biblioteca Digital & $\mathbf{R}$ & $\mathbf{F}$ & \\
\hline 5.1 & $<U R L>$ & $\begin{array}{l}\text { Formato } \\
\text { Idioma }\end{array}$ & $\begin{array}{l}\text { Endereço eletrônico do arquivo da tese ou dissertação e/ou página de apresentação } \\
\text { dos metadados na biblioteca digital de origem }\end{array}$ & NR & 0 & Padrão URI \\
\hline 5.2 & $<$ Legenda $>$ & Idioma & Legenda para o arquivo, descrição de seu conteúdo & $\mathrm{R}$ & $\mathrm{F}$ & -- \\
\hline
\end{tabular}




\begin{tabular}{|c|c|c|c|c|c|c|}
\hline № & NomedoElemento & Atributos & Conteúdo & R/NR & $0 / \mathrm{F}$ & Padrão \\
\hline 5.3 & <NivelAcesso> & & Restrição de acesso ao arquivo & $\mathrm{NR}$ & $\overline{0}$ & $\begin{array}{c}\text { [Restrito, } \\
\text { Publico] }\end{array}$ \\
\hline 7 & $<$ Grau $>$ & & Grau acadêmico associado à tese ou dissertação & NR & 0 & $\begin{array}{c}\text { Tabela de } \\
\text { Grau }\end{array}$ \\
\hline 9 & $\langle$ Resumo $>$ & Idioma & Resumo da tese ou dissertação & $\mathbf{R}$ & 0 & -- \\
\hline 10 & $<$ Cobertura $>$ & Idioma & Escopo espacial ou temporal da tese ou dissertação & $\mathbf{R}$ & $\mathbf{F}$ & -- \\
\hline 11 & $<$ Assunto $>$ & $\begin{array}{l}\text { Idioma } \\
\text { Esquema }\end{array}$ & $\begin{array}{l}\text { Tópicos tratados na tese ou dissertação e a tabela de onde estes tópicos foram } \\
\text { extraídos, quando for o caso }\end{array}$ & $\mathbf{R}$ & $\mathbf{F}$ & -- \\
\hline 12.1 & $<$ Cidade $>$ & & Cidade onde foi defendida a tese ou dissertação & NR & $\mathrm{O}$ & -- \\
\hline 12.2 & $\langle U F\rangle$ & & UF da cidade onde foi defendida a tese ou dissertação & NR & $\mathrm{F}$ & $\begin{array}{l}\text { Unidade da } \\
\text { Federação }\end{array}$ \\
\hline 12.3 & <País> & & País onde foi defendida a tese ou dissertação & NR & 0 & ISO 3166 \\
\hline 13 & $<$ DataDefesa $>$ & & Data em que foi defendida a tese ou dissertação & NR & 0 & ISO 8601 \\
\hline 14 & <Autor> & & Autor da tese ou dissertação & $\mathbf{R}$ & 0 & -- \\
\hline
\end{tabular}




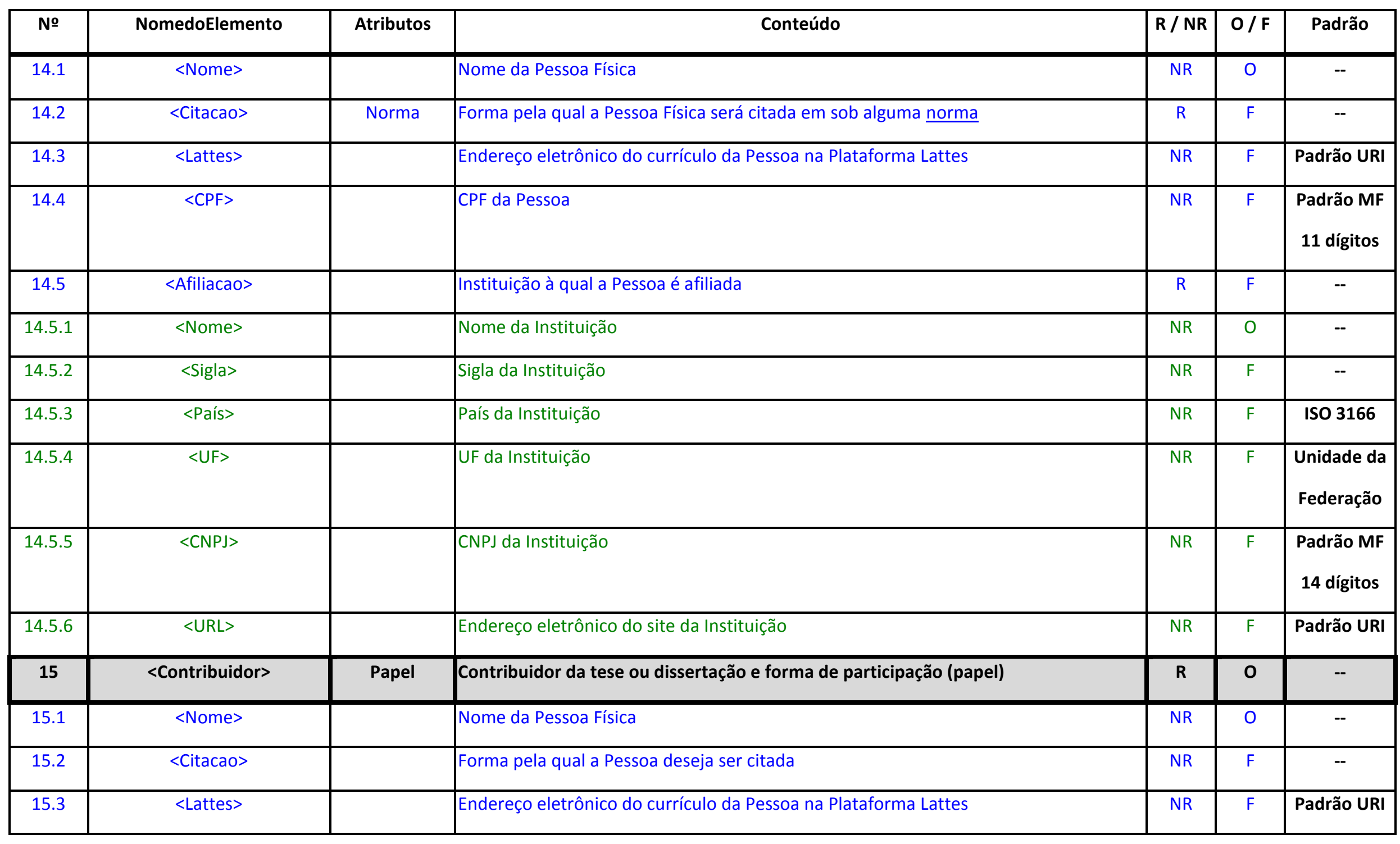




\begin{tabular}{|c|c|c|c|c|c|c|}
\hline № & NomedoElemento & Atributos & Conteúdo & R/NR & $0 / \mathrm{F}$ & Padrão \\
\hline 15.4 & $\langle\mathrm{CPF}\rangle$ & & CPF da Pessoa & NR & $\mathrm{F}$ & $\begin{array}{l}\text { Padrão MF } \\
11 \text { dígitos }\end{array}$ \\
\hline 15.5 .1 & $<$ Nome $>$ & & Nome da Instituição & NR & 0 & -- \\
\hline 15.5 .2 & $<$ Sigla $>$ & & Sigla da Instituição & NR & $\mathrm{F}$ & -- \\
\hline 15.5 .4 & $\langle U F\rangle$ & & UF da Instituição & NR & $\mathrm{F}$ & $\begin{array}{l}\text { Unidade da } \\
\text { Federação }\end{array}$ \\
\hline 15.5 .5 & $\langle$ CNPJ $\rangle$ & & CNPJ da Instituição & NR & $\mathrm{F}$ & 14 dígitos \\
\hline 15.5 .6 & $<U R L>$ & & Endereço eletrônico do site da Instituição & NR & $\mathrm{F}$ & Padrão URI \\
\hline 16.2 & $<$ Sigla $>$ & & Sigla da Instituição & NR & $\mathrm{F}$ & \\
\hline 16.3 & <Pais> & & País da Instituição & NR & $\mathrm{F}$ & ISO 3166 \\
\hline 16.4 & $<U F>$ & & UF da Instituição & NR & $\mathrm{F}$ & $\begin{array}{l}\text { Unidade da } \\
\text { Federação }\end{array}$ \\
\hline 16.5 & $\langle$ CNPJ $\rangle$ & & CNPJ da Instituição & NR & $\mathrm{F}$ & $\begin{array}{l}\text { Padrão MF } \\
14 \text { dígitos }\end{array}$ \\
\hline
\end{tabular}




\begin{tabular}{|c|c|c|c|c|c|c|}
\hline № & NomedoElemento & Atributos & Conteúdo & R/NR & $0 / \mathrm{F}$ & Padrão \\
\hline 16.6 & $<U R L>$ & & Endereço eletrônico do site da Instituição & NR & $\mathrm{F}$ & Padrão URI \\
\hline 16.7 & $<$ Programa $>$ & & Programa de pós-graduação onde a tese ou dissertação foi defendida & $\mathrm{R}$ & $\mathrm{F}$ & \\
\hline 16.7 .1 & $<$ Nome $>$ & & Nome do Programa de Pós-Graduação & NR & 0 & \\
\hline 16.7 .2 & $<$ Area $>$ & & Área de concentração do Programa de Pós-Graduação & NR & $\mathrm{F}$ & \\
\hline 17.2 & $\langle$ Sigla $>$ & & Sigla da Instituição & NR & $\mathrm{F}$ & - \\
\hline 17.3 & <País> & & País da Instituição & NR & $\mathrm{F}$ & ISO 3166 \\
\hline 17.4 & $\langle\mathrm{UF}\rangle$ & & UF da Instituição & NR & $\mathrm{F}$ & $\begin{array}{l}\text { Unidade da } \\
\text { Federação }\end{array}$ \\
\hline 17.6 & $\langle$ UURL $>$ & & Endereço eletrônico do site da Instituição & NR & $\mathrm{F}$ & Padrão URI \\
\hline 18 & <Direitos> & Idioma & Informa as condições de distribuição, reprodução e utilização da tese ou dissertação & $\mathbf{R}$ & $\mathbf{F}$ & \\
\hline 19 & $<$ Extensao > & Namespace & Reservado para a criação de sub-itens (subcampos) para uso específico & NR & $\mathbf{F}$ & \\
\hline
\end{tabular}




\section{Anexo II - Novo Padrão Brasileiro de Metadados da Biblioteca Digital Brasileira de Teses e Dissertações (BDTD)}

\begin{tabular}{|c|c|c|c|c|}
\hline \multicolumn{2}{|c|}{ OBR - Obrigatório } & \multicolumn{2}{|l|}{ PC - Opcional } & \\
\hline 2 & OPC & Sim & dc.creator.ID & ID do autor \\
\hline 4 & OBR & Sim & dc.contributor.advisor1 & Orientador1 \\
\hline 5 & OPC & Sim & dc.contributor.advisor1ID & ID do orientador1 \\
\hline 6 & OPC & Não & dc.contributor.advisor1Lattes & ID Lattes do orientador1 \\
\hline 9 & OPC & Não & dc.contributor.advisor2Lattes & ID Lattes do orientador2 \\
\hline 10 & OPC & Não & dc.contributor.advisor-co & Co-orientador \\
\hline 11 & OPC & Sim & dc.contributor.advisor-colD & ID do co-orientador \\
\hline 12 & OPC & Não & dc.contributor.advisor-colDLattes & ID Lattes do co-orientador \\
\hline 13 & OPC & Sim & dc.contributor.referee1 & Membro da banca1 \\
\hline 18 & OPC & Não & dc.contributor.referee2Lattes & Lattes do membro da banca 2 \\
\hline 19 & OPC & Sim & dc.contributor.referee3 & Membro da banca3 \\
\hline 20 & OPC & Sim & dc.contributor.referee3ID & ID do membro da banca3 \\
\hline
\end{tabular}




\begin{tabular}{|c|c|c|c|c|}
\hline 21 & OPC & Não & dc.contributor.referee3Lattes & Lattes do membro da banca3 \\
\hline 22 & OPC & Sim & dc.contributor.referee4 & Membro da banca4 \\
\hline 23 & OPC & Sim & dc.contributor.referee4ID & ID do membro da banca4 \\
\hline & & REPETITIVO & METADADO & VALOR \\
\hline 24 & OPC & Não & dc.contributor.referee4Lattes & Lattes do membro da banca4 \\
\hline 25 & OPC & Sim & dc.contributor.referee5 & Membro da banca5 \\
\hline 26 & OPC & Sim & dc.contributor.referee5ID & ID do membro da banca5 \\
\hline 27 & OPC & Não & dc.contributor.referee5Lattes & Lattes do membro da banca5 \\
\hline 28 & OBR & Não & dc.date.accessioned & Preenchido automaticamente pelo sistema \\
\hline 29 & OPC & Não & dc.date.available & Data de embargo \\
\hline 30 & OBR & Não & dc.date.issued & Data de defesa \\
\hline 31 & OPC & Não & dc.identifier.uri & Identificador persistente \\
\hline 32 & OPC & Não & dc.identifier.citation & Citação do documento \\
\hline 33 & OPC & Não & dc.identifier.doi & Identificador permanente - DOI \\
\hline 34 & OBR & Sim & dc.description.abstract & Resumo \\
\hline 35 & OBR & Sim & dc.description.abstract & Abstract \\
\hline 36 & OBR & Sim & dc.description.sponsorship & Agência de fomento \\
\hline 37 & OBR & Sim & dc.publisher & Nome da instituição por extenso \\
\hline 38 & OBR & Não & dc.publisher.country & País da instituição \\
\hline 39 & OBR & Sim & dc.publisher.department & Nome da faculdade, instituto ou departamento por extenso \\
\hline 40 & OBR & Sim & dc.publisher.program & Nome do Programa de Pós-Graduação por extenso \\
\hline 41 & OBR & Sim & dc.publisher.initials & Sigla da instituição \\
\hline 42 & OBR & Não & dc.type & Tipo do documento: tese ou dissertação \\
\hline 43 & OBR & Não & dc.title & O título e subtítulo da tese ou dissertação na língua do documento \\
\hline 44 & OPC & Sim & dc.title.alternative & $\begin{array}{l}\text { Título alternativo do documento e/ou traduzido em outro idioma do } \\
\text { documento }\end{array}$ \\
\hline 45 & OBR & Não & dc.language & Idioma \\
\hline 46 & OBR & Não & dc.rights & Direitos de acesso ao documento \\
\hline
\end{tabular}




\begin{tabular}{|c|c|c|c|c|}
\hline 47 & OPC & Não & dc.rights.uri & \\
\hline 48 & OBR & Sim & dc.subject & Palavras-chave que descrevem o assunto do documento \\
\hline \multirow[t]{2}{*}{49} & OBR & Sim & dc.subject.cnpq & Área(s) do conhecimento do documento (Tabela CNPq) \\
\hline & & REPETITIVO & METADADO & VALOR \\
\hline 50 & OPC & Sim & dc.format & Formato do documento \\
\hline 51 & OPC & Sim & dc.relation & $\begin{array}{c}\text { Relação, quando for o caso, com outros materiais produzidos para a } \\
\text { elaboração da tese/dissertação ou comentários do próprio autor } \\
\text { sobre a tese/dissertação }\end{array}$ \\
\hline 52 & OPC & Não & dc.relation.references & Referências citadas na tese ou dissertação \\
\hline 53 & OPC & Sim & dc.description.thumbnail & Arquivo (imagem) \\
\hline
\end{tabular}

OBR - Obrigatório OPC - Opcional 